ELIVALdo ELENILdO DA SILVA

\title{
OTIMIZAÇÃO DE ESTRUTURAS DE CONCRETO ARMADO UTILIZANDO ALgORITMOS GENÉTICOS
}

\author{
Dissertação apresentada à Escola Politécnica \\ da Universidade de São Paulo para obtenção \\ do título de Mestre em Engenharia
}




\title{
ELIVALdo ELENILDO DA SILVA
}

Engenheiro Civil pela UFPE, 2000

\section{OTIMIZAÇÃO DE ESTRUTURAS DE CONCRETO ARMADO UTILIZANDO ALgORITMOS GENÉTICOS}

\author{
Dissertação apresentada à Escola Politécnica \\ da Universidade de São Paulo para obtenção \\ do título de Mestre em Engenharia \\ Área de Concentração: \\ Engenharia de Estruturas \\ Orientador: \\ Paulo de Mattos Pimenta
}


FICHA CATALOGRÁFICA

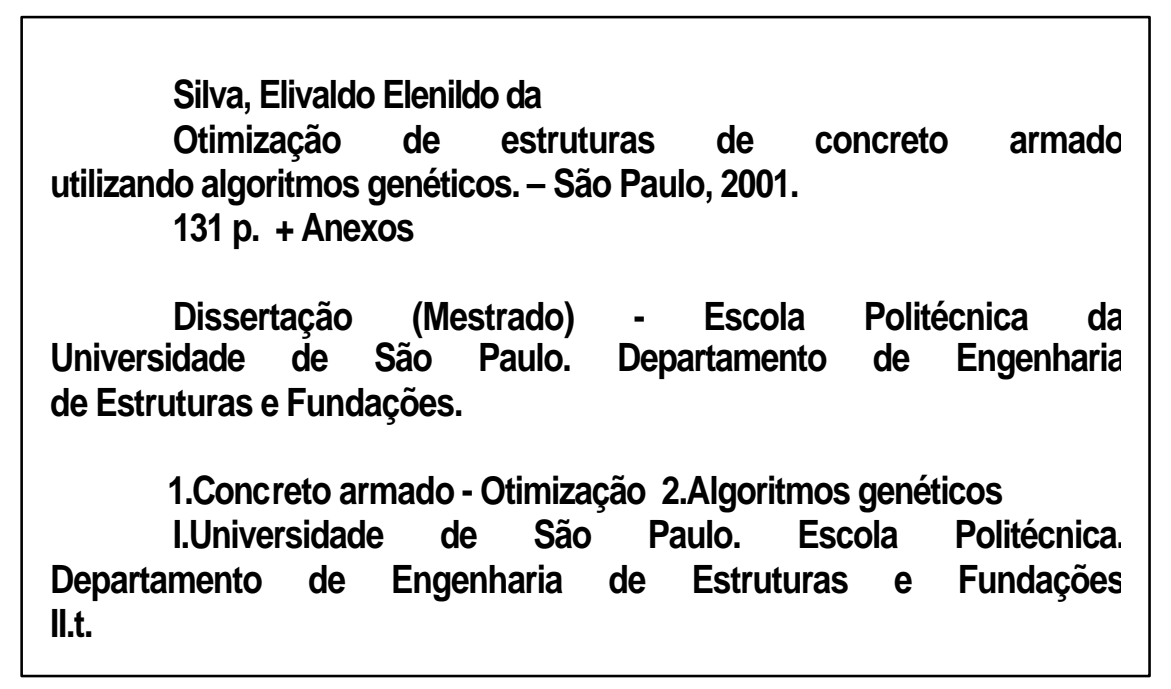


A Deus,

Aos meus Pais, Elenildo e Josefa, Às minhas Irmãs, Edilza e Noelisa,

A Karina Moreira 
"Comece fazendo o que é necessário, depois o que é possível, e de repente você estará fazendo o impossível."

São Francisco de Assis 


\section{AGRADECIMENTOS}

Ao Prof. Dr. Paulo de Mattos Pimenta, pela orientação brilhante e pelo apoio na execução deste trabalho,

Ao Prof. Dr. Ricardo Leopoldo França, por sua dedicação ao ensino de Concreto Armado e pelo período de orientação,

Aos Professores do PEF (Departamento de Estruturas e Fundações) da EPUSP (Escola Politécnica da Universidade de São Paulo), cuja troca de idéias em muito enriqueceu este trabalho,

Aos funcionários do PEF, em especial à Marly, pelas palavras amigas e pelo apoio,

Aos meus colegas do Curso de Graduação pelo incentivo e apoio em minha decisão,

Aos grandes amigos Jamilton Lopes Pacheco e Evandro Rossi Dasambiagio pela constante troca de idéias,

Aos amigos de Pós-Graduação pela conversa sempre amigável e pela paciência nos momentos difíceis,

A CAPES, pela concessão de uma bolsa de Mestrado durante estes dois anos de trabalho. 
Neste trabalho são apresentadas duas importantes áreas de pesquisa voltadas para problemas de otimização: a Programação Matemática e, especialmente, os Algoritmos Genéticos.

São classificados grande parte dos métodos clássicos da Programação Matemática, com uma breve apresentação das suas classes de subproblemas, bem como detalhes de alguns métodos.

O desenvolvimento da ciência que explica a evolução das espécies é descrito, como uma ponte para a compreensão da técnica dos Algoritmos Genéticos.

Apresentam-se as diferenças básicas entre os Métodos Clássicos e os Algoritmos Genéticos, com posterior análise das vantagens e desvantagens entre estas duas classes de ferramentas de otimização.

São apresentados os principais parâmetros de influência no funcionamento de um Algoritmo Genético e algumas recomendações quanto às suas configurações.

A essência desse trabalho se constitui em alguns exemplos de otimização de estruturas de concreto armado, como o de um trecho de Pilar dimensionado à Flexão Composta Obliqua e um Pórtico Plano de Concreto Armado de Cinco Pavimentos.

Finalizando, conclui-se pela tendência promissora dos Algoritmos Genéticos para os próximos anos, o que tornará esta técnica uma das mais importantes e empregadas na resolução de uma vasta gama de aplicações. 


\section{ABSTRACT}

This work addresses two important issues of Optimization: Mathematical Programming and Genetic Algorithms.

First, classes of optimization problems, that can be handled by the classical methods of Mathematical Programming, are briefly presented.

After that, the techniques of Genetic Algorithms are displayed in detail. Such methods are inspired by the laws that rules the evolution of the species.

The basic differences between the Mathematical Programming and Genetic Algorithms are deeply discussed.

The main parameters that control Genetic Algorithms are described and some recommendations about their values are made.

The work is concluded by some optimization examples of reinforced concrete structures, as a column under combined axial load and bi-axial bending and a five floor reinforced concrete plane frame. 


\section{CONTEÚDO}

1. Introdução 1

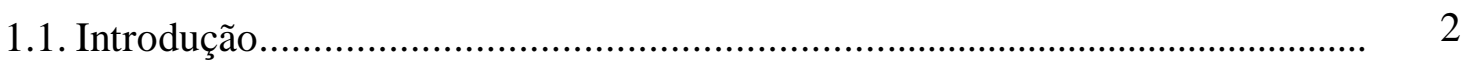

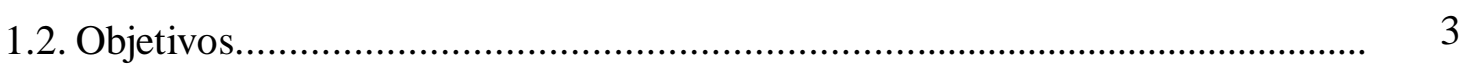

1.3. Escopo da Dissertação............................................................................ 3

2. Elementos de Matemática Aplicada 6

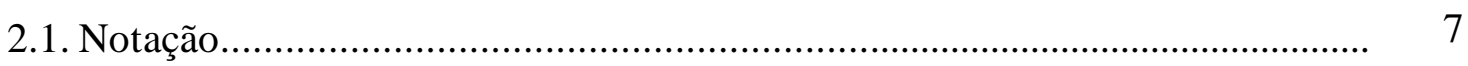

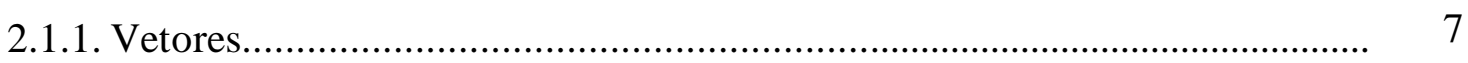

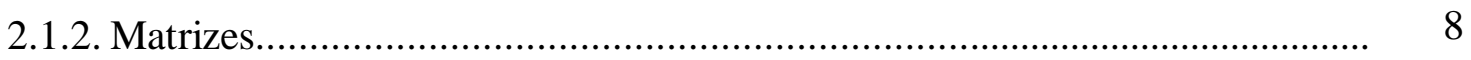

2.1.3. Função Real de Várias Variáveis............................................................. 9

2.1.4. Função Vetorial...................................................................................

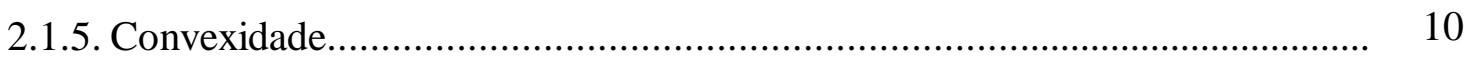

2.1.6. Mínimo Local e Mínimo Global............................................................. 10

2.2. Sistemas de Equações Lineares............................................................... 11

2.2.1. Métodos Diretos................................................................................ 12

2.2.1.1. Método de Crout....................................................................................... 12

2.2.1.2. Método de Choleski............................................................................... 14

2.2.2. Métodos Indiretos........................................................................... 15

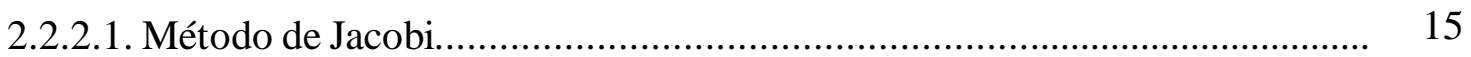

2.2.2.2. Método de Gauss-Seidel................................................................... 16

2.3. Sistemas de Equações Não-Lineares......................................................... 17

3. Programação Matemática $\quad 18$

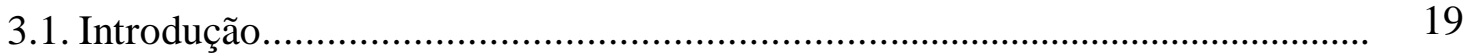

3.2. Definições Básicas - Terminologia............................................................ 19

3.3. Algoritmos de Programação Matemática..................................................... 22

3.3.1. Programação Linear.................................................................................. 23

3.3.2. Programação Não-Linear......................................................................... 24

3.3.2.1. Otimização sem Restrições...................................................................... 24

3.3.2.1.1. Método de Newton-Raphson............................................................ 26

3.3.2.1.2. Método Quase-Newton (BFGS) ........................................................ 27 
3.3.2.1.3. Método Quase-Newton (DFP) ........................................................ 29

3.3.2.2. Otimização com Restrições............................................................ 31

3.3.2.2.1. Otimização com Restrições de Igualdade........................................... 31

3.3.2.2.1.1. Método do Lagrangiano................................................................. 33

3.3.2.2.1.2. Método da Penalidade................................................................... 35

3.3.2.2.1.3. Método do Lagrangiano Aumentado.................................................... 36

3.3.2.2.2. Otimização com Restrições de Desigualdade...................................... 36

3.3.2.2.2.1. Método da Penalidade .................................................................. 38

3.3.2.2.2.2. Método do Lagrangiano Aumentado.................................................. 38

3.3.2.2.3. Otimização com Restrições Mistas...................................................... 39

3.3.2.2.3.1. Método da Penalidade ............................................................... 39

3.3.2.2.3.2. Método do Lagrangiano Aumentado............................................... 40

3.3.3. Programação Multi-Objetivos.................................................................. 40

4. Algoritmos Genéticos $\quad \mathbf{4 2}$

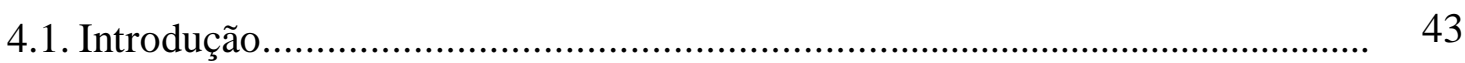

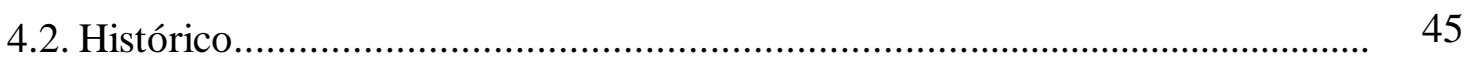

4.3. Definições Básicas - Terminologia............................................................ 47

4.4. Representação dos Parâmetros.................................................................... 49

4.5. Algoritmos Genéticos e Otimização Convencional...................................... 49

4.6. Diferenças entre os AGs e os Métodos Clássicos.......................................... 52

4.7. Estrutura dos Algoritmos Genéticos.......................................................... 53

4.7.2. Algoritmo Genético Geracional............................................................ 53

4.7.3. Algoritmo Genético em Regime............................................................. 54

4.8. Principais Aspectos dos Algoritmos Genéticos............................................. 55

4.8.1. A Função Objetivo...................................................................... 55

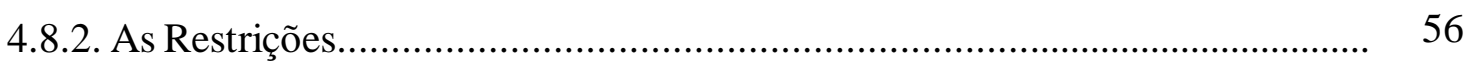

4.8.3. Problemas de Convergência............................................................ 58

4.8.4. Critérios de Parada........................................................................ 59

4.8.5. Representação e Codificação.................................................................... 59

4.8.6. Geração da População Inicial.................................................................. 60

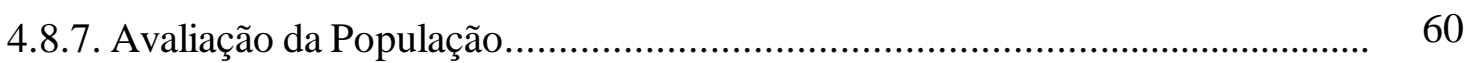

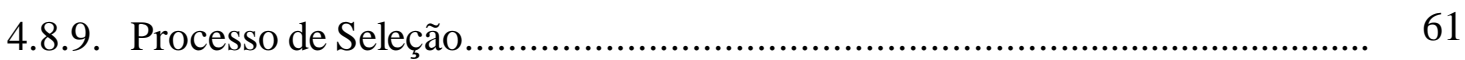

4.8.9.1. Mapeamento da Função Objetivo......................................................... 61

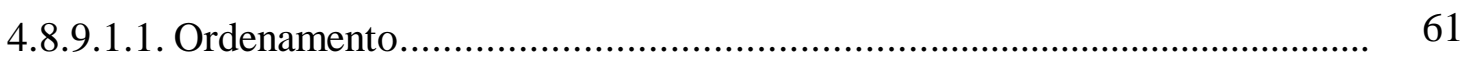


4.8.9.1.2. Escalonamento Linear.................................................................. 62

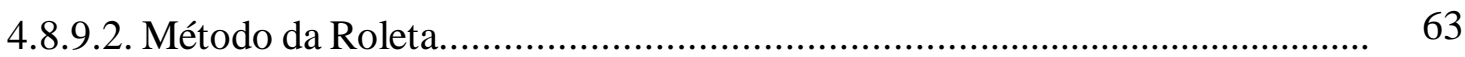

4.8.9.3. Processo de Seleção por Torneio.............................................................. 64

4.8.10. Reprodução ou Cruzamento................................................................... 64

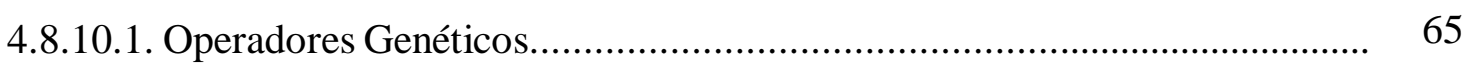

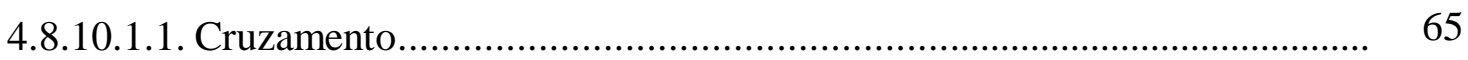

4.5.10.1.1.1. Cruzamento de 1 Ponto................................................................ 65

4.8.10.1.1.2. Cruzamentos de 2 Pontos e N Pontos.............................................. 66

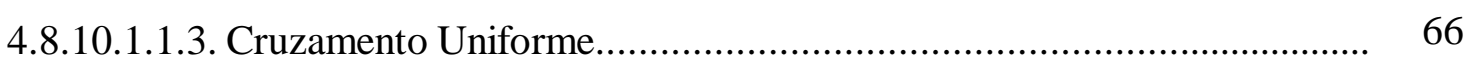

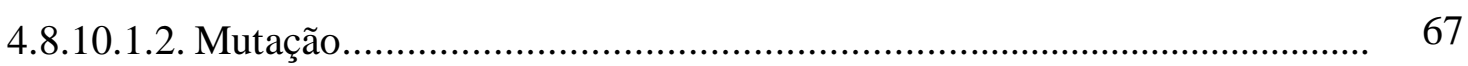

4.8.10.1.3. Elitismo.................................................................................... 68

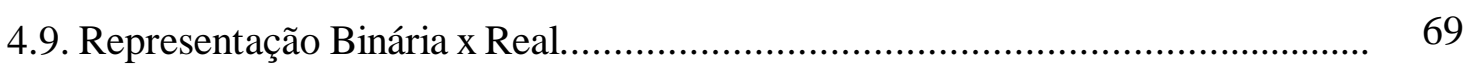

4.10. Parâmetros de Influência e Configuração.................................................... 69

4.10.1. Tamanho da População.................................................................. 69

4.10.2. Taxa ou Probabilidade de Cruzamento.................................................. 70

4.10.3. Taxa ou Probabilidade de Mutação...................................................... 70

4.11. Vantagens e Desvantagens dos AGs....................................................... 71

4.11.1. Vantagens dos Algoritmos Genéticos.................................................... 71

4.11.2. Desvantagens dos Algoritmos Genéticos............................................ 72

4.12. Estratégias Empregáveis aos AGs............................................................. 72

4.12.1. Hibridização................................................................................ 72

4.12.2. Computação Paralela.................................................................. 72

5. Análise Estrutural

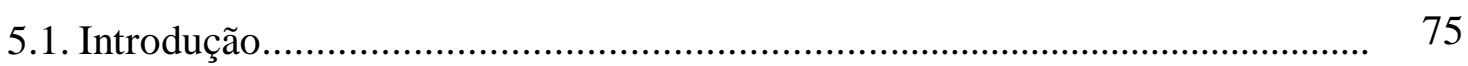

5.2. Análise Matricial de Estruturas............................................................ 77

5.2.1. Matriz de Rigidez de um Elemento de Barra.......................................... 79

5.2.2. Carregamentos no Elemento ........................................................................ $\quad 80$

5.2.3. Matriz de Transformação........................................................................... 80

5.2.4. Espalhamento da Matriz de Rigidez Local na Matriz de Rigidez Global ..... 82

5.2.5. Resolução do Sistema de Equações ........................................................ 83

5.2.6. Obtenção dos Esforços nas Extremidades de cada Elemento..................... 84

5.3. Estados Limites................................................................................. 85

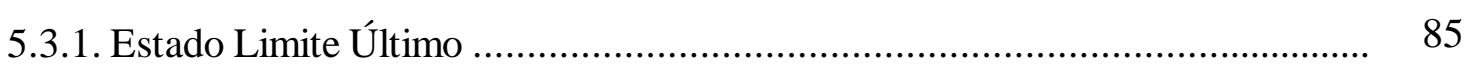

5.3.2 Estado Limite de utilização ou de Serviço............................................... 86 
5.4. Domínios de Deformação...................................................................... 86

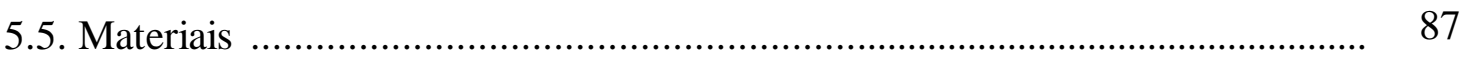

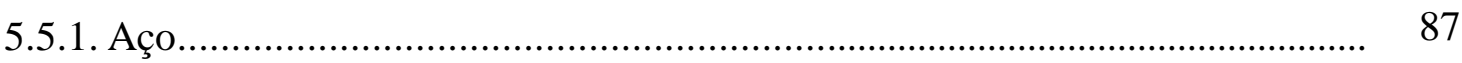

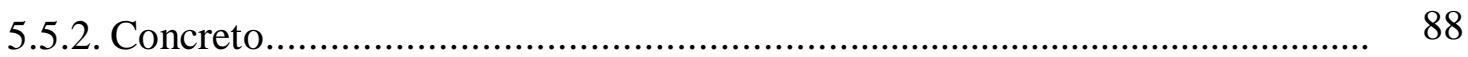

5.6. Flexão Composta Oblíqua - FCO........................................................ 89

5.6.1. Integrais dos Esforços Resistentes.......................................................... $\quad 90$

5.6.2. Cálculo da Matriz Jacobiana dos Esforços Resistentes.............................. 91

5.7. Flexão Composta Normal - FCN ................................................................. 93

5.7.1. Integrais dos Esforços Resistentes.......................................................... 96

5.7.2. Calculo da Matriz Jacobiana para FCN.................................................. 96

5.8. Critérios Normativos.......................................................................... 98

5.8.1. Segurança em Relação aos ELU............................................................. 98

5.8.2. Segurança em Relação aos ELS ........................................................... 99

5.8.3. Taxas da Armadura.......................................................................... 99

5.8.3.1. Princípios Básicos.................................................................................. 99

5.8.3.2. Taxa de Armadura para Vigas........................................................... 99

5.8.3.3. Taxa de Armadura para Pilares........................................................... 100

5.8.4. Distribuição das Armaduras.................................................................... 101

5.8.4.1. Espaçamento entre Barras da Armadura nas Vigas................................ 101

5.8.4.2. Espaçamentos entre Armaduras nos Pilares............................................ 101

5.8.5 Deslocamentos Limites...................................................................... 102

6. Aplicações ao Concreto Armado $\quad 104$

6.1. Otimização de um Trecho de Pilar a Flexão Composta Oblíqua...................... 105

6.1.1. Descrição do Problema de Otimização...................................................... 105

6.1.1.1. Descrição das Variáveis.......................................................................... 106

6.1.1.2. A Função Objetivo............................................................................ 106

6.1.1.3. As Restrições do Problema................................................................... 106

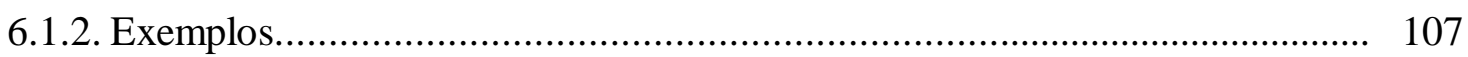

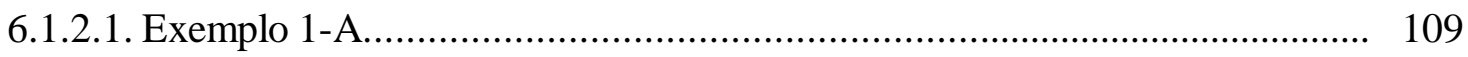

6.1.2.2. Exemplo 1-B............................................................................ 110

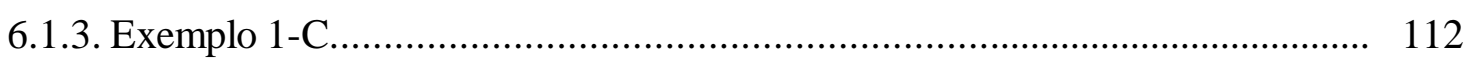

6.1.4. Conclusões Preliminares...................................................................... 114

6.2. Otimização de um Pórtico Plano de Concreto Armado................................. 115

6.2.1. Descrição do Problema de Otimização...................................................... 116 
6.2.1.1. Descrição das Variáveis............................................................................ 116

6.2.1.2. A Função Objetivo.............................................................................. 117

6.2.1.3. As Restrições do Problema....................................................................... 117

6.2.1.4. Funções de Penalização........................................................................ 118

6.2.1.5. Critérios de Parada (Convergência) ......................................................... 119

6.2.2. Esquema Estrutural do Pórtico............................................................... 120

6.2.3. Conclusões Preliminares..................................................................... 122

7. Conclusões e Comentários $\quad 124$

7.1. Sobre a Otimização de Estruturas............................................................... 125

7.2. Sobre os Algoritmos Genéticos............................................................... 126

7.3. Sobre a Análise Estrutural........................................................................ 127

7.4. Sobre os Exemplos Elaborados................................................................... 129

7.5. Sugestões para Trabalhos Futuros................................................................ 130

\section{Bibliografia}

Anexo A

Anexo B

Anexo C 


\section{Capítulo 1}

\section{INTRODUÇÃO}

W $\begin{aligned} & \text { este capítulo apresentam-se as motivações que levaram à escolha } \\ & \text { desse tema, objetivos pretendidos e uma breve descrição do conteúdo }\end{aligned}$ dos demais capítulos desta dissertação. Encontram-se também indicados para cada um dos capítulos uma bibliografia básica que estará representada entre colchetes com a seguinte notação[ Letra-Número].

“As boas idéias não tem idade, apenas têm futuro". 


\subsection{INTRODUÇÃO}

Nos últimos anos, o mercado competitivo criado entre as empresas de engenharia aumentou a preocupação com a redução de custos dos empreendimentos. Atualmente a otimização de estruturas tem se mostrado uma ferramenta importante para tornar as empresas mais competitivas num mercado globalizado. A otimização pode ser entendida como uma maneira hábil de se identificar a melhor solução dentre as inúmeras disponíveis.

Algoritmos Genéticos (AGs) não são simples algoritmos aleatórios de otimização, eles exploram com eficiência informações que servirão para auxiliar na busca de novas soluções melhorando o seu desempenho a cada geração. As pesquisas com algoritmos aleatórios têm alcançado grande importância devido à sua eficiência na otimização de problemas complexos em contraste com sua relativa simplicidade de programação.

A otimização de estruturas com adequação às características práticas de projeto é hoje algo com um grande potencial para ser aplicado nos escritórios de cálculo. $\mathrm{O}$ processamento completo de estruturas utilizando AGs é bastante dispendioso computacionalmente, já que cada indivíduo da população é uma nova estrutura a ser resolvida. Como o número de variáveis nos projetos é bastante grande, o tamanho da população de indivíduos a ser analisada também o será, o que resulta na necessidade de algoritmos e métodos cada vez mais eficientes, no desenvolvimento de tais métodos pode-se optar pela interação entre Algoritmos Genéticos e outras técnicas de otimização. Os Algoritmos Genéticos se adaptam muito bem às técnicas de Processamento Paralelo, atualmente em grande desenvolvimento, podendo desta forma resolver problemas cada vez maiores em menor tempo.

A utilização maciça de computadores na atividade de projeto estrutural tornou usual a análise de pórticos espaciais. O dimensionamento pelos esforços obtidos dessa análise torna-se complexo uma vez que as peças estruturais passam a trabalhar sob a ação de esforços solicitantes combinados (flexão composta, torção, cortante). As variáveis de projeto são muitas (geometria da seção, materiais, bitolas das barras de aço, distribuição da armadura, etc). Dessa forma, adotando-se diversos desses parâmetros e verificando o equilíbrio e as diversas restrições previstas pelas normas, o problema passa a ser de verificação e não de dimensionamento. Aliando esse processo com um critério, como o 
de mínimo custo por exemplo, pode-se buscar a estrutura ótima dentre as diversas combinações possíveis. Partindo-se de uma população inicial de estruturas, o computador passa a fazer todas as verificações necessárias, criando novas populações a partir da geração anterior até obter, entre seus indivíduos, a estrutura que possui o menor custo.

\subsection{OBJETIVOS}

Os objetivos que se pretende alcançar ao longo deste trabalho podem ser descritos como :

- Melhor entendimento dos processos de otimização empregados, bem como as diferenças existentes entre eles ;

- Estudo detalhado dos Algoritmos Genéticos, visando conhecer suas características, vantagens e aplicabilidade ;

- Otimização de Elementos Estruturais, a saber: Pilares e Vigas ;

- A elaboração de um programa para Otimização de Pórticos Planos de Concreto Armado (OTIMPORCA);

- Formular exemplos de validação para os programas implementados;

- Comparar os resultados obtidos pelo programa com os obtidos da forma convencional.

\subsection{ESCOPO DA DISSERTAÇÃO}

Abaixo será descrito de forma bastante sucinta como está organizada esta dissertação:

No Capítulo 2 é feita uma apresentação da nomenclatura utilizada e das principais ferramentas matemáticas empregadas ao longo do texto. Os tópicos abordados neste capítulo são: vetores, matrizes, função real de várias variáveis, convexidade, mínimo local e global, sistemas de equações lineares e sistema de equações não-lineares.

No Capítulo 3 são descritos os conceitos envolvidos na resolução dos problemas de otimização via Métodos de Programação Matemática ([F-1], [F-2], [G-1], [H-1], [L3]). Estes métodos serão apresentados de forma rápida e objetiva com enfoque nas suas principais características.

Os Algoritmos Genéticos são abordados no Capítulo 4. Este capítulo apresentará a origem e os fundamentos dos Algoritmos Genéticos ([A-1], [D-1], [G-2], [L-1], [M-7], 
[S-1], [W-1]), e seus principais aspectos e características que o tornaram uma ferramenta de busca e otimização bastante promissora para a solução de uma vasta gama de aplicações. Serão também mostradas as diversas operações utilizadas pelos Algoritmos Genéticos. Para cada um destes processos será dado um exemplo para tornar mais claro o seu significado.

No Capítulo 5 serão apresentados alguns conceitos da análise de estruturas reticuladas e também a verificação de estruturas de concreto armado. Como o enfoque principal desta dissertação será a Otimização de Estruturas de Concreto Armado, neste capítulo haverá um breve resumo dos tópicos que serão abordados nos exemplos de validação do capítulo seguinte.

Tópicos abordados neste capítulo:

- Materiais Empregados;

- Aspectos sobre a verificação de estruturas de Concreto Armado ([F-4], [L-2], [M1], [P-1]): Estado Limite Último (ELU) e Estado Limite de Serviço (ELS);

Para validar a implementação feita, no Capítulo 6 são apresentadas algumas aplicações em estruturas convencionais de concreto armado e feitos alguns comentários sobre a eficiência dos processos utilizados. Neste capítulo também é feita uma comparação entre um projeto feito da forma convencional com o mesmo feito totalmente pelo programa implementado.

Os exemplos apresentados neste capítulo servirão como validação para os programas elaborados. Estes exemplos estão especificados abaixo:

- Otimização de um tramo de pilar de Concreto Armado (CA) com verificação da Flexão Composta Oblíqua (FCO);

- Otimização de um Pórtico de Concreto Armado.

Finalizando com o Capítulo 7 no qual são apresentadas as conclusões obtidas com o desenvolvimento do trabalho e onde são apresentadas algumas propostas para outros possíveis trabalhos nesta área.

Nos anexos serão colocados alguns algoritmos para os Métodos de Programação Matemática bem como um manual de utilização do OTIMPORCA. Ao final dos anexos consta também um fluxograma dos módulos desenvolvidos com uma pequena descrição 
para cada módulo. Este manual de utilização juntamente com os fluxogramas têm a função de facilitar a outros usuários o acesso aos dados desta pesquisa.

Os anexos estão assim distribuídos:

- No Anexo A encontram-se os algoritmos para os métodos de otimização via programação matemática.

- No Anexo $B$ encontra-se um exemplo de arquivo de entrada e o respectivo arquivo de saída (resultados) do programa OTIMPORCA.

- No Anexo $C$ estão comentados os diversos módulos do programa. 


\section{CAPÍtulo 2}

\section{Elementos de Matemática A Plicada}

este capítulo serão introduzidas algumas notações e apresentados
alguns conceitos matemáticos sobre vetores, matrizes, funções reais de várias variáveis, funções vetoriais, convexidade, máximos e mínimos de funções, sistemas de equações lineares e sistemas de equações não-lineares.

"Faça as coisas o mais simples que você puder, porém não as mais simples". 


\subsection{NoTAÇÃo}

Neste capítulo serão introduzidos os conceitos matemáticos básicos para vetores, matrizes, funções reais de várias variáveis, funções vetoriais, convexidade, mínimos de funções e otimização. Cada um dos conceitos será abordado de forma rápida, tendo apenas a função de familiarizar o leitor com a notação que será utilizada nos demais capítulos desta dissertação.

\subsubsection{VETORES}

Um vetor em $\mathfrak{R}^{n}$ será indicado por

$$
\boldsymbol{x}=\left(\begin{array}{c}
x_{1} \\
x_{2} \\
\vdots \\
x_{n}
\end{array}\right),
$$

onde $x_{i} \in \mathfrak{R}$ para $\mathrm{i}=1,2, \ldots, \mathrm{n}$ são as $\mathrm{i}$-ésimas componentes do vetor em relação a uma base pré-definida.

0 produto escalar de $\boldsymbol{x}$ e $\boldsymbol{y}$ em $\mathfrak{R}^{n}$ será definido por

$$
\boldsymbol{x} \cdot \boldsymbol{y}=\sum_{i=1}^{n} x_{i} \cdot y_{i}=\boldsymbol{x}^{T} \cdot \boldsymbol{y}
$$

A norma Euclidiana de um vetor $\boldsymbol{x}$ de $\mathfrak{R}^{n}$ é definida por

$$
\|\boldsymbol{x}\|=\sqrt{\left(x_{1}^{2}+x_{2}^{2}+\cdots+x_{n}^{2}\right)}=\sqrt{\boldsymbol{x}^{T} \cdot \boldsymbol{x}} .
$$

Diz-se que 0 s vetores $\left\{\boldsymbol{x}_{1}, \boldsymbol{x}_{2}, \ldots, \boldsymbol{x}_{m}\right\}$, onde $x_{i} \in \mathfrak{R}$ para $\mathrm{i}=1,2, \ldots, \mathrm{m}$, são linearmente independentes (LI) se $a_{1} \cdot x_{1}+a_{2} \cdot x_{2}+\cdots+a_{m} \cdot x_{m}=0$ implicar em $a_{1}=a_{2}=\cdots=a_{n}=0$, caso contrário são linearmente dependentes (LD).

A distância entre dois pontos $\boldsymbol{x}$ e $\boldsymbol{y}$ em $\mathfrak{R}^{n}$ será definida pela notação

$$
d(\boldsymbol{x}, \boldsymbol{y})=\|\boldsymbol{y}-\boldsymbol{x}\|
$$


Usa-se a notação $\langle\bullet\rangle$ para os Colchete de Mc Cauley definidos como

$$
\langle\boldsymbol{x}\rangle=\left\{\begin{array}{l}
0, \text { se } x \leq 0 \\
x, \text { se } x \geq 0
\end{array} .\right.
$$

A mesma definição $\langle\bullet\rangle$ será utilizada no caso de funções, ou seja,

$$
\langle f(x)\rangle=\left\{\begin{array}{l}
0, \text { se } f(x) \leq 0 \\
f(x), \text { se } f(x) \geq 0
\end{array} .\right.
$$

\subsubsection{MATRIZES}

Uma matriz em $\Re^{m \times n}$ será indicada por

$$
\boldsymbol{A}=\left[\begin{array}{cccc}
a_{11} & a_{12} & \cdots & a_{1 n} \\
a_{21} & a_{22} & \cdots & a_{2 n} \\
\vdots & \vdots & \ddots & \vdots \\
a_{m 1} & a_{m 2} & \cdots & a_{m n}
\end{array}\right]=\left[a_{i j}\right],
$$

onde $m$ é 0 número de linhas da matriz e $n$ é o número de colunas da mesma.

Apresenta-se a seguir algumas notações e propriedades de matrizes que serão utilizadas a o longo do texto:

i. $\quad \boldsymbol{A}^{T}$ : matriz transposta de $\boldsymbol{A}=\left[a_{i j}\right]$, onde $\boldsymbol{A}^{T}=\left[a_{j i}\right]$

ii. I : matriz identidade, onde: $\left\{\begin{array}{lll}a_{i j}=1 & \text { se } & i=j \\ a_{i j}=0 & \text { se } & i \neq j\end{array}\right.$

iii. $\boldsymbol{A}^{-1}$ : matriz inversa de $\boldsymbol{A}$

iv. Uma matriz quadrada $\boldsymbol{A}$ é simétrica se: $\quad a_{i j}=a_{j i}$ para todo $i$ e $j$

v. Uma matriz $\boldsymbol{A}$ é semi-definida positiva se: $\boldsymbol{x}^{T} \cdot \boldsymbol{A} \cdot \boldsymbol{x} \geq 0 \quad \forall \quad \boldsymbol{x} \in \mathfrak{R}^{n}$

vi. Uma matriz $\boldsymbol{A}$ é definida positiva se e somente se :

$$
\left\{\begin{array}{lll}
\boldsymbol{x}^{T} \cdot \boldsymbol{A} \cdot \boldsymbol{x} \geq 0 & \forall & \boldsymbol{x} \in \mathfrak{R}^{n} \\
\boldsymbol{x}^{T} \cdot \boldsymbol{A} \cdot \boldsymbol{x}=0 & \Leftrightarrow \quad \boldsymbol{x}=0
\end{array}\right.
$$

vii. Define-se por $\operatorname{det}(\boldsymbol{A})$ o determinante da matriz $\boldsymbol{A}$, cujo algoritmo de cálculo será apresentado posteriormente. 


\subsubsection{FunÇão REAL de VÁRIAS V ARIÁ VEIS}

As funções que serão tratadas nesta dissertação são definidas num conjunto $\Gamma \subset \mathfrak{R}^{n}$ e assumem valores em $\mathfrak{R}$, isto é, $f: \Gamma \rightarrow \mathfrak{R}$.

0 vetor das derivadas parciais de $f(\boldsymbol{x})$ em um ponto $\boldsymbol{x}$, é denominado de vetor gradiente e será indicado por

$$
\mathcal{G}=\nabla f(\boldsymbol{x})=\left[\frac{\partial f(\boldsymbol{x})}{\partial x_{i}}\right]=\left[\begin{array}{c}
\frac{\partial f(\boldsymbol{x})}{\partial x_{1}} \\
\frac{\partial f(\boldsymbol{x})}{\partial x_{2}} \\
\vdots \\
\frac{\partial f(\boldsymbol{x})}{\partial x_{n}}
\end{array}\right]
$$

A matriz das derivadas parciais de segunda ordem de $f(\boldsymbol{x})$ em um ponto $\boldsymbol{x}$, denominada de matriz Hessiana será indicada por

$$
\mathbb{H}=\nabla^{2} f(\boldsymbol{x})=\left[\frac{\partial^{2} f(\boldsymbol{x})}{\partial x_{i} \cdot \partial x_{j}}\right]=\left[\begin{array}{cccc}
\frac{\partial^{2} f(\boldsymbol{x})}{\partial x_{1} \cdot \partial x_{1}} & \frac{\partial^{2} f(\boldsymbol{x})}{\partial x_{1} \cdot \partial x_{2}} & \cdots & \frac{\partial^{2} f(\boldsymbol{x})}{\partial x_{1} \cdot \partial x_{n}} \\
\frac{\partial^{2} f(\boldsymbol{x})}{\partial x_{2} \cdot \partial x_{1}} & \frac{\partial^{2} f(\boldsymbol{x})}{\partial x_{2} \cdot \partial x_{2}} & \cdots & \frac{\partial^{2} f(\boldsymbol{x})}{\partial x_{2} \cdot \partial x_{n}} \\
\vdots & \vdots & \ddots & \vdots \\
\frac{\partial^{2} f(\boldsymbol{x})}{\partial x_{n} \cdot \partial x_{1}} & \frac{\partial^{2} f(\boldsymbol{x})}{\partial x_{n} \cdot \partial x_{2}} & \cdots & \frac{\partial^{2} f(\boldsymbol{x})}{\partial x_{n} \cdot \partial x_{n}}
\end{array}\right]
$$

\subsubsection{FUNÇão VETORIAL}

0 conjunto de várias funções a valores reais $f_{1}, f_{2}, \ldots, f_{m}$ em $\mathfrak{R}^{n}$, pode ser visto como uma função vetorial $\boldsymbol{f}(\boldsymbol{x})$. Essa função determina o vetor $\boldsymbol{f}(\boldsymbol{x})$ definido por $f: \Re^{n} \rightarrow \mathfrak{R}^{m}$, ou seja,

$$
\boldsymbol{f}(\boldsymbol{x})^{T}=\left[\begin{array}{llll}
f_{1}(\boldsymbol{x}) & f_{2}(\boldsymbol{x}) & \cdots & f_{m}(\boldsymbol{x})
\end{array}\right] .
$$


Supondo que a função $\boldsymbol{f}(\boldsymbol{x})$ seja contínua com derivadas parciais contínuas, a matriz $\mathbb{J}$ das derivadas parciais de $f_{i}$ em relação às variáveis $x_{j}$, denomina-se matriz Jacobiana e será indicada por

$$
\mathbb{J}=\nabla \boldsymbol{f}(\boldsymbol{x})=\left[\frac{\partial f_{i}(\boldsymbol{x})}{\partial x_{j}}\right]=\left[\begin{array}{cccc}
\frac{\partial f_{1}(\boldsymbol{x})}{\partial x_{1}} & \frac{\partial f_{1}(\boldsymbol{x})}{\partial x_{2}} & \cdots & \frac{\partial f_{1}(\boldsymbol{x})}{\partial x_{n}} \\
\frac{\partial f_{2}(\boldsymbol{x})}{\partial x_{1}} & \frac{\partial f_{2}(\boldsymbol{x})}{\partial x_{2}} & \cdots & \frac{\partial f_{2}(\boldsymbol{x})}{\partial x_{n}} \\
\vdots & \vdots & \ddots & \vdots \\
\frac{\partial f_{n}(\boldsymbol{x})}{\partial x_{1}} & \frac{\partial f_{n}(\boldsymbol{x})}{\partial x_{2}} & \cdots & \frac{\partial f_{n}(\boldsymbol{x})}{\partial x_{n}}
\end{array}\right]
$$

\subsubsection{CONVEXIDADE}

Diz-se que um conjunto não vazio $\wp$ em $\mathfrak{R}^{n}$ é convexo se para dois pontos quaisquer $\boldsymbol{x}_{1}, \boldsymbol{x}_{2} \in \wp$ o ponto $\lambda \cdot \boldsymbol{x}_{1}+(1-\lambda) \cdot \boldsymbol{x}_{2} \in \wp$, para todo $0 \leq \lambda \leq 1$

Uma função real $f(\boldsymbol{x})$ definida em um conjunto convexo $\wp$ em $\mathfrak{R}^{n}$, diz-se convexa se para dois pontos quaisquer $\boldsymbol{x}_{1}, \boldsymbol{x}_{2} \in \wp$ e qualquer $\lambda$ real, $0 \leq \lambda \leq 1$ tem-se $f\left(\lambda \cdot x_{1}+(1-\lambda) \cdot x_{2}\right) \leq \lambda \cdot f\left(x_{1}\right)+(1-\lambda) \cdot f\left(x_{2}\right)$.

\subsubsection{Mínimo Local E Mínimo GlobaL}

Nos processo de minimização de funções podemos obter como solução dos problemas, diversos tipos de pontos de mínimo. Abaixo estão descritos de forma bastante sucinta estes diferentes tipos.

Tipos de Pontos de Mínimo:

- Mínimo Local: $x^{*} \in \Gamma$

Se num a vizinhança aberta de $x^{*}, \Lambda_{\mathrm{a}}\left(x^{*}, r\right) \Rightarrow f(x) \geq f\left(x^{*}\right) \forall x \in \Lambda_{\mathrm{a}}\left(x^{*}, r\right)$

○ Mínimo Local Estrito: $x^{*} \in \Gamma$

Se numa vizinhança aberta de $x^{*}, \Lambda_{\mathrm{a}}\left(x^{*}, r\right) \Rightarrow f(x)>f\left(x^{*}\right) \forall x \in \Lambda_{\mathrm{a}}\left(x^{*}, r\right)$ e $x \neq x^{*}$

○ Mínimo Global: $x^{*} \in \Gamma$

Se num a vizinhança aberta de $x^{*}, \Lambda_{\mathrm{a}}\left(x^{*}, r\right) \Rightarrow f(x) \geq f\left(x^{*}\right) \forall x \in \Gamma$

- Mínimo Global Estrito: $x^{*} \in \Gamma$

Se numa vizinhança aberta de $x^{*}, \Lambda_{\mathrm{a}}\left(x^{*}, r\right) \Rightarrow f(x)>f\left(x^{*}\right) \forall x \in \Gamma$ e $x \neq x^{*}$ 


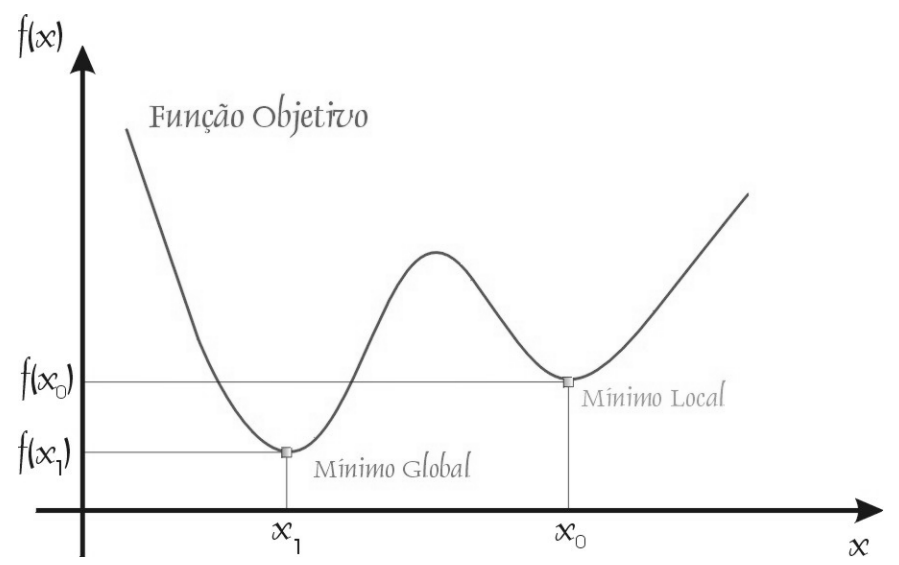

Figura 2-1 - Mínimo Globale Mínimo Local

\subsection{SiSTEMAS DE EQUAÇÕES LINEARES}

Defini-se como Equação Linear às equações do tipo

$$
a \cdot x=b \quad \Rightarrow \quad x=\frac{b}{a}, a \neq 0 .
$$

Da mesma forma que para Equações Lineares pode-se definir um Sistema de Equações Lineares da seguinte forma $\boldsymbol{A} \cdot \boldsymbol{x}=\boldsymbol{b} \Rightarrow \boldsymbol{x}=\boldsymbol{A}^{-1} \cdot \boldsymbol{b}, \operatorname{det}(\boldsymbol{A}) \neq 0$, onde $\boldsymbol{A}$ é uma matriz quadrada $n \times n$.

Pode-se também escrever um Sistema de Equações Lineares da seguinte forma

$$
\left\{\begin{array}{c}
a_{11} \cdot x_{1}+a_{12} \cdot x_{2}+\cdots+a_{1 n} \cdot x_{n}=b_{1} \\
a_{21} \cdot x_{1}+a_{22} \cdot x_{2}+\cdots+a_{2 n} \cdot x_{n}=b_{2} \\
\vdots \\
a_{n 1} \cdot x_{1}+a_{n 2} \cdot x_{2}+\cdots+a_{n n} \cdot x_{n}=b_{n}
\end{array} .\right.
$$

Existem diversos métodos para solução de tais sistemas, que podem ser classificados como:

- Métodos Diretos

No caso dos métodos diretos, $\boldsymbol{x}$ é encontrado após um número previsível de operações.

- Métodos Indiretos

Neste caso $\boldsymbol{x}$ é encontrado após um número não previsível de operações. 


\subsubsection{MÉTODOS DIRETOS}

Os Métodos Diretos de solução de sistemas de equações lineares serão apresentados de forma bastante resumida. Mais detalhes sobre tais métodos podem ser encontradas em ([R-1], [D-2]). Apresentaremos aqui apenas dois destes métodos: Método de Crout e o Método de Choleski.

\subsubsection{MÉTODO DE CROUT}

0 Método de Crout consiste em fazer uma decomposição da matriz $\boldsymbol{A}$ em três matrizes $\boldsymbol{L}, \boldsymbol{D}$ e $\boldsymbol{U}$ com a seguinte propriedade $\boldsymbol{A}=\boldsymbol{L} \cdot \boldsymbol{D} \cdot \boldsymbol{U}$.

As matrizes $\boldsymbol{L}, \boldsymbol{D}$ e $\boldsymbol{U}$ são definidas como,

$$
\begin{aligned}
& \boldsymbol{A}=\left[\begin{array}{cccc}
a_{11} & a_{12} & \cdots & a_{1 n} \\
a_{21} & a_{22} & & \vdots \\
\vdots & & \ddots & a_{n-1, n} \\
a_{n 1} & \cdots & a_{n, n-1} & a_{n n}
\end{array}\right] \\
& \boldsymbol{L}=\left[\begin{array}{cccc}
1 & 0 & \cdots & 0 \\
l_{21} & 1 & & \vdots \\
\vdots & & \ddots & 0 \\
l_{n 1} & \cdots & l_{n, n-1} & 1
\end{array}\right] \quad \boldsymbol{D}=\left[\begin{array}{cccc}
d_{11} & 0 & \cdots & 0 \\
0 & d_{22} & & \vdots \\
\vdots & & \ddots & 0 \\
0 & \cdots & 0 & d_{n n}
\end{array}\right] \quad \boldsymbol{U}=\left[\begin{array}{cccc}
1 & u_{12} & \cdots & u_{1 n} \\
0 & 1 & & \vdots \\
\vdots & & \ddots & u_{n-1, n} \\
0 & \cdots & 0 & 1
\end{array}\right]
\end{aligned}
$$
$\operatorname{det}(\boldsymbol{A}) \neq 0$, onde $\boldsymbol{L}$ é uma matriz triangular inferior de diagonal unitária, $\boldsymbol{D}$ é uma matriz diagonal e $\boldsymbol{U}$ é uma matriz triangular superior de diagonal unitária, desta forma podemos escrever as matrizes $\boldsymbol{L}, \boldsymbol{D}$ e $\boldsymbol{U}$ a partir da matriz $\boldsymbol{A}$. As equações escritas abaixo da seguinte forma,

$$
\begin{array}{ll}
d_{11}=a_{11} & \\
d_{i j}=a_{i j}-\sum_{k=1}^{i-1} l_{i k} \cdot d_{k k} \cdot u_{k j} & i=j>1 \\
u_{1 j}=\frac{a_{1 j}}{d_{11}} & i=1, j>i \\
u_{i j}=\frac{a_{i j}-\sum_{k=1}^{i-1} l_{i k} \cdot d_{k k} \cdot u_{k j}}{d_{i i}} & i>1, j>i
\end{array}
$$




$$
\begin{array}{ll}
l_{1 j}=\frac{a_{i 1}}{d_{11}} & j=1, i>j \\
l_{i j}=\frac{a_{i j}-\sum_{k=1}^{j-1} l_{i k} \cdot d_{k k} \cdot u_{k j}}{d_{j j}} & j>1, i>j
\end{array}
$$

Se a matriz $\boldsymbol{A}$ for simétrica pode-se mostrar que $\boldsymbol{L}=\boldsymbol{U}^{T}$ e, portanto, $\boldsymbol{A}=\boldsymbol{U}^{T} \cdot \boldsymbol{D} \cdot \boldsymbol{U}$, obtendo-se as seguintes expressões,

$$
\begin{array}{ll}
d_{11}=a_{11} & \\
d_{i j}=a_{i j}-\sum_{k=1}^{i-1} u_{k i} \cdot d_{k k} \cdot u_{k j} & i=j>1 \\
u_{1 j}=\frac{a_{1 j}}{d_{11}} & i=1, j>i . \\
u_{i j}=\frac{a_{i j}-\sum_{k=1}^{i-1} u_{k i} \cdot d_{k k} \cdot u_{k j}}{d_{i i}} & i>1, j>i
\end{array}
$$

Depois de decomposta a matriz $\boldsymbol{A}$ o sistema de equações lineares pode ser escrito como,

$$
\boldsymbol{L} \cdot \boldsymbol{D} \cdot \boldsymbol{U} \cdot \boldsymbol{x}=\boldsymbol{b}
$$

faz-se $\boldsymbol{D} \cdot \boldsymbol{U} \cdot \boldsymbol{x}=\boldsymbol{y}$ obtendo-se um novo sistema $\boldsymbol{L} \cdot \boldsymbol{y}=\boldsymbol{b}$ que pode ser resolvido por redução progressiva, ou seja,

$$
y_{i}=b_{i}-\sum_{k=1}^{i-1} l_{i k} \cdot y_{k}
$$

Faz-se agora $\boldsymbol{U} \cdot \boldsymbol{x}=\boldsymbol{z}$ obtendo outro sistema $\boldsymbol{D} \cdot \boldsymbol{z}=\boldsymbol{y}$ que facilmente é resolvido por redução diagonal,

$$
z_{i}=\frac{y_{i}}{d_{i i}}
$$

Por ultimo obtém-se o sistema $\boldsymbol{U} \cdot \boldsymbol{x}=\boldsymbol{z}$ que é resolvido por redução retroativa,

$$
x_{i}=z_{i}-\sum_{k=i+1}^{n} u_{i k} \cdot x_{k} \text {. }
$$

O determinante da matriz $\boldsymbol{A}$ é igual ao determinante da matriz $\boldsymbol{D}$, ou seja,

$$
\operatorname{det}(\boldsymbol{A})=\operatorname{det}(\boldsymbol{D})=\prod_{k=1}^{n} d_{k k}
$$




\subsubsection{MÉTODO DE CHOLESKI}

O Método de Choleski só pode ser utilizado para resolução de sistemas de equações lineares, quando a matriz $\boldsymbol{A}$ for simétrica e definida positiva.

Para a resolução do sistema de equações lineares $\boldsymbol{A} \cdot \boldsymbol{x}=\boldsymbol{b}$ pelo Método de Choleski, devemos decompor a matriz $\boldsymbol{A}$ da seguinte forma $\boldsymbol{A}=\boldsymbol{C}^{T} \cdot \boldsymbol{C}$.

Desta forma 0 sistema de equações fica descrito pela equação $\boldsymbol{C}^{T} \cdot \boldsymbol{C} \cdot \boldsymbol{x}=\boldsymbol{b}, \mathrm{com}$ $\boldsymbol{C}=\boldsymbol{D}^{1 / 2} \cdot \boldsymbol{U}$, onde $\boldsymbol{D}$ é uma matriz diagonal, $\boldsymbol{U}$ é uma matriz triangular superior de diagonal unitária e desta forma $\boldsymbol{C}$ é uma matriz triangular superior.

Pode-se obter as matrizes $\boldsymbol{D}$ e $\boldsymbol{U}$ pelo seguinte algoritmo:

$$
\begin{array}{ll}
c_{11}=\sqrt{a_{11}} & \\
c_{1 j}=\frac{a_{1 j}}{c_{11}} & i=1, j>i \\
c_{i j}=\sqrt{a_{i j}-\sum_{k=1}^{i-1}\left(c_{k i}\right)^{2}} & i=j>1 \\
c_{i j}=\frac{a_{i j}-\sum_{k=1}^{i-1}\left(c_{k i} \cdot c_{k j}\right)}{c_{i i}} & i>1, j>1, j>i \\
d_{i j}=\left(c_{i j}\right)^{2} & i=j \\
u_{i j}=1 & i<j \\
u_{i j}=\frac{c_{i j}}{\sqrt{d_{i i}}} &
\end{array}
$$

Faz-se $\boldsymbol{C} \cdot \boldsymbol{x}=\boldsymbol{y}$, desta forma teremos que resolver o $\boldsymbol{C}^{T} \cdot \boldsymbol{y}=\boldsymbol{b}$ e por redução progressiva podemos escrever que

$$
y_{i}=\frac{b_{i}-\sum_{k=1}^{i-1} c_{k i} \cdot y_{k}}{c_{i i}} .
$$

Por fim resolve-se 0 sistema $\boldsymbol{C} \cdot \boldsymbol{x}=\boldsymbol{y}$ que por redução retroativa pode-se escrever

$$
x_{i}=\frac{y_{i}-\sum_{k=i+1}^{n} c_{i k} \cdot x_{k}}{c_{i i}} .
$$


Em problemas estruturais envolvendo o método dos elementos finitos, a matriz de rigidez $\boldsymbol{A}$ tem uma estrutura simétrica e esparsa, conhecida como perfil "skyline". Uma das vantagens de utilizarmos os Métodos de Crout e Choleski, é que ambos mantêm o perfil ou envelope da matriz $\boldsymbol{A}$, economizando memória. Uma das desvantagens destes métodos, é que quando existem muitos zeros internos ao perfil, torna-se difícil tirar proveito desta esparsidade.

0 Método de Crout é utilizado em qualquer matriz não singular, enquanto que no Método de Choleski, a matriz além de ser não singular tem que ser simétrica e definida positiva.

\subsubsection{MÉTODOS INDIRETOS}

Da mesma forma que nos métodos diretos de solução de sistemas de equações lineares apresentaremos apenas dois métodos indiretos de resolução: Método de Jacobi e o Método de Gauss-Seidel. Mais detalhes sobre estes métodos e sobre os demais métodos de resolução podem ser encontrados em ([R-1], [D-2]).

\subsubsection{MÉTODO DE JACOBI}

O Método de Jacobi consiste na decomposição da matriz $\boldsymbol{A}$ na soma de três matrizes $\boldsymbol{L}, \boldsymbol{D}$ e $\boldsymbol{U}$ onde $\boldsymbol{L}$ é uma matriz triangular inferior de diagonal nula, $\boldsymbol{D}$ é uma matriz diagonal e $\boldsymbol{U}$ é uma matriz triangular superior de diagonal nula, todas obtidas a partir da matriz $\boldsymbol{A}$ da seguinte forma

$$
A=L+D+U \Rightarrow D \cdot x=b-(L+U) \cdot x
$$

$\boldsymbol{L}=\left[\begin{array}{cccc}0 & 0 & \cdots & 0 \\ a_{21} & 0 & & \vdots \\ \vdots & & \ddots & 0 \\ a_{n 1} & \cdots & a_{n, n-1} & 0\end{array}\right] \quad \boldsymbol{D}=\left[\begin{array}{cccc}a_{11} & 0 & \cdots & 0 \\ 0 & a_{22} & & \vdots \\ \vdots & & \ddots & 0 \\ 0 & \cdots & 0 & a_{n n}\end{array}\right] \quad \boldsymbol{U}=\left[\begin{array}{cccc}0 & a_{12} & \cdots & a_{1 n} \\ 0 & 0 & & \vdots \\ \vdots & & \ddots & a_{n-1, n} \\ 0 & \cdots & 0 & 0\end{array}\right]$

0 método iterativo consiste em se arbitrar uma aproximação inicial para o vetor $\boldsymbol{x}$ como sendo $\boldsymbol{x}^{0}$ e obter os demais a partir da equação

$$
\boldsymbol{x}^{k+1}=\boldsymbol{D}^{-1} \cdot\left[\boldsymbol{b}-(\boldsymbol{L}+\boldsymbol{U}) \cdot \boldsymbol{x}^{k}\right]
$$


Como $\boldsymbol{D}$ é uma matriz diagonal sua inversa é facilmente obtida dividindo os termos da diagonal pelo determinante da matriz, da seguinte forma

$$
D^{-1}=\left[d_{i i}\right]^{-1}=\frac{1}{d_{i i}}
$$

sendo $n$ a dimensão da matriz.

\subsubsection{MÉTODO DE GAUSS-SEIDEL}

O Método de Gauss-Seidel consiste na decomposição da matriz $\boldsymbol{A}$ na soma de três matrizes $\boldsymbol{L}, \boldsymbol{D}$ e $\boldsymbol{U}$ onde $\boldsymbol{L}$ é uma matriz triangular inferior de diagonal nula, $\boldsymbol{D}$ é uma matriz diagonal e $\boldsymbol{U}$ é uma matriz triangular superior de diagonal nula, todas obtidas a partir da matriz $\boldsymbol{A}$ da seguinte forma

$$
\begin{gathered}
\boldsymbol{A}=\boldsymbol{L}+\boldsymbol{D}+\boldsymbol{U}=\boldsymbol{b} \\
\boldsymbol{L}=\left[\begin{array}{cccc}
0 & 0 & \cdots & 0 \\
a_{21} & 0 & & \vdots \\
\vdots & & \ddots & 0 \\
a_{n 1} & \cdots & a_{n, n-1} & 0
\end{array}\right] \quad \boldsymbol{D}=\left[\begin{array}{cccc}
a_{11} & 0 & \cdots & 0 \\
0 & a_{22} & & \vdots \\
\vdots & & \ddots & 0 \\
0 & \cdots & 0 & a_{n n}
\end{array}\right] \quad \boldsymbol{U}=\left[\begin{array}{cccc}
0 & a_{12} & \cdots & a_{1 n} \\
0 & 0 & & \vdots \\
\vdots & & \ddots & a_{n-1, n} \\
0 & \cdots & 0 & 0
\end{array}\right]
\end{gathered}
$$

0 método iterativo consiste em se arbitrar uma aproximação inicial para o vetor $\boldsymbol{x}$ como sendo $\boldsymbol{x}^{0}$ e obter os demais a partir da equação

$$
\boldsymbol{x}^{k+1}=(\boldsymbol{L}+\boldsymbol{D})^{-1} \cdot\left[\boldsymbol{b}-\boldsymbol{U} \cdot \boldsymbol{x}^{k}\right]
$$

outro artifício também utilizado é usar $w$ como um coeficiente para melhorar a convergência do método ficando a equação da seguinte forma

$$
[\boldsymbol{L}+(1-w) \cdot \boldsymbol{D}] \boldsymbol{x}^{k+1}=\boldsymbol{b}-(\boldsymbol{U}+w \cdot \boldsymbol{D}) \cdot \boldsymbol{x}^{k}
$$

sendo este processo conhecido como Método da Relaxação Dinâmica. 


\subsection{SiSTEMAS DE EQUAÇÕES NÃ 0-LINEARES}

Para solução de sistemas de equações não-lineares, apresenta-se apenas o Método de Newton. Outros métodos de resolução de sistemas não-lineares podem ser vistos em [D-2].

0 Método de Newton original pode ser formulado da seguinte forma

$$
\text { Solucionar } \begin{gathered}
f(\boldsymbol{x})=\boldsymbol{0} \\
\boldsymbol{x} \in \mathfrak{R}^{n}
\end{gathered}
$$

onde a função vetorial $f: \Re^{n} \rightarrow \mathfrak{R}^{n}$ é contínua com derivadas parciais contínuas até a primeira ordem.

Expandindo a função $\boldsymbol{f}(\boldsymbol{x})$ em série de Taylor em torno do ponto $\boldsymbol{x}^{k}$ e truncando-a no termo de primeira ordem, obtemos a seguinte expressão aproximada $\boldsymbol{f}(\boldsymbol{x}) \cong \boldsymbol{f}\left(\boldsymbol{x}^{k}\right)+\nabla \boldsymbol{f}\left(\boldsymbol{x}^{k}\right) \cdot\left(\boldsymbol{x}-\boldsymbol{x}^{k}\right)$.

0 Método de Newton é iterativo, ou seja no decorrer do problema é gerada uma seqüência de pontos a partir de um ponto inicial $\boldsymbol{x}^{0}$. Na k-ésima iteração, o ponto $\boldsymbol{x}^{k+1}$ é gerado a partir do ponto anterior $\boldsymbol{x}^{k}$ pela função

$$
\boldsymbol{x}^{k+1}=\boldsymbol{x}^{k}-\mathbb{J}^{-1} \cdot \boldsymbol{f}\left(\boldsymbol{x}^{k}\right) .
$$

0 processo iterativo do Método de Newton para funções de uma variável real pode ser observado na Figura 2 - 2. A solução $x^{*}$ é calculada pelo Método das Tangentes. 0 novo ponto $x^{k+1}$ é estimado pelo ponto no qual a tangente corta o eixo das abscissas.

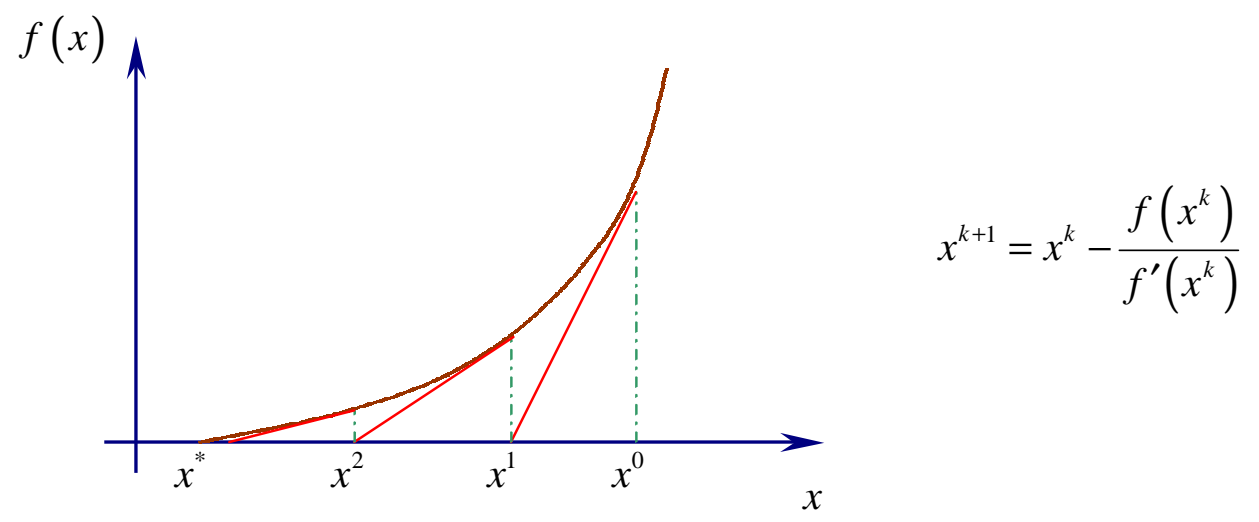

Figura 2 - 2 - Método de New ton Unidimensional 


\section{CAPÍtulo 3}

\section{ProgramaÇão Matemática}

este capítulo é apresentada uma abordagem geral, rápida e objetiva sobre a
Programação Matemática, com enfoque em alguns dos principais métodos empregados em problemas de otimização, apresentando suas idéias básicas e alguns comentários relevantes. Em cada método será descrita sua formulação e as referências bibliográficas nas quais podem ser encontrados de forma mais detalhada. Nos anexos constam alguns algoritmos ilustrando os métodos freqüentemente aplicados. Estão incluídos nestes anexos os algoritmos para os métodos abordados nesta dissertação.

"Vê mais longe a gaivota que voa mais alto" Richard Bach 


\subsection{INTRODUÇ̃̃ 0}

A Programação Matemática trata do estudo dos problemas de otimização junto com a determinação do algoritmo mais adequado para sua solução. Para isso é necessário um estudo da estrutura de cada um desses métodos visando um melhor entendimento dos processos matemáticos envolvidos.

Encontrar a solução de um problema de otimização significa descobrir o(s) ponto(s) de máximo ou de mínimo da função que o descreve. Esse processo envolve conceitos e definições largamente empregados pela literatura e que, portanto, serão apresentados a seguir.

Define-se o Problema Clássico de Otimização da seguinte forma

$$
\begin{array}{lll}
\text { Minimizar } & f(\boldsymbol{x}) & \\
\text { Sujeito } a & g_{\alpha}(\boldsymbol{x})=0 & \alpha \in I \\
& g_{\beta}(\boldsymbol{x})=0 & \beta \in D \\
& \boldsymbol{x} \in \Omega &
\end{array}
$$

onde $I$ é o conjunto de índices com restrições de comportamento, $D$ é o conjunto de índices com restrições laterais e $\boldsymbol{x}^{*}$ é denominado de solução ou ponto ótimo.

Se um ponto $\boldsymbol{x} \in \Omega$ obedece às condições de restrição ele é dito um ponto viável e 0 conjunto $\Gamma$ de todos os pontos viáveis é denominado de região viável.

Admite-se que a função $f(\boldsymbol{x})$ seja contínua e possua derivadas parciais contínuas até segunda ordem e as funções $g_{\alpha}(\boldsymbol{x})$ e $g_{\beta}(\boldsymbol{x})$ sejam contínuas e possuam derivadas parciais contínuas até primeira ordem.

\subsection{DEFINIÇões BÁSICAS - TERMINOLOGIA}

- Variáveis de Projeto: As variáveis de projeto são aquelas que se alteram durante 0 processo de otimização. Elas podem ser contínuas (reais), inteiras ou discretas (valores compreendidos dentro de um certo conjunto fixo).

De um ponto de vista físico, as variáveis de projeto podem representar as seguintes informações sobre a estrutura:

- Propriedades mecânicas ou físicas do material;

- A topologia da estrutura, isto é, o padrão de conexão dos elementos ou o número de elementos numa estrutura; 
- A configuração ou a forma geométrica da estrutura;

- Dimensões de seções transversais ou comprimento dos elementos.

- Restrições: As restrições são funções de igualdade ou desigualdade que descrevem situações indesejáveis de projeto. Podem ser divididas em dois grupos:

- Restrições Laterais: Efetuadas diretamente sobre as variáveis de projeto, limitando seus valores;

- Restrições de Comportamento: Condições desejáveis de limites de tensões, deslocamentos, freqüências naturais de vibração, etc.

- Espaço de Busca ou Região Viável: É o conjunto, espaço ou região que compreende as soluções possíveis ou viáveis do problema a ser otimizado. É caracterizado pelas funções de restrição.

- Função Objetivo ou de Avaliação: É a função que se quer otimizar. Pode ser de uma ou mais variáveis, classificadas como otimização unidimensional e multidimensional respectivamente.

- Ponto Ótimo: É o ponto caracterizado pelo vetor $\boldsymbol{x}^{*}=\left(x_{1}, x_{2}, \ldots, x_{n}\right)$, formado pelas variáveis de projeto que minimizam a função objetivo e satisfazem as restrições do problema.

- Valor Ótimo: É o valor da função objetivo $f\left(\boldsymbol{x}^{*}\right)$ no ponto ótimo.

- Solução Ótima: É o par (de solução) formado pelo ponto ótimo e valor ótimo $\left[\boldsymbol{x}^{*}, f\left(\boldsymbol{x}^{*}\right)\right]$, podendo ainda ser:

- Local: Quando o valor ótimo é localizado (vizinhança);

○ Global: Quando o valor ótimo é global na região viável;

- Restringida: Quando atende todas as restrições;

○ Não-restringida: Quando não atende a alguma das restrições.

Todos os métodos matemáticos que serão citados, usualmente apresentam teoremas provando a sua convergência. Entretanto, nenhum deles garante que a solução obtida seja 0 ponto de ótimo global, a solução obtida depende em geral do ponto de partida fornecido. 
Esta característica dos métodos clássicos ou matemáticos é uma das suas fraquezas que há muito se procura superar, porém, ainda sem sucesso.

De acordo com as características da função objetivo e das restrições, classificam-se os problemas de otimização nas seguintes sub-áreas da Programação Matemática:

- Programação Linear: Quando a função objetivo e as restrições são funções lineares das variáveis de projeto;

- Programação Não-Linear: Quando a função objetivo ou pelo menos uma das restrições é função não-linear das variáveis de projeto.

Posteriormente, outras subáreas foram aparecendo com o objetivo de maior especialização nos problemas a serem resolvidos, deste modo tem-se:

- Programação Quadrática: Quando a função objetivo é quadrática e as restrições são funções lineares das variáveis de projeto;

Uma extensão da Programação Matemática, sem no entanto fazer parte dela, seria a Programação Multi-Objetivo, que trata o problema de otimização de maneira diferente da anteriormente apresentada, ou seja, ao invés de uma, têm-se várias funções objetivo a serem otimizadas.

Embora um problema de otimização clássico possa ser resolvido pela programação Multi-Objetivo, deve-se destacar que as metodologias, conceitos e idéias são diferentes entre as duas formulações.

Os problemas de otimização não precisam necessariamente apresentar restrições, caracterizando a divisão dos problemas em duas grandes classes: Problemas de Otimização "com restrições" e "sem restrições".

Inúmeros são os métodos criados para tratamento de problemas de otimização, bem como inúmeras são as classificações realizadas pelos autores para estes métodos. Na Figura 3-1 é apresentada uma possível classificação geral de uma vasta gama de métodos existentes.

Como o número de métodos desenvolvidos para problemas de otimização é vasto, este trabalho apresenta apenas informações gerais das classes de problemas mais comuns, bem como comentários ou enfoques em determinados métodos. Para cada um deles será apresentada uma bibliografia na qual o assunto é desenvolvido de forma mais detalhada. 
PROGRAMAÇÃO LINEAR $\longrightarrow$ MÉTODO SIMPLEX

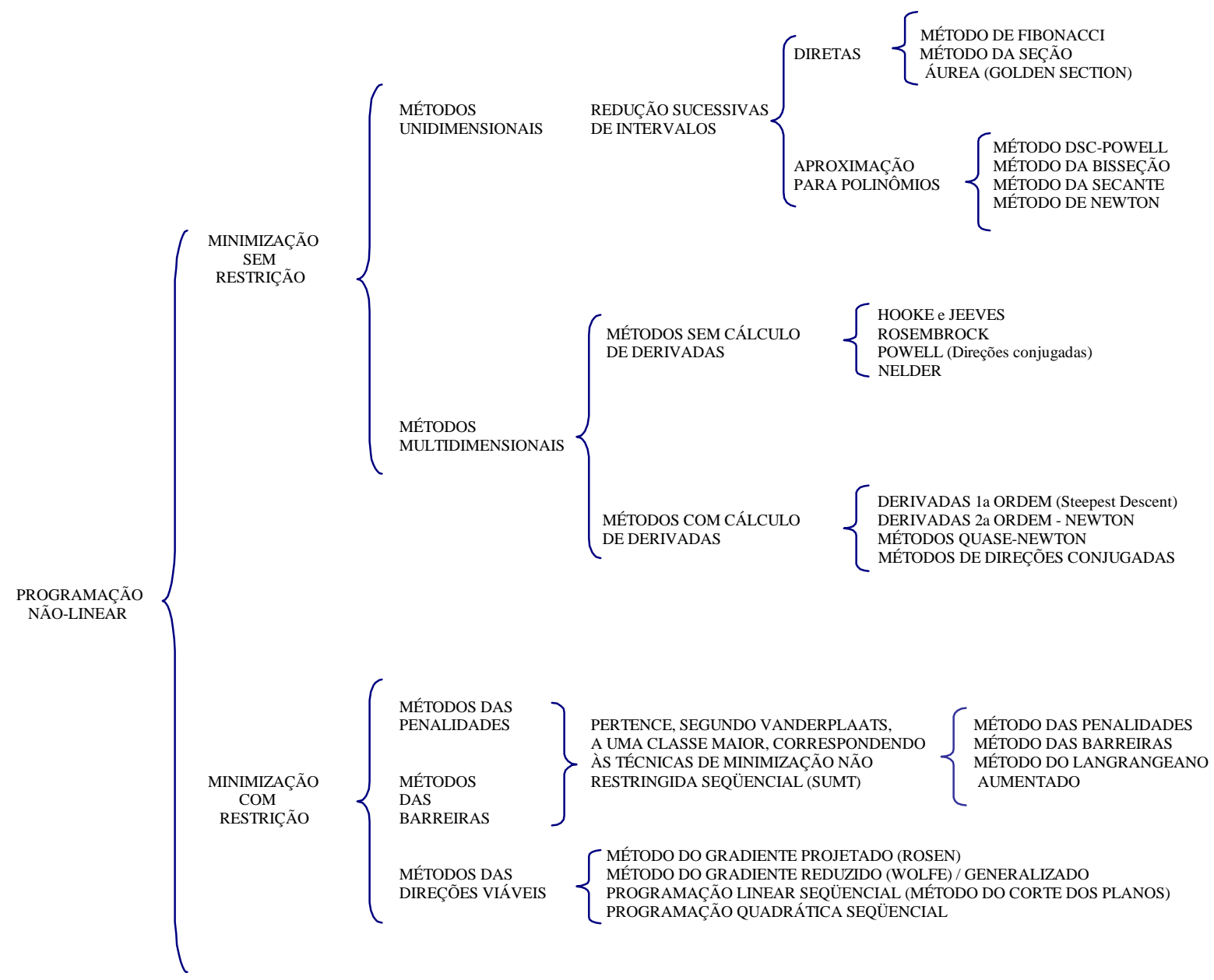

Figura 3 - 1 - Classificação Geral dos Métodos Clássicos

\subsection{Algoritmos de ProgramaÇão Matemática}

Dependendo do tipo de problema de otimização, ou seja, linear ou não-linear, com ou sem restrições, aplica-se diferentes métodos de programação matemática para resolvê-los.

Os métodos foram desenvolvidos de forma a agrupar os problemas em função da forma da função objetivo e das restrições do problema. Assim, quanto às restrições dos problemas, iremos subdividir os métodos apresentados em três grupos:

1. Métodos com Restrições de Igualdade

2. Métodos com Restrições de Desigualdade

3. Métodos com Restrições Mistas. 
Nos últimos anos estes processos de otimização têm sido utilizados em diversas áreas. Em função do avanço computacional, as empresas têm buscado cada vez mais utilizar estas ferramentas para maximizar lucros e minimizar custos de processos de produção, tornando desta forma a otimização uma área de pesquisa bastante promissora.

Como a maior parte dos problemas de otimização é resolvida por meio de computadores e os problemas gerados são cada vez maiores, deve-se procurar algoritmos cada vez mais eficientes para sua solução. Neste trabalho são apresentados alguns dos algoritmos existentes na literatura. Como se verá a seguir são vistos mais detalhadamente apenas os algoritmos de program ação não-linear.

\subsubsection{PROGRAMAÇão LINEAR}

A programação linear está ligada a solução de um tipo muito especial de problema aquele no qual todas as relações entre as variáveis são lineares, tanto nas restrições como na função a ser otimizada (função objetivo).

Pode-se definir o problema geral da Programação Linear da seguinte forma, dado um conjunto de " $m$ " desigualdades ou equações lineares em " $r$ " variáveis, queremos determinar valores não negativos dessas variáveis que satisfarão as restrições e minimizarão alguma função linear das variáveis.

Matematicamente isto pode ser escrito pela equação

$$
\begin{aligned}
\text { Minimizar } & f(\boldsymbol{x}) \\
\text { Sujeito a } & \boldsymbol{A} \cdot \boldsymbol{x}=\boldsymbol{b} \\
\text { ou } & \boldsymbol{A} \cdot \boldsymbol{x} \geq \boldsymbol{b} \\
\text { ou } & \boldsymbol{A} \cdot \boldsymbol{x} \leq \boldsymbol{b} \\
& x_{j} \geq 0 \quad j=1 \ldots q
\end{aligned}
$$

Uma propriedade importante dos problemas de Programação Linear origina-se do fato de nós podermos garantir que a solução ótima encontra-se no contorno da região de soluções viáveis.

0 método mais conhecido e largamente usado para a solução de problemas de programação linear é chamado de Método Simplex, que foi desenvolvido por George Dantzig em 1955 .

Hoje temos já algumas modificações em relação ao método original proposto que são: 
- Método Simplex Generalizado

- Método Simplex Revisado

É comum, no emprego do método, a transformação do problema a ser resolvido numa forma conhecida como "forma padrão", que introduz variáveis de folga nas restrições de desigualdade para obter-se somente restrições de igualdade, além de variáveis artificiais nas restrições originalmente de igualdade.

Quando se tem variáveis de projeto que admitam valores negativos, transformam-se as mesmas pela soma de valores altos, objetivando-se trabalhar com todas as variáveis positivas, o que melhora a convergência computacional do método.

Mais detalhes sobre o Método Simplex podem ser obtidos nas referencias [F-2], [H-1] e [L-3] apresentadas na bibliografia.

\subsubsection{ProgramaÇão NÃ 0-Linear}

A Programação Não-Linear trata dos problemas onde, ou a função objetivo ou alguma das restrições são funções não-lineares das variáveis de projeto. Os problemas se dividem em restritos ou não-restritos e uni ou multidimensionais, onde para cada caso há uma enormidade de métodos aplicáveis, alguns deles apresentados na classificação geral dos métodos de Programação Matemática anteriormente exibida na Figura 3 - 1.

Os métodos de Programação Não-Linear serão aqui subdivididos da seguinte forma:

1. O timização sem Restrições

2. O timização com Restrições

\subsubsection{OTIMIZAÇÃO SEM RESTRIÇÕES}

Os algoritmos de otimização para problemas de Programação Não-Linear sem restrições possuem, em geral, uma estrutura comum de resolução que consiste em se aplicar, de forma iterativa, a equação de recorrência $\boldsymbol{x}^{k}=\boldsymbol{x}^{k-1}+\alpha^{k} \cdot \boldsymbol{d}^{k}$, onde $\boldsymbol{x}$ é 0 vetor das variáveis de projeto, $\alpha$ é o tamanho do passo, $\boldsymbol{d}$ é a direção de busca e 0 índice $k$ representa a iteração corrente.

A diferença básica entre os diversos algoritmos de solução de problemas de otimização consiste na estratégia empregada para obtenção do vetor $\boldsymbol{d}^{k}$, correspondente às sucessivas direções de busca. Entre os vários métodos existentes para solução de problemas de Programação Não-Linear sem restrições, alguns necessitam apenas informações sobre o 
valor da função, outros, além do valor da função, utilizam a primeira derivada; e há ainda os que utilizam a segunda derivada. Estes métodos são denominados métodos de ordem zero, um e dois, respectivamente. Inúmeros são os métodos empregáveis a esta classe de problemas, dentre os quais: Gradiente, Newton e Quase-Newton [F-1].

0 problem a geral neste caso consiste em

$$
\text { Minimizar } f(x), \quad x \in \Re^{n}
$$

As condições necessárias e suficientes para se ter um mínimo local são:

1) Condição necessária de primeira ordem é $\nabla f\left(\boldsymbol{x}^{*}\right)=\boldsymbol{0}, \quad$ sendo $\nabla f\left(\boldsymbol{x}^{*}\right)=\boldsymbol{0} \Rightarrow \boldsymbol{x}^{*}$ é um ponto estacionário

2) Condição necessária de segunda ordem: $\left\{\begin{array}{c}\nabla f\left(\boldsymbol{x}^{*}\right)=0 \\ \boldsymbol{d}^{T} \cdot \nabla^{2} f\left(\boldsymbol{x}^{*}\right) \cdot \boldsymbol{d} \geq \boldsymbol{0} \quad \forall \boldsymbol{d} \neq \mathbf{0}\end{array}\right.$

3) Condição suficiente de segunda ordem : $\left\{\begin{array}{c}\nabla f\left(\boldsymbol{x}^{*}\right)=0 \\ \boldsymbol{d}^{T} \cdot \nabla^{2} f\left(\boldsymbol{x}^{*}\right) \cdot \boldsymbol{d}>\boldsymbol{0} \quad \forall \boldsymbol{d} \neq \boldsymbol{0}\end{array}\right.$

Os Métodos que serão apresentados para resolução de Problemas de otimização sem restrições são os seguintes:

- Método de Newton-Raphson

- Método Quase-Newton (BFGS)

- Método Quase-Newton (DFP)

Nos anexos temos os algoritmos para estes métodos bem como o algoritmo para 0 Método de Newton/Quase-Newton que utiliza as idéias tanto do Método de Newton como a aproximação feita pelo BFGS [F-1]. 


\subsection{MÉTODO DE NEWTON-RAPHSON}

Cosidere-se o problema de otimização dado por

$$
\text { Minimizar } f(\boldsymbol{x}) \quad \boldsymbol{x} \in \mathfrak{R}^{n}
$$

sendo $f(\boldsymbol{x})$ contínua com derivadas parciais contínuas até a segunda ordem.

Pode-se formular o Método de Newton original para este problema da seguinte forma

$$
\begin{gathered}
\text { Sol. } f(x)=0 \quad x \in \mathfrak{R}^{n} \\
\mathrm{e}: \mathfrak{R}^{n} \rightarrow \mathfrak{R},
\end{gathered}
$$

onde $f(\boldsymbol{x})$ é contínua com derivadas parciais contínuas até a segunda ordem.

Expandindo a função $f(\boldsymbol{x})$ em série de Taylor em torno do ponto $\boldsymbol{x}^{k}$ e truncando-a no termo de primeira ordem, obtém-se que

$$
f(x) \cong f\left(x^{k}\right)+\nabla f\left(x^{k}\right) \cdot\left(x-x^{k}\right),
$$

desta forma substituindo $f(\boldsymbol{x})=0$ na equação acima, tem-se

$$
\boldsymbol{x} \cong \boldsymbol{x}^{k}-\left[\nabla f\left(\boldsymbol{x}^{k}\right)\right]^{-1} \cdot f\left(\boldsymbol{x}^{k}\right)
$$

com isso formula-se finalmente a expressão

$$
\boldsymbol{x}^{k+1}=\boldsymbol{x}^{k}-\left[\nabla f\left(\boldsymbol{x}^{k}\right)\right]^{-1} \cdot f\left(\boldsymbol{x}^{k}\right)
$$

que é a formula iterativa utilizada para resolução do problema.

0 algoritmo para o Método de New ton pode ser visto no Anexo A no algoritmo A-3.1.

As principais características deste método são:

- 0 método tem convergência quadrática;

- Pelas condições suficientes de segunda ordem, para que um ponto $\boldsymbol{x}^{*}$ seja um mínimo local do problema, a matriz Hessiana $\nabla^{2} f\left(\boldsymbol{x}^{*}\right)$ deve ser positiva definida, desta forma, em um ponto próximo a $\boldsymbol{x}^{*}$ ela também 0 será garantindo um bom comportamento do método perto da solução.

- Para valores distantes da solução, o Método de New ton perde sua eficiência. 
Uma modificação usual que se faz ao Método de Newton é a introdução da Busca Unidimensional, ou seja, um parâmetro sé introduzido resultando na seguinte equação

$$
\boldsymbol{x}^{k+1}=\boldsymbol{x}^{k}-\mathrm{s}^{k} \cdot\left[\nabla^{2} f\left(\boldsymbol{x}^{k}\right)\right]^{-1} \cdot \nabla f\left(\boldsymbol{x}^{k}\right),
$$

onde $s^{k}$ é um escalar positivo que minimiza $f(\boldsymbol{x})$ na direção $\boldsymbol{d}^{k}$, dada por

$$
\boldsymbol{d}^{k}=\left[\nabla^{2} f\left(\boldsymbol{x}^{k}\right)\right]^{-1} \cdot \nabla f\left(\boldsymbol{x}^{k}\right)
$$

perto da solução teremos $s^{k} \cong 1$.

O Método de Newton com busca unidimensional está esquematicamente descrito no Anexo A no Algoritmo A-3.3 e o algoritmo da Busca Unidimensional é apresentado no Anexo A no Algoritmo A-3.2.

\subsection{MÉTOdO QUASE-NEWTON (B F GS)}

Seja o problema de otimização dado por

$$
\text { Minimizar } f(\boldsymbol{x}) \quad \boldsymbol{x} \in \mathfrak{R}^{n},
$$

sendo $f(\boldsymbol{x})$ contínua com derivadas parciais contínuas até a segunda ordem.

Para que se possa diferenciar este método do Método de Newton apresentam-se a seguir algumas características do método:

- 0 método surgiu para melhorar o Método de Newton, obtendo uma versão do método que também convergisse para valores iniciais "distantes da solução".

- Os Métodos Quase-Newton estão enquadrados em um grupo de métodos de decréscimos, que geram seqüências de pontos a partir de um ponto inicial $\boldsymbol{x}^{0}$. A solução $\boldsymbol{x}^{*}$ é calculada pelo Método das Secantes. Na k-ésima iteração, o ponto $\boldsymbol{x}^{k+1}$ é gerado a partir do ponto $\boldsymbol{x}^{k}$ da seguinte forma: $\boldsymbol{x}^{k+1}=\boldsymbol{x}^{k}-s^{k} \cdot \boldsymbol{d}^{k}$, onde $s^{k}$ é um escalar que minimiza a função $k \cdot n^{2}$ e $\boldsymbol{d}^{k}$ é uma direção de decréscimo.

Considere-se a definição dos seguintes vetores

$$
\boldsymbol{\delta}^{k}=\boldsymbol{x}^{k+1}-\boldsymbol{x}^{k} \quad \text { e } \quad \boldsymbol{\gamma}^{k}=\nabla f\left(\boldsymbol{x}^{k+1}\right)-\nabla f\left(\boldsymbol{x}^{k}\right)
$$


A condição Quase-Newton, ou condição secante, que garante que a matriz, $\boldsymbol{B}^{k} \cong\left[\nabla^{2} f\left(\boldsymbol{x}^{k}\right)\right]^{-1}$ é definida por

$$
\boldsymbol{B}^{k} \cdot \boldsymbol{\gamma}^{k}=\boldsymbol{\delta}^{k}
$$

Nos Métodos Quase-New ton a seqüência de pontos é definida por

$$
\boldsymbol{x}^{k+1}=\boldsymbol{x}^{k}-s^{k} \cdot \boldsymbol{B}^{k} \cdot \nabla f\left(\boldsymbol{x}^{k}\right),
$$

sendo $s^{k}$ um escalar positivo e $\boldsymbol{B}^{k}$ a aproximação da inversa da Matriz Hessiana da função $f(\boldsymbol{x})$ e neste caso a direção de decréscimo definida por

$$
\boldsymbol{d}^{k}=\boldsymbol{B}^{k} \cdot \nabla f\left(\boldsymbol{x}^{k}\right)
$$

As principais diferenças entre este método e 0 Método de Newton original são apresentadas na seqüência:

1. Acréscimos do coeficiente $s^{k}$ (Busca unidimensional);

2. A proximação da inversa da Matriz Hessiana.

A atualização da inversa da Matriz Hessiana se dá a partir da geração de uma seqüência de matrizes $\boldsymbol{B}^{0}, \boldsymbol{B}^{1}, \ldots, \boldsymbol{B}^{k-1}, \boldsymbol{B}^{k}$, onde em cada iteração a matriz $\boldsymbol{B}^{k+1}$ é calculada a partir da matriz imediatamente anterior $\boldsymbol{B}^{k}$. Se não for possível obter as informações iniciais da Matriz Hessiana, adota-se como aproximação inicial de $\boldsymbol{B}^{0}$ a matriz identidade. Depois de determinar o ponto $\boldsymbol{x}^{k+1}$, uma nova aproximação $\boldsymbol{B}^{k+1}$ é obtida atualizando $\boldsymbol{B}^{k}$, ou seja,

$$
\boldsymbol{B}^{k+1}=\boldsymbol{B}^{k}+\boldsymbol{U}^{k}
$$

onde $\boldsymbol{U}^{k}$ é uma matriz de atualização.

A formula para atualização da matriz Hessiana para o Método Quase-Newton BFGS (Broyden, Fletcher, Goldfarb, Shanno) é apresentada a seguir

$$
\boldsymbol{B}^{k+1}=\boldsymbol{B}^{k}+\left(1+\frac{\left(\boldsymbol{\gamma}^{k}\right)^{T} \cdot \boldsymbol{B}^{k} \cdot \boldsymbol{\gamma}^{k}}{\left(\boldsymbol{\delta}^{k}\right)^{T} \cdot \boldsymbol{\gamma}^{k}}\right) \cdot \frac{\boldsymbol{\delta}^{k} \cdot\left(\boldsymbol{\delta}^{k}\right)^{T}}{\left(\boldsymbol{\delta}^{k}\right)^{T} \cdot \boldsymbol{\gamma}^{k}}-\left(\frac{\boldsymbol{\delta}^{k} \cdot\left(\boldsymbol{\gamma}^{k}\right)^{T} \cdot \boldsymbol{B}^{k}+\boldsymbol{B}^{k} \cdot \boldsymbol{\gamma}^{k} \cdot\left(\boldsymbol{\delta}^{k}\right)^{T}}{\left(\boldsymbol{\delta}^{k}\right)^{T} \cdot \boldsymbol{\gamma}^{k}}\right)
$$

A mesma expressão pode ser reescrita como se segue

$$
\boldsymbol{B}^{k}=\left(\boldsymbol{I}+\boldsymbol{v}^{k} \cdot\left(\boldsymbol{\omega}^{k}\right)^{T}\right) \cdot \boldsymbol{B}^{k-1} \cdot\left(\boldsymbol{I}+\boldsymbol{\omega}^{k} \cdot\left(\boldsymbol{v}^{k}\right)^{T}\right)
$$


onde

$$
\boldsymbol{v}^{k}=\frac{\boldsymbol{\delta}^{k}}{\boldsymbol{\delta}^{k} \cdot \boldsymbol{\gamma}^{k}} \quad \alpha^{k}=\sqrt{\frac{-s^{k} \cdot \boldsymbol{\gamma}^{k} \cdot \boldsymbol{\delta}^{k}}{\nabla f\left(\boldsymbol{x}^{k-1}\right) \cdot \boldsymbol{\delta}^{k}}} \quad \boldsymbol{\omega}^{k}=-\boldsymbol{\gamma}^{k}+\alpha^{k} \cdot \nabla f\left(\boldsymbol{x}^{k-1}\right)
$$

Substituindo as expressões acima na equação $\boldsymbol{d}^{k}=\boldsymbol{B}^{k} \cdot \nabla f\left(\boldsymbol{x}^{k}\right)$, que calcula o direção de decréscimo, obtém-se

$$
\boldsymbol{d}^{k}=\left(\boldsymbol{I}+\boldsymbol{v}^{k} \cdot\left(\boldsymbol{\omega}^{k}\right)^{T}\right) \cdot \boldsymbol{B}^{k-1} \cdot\left(\boldsymbol{I}+\boldsymbol{\omega}^{k} \cdot\left(\boldsymbol{v}^{k}\right)^{T}\right) \cdot \nabla f\left(\boldsymbol{x}^{k}\right)
$$

As principais características dos Métodos de Quase-Newton são:

- Necessita-se apenas da primeira derivada da função $f$;

- A matriz $\boldsymbol{B}^{k}$ é uma matriz positiva definida;

- São realizadas $O \cdot n^{2}$ multiplicações por iteração enquanto no Método de Newton são realizadas $O \cdot n^{3}$.

\subsection{MÉTODO QUASE-NEWTON (DFP)}

Foram propostas diversas formulas para atualização da matriz Hessiana, outra formula bastante utilizada será apresentada a seguir e foi proposta por Davidon, Fletcher e Powell (DFP).

A atualização da matriz Hessiana neste caso é feita da seguinte forma

$$
\boldsymbol{B}^{k+1}=\boldsymbol{B}^{k}+\frac{\boldsymbol{\delta}^{k} \cdot\left(\boldsymbol{\delta}^{k}\right)^{T}}{\left(\boldsymbol{\delta}^{k}\right)^{T} \cdot \boldsymbol{\gamma}^{k}}-\left(\frac{\boldsymbol{B}^{k} \cdot \boldsymbol{\gamma}^{k} \cdot\left(\boldsymbol{\delta}^{k}\right)^{T} \cdot \boldsymbol{B}^{k}}{\left(\boldsymbol{\gamma}^{k}\right)^{T} \cdot \boldsymbol{B}^{k} \cdot \boldsymbol{\gamma}^{k}}\right)
$$

É fácil mostrar que existem algumas relações entre as equações obtidas para os métodos BFGS e DFP, tais relações são mostradas logo abaixo.

Definindo-se uma matriz $\boldsymbol{H}$ como sendo a inversa da matriz Hessiana aproximada obtida nos Métodos Quase-Newton tem-se

$$
\boldsymbol{H}^{k}=\left(\boldsymbol{B}^{k}\right)^{-1} \quad \Rightarrow \quad \boldsymbol{H}^{k} \cdot \boldsymbol{\delta}^{k}=\boldsymbol{\gamma}^{k}
$$

desta forma a expressão da matriz $\boldsymbol{H}$ para ambos os métodos é definida da seguinte forma 


$$
\begin{gathered}
\boldsymbol{H}_{D F P}^{k+1}=\boldsymbol{H}^{k}+\left(1+\frac{\left(\boldsymbol{\delta}^{k}\right)^{T} \cdot \boldsymbol{H}^{k} \cdot \boldsymbol{\delta}^{k}}{\left(\boldsymbol{\gamma}^{k}\right)^{T} \cdot \boldsymbol{\delta}^{k}}\right) \cdot \frac{\boldsymbol{\gamma}^{k} \cdot\left(\boldsymbol{\delta}^{k}\right)^{T}}{\left(\boldsymbol{\gamma}^{k}\right)^{T} \cdot \boldsymbol{\delta}^{k}}-\left(\frac{\boldsymbol{\gamma}^{k} \cdot\left(\boldsymbol{\delta}^{k}\right)^{T} \cdot \boldsymbol{H}^{k}+\boldsymbol{H}^{k} \cdot \boldsymbol{\delta}^{k} \cdot\left(\boldsymbol{\gamma}^{k}\right)^{T}}{\left(\boldsymbol{\gamma}^{k}\right)^{T} \cdot \boldsymbol{\delta}^{k}}\right) \\
\mathrm{e} \\
\boldsymbol{H}_{B F G S}^{k+1}=\boldsymbol{H}^{k}+\frac{\boldsymbol{\gamma}^{k} \cdot\left(\boldsymbol{\gamma}^{k}\right)^{T}}{\left(\boldsymbol{\gamma}^{k}\right)^{T} \cdot \boldsymbol{\delta}^{k}}-\left(\frac{\boldsymbol{H}^{k} \cdot \boldsymbol{\delta}^{k} \cdot\left(\boldsymbol{\gamma}^{k}\right)^{T} \cdot \boldsymbol{H}^{k}}{\left(\boldsymbol{\delta}^{k}\right)^{T} \cdot \boldsymbol{H}^{k} \cdot \boldsymbol{\delta}^{k}}\right)
\end{gathered}
$$

ou seja,

$$
\boldsymbol{B}_{B F G S}^{k+1} \cdot \boldsymbol{H}_{B F G S}^{k+1}=\boldsymbol{I} \quad \text { e } \quad \boldsymbol{B}_{D F P}^{k+1} \cdot \boldsymbol{H}_{D F P}^{k+1}=\boldsymbol{I} .
$$

Pode-se ainda citar uma outra fórmula que tenta unir os dois métodos anteriormente apresentados com a seguinte expressão

$$
\boldsymbol{B}_{\phi}^{(k+1)}=(1-\phi) \cdot \boldsymbol{B}_{D F P}^{(k+1)}+\phi \cdot \boldsymbol{B}_{B F G S}^{(k+1)},
$$

com 0 valor de $\phi$ obtido pela Fórmula de Hoshino para cada iteração

$$
\phi=\frac{1}{1 \pm \frac{\gamma^{T} \cdot \boldsymbol{B} \cdot \boldsymbol{\gamma}}{\delta^{T} \cdot \boldsymbol{\gamma}}} .
$$

A fórmula BFGS em particular têm sido mais utilizada na prática, talvez por ser melhor que a fórmula DFP e já representar a inversa da matriz Hessiana não sendo mais necessário inverter a matriz no algoritmo de resolução.

A seguir são apresentadas algumas propriedades comuns para os Métodos Quase-Newton DFP e BFGS:

- Pode-se demonstrar que para funções quadráticas:

- Concluídas as $k$ iterações $\boldsymbol{B}^{k+1}=\left[\nabla^{2} f(\boldsymbol{x})\right]^{-1}$ obtendo desta forma a solução do problema;

- Preserva-se as condições do Método Quase-Newton;

- Os métodos geram direções conjugadas e gradientes conjugados quando $\boldsymbol{B}=\boldsymbol{I} ;$

- Quando se tratar de funções em geral, pode demonstrar que:

- Os métodos preservam a matriz $\boldsymbol{B}^{k}$ como positiva definida;

○ Requer $3 \cdot n^{2}+k \cdot n$ multiplicações por iteração; 
- Possuem convergência numa razão super linear;

- Possuem convergência global para funções estritamente convexas;

\subsubsection{O TIMIZAÇÃO COM RESTRIÇõeS}

Os métodos de otimização com restrições buscam descrever o problema de forma a transforma-lo em um problema de otimização sem restrições, sendo desta forma possível resolver os mesmos com os métodos anteriormente apresentados.

Considere-se o problema geral de otimização com restrições da forma

$$
\begin{array}{ll}
\text { Minimizar } & f(\boldsymbol{x}) \\
\text { Sujeito } a & g_{i}(\boldsymbol{x})=0, \quad i=1 \ldots m \\
& g_{j}(\boldsymbol{x}) \leq 0, \quad j=1 \ldots q \\
& \boldsymbol{x} \in \Omega \subset \mathfrak{R}^{n} \\
& \Gamma=\left\{x \in \Omega \mid g_{i}(\boldsymbol{x})=0, \quad i=1 \ldots m\right.
\end{array},
$$

onde $\Gamma$ é denominada de região viável e com a função $f(\boldsymbol{x})$ contínua e com derivadas parciais contínuas até a segunda ordem e as funções $g_{i}(\boldsymbol{x})$ e $g_{j}(\boldsymbol{x})$ contínuas e com derivadas parciais contínuas até a primeira ordem.

Para um melhor entendimento dos métodos que serão apresentados a seguir, estes serão subdivididos da seguinte forma:

1. Métodos com Restrições de Igualdade

2. Métodos com Restrições de Desigualdade

3. Métodos com Restrições Mistas

\subsection{O TIMIZAÇão COM RESTRIÇõES DE IGUALDADE}

Considere-se o problem a geral de otimização com restrições de igualdade da forma

$$
\begin{array}{ll}
\text { Minimizar } & f(\boldsymbol{x}) \\
\text { Sujeito } a & g_{i}(\boldsymbol{x})=0, \quad i=1 \ldots m \\
& \boldsymbol{x} \in \Omega \subset \Re^{n} \\
& \Gamma=\left\{x \in \Omega \mid g_{i}(\boldsymbol{x})=0, \quad i=1 \ldots m\right\}
\end{array}
$$

A seguir são apresentadas algumas definições que posteriormente são utilizadas nos métodos

- $\boldsymbol{\delta} \in \mathfrak{R}^{n}$ é um incremento viável em um ponto $\boldsymbol{x} \in \Gamma \Leftrightarrow \boldsymbol{x}+\boldsymbol{\delta} \in \Gamma$; 
- Diz-se que uma direção $\boldsymbol{d}$ é uma direção de decréscimo em $\boldsymbol{x} \Leftrightarrow \boldsymbol{d}^{T} \cdot \nabla f\left(\boldsymbol{x}^{*}\right)<0$ e se o ponto $\boldsymbol{x}^{*}$ é um ponto de mínimo local, não existe $\boldsymbol{d}$ tal que

$$
\left\{\begin{array}{l}
\boldsymbol{d}^{T} \cdot \nabla g_{i}\left(\boldsymbol{x}^{*}\right)=0 \\
\boldsymbol{d}^{T} \cdot \nabla f\left(\boldsymbol{x}^{*}\right)<0
\end{array} \quad i=1 \ldots m ;\right.
$$

- Diz-se que um ponto $\boldsymbol{x}^{*}$, que satisfaz as restrições $g_{i}(\boldsymbol{x})=0$ para $i=1 \ldots m$, é um ponto regular se os vetores gradientes $\nabla g_{1}\left(\boldsymbol{x}^{*}\right), \nabla g_{2}\left(\boldsymbol{x}^{*}\right), \ldots, \nabla g_{m}\left(\boldsymbol{x}^{*}\right)$ forem LI;

- Sendo $\boldsymbol{x}^{*}$ um ponto regular e como o sistema

$$
\left\{\begin{array}{l}
\boldsymbol{d}^{T} \cdot \nabla g_{i}\left(\boldsymbol{x}^{*}\right)=0 \\
\boldsymbol{d}^{T} \cdot \nabla f\left(\boldsymbol{x}^{*}\right)<0
\end{array} \quad i=1 \ldots m\right.
$$

não tem solução, podemos garantir que existem $\lambda_{i}^{*} \operatorname{com} i=1 \ldots m$, tais que $\nabla f\left(\boldsymbol{x}^{*}\right)-\sum_{i=1}^{m} \lambda_{i}^{*} \cdot \nabla g_{i}\left(\boldsymbol{x}^{*}\right)=0$, onde os números $\lambda_{i}^{*}$ são denominados Multiplicadores de Lagrange;

- Denomina-se de Função Lagrangiana a função definida por

$$
L(x, \lambda)=f(x)-\sum_{i=1}^{m} \lambda_{i} \cdot g_{i}(x)
$$

- A condição necessária de primeira ordem para que um ponto viável seja um mínimo local, é dada por $\nabla f\left(x^{*}\right)-\sum_{i=1}^{m} \lambda_{i}^{*} \cdot \nabla g_{i}\left(x^{*}\right)=0$, ou seja, 0 gradiente da função objetivo deve ser uma combinação linear dos gradientes das restrições;

- A condição necessária de primeira ordem para que o ponto $\left(\boldsymbol{x}^{*}, \lambda^{*}\right)$ seja um ponto estacionário da Função Lagrangeana é dada por $\nabla L\left(\boldsymbol{x}^{*}, \lambda^{*}\right)=0$, com $\nabla=\left[\begin{array}{c}\nabla_{x} \\ \nabla_{\lambda}\end{array}\right]$.

Os métodos apresentados nesta seção serão os seguintes:

- Método do Lagrangiano

- Método da Penalidade

- Método do Lagrangiano Aumentado 


\subsection{MÉTODO DO LAGRANGIANO}

Considere-se o seguinte problema geral de otimização com restrições de igualdade da seguinte forma

$$
\begin{array}{ll}
\text { Minimizar } & f(\boldsymbol{x}) \\
\text { Sujeito } \quad a & g_{i}(\boldsymbol{x})=0 \quad i=1 \ldots m \\
& \boldsymbol{x} \in \mathfrak{R}^{n}
\end{array}
$$

com a função $f(\boldsymbol{x})$ contínua e com derivadas parciais contínuas até a segunda ordem e a(s) função(ões) $g_{i}(\boldsymbol{x})$ contínua(s) e com derivadas parciais contínuas até a primeira ordem.

A condição necessária de primeira ordem para que 0 ponto $\left(\boldsymbol{x}^{*}, \boldsymbol{\lambda}^{*}\right)$ seja ponto estacionário da Função Lagrangiana como foi visto na seção anterior é $\nabla L\left(\boldsymbol{x}^{*}, \lambda^{*}\right)=0$, onde $L(x, \lambda)=f(x)-\sum_{i=1}^{m} \lambda_{i} \cdot g_{i}(x)$

Pode-se agora definir as funções $\boldsymbol{f}_{1}\left(\boldsymbol{x}^{*}\right)$ e $\boldsymbol{f}_{2}\left(\boldsymbol{x}^{*}\right)$ da seguinte forma

$$
\begin{gathered}
\boldsymbol{f}_{1}\left(\boldsymbol{x}^{*}\right)=\nabla f\left(\boldsymbol{x}^{*}\right)+\sum_{i=1}^{m} \lambda_{i}^{*} \cdot \nabla g_{i}\left(\boldsymbol{x}^{*}\right)=\mathbf{0} \\
\boldsymbol{f}_{2}\left(\boldsymbol{x}^{*}\right)=\left[\begin{array}{c}
g_{1}\left(\boldsymbol{x}^{*}\right) \\
g_{2}\left(\boldsymbol{x}^{*}\right) \\
\vdots \\
g_{m}\left(\boldsymbol{x}^{*}\right)
\end{array}\right]=\mathbf{0}
\end{gathered}
$$

$\log _{0} 0$ sistem a acima pode ser representado por

$$
t(x, \lambda)=\left\{\begin{array}{c}
\nabla f\left(x^{*}\right)+\sum_{i=1}^{m} \lambda_{i}^{*} \cdot \nabla g_{i}\left(x^{*}\right) \\
\nabla g_{1}\left(x^{*}\right) \\
\vdots \\
\nabla g_{m}\left(x^{*}\right)
\end{array}\right\}=\left\{\begin{array}{l}
f_{1} \\
f_{2}
\end{array}\right\}=0
$$

Utilizando o Método de Newton para resolver o sistema tem-se

$$
\left[\begin{array}{l}
\boldsymbol{x} \\
\lambda
\end{array}\right]^{k+1}=\left[\begin{array}{l}
\boldsymbol{x} \\
\boldsymbol{\lambda}
\end{array}\right]^{k}-\left[\nabla t\left(\boldsymbol{x}^{k}, \lambda^{k}\right)\right]^{-1} \cdot t\left(\boldsymbol{x}^{k}, \lambda^{k}\right)
$$


0 que equivale a resolver $\nabla t\left(\boldsymbol{x}^{k}, \lambda^{K}\right) \cdot \boldsymbol{d}^{k}=-t\left(\boldsymbol{x}^{k}, \lambda^{K}\right)$, onde $\boldsymbol{d}^{k}$ e $\nabla t\left(\boldsymbol{x}^{k}, \lambda^{K}\right)$ são respectivamente

$$
\boldsymbol{d}^{k}=\left[\begin{array}{c}
\boldsymbol{x} \\
\lambda
\end{array}\right]^{k+1}-\left[\begin{array}{l}
\boldsymbol{x} \\
\lambda
\end{array}\right]^{k} \quad \text { e } \quad \nabla t\left(\boldsymbol{x}^{k}, \lambda^{k}\right)=\left[\begin{array}{ll}
\frac{\partial \boldsymbol{f}_{1}}{\partial \boldsymbol{x}} & \frac{\partial \boldsymbol{f}_{1}}{\partial \lambda} \\
\frac{\partial \boldsymbol{f}_{2}}{\partial \boldsymbol{x}} & \frac{\partial \boldsymbol{f}_{2}}{\partial \lambda}
\end{array}\right]
$$

Apenas escrevendo de outra forma tem-se que

$$
\nabla t\left(\boldsymbol{x}^{k}, \boldsymbol{\lambda}^{k}\right)=\left[\begin{array}{cc}
\nabla^{2} f\left(\boldsymbol{x}^{k}\right)+\sum_{i=1}^{m} \lambda_{i}^{k} \cdot \nabla^{2} g_{i}\left(\boldsymbol{x}^{k}\right) & \nabla g\left(\boldsymbol{x}^{k}\right) \\
{\left[\nabla g\left(\boldsymbol{x}^{k}\right)\right]} & 0
\end{array}\right]
$$

Para resolver o sistema de equações acima descrito será necessário inverter a matriz $\nabla t\left(\boldsymbol{x}^{k}, \lambda^{K}\right)$, desta forma pode-se fazer simplificar os cálculos da seguinte forma, adota-se para as matrizes $\boldsymbol{A}$ e $\boldsymbol{B}$ as seguinte expressões

$$
\boldsymbol{A}=\nabla^{2} f\left(\boldsymbol{x}^{k}\right)+\sum_{i=1}^{m} \lambda_{i}^{k} \cdot \nabla^{2} g_{i}\left(\boldsymbol{x}^{k}\right) \quad \text { e } \quad \boldsymbol{B}=\nabla g\left(\boldsymbol{x}^{k}\right)
$$

Desta forma inverter a matriz $\nabla t\left(\boldsymbol{x}^{k}, \lambda^{K}\right)$ é o mesmo que determinar as matrizes $\boldsymbol{C}$, $\boldsymbol{D}$ e $\boldsymbol{E}$ de forma que

$$
\left[\begin{array}{cc}
\boldsymbol{A} & \boldsymbol{B} \\
\boldsymbol{B}^{T} & \boldsymbol{O}
\end{array}\right] \cdot\left[\begin{array}{cc}
\boldsymbol{C} & \boldsymbol{D} \\
\boldsymbol{D}^{T} & \boldsymbol{E}
\end{array}\right]=\left[\begin{array}{cc}
\boldsymbol{I} & \boldsymbol{O} \\
\boldsymbol{O} & \boldsymbol{I}
\end{array}\right]
$$

Pode-se facilmente obter a partir de algumas operações as expressões

$$
\begin{gathered}
C=A^{-1}-A^{-1} \times B \times\left(B^{T} \times A^{-1} \times B\right)^{-1} \times B^{T} \times A^{-1}, \\
D=A^{-1} \cdot B \cdot\left(B^{T} \cdot A^{-1} \cdot B\right)^{-1} \text { e } \quad E=-\left(B^{T} \cdot A^{-1} \cdot B\right)^{-1} .
\end{gathered}
$$

Logo o problema fica resumido a resolver o seguinte sistem a de equações

$$
\left[\begin{array}{l}
\boldsymbol{d}_{1} \\
\boldsymbol{d}_{2}
\end{array}\right]^{k}=\left[\begin{array}{cc}
\boldsymbol{C} & \boldsymbol{D} \\
\boldsymbol{D}^{T} & \boldsymbol{E}
\end{array}\right] \cdot\left[\begin{array}{l}
\boldsymbol{f}_{1} \\
\boldsymbol{f}_{2}
\end{array}\right],
$$

de onde se obtém as seguintes expressões finais

$$
\begin{gathered}
\boldsymbol{d}_{1}{ }^{k}=-\boldsymbol{A}^{-1} \cdot \boldsymbol{f}_{1}-\boldsymbol{A}^{-1} \cdot \boldsymbol{B} \cdot \boldsymbol{d}_{2}{ }^{k} \\
\boldsymbol{d}_{2}{ }^{k}=\left(\boldsymbol{B}^{T} \cdot \boldsymbol{A}^{-1} \cdot \boldsymbol{B}\right)^{-1} \cdot\left[\boldsymbol{B}^{T} \cdot \boldsymbol{A}^{-1} \cdot \boldsymbol{f}_{1}+\boldsymbol{f}_{2}\right]
\end{gathered}
$$


0 algoritmo para o Método do Lagrangiano com restrições de igualdade está apresentado no Anexo A pelo Algoritmo A-3.10. No algoritmo A-3.9 do Anexo A é mostrado esquematicamente o calculo da direção de decréscimo $\boldsymbol{d}^{k}$ para o Método do Lagrangiano.

\subsection{MÉTOdo da Penalidade}

O Método da Penalidade tem como idéia básica transformar o problema de otimização com restrições de igualdade em um problema sem restrições.

A idéia é montar uma Função de Penalidade na qual se combinam a função objetivo $f(\boldsymbol{x})$ com as restrições $g_{i}(\boldsymbol{x})$ possibilitando desta forma a minimização de $f(\boldsymbol{x})$ ao mesmo tempo em que são satisfeitas as restrições $g_{i}(\boldsymbol{x})$, penalizando-as.

A Função de Penalidade do problema pode ser definida como

$$
P(x, \xi)=f(x)+\frac{1}{2} \cdot \xi \cdot \sum_{i=1}^{m} g_{i}^{2}(x)
$$

onde $\xi$ é denominado de parâmetro de penalidade.

0 processo de resolução consiste em adotar uma seqüência de escalares tendendo ao infinito como por exemplo $\left\{1,10,10^{2}, 10^{3}, 10^{4}, \ldots\right\}$, e resolver 0 problema atribuindo cada valor a $\xi^{(m)}$, gerando assim, uma seqüência de solução $\boldsymbol{x}^{(m)}$.

Demonstra-se que quando $\xi^{(m)} \rightarrow \infty$ então $\boldsymbol{x}^{(m)} \rightarrow \boldsymbol{x}^{*}$ que é um mínimo local do problema. Além disso, a convergência é global, ou seja, a convergência de um mínimo local independe do valor inicial adotado.

Da mesma forma que no método anterior a utilização de uma função única que se deseja otimizar com as restrições gera um novo problema que é representado pela minimização da função $P\left(\boldsymbol{x}, \boldsymbol{\xi}^{k}\right)$ sem restrições, com isso pode-se utilizar para tal quaisquer um dos métodos de minimização sem restrições anteriormente apresentados.

0 gradiente da Função de Penalidade $\nabla P\left(x, \xi^{k}\right)$ é dado pela seguinte equação

$$
\nabla P\left(\boldsymbol{x}, \boldsymbol{\xi}^{k}\right)=\nabla f(\boldsymbol{x})+\xi^{k} \cdot \sum_{i=1}^{m} g_{i}(\boldsymbol{x}) \cdot \nabla g_{i}(\boldsymbol{x})
$$

O Algoritmo do Método da Penalidade com restrições de igualdade pode ser visto no Anexo A no Algoritmo A-3.11. 


\subsection{MÉTOdo do LAgRangiano Aumentado}

O Método do Lagrangiano Aumentado (MLA) consiste em resolver uma série de problemas de minimização sem restrições. Ele utiliza a idéia do Método do Lagrangiano descrito no item 3.3.2.2.1.1 acrescentando na Função Lagrangiana um termo a mais que penaliza as restrições, ou seja, algo equivalente a Método da Penalidade.

0 Lagrangiano Aumentado do problema é definido da seguinte forma

$$
A(x, \lambda, \xi)=f(x)+\sum_{i=1}^{m} \lambda_{i} \cdot g_{i}(x)+\sum_{i=1}^{m} \frac{1}{2} \cdot \xi \cdot g_{i}^{2}(x),
$$

onde $\xi$ é o parâmetro de penalidade e $\lambda$ é o vetor que contém os multiplicador de Lagrange.

A idéia geral do método consiste em minimizar a função $A(\boldsymbol{x}, \lambda, \xi)$. Os valores de $\boldsymbol{\xi}$ e $\lambda^{k}$ são escolhidos e fixados no começo de cada minimização sem restrições e posteriormente o funcional $A(\boldsymbol{x}, \boldsymbol{\lambda}, \boldsymbol{\xi})$ é minimizado em relação a $\boldsymbol{x}$.

No final de cada minimização, os valores de $\lambda$ são atualizados e 0 processo continua até atingir a convergência.

A atualização dos Multiplicadores de Lagrange pode ser feita pela seguinte equação

$$
\lambda^{k+1}=\lambda^{k}+\xi \cdot g(x) .
$$

Para ocorrer a convergência no MLA, 0 valor da penalidade $\xi$ basta ser finito, enquanto no Método da Penalidade este valor tinha que tender ao infinito o que acarreta problemas computacionais.

0 algoritmo do Método do Lagrangiano Aumentado com restrições de igualdade pode ser visto no Anexo A no algoritmo A-3.12.

\subsection{O TIMIZAÇÃ̃ COM RESTRIÇõES DE DESIGUALDADE}

Considere-se 0 problema geral de otimização com restrições de desigualdade da forma seguinte

$$
\begin{array}{ll}
\text { Minimizar } & f(\boldsymbol{x}) \\
\text { Sujeito } a \quad & g_{j}(\boldsymbol{x}) \leq 0, \quad j=1 \ldots q, \\
& x \in \Omega \subset \mathfrak{R}^{n} \\
& \Gamma=\left\{x \in \Omega \mid g_{j}(\boldsymbol{x}) \leq 0, \quad j=1 \ldots q\right\}
\end{array}
$$


onde $\Gamma$ é denominada de região viável e a função $f(\boldsymbol{x})$ sendo contínua e com derivadas parciais contínuas até segunda ordem e as funções $g_{j}(\boldsymbol{x})$ contínuas e com derivadas parciais contínuas até primeira ordem.

A condição necessária de primeira ordem para um ponto $\boldsymbol{x}^{*}$ seja um ponto de mínimo local do problema de minimização descrito acima pode ser vista pelas equações

$$
\begin{array}{cc}
\nabla f\left(x^{*}\right)-\sum_{j=1}^{q} \lambda_{j}^{*} \cdot g_{j}\left(x^{*}\right)=0 & \\
g_{j}\left(x^{*}\right) \leq 0 & j=1 \ldots q \\
\lambda_{j}^{*} \geq 0 & \\
\lambda_{j}^{*} \cdot g_{j}\left(x^{*}\right)=0 &
\end{array}
$$

Considere-se $\Xi\left(\boldsymbol{x}^{*}\right)$ o conjunto das restrições de desigualdade ativas na solução $\boldsymbol{x}^{*}$, ou seja, $\boldsymbol{\Xi}\left(\boldsymbol{x}^{*}\right)$ é 0 conjunto dos índices $j$ tal que $g_{j}\left(\boldsymbol{x}^{*}\right)=0$. Então, as condições necessárias podem ser escritas da forma seguinte

$$
\begin{array}{cc}
\nabla f\left(x^{*}\right)-\sum_{j=1}^{q} \lambda_{j}^{*} \cdot g_{j}\left(x^{*}\right)=0 \\
g_{j}\left(x^{*}\right)=0 & j \in \Xi\left(x^{*}\right) \\
g_{j}\left(x^{*}\right)<0 & j \notin \Xi\left(x^{*}\right) \\
\lambda_{j}^{*} \geq 0 & j=1 \ldots q \\
\lambda_{j}^{*}=0 & j \in \Xi\left(x^{*}\right)
\end{array}
$$

Uma das formas de se resolver os problemas com restrições de desigualdade é através do Método dos Conjuntos Ativos que tem como objetivo definir a cada iteração um conjunto de restrições, chamado de conjunto de trabalho, que se tratará de uma estimativa do conjunto $\Xi\left(x^{*}\right)$. O método consiste em determinar um conjunto de trabalho atual, que é um subconjunto das restrições, e efetuar uma minimização sob restrições de igualdade para este conjunto. Se este ponto não satisfizer as condições do problema, é feita uma atualização do conjunto de trabalho e em seguida calcula-se o novo ponto. Quando a solução for obtida, 0 conjunto de trabalho passa a ser o conjunto ativo correto $\Xi\left(\boldsymbol{x}^{*}\right)$.

Dentre os vários métodos existentes serão aqui apresentados apenas dois que são:

- Método da Penalidade

- Método do Lagrangiano Aumentado 
Os outros métodos podem ser encontrados na bibliografia sobre o assunto citada no Capítulo 1 desta dissertação.

\subsection{MÉTOdO da PENALIDAde}

No caso de problemas com restrições de igualdade, para obtermos um ponto que satisfaça às condições necessárias do problema de otimização com restrições de desigualdade anteriormente apresentadas, basta resolvermos um sistema não-linear de equações. Entretanto, em problemas que incluem restrições de desigualdade, além da resolução do sistema não-linear de equações, torna-se necessário que a solução deste sistema satisfaça a essas restrições. Neste caso, constrói-se uma nova Função de Penalidade.

A nova Função de Penalidade para o problema pode ser vista da seguinte forma

$$
P(x, \xi)=f(x)+\frac{1}{2} \cdot \xi \cdot \sum_{j=1}^{q}\left\langle g_{j}(x)\right\rangle^{2},
$$

onde $\xi$ é chamado de parâmetro de penalização.

Como estes processos são resolvidos de forma iterativa, a cada passo do processo a função $\left\langle g_{j}(\boldsymbol{x})\right\rangle$ é verificada em função do valor de $\boldsymbol{x}$ para esta iteração e desta forma será considerado ou não no processo, ou seja, é verificada se a restrição está ou não ativa.

0 algoritmo para o Método da Penalidade com restrições de desigualdade pode ser visto no Anexo A no algoritmo A-3.13.

\subsection{MÉTOdO DO LAGRANGIANO AUMENTAdO}

Da mesma forma que no Método da Penalidade serão feitas algumas alterações no funcional $A(x, \lambda, \xi)$ resultando a equação

$$
A(\boldsymbol{x}, \lambda, \xi)=f(\boldsymbol{x})+\sum_{j=1}^{q} \lambda_{j} \cdot\left\langle g_{j}(\boldsymbol{x})\right\rangle+\sum_{j=1}^{q} \frac{1}{2} \cdot \xi \cdot\left\langle g_{j}(\boldsymbol{x})\right\rangle^{2}
$$

onde $\xi$ é 0 parâmetro de penalidade e $\lambda$ são os multiplicadores de Lagrange. Outra diferença se dá na atualização dos multiplicadores de Lagrange que nesta versão do método são dados pela equação

$$
\lambda^{k+1}=\left\langle\lambda^{k}+\xi \cdot g(\boldsymbol{x})\right\rangle .
$$

0 algoritmo para o Método do Lagrangiano Aumentado com restrições de desigualdade pode ser visto no Anexo A no algoritmo A-3.14. 


\subsection{O TIMIZAÇÃO COM RESTRIÇõES M ISTAS}

Quando falamos em otimização com restrições mistas estamos nos referindo ao problema geral da Programação Matemática. Os métodos apresentados a seguir podem ser utilizados para resolução de todos os problemas anteriormente apresentados.

Dentre deste contexto serão aqui apresentados apenas dois métodos que são:

- Método da Penalidade

- Método do Lagrangiano Aumentado

\subsection{MÉTodo da Penalidade}

Considere-se o seguinte problema geral de otimização definido da seguinte forma

$$
\begin{array}{lll}
\text { Minimizar } & f(\boldsymbol{x}) \\
\text { Sujeito } a & g_{i}(\boldsymbol{x})=0 \quad i=1 \ldots m \\
& g_{j}(\boldsymbol{x}) \leq 0 \quad j=1 \ldots q \\
& \boldsymbol{x} \in \mathfrak{R}^{n}
\end{array}
$$

onde a função $f(\boldsymbol{x})$ é contínua e com derivadas parciais contínuas até segunda ordem e as funções $g_{i}(\boldsymbol{x})$ e $g_{j}(\boldsymbol{x})$ são contínuas e com derivadas parciais contínuas até primeira ordem.

A Função de Penalidade do problema geral pode ser escrita da seguinte forma

$$
P(\boldsymbol{x}, \boldsymbol{\xi})=f(\boldsymbol{x})+\frac{1}{2} \cdot \boldsymbol{\xi} \cdot \sum_{i=1}^{m} g_{i}^{2}(\boldsymbol{x})+\frac{1}{2} \cdot \xi \cdot \sum_{j=1}^{q}\left\langle g_{j}(\boldsymbol{x})\right\rangle^{2}
$$

com $\xi$ sendo o parâmetro de penalidade. Pode-se observar que $P(\boldsymbol{x}, \boldsymbol{\xi})$ é a mesma função dos problemas anteriores só que neste caso estão considerados tanto as restrições de igualdade como as restrições de desigualdade.

Depois de definida a função $P(\boldsymbol{x}, \boldsymbol{\xi})$, basta apenas resolver o problema de forma iterativa como sendo uma minimização com restrições de igualdade, pois a cada iteração a função $\left\langle g_{j}(\boldsymbol{x})\right\rangle$ pode estar ativa ou inativa.

0 algoritmo do Método da Penalidade com restrições mistas pode ser visto no Anexo A no algoritmo A-3.15. 


\subsection{MÉTOdo do LAgrangiano Aumentado}

Considere-se o seguinte problem a geral de otimização definido da seguinte forma

$$
\begin{array}{lll}
\text { Minimizar } & f(\boldsymbol{x}) & \\
\text { Sujeito } a & g_{i}(\boldsymbol{x})=0 & i=1 \ldots m \\
& g_{j}(\boldsymbol{x}) \leq 0 & j=1 \ldots q \\
& \boldsymbol{x} \in \mathfrak{R}^{n} &
\end{array}
$$

onde a função $f(\boldsymbol{x})$ é contínua e com derivadas parciais contínuas até segunda ordem e as funções $g_{i}(\boldsymbol{x})$ e $g_{j}(\boldsymbol{x})$ contínuas e com derivadas parciais contínuas até primeira ordem.

A função do Lagrangiano Aumentado para o problema pode ser escrita da seguinte forma

$$
A(\boldsymbol{x}, \lambda, \xi)=f(\boldsymbol{x})+\sum_{i=1}^{m} \lambda_{i} \cdot g_{i}(\boldsymbol{x})+\sum_{i=1}^{m} \frac{1}{2} \cdot \xi \cdot g_{i}^{2}(\boldsymbol{x})+\sum_{j=1}^{q} \lambda_{j} \cdot\left\langle g_{j}(\boldsymbol{x})\right\rangle+\sum_{j=1}^{q} \frac{1}{2} \cdot \xi \cdot\left\langle g_{j}(\boldsymbol{x})\right\rangle^{2},
$$

onde $\xi$ é 0 parâmetro de penalidade e $\lambda$ são os multiplicador de Lagrange. A atualização dos multiplicadores de Lagrange é feita conforme se mostra nas equações abaixo

$$
\begin{gathered}
\lambda^{k+1}=\lambda^{k}+\xi \cdot g_{i}(\boldsymbol{x}) \rightarrow \text { Para restrições de igualdade } \\
\lambda^{k+1}=\left\langle\lambda^{k}+\xi \cdot g_{j}(\boldsymbol{x})\right\rangle \rightarrow \text { Para restrições de desigualdade }
\end{gathered}
$$

Depois de definida a função $A(\boldsymbol{x}, \boldsymbol{\lambda}, \boldsymbol{\xi})$, basta apenas resolver o problema de forma iterativa como sendo uma minimização com restrições de igualdade, pois a cada iteração a função $\left\langle g_{j}(\boldsymbol{x})\right\rangle$ pode estar ativa ou inativa.

0 algoritmo do Método do Lagrangiano Aumentado com restrições mistas pode ser visto no Anexo A no algoritmo A-3.17.

\subsubsection{ProgramaÇão Multi-0 bjetivos}

Em muitos problemas correntes, não se deseja alcançar tão somente um objetivo, e sim vários deles. Um exemplo seria o projeto de uma ponte onde o projetista deseja minimizar o peso da mesma e, ao mesmo tempo, maximizar as freqüências naturais de vibração. Ou num projeto de rodovia quando se tem por objetivos minimizar as distâncias de percurso, bem como os volumes de terras transportados. 
Desta maneira, uma vez que inúmeros problemas do cotidiano apresentam mais de um objetivo a serem perseguidos simultaneamente, surgiu a Programação com Multiobjetivos.

Em geral, qualquer modelo de programação clássica com apenas um objetivo e várias restrições, pode ser modelado e resolvido empregando-se a técnica para Multiobjetivos, contudo, muitas diferenças existem na formulação e conceitos entre estas duas técnicas de otimização.

Um dos métodos mais utilizados na programação com Multi-objetivos é o Goal Programming, que funciona verdadeiramente como um tomador de decisões. As diferenças entre as formulações são tão grandes que um problema de otimização que sequer apresente uma região viável e que, com tratamento clássico seria de impossível resolução, com o Goal Programming obtêm-se uma solução. Embora esta solução viole alguma ou algumas das restrições, ela será a melhor solução encontrada para aquelas metas estabelecidas. 


\section{CAPítulo 4}

\section{ALGORITMOS GENÉTICOS}

ste capítulo apresenta a origem, os fundamentos dos Algoritmos
Genéticos e seus principais aspectos e características que o tornam uma ferramenta de busca e otimização bastante promissora para uma vasta gama de aplicações.

Pretende-se também, mostrar as diversas operações utilizadas pelos algoritmos genéticos no processo de otimização. São descritos os parâmetros de controle do processo de otimização, sua forma de codificação e de avaliação da função objetivo. Finalmente são feitos comentários sobre as vantagens e desvantagens do uso desta técnica de otimização.

"A imaginação é mais importante que o conhecimento". 


\subsection{INTRODUÇão}

Há muito tempo, o homem tem se servido das características e princípios existentes na natureza para a criação de máquinas, métodos e técnicas que "melhorem" sua qualidade de vida neste planeta. Alguns exemplos típicos desta afirmação são os aviões baseados nas características dos pássaros, submarinos com sistemas de imersão semelhante ao dos peixes, sonares baseados nos morcegos, entre outros.

O homem inspirado na natureza ou na biologia cria novas técnicas, como as "Redes Neurais", baseadas no funcionamento do cérebro humano, para possibilitar aos computadores a chamada "Inteligência Artificial".

Dentro deste contexto, surgiu em meados do século XIX um dos mais importantes princípios no campo da evolução da vida, "A Seleção Natural de Darwin", que defendia a idéia de que na natureza dos seres vivos, aqueles com melhores características, "adaptabilidades", tendem a sobreviver frente aos demais. Desde então, a medicina e suas ciências afins vêm numa busca acelerada tentando "mapear" todas as informações da genética humana, relacionando deste modo cada gene de cada cromossomo às características que eles representam nos indivíduos: hereditárias, físicas e funcionais.

Há oito anos começou o projeto Genoma em diversos centros do mundo, liderados pelo instituto Nacional de Saúde dos Estados Unidos, que contou com investimento inicial de três bilhões de dólares. O principal objetivo do projeto é descobrir, até o ano 2005, todos os genes do corpo humano e identificar mais de três bilhões de seqüências genéticas de cromossomos.

Os cientistas querem conhecer, antes do nascimento, a possibilidade de cada ser humano desenvolver doenças com fatores hereditários, podendo assim, evitar o desenvolvimento do mal, seja com terapias genéticas, se a doença for congênita, ou com a interferência no estilo de vida do portador da mutação. Eles calculam que 2/3 dos 30 mil genes do organismo humano já tenham sido mapeados, embora se conheça a função de apenas $4 \%$ deles.

Foi nos últimos anos que a genética alavancou-se com as primeiras clonagens realizadas no mundo, tendo como marco a famosa ovelha Dolly na Inglaterra. 
A clonagem, assim como os possíveis objetivos e conseqüências desta descoberta provocaram inúmeras discordâncias e precauções por todo o planeta, afinal, quais seriam os rumos da aplicação destes conhecimentos. Indiscutíveis são as vantagens oferecidas na prevenção de doenças, contudo, assustadoras são as possibilidades da criação de novas doenças, mutações, clonagens individuais, entre outras mais.

Cercadas por todas estas discussões, outras ciências, aliadas às vantagens computacionais hoje oferecidas, inspiram-se mais uma vez nestes princípios para a solução numérica de problemas práticos, dando origem a mais uma técnica de inteligência artificial denominada “Algoritmos Genéticos".

Os Algoritmos Genéticos são algoritmos de busca, fundamentados no processo da seleção natural proposto por Charles Darwin, inicialmente propostos por John Holland em seu livro no ano de 1975.

Os Algoritmos Genéticos (AGs) são muito utilizados em problemas onde, dado um conjunto de elementos ou indivíduos, deseja-se encontrar aquele ou aqueles que melhor atendam a certas condições previamente especificadas.

Os AGs, a partir de uma população de indivíduos, cada um com um valor de adaptabilidade associado chamado aptidão, desenvolvem, através de operações genéticas como cruzamentos e mutações, uma nova geração de indivíduos usando os princípios Darwinianos de reprodução e sobrevivência dos mais aptos. Cada indivíduo na população representa uma possível solução para um dado problema. O que o Algoritmo Genético faz é procurar aquela que seja muito boa ou a melhor, visando à otimização da função objetivo.

Representando de forma abstrata no eixo das abscissas todos os problemas cujas soluções podem ser obtidas por algoritmos de otimização e no eixo das ordenadas suas respectivas eficiências, pode-se determinar curvas indicativas da Aplicabilidade $\mathrm{x}$ Eficiência dos métodos disponíveis, conforme Figura 4 - 1.

Através desse recurso, pode-se distinguir três tipos extremos de métodos, que são ilustrados a seguir : 


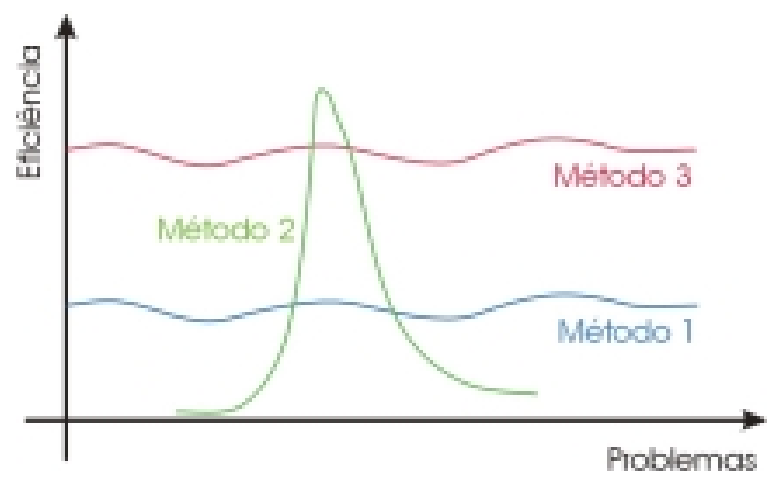

Figura 4 - 1- Aplicabilidade em Problemas x Eficiência de Resolução dos Métodos

○ Método 1 : Pouco eficientes para a totalidade dos problemas existentes.

- Método 2: Altamente eficiente para uma pequena faixa de problemas, entretanto, pouco eficiente ou nem aplicável para a maior parte deles.

- Método 3: Razoavelmente eficiente para a totalidade dos problemas existentes.

Dentro deste contexto, os AGs se aproximariam da terceira classe de métodos, não sendo mais eficiente que aqueles projetados especificamente para determinado problema, contudo, perturbações no problema original trariam poucos, ou quase nenhum, prejuízo aos AGs, mas possivelmente, a inutilidade de outros métodos.

\subsection{HiSTóRICO}

A seleção natural é apenas um dos elementos da adaptação que se une a outros como a relação entre organismo e ambiente e a hereditariedade. Além disso, é preciso distinguir adaptação de adaptabilidade. Enquanto adaptação é o preparo do organismo para sobreviver num ambiente, adaptabilidade é a capacidade de tirar partido do ambiente e, até mesmo, controlá-lo. No sentido de adaptabilidade, o homem é indubitavelmente o "rei da criação". Mas, embora toda história da civilização humana nada mais seja que uma constante mudança no sentido de aumentar a amplitude e variedade do ajustamento ao ambiente, a evolução nos ensina que o homem não é fruto de uma criação especial, pois faz parte da natureza e é feito da mesma essência de tudo o que é vivo.

O desenvolvimento da genética estabeleceu que as características hereditárias são transmitidas através de genes (unidades químicas que se localizam no núcleo das células). Os genes são constituídos por uma substância química, o ADN, ou ácido 
desoxirribonucléico. Dispõem-se aos pares, dentro de filamentos visíveis ao microscópio, chamados cromossomos. A propriedade fundamental dos genes é que eles se auto-reproduzem fielmente. Entretanto, não há uma precisão absoluta nessa autoreprodução, podendo ocorrer mutações gênicas ou seja, o gene que até aquele momento produzia determinada característica passa a produzir outra.

Uma Breve História da Genética:

- 1866 - Ao cultivar ervilhas, o monge austríaco George Mendel percebe que uma geração de plantas pode passar certas características às seguintes. Com isso, estabelece as leis da hereditariedade;

- 1910 - Ao estudar as moscas da fruta, as drosófilas, o americano Thomas Morgan demonstra que os cromossomos contêm os genes, unidade básica da herança genética;

- 1954 - O americano James Watson e o inglês Francis Crick enxergam pela primeira vez a estrutura do DNA como uma escada espiralada;

- 1961 - Descobre-se que o funcionamento do código genético em todos os seres vivos, do vírus ao homem, passando por bactérias, plantas e animais, usa o mesmo mecanismo para instruir as células a produzirem proteínas;

- 1977 - Pesquisadores decodificam o código genético do primeiro ser vivo, um vírus;

- 1978 - Alterações genéticas em bactérias as transformam nas primeiras fábricas biológicas de insulina;

- 1984 - Surge a técnica que permite identificar pessoas pelo DNA;

- 1989 - Lançado o Projeto Genoma, o ambicioso projeto de mapear a sequiência genética do DNA humano;

- 1997 - Nasce a ovelha Dolly, o primeiro mamífero clonado produzido a partir de uma célula comum de um animal adulto;

- 2000 - Apresentação do primeiro esboço do Genoma Humano.

Nas décadas de 50 e 60, muitos biólogos começaram a desenvolver simulações computacionais de sistemas genéticos, entretanto, foi John Holland quem começou, 
seriamente, a refinar idéias sobre o tema, culminando, em 1975, na publicação de seu livro, "Adaptation in Natural and Artificial Systems", hoje considerado um marco dos Algoritmos Genéticos. Desde então, tais algoritmos vêm sendo aplicados com sucesso nas mais diversas áreas, entre elas a otimização e o aprendizado de máquinas.

\subsection{DEFINIÇÕES BÁSICAS - TERMINOLOGIA}

Na biologia, a teoria da evolução diz que o meio ambiente seleciona, em cada geração, os seres vivos mais aptos de uma população. Como resultado, somente os mais aptos conseguem se reproduzir, uma vez que os menos adaptados geralmente são eliminados antes de gerarem descendentes. Durante a reprodução, ocorrem, entre outros, fenômenos como mutações e cruzamentos, que atuam sobre o material genético armazenado nos cromossomos. Estes fenômenos levam à variabilidade dos seres vivos da população. Sobre esta população diversificada age a seleção natural, permitindo a sobrevivência apenas dos seres mais adaptados.

Um Algoritmo Genético (AG) é a metáfora desses fenômenos, o que explica porque AGs possuem muitos termos originados da biologia. A lista apresentada a seguir descreve os principais termos encontrados na literatura.

As principais definições relacionadas com os AGs são:

- Cromossomo e Genoma: Na biologia, genoma é o conjunto completo de genes de um organismo. Um genoma pode ter vários cromossomos. Nos AGs, os dois representam a estrutura de dados que codifica uma solução para um problema, ou seja, um cromossomo ou genoma representa um simples ponto do espaço de busca.

- Gen ou Gene: Na biologia, é a unidade de hereditariedade que é transmitida pelo cromossomo e que controla as características do organismo. Nos AGs, é um parâmetro codificado no cromossomo, ou seja, um elemento do vetor que representa o cromossomo.

- Indivíduo: Um simples membro da população. Nos AGs, um indivíduo é formado pelo cromossomo e sua aptidão.

- Genótipo: Na biologia, representa a composição genética contida no Genoma. Nos AGs, representa a informação contida no cromossomo ou genoma. 
- Fenótipo: Nos Algoritmos Genéticos, representa o objeto, estrutura ou organismo construído a partir das informações do genótipo. É o cromossomo decodificado. Por exemplo, considere que o cromossomo codifica parâmetros como as dimensões das vigas em um projeto de construção de um edifício, ou as conexões e pesos de uma Rede Neural. O fenótipo seria o edifício construído ou a Rede Neural.

- Alelo: Na biologia, representa uma das formas alternativas de um gene. Nos AGs, representa os valores que o gene pode assumir. Por exemplo, um gene que representa o parâmetro cor de um objeto poderia ter o alelo azul, preto, verde, etc.

- Epistasia: Interação entre genes do cromossomo, isto é, quando um valor de gene influência o valor de outro gene. Problemas com alta epistasia são de difícil solução por AGs.

- População: Conjunto de cromossomos ou soluções.

- Geração: O número da iteração que o Algoritmo Genético executa.

- Operações Genéticas: Operações que o Algoritmo Genético realiza sobre cada um dos cromossomos.

- Espaço de Busca ou Região Viável: É o conjunto, espaço ou região que compreende as soluções possíveis ou viáveis do problema a ser otimizado. Deve ser caracterizado pelas funções de restrição, que definem as soluções de forma viável ao problema a ser resolvido.

- Função Objetivo ou de Avaliação: É a função que se quer otimizar. Ela contém a informação numérica do desempenho de cada cromossomo na população. Nela estão representadas as características do problema que o Algoritmo Genético necessita para realizar seu objetivo, sendo expressa normalmente como $\mathcal{F}=f\left(x_{1}, x_{2}, \ldots, x_{n}\right)$, onde $x_{1}, x_{2}, \ldots, x_{n}$ são as variáveis que o algoritmo procura determinar para otimizar $\mathcal{F}$. Esta função objetivo é em princípio, calculada para cada cromossomo $\S_{i}$ da população. 


\subsection{REPRESENTAÇÃo dOS PARÂMETROS}

Um AG processa populações de cromossomos. Um cromossomo $\S_{i}$ é uma estrutura de dados, geralmente vetor ou cadeia de bits (cadeia de bits é a estrutura mais tradicional, porém nem sempre é a melhor) que representa uma possível solução do problema a ser otimizado. Em geral, um cromossomo representa um conjunto de parâmetros da função objetivo cuja resposta será maximizada ou minimizada. O conjunto de todas as configurações que o cromossomo pode assumir forma o seu espaço de busca. Se o cromossomo representa $n$ parâmetros de uma função, então o espaço de busca é um espaço com $n$ dimensões.

Vale observar que funções objetivo com múltiplos parâmetros, tem os mesmos representados na mesma cadeia de bits, com cada um ocupando uma parte da cadeia. A cada cromossomo $\S_{i}$ é atribuída uma aptidão $\mathcal{F}_{i}$. Aptidão é uma nota que mede quão boa é a solução codificada em $\S_{i}$. É baseada no valor da função objetivo, e será discutida posteriormente.

\subsection{Algoritmos Genéticos E OTIMIZAÇÃo CONVENCIONAL}

Visando situar Algoritmos Genéticos no contexto de otimização em geral, considerem-se algumas das principais classes de métodos de otimização:

- Gerar-e-Testar: O algoritmo Gerar-e-testar (também conhecido como método da busca exaustiva ou aleatória) é uma abordagem tipo "força bruta". Emprega dois módulos: o módulo de geração, que enumera possíveis soluções de forma sistemática ou aleatória, e o módulo de teste, que avalia cada possível solução, podendo aceitá-la ou rejeitá-la. O módulo gerador pode produzir todas as possíveis soluções antes do módulo de teste começar a agir. O mais comum é o uso intercalado destes dois módulos. O método pode encerrar sua execução quando uma solução satisfatória for encontrada, depois de encontrar um número de soluções satisfatórias ou continuar até que todas as possíveis soluções sejam obtidas.

- Métodos Analíticos: Os métodos analíticos utilizam técnicas do Cálculo Diferencial para determinar os pontos extremos de uma função e apresentam várias desvantagens: não informam se o ponto encontrado é um ponto de 
mínimo local ou global; requerem funções com derivadas e, além disso, quando existe grande número de parâmetros torna-se difícil encontrar, analiticamente, todos os pontos de mínimo e máximo. Tornando estes métodos impraticáveis para otimizar diversos problemas do mundo real.

- Subida de Encosta: Os Métodos de Subida de Encosta investigam os pontos adjacentes do espaço de busca e move-se na direção que melhore o valor da função objetivo. Observa-se, porém, que para funções com muitos ótimos locais, um método de Subida de Encosta terá dificuldades em localizar qual "encosta" leva ao ótimo global. Métodos de Subida de Encosta também têm dificuldades quando existem planícies ou platôs na superfície de busca. Contudo, métodos de Subida de Encosta são geralmente rápidos. Um grande número de técnicas importantes de otimização segue os princípios da Subida de Encosta. Um exemplo é o método do gradiente.

Os métodos Gerar-e-Testar possuem a característica de explorar pontos inteiramente novos do espaço de busca. Os métodos de Subida de Encosta, por outro lado, caracterizam-se por utilizar a informação oriunda de pontos anteriormente visitados para encontrar os melhores. Um algoritmo de otimização eficiente deve usar estas duas técnicas (denominadas de Exploration e Exploitation, respectivamente) para encontrar o ótimo global da função objetivo. Ambas as técnicas têm a mesma tradução para o português, exploração. Entretanto, Exploitation significa exploração no sentido de tirar informações presentes nas soluções encontradas e Exploration diz respeito à exploração no sentido de visitar pontos desconhecidos no espaço de busca a procura por novas soluções.

O cruzamento e a mutação são dois mecanismos de busca dos AGs que levam à exploração de pontos inteiramente novos do espaço de busca (Exploration). Enquanto a seleção dirige a busca em direção aos melhores pontos do espaço de busca (Exploitation), a pressão da seleção, dada pela razão entre aptidão máxima da população e a aptidão média, influencia a quantidade de Exploitation e Exploration. Quando a pressão de seleção é muito baixa (i.e., a aptidão é praticamente a mesma para toda a população), o AG assume um comportamento aleatório, pois não há seleção. Isto torna o AG semelhante à busca aleatória dos métodos Gerar-e-Testar (muito Exploration). Quando a pressão de seleção é muito alta, o AG assume o comportamento dos métodos 
de Subida de Encosta (muito Exploitation). Na prática, é difícil determinar qual a pressão de seleção que fornece o equilíbrio ideal.

O primeiro passo de um Algoritmo Genético típico é a geração de uma população inicial de cromossomos, que é formada por um conjunto aleatório de cromossomos que representam possíveis soluções do problema a ser resolvido. Durante o processo evolutivo, esta população é avaliada e cada cromossomo recebe uma nota (denominada de aptidão no jargão da literatura de AGs), refletindo a qualidade da solução que ele representa.

\section{A 4.1 - Algoritmo Genético TípICo}

Seja $\mathbb{P}_{k}$ a população de cromossomos na geração $k$.

$$
\begin{aligned}
& k \leftarrow 0 \\
& \text { iniciar } \mathbb{P}_{k} \\
& \text { avaliar } \mathbb{P}_{k}
\end{aligned}
$$

Enquanto o critério de parada não for satisfeito faça

$$
k \leftarrow k+1
$$

selecionar $\mathbb{P}_{k}$ a partir de $\mathbb{P}_{k-1}$

aplicar cruzamento sobre $\mathbb{P}_{k}$

aplicar mutação sobre $\mathbb{P}_{k}$

avaliar $\mathbb{P}_{k}$

\section{Fim enquanto}

\section{Algoritmo 4 - 1 - Algoritmo Genético Típico}

Em geral, os cromossomos mais aptos são selecionados e os menos aptos são descartados (Darwinismo). Os membros selecionados podem sofrer modificações em suas características fundamentais através dos operadores de cruzamento e mutação, gerando descendentes para a próxima geração. Este processo é repetido até que uma solução satisfatória seja encontrada. O Algoritmo 4 - 1 ilustra este procedimento. Na seção 4.9. são descritos com mais detalhes cada uma das etapas deste algoritmo. 


\subsection{DiferenÇAS entre os AGs e os Métodos ClásSicos}

Os métodos clássicos de otimização iniciam-se com um único candidato, chamado de solução básica, e pelo cálculo de derivadas se determina para qual direção se deve caminhar na busca do próximo candidato. Por trabalharem com o cálculo de derivadas, são denominados algoritmos de ordem $n$, onde $n$ é a maior derivada utilizada.

Exemplos típicos são o Método dos Gradientes Conjugados e o Método de Newton que, por utilizarem respectivamente derivadas primeiras e segundas, são caracterizados como algoritmos de primeira e segunda ordem. Todavia, classificações intermediárias também são possíveis, como é o caso dos Métodos Quase-Newton que se situaria entre os dois anteriores.

O maior problema destes algoritmos matemáticos é que não existe nenhuma garantia da obtenção de um ponto extremo global, ou seja, o algoritmo convergirá para o extremo local mais próximo da direção de busca determinada pelas derivadas. Por esta razão, tais algoritmos são mais convenientemente empregados para problemas unimodais, aqueles que apresentam apenas um extremo no intervalo considerado. A aplicação destes algoritmos para problemas multimodais não é tão simples, já que a solução encontrada dependerá do ponto de partida inicial, podendo na maioria das vezes se encontrar uma solução extrema local distante da solução ótima global procurada.

Os Algoritmos Genéticos representam uma classe de ferramentas muito versátil e robusta a ser empregada na solução de problemas de otimização, embora não devam ser considerados estritamente extremizadores de funções. Assim como outros métodos, por não empregarem o cálculo de derivadas, mas sim atuarem diretamente na busca das soluções no espaço viável, ele é classificado como método direto ou de ordem zero.

Quando utilizado no contexto de otimização, os Algoritmos Genéticos distinguem-se dos métodos clássicos de Programação Matemática basicamente pelos seguintes aspectos:

○ Emprega sempre uma população de indivíduos, ou soluções;

- Opera com uma codificação das possíveis soluções (genótipos) e não com as soluções propriamente ditas (fenótipos);

- Trabalha com regras de transição probabilísticas; 
○ Não requer informações adicionais (derivadas, por exemplo) sobre a função a otimizar.

Deste modo, a busca por soluções pode ser feita sobre conjuntos não-convexos e mesmo disjuntos, com funções objetivo também não convexas e não-diferenciáveis e simultaneamente com variáveis reais, lógicas e inteiras.

Outra grande diferença dos métodos clássicos para os Algoritmos Genéticos é que estes não se prendem tão facilmente a extremos locais, uma vez que trabalha com uma população de indivíduos e realiza a busca dentro de toda a região viável disponível.

\subsection{ESTRUTURA dOS Algoritmos GENÉticos}

Existem inúmeras versões dos Algoritmos Genéticos, quanto aos passos e operadores empregados. Entretanto, as duas formas mais freqüentes quanto à estrutura dos Algoritmos Genéticos Genéricos são:

- Algoritmo Genético Geracional

- Algoritmo Genético em Regime

\subsubsection{Algoritmo GenÉtico Geracional}

Neste extremo de algoritmo, "toda" a população é substituída por novos indivíduos gerados pelo processo de seleção e aplicação dos operadores genéticos.

Deve-se observar que como toda a geração (de "Pais") é integralmente substituída por outra mais nova (de "filhos"), não existe "convivência", havendo a perda de bons indivíduos no processo. Por esta razão, especialmente em problemas de otimização, um procedimento freqüentemente empregado é o elitismo, ou seja, o(s) melhor (es) indivíduo(s) de uma geração é (são) preservado(s), passando diretamente para a geração seguinte. O elitismo ou estratégia elitista será apresentado na seqüência no tópico 4.8.10.1.3.

O processo é mostrado esquematicamente no algoritmo a seguir: 


\section{A 4.2 - Algoritmo GenÉtico Geracional}

Passo 1: Inicie a população $\mathbb{P}_{k}$ de cromossomos $(k=1)$

Passo 2: Avalie indivíduos na população $\mathbb{P}_{k}$

Passo 3: (repita este processo até obter a convergência)

\section{Repetir}

\section{1) Repetir}

I. Selecione 2 indivíduos em $\mathbb{P}_{k}$ para reprodução;

II. Aplique operador de recombinação, probabilidade $\mathcal{P}_{\mathcal{C}}$;

III. Aplique operador de mutação, probabilidade $\mathcal{P}_{m}$;

IV. Insira novo indivíduo em $\mathbb{P}_{k}^{\prime}$;

Até população $\mathbb{P}_{k}^{\prime}$ completa

2) Avalie indivíduos na população $\mathbb{P}_{k}^{\prime}$

3) $k=k+1$

4) $\mathbb{P}_{k} \leftarrow \mathbb{P}_{k-1}^{\prime}$

Até objetivo final ou máximo de gerações

Algoritmo 4 - 2 - Algoritmo Genético Geracional

\subsubsection{Algoritmo GenÉtico EM REgime}

Neste outro extremo de algoritmo, apenas "um" indivíduo é criado de cada vez e, depois de sua avaliação, ele será inserido na população em substituição a algum outro elemento, por exemplo, o pior de todos já existentes. Caso ele seja pior que todos os já existentes então nada é alterado e procede-se uma nova criação de indivíduo.

Com o intuito de facilitar a comparação do indivíduo gerado com os indivíduos já existentes na população, utiliza-se um "ranking" dentro da população, desta forma, o indivíduo gerado é comparado apenas com o último indivíduo do ranking, caso seja superior a ele, assumirá sua posição correspondente no ranking, sendo o último eliminado pela seleção natural. 


\section{A 4.3 - Algoritmo Genético em Regime}

Passo 1: Inicie a população $\mathbb{P}_{k}$ de cromossomos

Passo 2: Avalie indivíduos na população $\mathbb{P}_{\mathbf{k}}$

Passo 3: (repita este processo até obter a convergência)

\section{Repetir}

1) Selecione operador genético;

2) Selecione indivíduo(s) para reprodução;

3) Aplique operador genético selecionado;

4) Avalie indivíduo(s) gerado(s);

5) Selecione indivíduo $\S$ para sobreviver;

6) Se $\S$ é melhor que o pior elemento de $\mathbb{P}_{k}$ então

Insira $\S$ em $\mathbb{P}_{\mathbb{k}}$ de acordo com seu "ranking"

Até objetivo final ou máximo de gerações

Algoritmo 4 - 3 - Algoritmo Genético em Regime

Entre estes dois extremos de algoritmos situam-se outros que somente uma parte da população é substituída: "pais" e "filhos" podem vir a coexistir. Outros esquemas de reprodução podem também ser encontrados na literatura.

\subsection{Principais Aspectos dos Algoritmos Genéticos}

\subsubsection{A FUNÇÃo OBJETIVO}

A função objetivo em alguns problemas pode ser bastante complicada, demandando um alto custo computacional. Por exemplo, há problemas em que, para avaliar um cromossomo é necessária uma simulação completa do processo, o que pode chegar a consumir horas. Haupt e Haupt (1998) fornecem algumas sugestões para lidar com tais funções objetivo, propondo cuidados a serem tomados para não avaliar cromossomos idênticos mais de uma vez, reutilizando deste modo a avaliação feita anteriormente. 
Isto pode ser feito de várias maneiras:

1. Evitando gerar cromossomos idênticos na população inicial;

2. Verificando se foi aplicado cruzamento ou mutação nos pais, pois, caso contrário, os filhos serão iguais aos pais;

3. Observando se o filho é igual a um dos pais;

4. Mantendo a população com todos os cromossomos distintos entre si, o que também ajuda na manutenção da diversidade (no AG do tipo Steady State isto é feito evitando inserção de cromossomos duplicatas na população);

5. Antes de avaliar um filho, verificar se já existe um cromossomo igual a este filho na população.

Em situações mais extremas, deve-se armazenar todos os cromossomos da geração atual e passada, verificando se algum deles é igual ao novo filho gerado. É claro que tais abordagens também incorporam um custo computacional extra ao AG. Deve-se analisar se este custo extra, compensará o tempo economizado na avaliação da função objetivo.

Uma outra abordagem é utilizar uma versão simplificada da função objetivo nas gerações iniciais para acelerar a busca por regiões promissoras do espaço. Nas gerações finais, a versão completa da função objetivo passa a ser utilizada para melhorar a precisão da solução.

Outro método é usar o AG para localizar a encosta do máximo global, e posteriormente, substituir o AG por um Método de Subida de Encosta que rapidamente encontre a solução (os AGs são bons para localizar velozmente as regiões promissoras do espaço de busca, porém são lentos para refinar as soluções).

Os parâmetros da função objetivo podem ser contínuos ou discretos. Otimização com parâmetros contínuos possui um número infinito de soluções. Otimização de parâmetros discretos, em geral tem somente um número finito de possíveis soluções, resultante de uma certa combinação dos parâmetros.

\subsubsection{As RESTRIÇÕES}

Embora os Algoritmos Genéticos tenham sido inicialmente aplicados com sucesso em problemas de otimização sem restrições, foi apenas uma questão de tempo 
para surgirem as primeiras utilizações da técnica na resolução de problemas com restrições.

Uma abordagem para lidar com restrições nos AGs é simplesmente atribuir aptidão zero aos cromossomos infactíveis (i.e. aqueles que não satisfazem as restrições). Porém, os cromossomos infactíveis próximos das regiões factíveis podem conter informações importantes para gerar filhos factíveis. Portanto, ao invés de zerar a aptidão de tais cromossomos, pode-se apenas penalizar a aptidão. Para isto, usa-se uma função de pênalti $\Phi_{j}(x)$, que define o quão a solução $\boldsymbol{x}$ viola a restrição $j$. (i.e. o quão distante o cromossomo infactível está da região factível).

Quando a restrição $j$ é uma inequação, a função de pênalti é dada por ,

$$
\Phi_{j}(\boldsymbol{x})=\max \left(0, g_{j}(\boldsymbol{x})\right)
$$

Quando a restrição $j$ é uma equação, a função de pênalti é dada da seguinte forma,

$$
\Phi_{j}(\boldsymbol{x})=\left|g_{j}(\boldsymbol{x})\right|
$$

Agora o problema de otimização torna-se irrestrito com a soma da antiga função objetivo com o termo de pênalti, isto é,

$$
\text { Minimizar } \begin{aligned}
& h(\boldsymbol{x})=f(\boldsymbol{x})+r \cdot \sum_{j=1}^{m} \Phi_{j}^{2}(\boldsymbol{x}), \\
& \boldsymbol{x} \in \mathfrak{R}^{n}
\end{aligned}
$$

onde $r$ é a constante de pênalti (serve para controlar o tamanho da penalidade).

Uma outra abordagem é fazer de cada restrição uma função objetivo diferente e resolver o problema como um problema de otimização Multi-objetivo. Mais detalhes sobre restrições ver (Michalewicz, 1997a, 1997b).

Na maioria das aplicações, são empregadas funções de penalização, de forma a "embutirem" as restrições na função objetivo, técnica esta também utilizada por uma parcela de métodos matemáticos de otimização. Todavia, já se encontram sugeridas formas de abordagem deste problema sem o emprego de funções de penalização ou mesmo outras alternativas mais inovadoras como os algoritmos co-evolucionários que preservam mais de uma população interagindo. 


\subsubsection{Problemas de Convergência}

O desaparecimento de determinados genes da população no decorrer das gerações impossibilita um Algoritmo Genético de explorar completamente o espaço de busca. Como resultado, o AG pode convergir para um mínimo ou máximo local. Este problema é conhecido como Convergência Prematura. Com taxas adequadas de mutação, é possível manter uma boa diversidade de genes da população a fim de compensar estas perdas de genes.

A convergência prematura é um conhecido problema dos AGs. Ocorre com o surgimento de cromossomos de alta aptidão, mas não com aptidão ótima, enquanto os cromossomos realmente ótimos ainda não estão presentes na população. Tais cromossomos (chamados de superindivíduos) geram um número excessivo de filhos que dominam a população, uma vez que a mesma é finita. Estes cromossomos espalham seus genes por toda a população, enquanto outros genes desaparecem. Como consequiência, o algoritmo converge para um máximo ou mínimo local, conforme a ilustra Figura 4 - 2.

Combate-se à convergência prematura limitando o número de filhos por cromossomos. Esta limitação pode ser realizada através do escalonamento da aptidão, ordenamento e outras técnicas a serem descritas mais adiante.

Uma outra alternativa de combate à convergência prematura é a manutenção da diversidade dos cromossomos na população. Isto pode ser alcançado através do aumento da taxa de mutação, e também evitando-se a inserção de filhos duplicados na população.

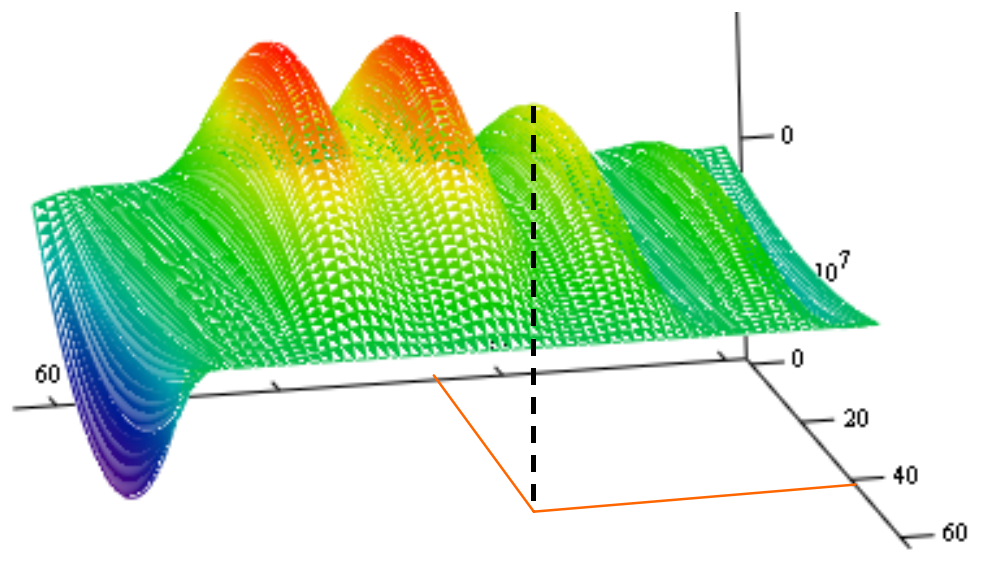

Figura 4 - 2 - Convergência Prematura 


\subsubsection{Critérios de Parada}

Alguns dos possíveis critérios de parada para os AGs, são:

1. Quando o AG atingir um dado número de gerações (ou avaliações);

2. Chegada a um determinado valor da função objetivo, definido a priori;

3. Convergência, isto é, quando não ocorrer melhoramento significativo no cromossomo de maior aptidão por um dado número de gerações.

Outras alternativas podem ser adotadas, como por exemplo, considerando que um gene converge se $90 \%$ da população têm o mesmo valor para este gene. Se entre $90 \%$ e $95 \%$ dos genes convergiram, o AG convergiu.

\subsubsection{REPRESENTAÇÃO E CODIFICAÇÃO}

A representação ou codificação das variáveis de projeto a serem otimizadas proporciona um grande impacto no desempenho da busca, devendo ser a mais simples possível, sem no entanto perder as características de representação do problema tratado.

Existem inúmeras formas de representação das variáveis, tais como: binária, números inteiros e números reais. A maioria dos trabalhos desenvolvidos utiliza a codificação binária, onde cada cromossomo é um vetor composto por zeros e uns, com cada bit representando um gene.

Para problemas de otimização com variáveis reais, uma codificação binária pode ser introduzida pela conversão de valores numéricos de ponto flutuante para valores binários de comprimentos fixos, sendo sempre necessário posteriormente, realizar o caminho inverso para avaliação da função de aptidão. Existe assim, uma grande desvantagem no caso da representação binária, que seriam as constantes conversões entre valores de pontos flutuantes e binários.

Uma vez definidas as variáveis de projeto relevantes para a resolução do problema de otimização e a forma como serão representadas, deve-se justapô-las de modo a formarem os cromossomos. Existe ainda a possibilidade de associar mais de um cromossomo a cada indivíduo, analogamente ao que ocorre na biologia, onde o Homo Sapiens, por exemplo, é diplóide, isto é, possui dois cromossomos. 


\subsubsection{GeraÇão da PoPUlaÇão INICIAL}

A população inicial de indivíduos ou cromossomos pode ser gerada de várias maneiras, na maioria das vezes realizada de forma aleatória, embora haja ocasiões onde é mais apropriada uma seleção heurística introduzindo, logo de início, um ou mais indivíduos "interessantes", como por exemplo, soluções aproximadas conhecidas contendo algum tipo de informação prévia.

Se uma população inicial pequena for gerada aleatoriamente, provavelmente, algumas regiões do espaço de busca não serão representadas. Este problema pode ser minimizado gerando a população inicial com uma distribuição uniforme. Outra alternativa é gerar a primeira metade da população aleatoriamente e a segunda metade a partir da primeira, invertendo os bits. Isto garante que cada posição da cadeia de bits tenha um representante na população com os valores 0 e 1 .

Pode ser interessante usar uma população inicial maior que a utilizada nas gerações subseqüentes, visando melhorar a representação do espaço de busca.

Uma técnica denominada "seeding” pode ser útil em vários problemas práticos. Consiste em colocar, na população inicial, soluções encontradas por outros métodos de otimização. Isto garante que a solução gerada pelos AGs seja, no mínimo, tão boa quanto a gerada por esses métodos.

\subsubsection{Avaliação da População}

A avaliação da população é realizada pela função de aptidão, que deve indicar a "qualidade" de cada indivíduo na população. Para problemas de otimização ela está intimamente ligada à função objetivo cujo extremo global deseja-se obter. Para problemas de maximização, a função de aptidão pode ser tomada da forma $f(\boldsymbol{x})=g(\boldsymbol{x})+C$, onde $C$ é uma constante introduzida para casos onde o processo de seleção exige que a aptidão seja positiva. Com o processo natural de evolução, os indivíduos passam a ter aptidão cada vez mais semelhante entre si e pode ser necessário aumentar a pressão de seleção adotando-se algo como: $f(\boldsymbol{x})=h(g(\boldsymbol{x}))$ com uma certa função $h$ convenientemente escolhida. 
Não há a necessidade de se calcular as derivadas da função objetivo e, portanto, um algoritmo genético pode ser utilizado sem nenhuma modificação, para otimizar funções não diferenciáveis.

É preciso lembrar, entretanto, que a escolha da função de aptidão é, para a maioria das aplicações, a etapa crítica do processo, já que deverá ser avaliada para cada cromossomo de cada população durante todo o processo evolutivo.

\subsubsection{Processo de SeleÇão}

A seleção dos indivíduos da população baseia-se no princípio da "sobrevivência dos melhores indivíduos", onde os cromossomos com mais alta probabilidade de sobrevivência são copiados de forma semi-randômica uma ou mais vezes para um novo conjunto que formará a próxima geração, denominada população temporária. Em contrapartida, os indivíduos com baixa aptidão serão descartados da população.

Inúmeros esquemas de seleção já foram propostos e aplicados aos Algoritmos Genéticos, todavia, apenas os mais empregados são aqui apresentados.

\subsubsection{MAPEAMENTO da FunÇão OBJETIVO}

Os valores da função objetivo nem sempre são adequados para serem utilizados como valores de aptidão. Por exemplo, a função objetivo pode assumir valores negativos (o Método da Roleta não funciona), pode fornecer valores muitos próximos (torna a seleção aleatória), alguns valores podem ser muito elevados em relação ao resto da população (causa a convergência prematura), etc.

O mapeamento da função objetivo para o valor da aptidão pode ser feito de vários modos, alguns dos quais serão discutidos a seguir.

\subsection{ORDENAMENTO}

No Método de Ordenamento Linear (Baker, 1987) e (Whitle, 1989), a aptidão é dada pela equação,

$$
\mathcal{F}_{k}=\operatorname{Min}+(\operatorname{Max}-\operatorname{Min}) \cdot \frac{\mathcal{N}-k}{\mathcal{N}-1}
$$

em que $k$ é o índice do cromossomo na população em ordem decrescente de valor da função objetivo e $\mathcal{N}$ é o tamanho da população. Normalmente é utilizado $1 \leq$ Max $\leq$ 
2 e $M a x+\operatorname{Min}=2$. Vale notar que deste modo a aptidão representa o número de filhos esperados do cromossomo e Max - Min representa a pressão de seleção (razão entre a maior aptidão e a aptidão média, $\mathcal{F}_{\text {max }} / \overline{\mathcal{F}}$ ).

No Método de Ordenamento Exponencial (Michalewicz, 1994), a aptidão é dada da seguinte forma $\mathcal{F}_{k}=q \cdot(1-q)^{k-1}$, onde que $q \in[0,1]$ e $k$ é o índice do cromossomo na população em ordem decrescente de valor da função objetivo. Alternativamente, a aptidão pode ser normalizada dividindo a equação anterior pelo fator $1-(1-q)^{\mathcal{N}}$. O ordenamento exponencial permite maior pressão de seleção do que o ordenamento linear.

\subsection{ESCALONAMENTO LINEAR}

No Método de Escalonamento Linear, a aptidão é obtida pela equação, $\mathcal{F}=a g+b$ em que $g$ é o valor da função objetivo (ver Figura $4-3$ ). Os coeficientes $a$ e $b$ são determinados de forma a limitar o número esperado de filhos dos cromossomos (filhos em excesso causam perda de diversidade). O escalonamento linear (Goldberg, 1989) transforma as aptidões de modo que a aptidão média torna-se igual ao valor médio da função objetivo (i.e. $\overline{\mathcal{F}}=\bar{g}$ ), e a aptidão máxima igual a $C$ vezes a aptidão média (i.e. $\mathcal{F}_{\max }=C \bar{g}$ ). Tipicamente, o valor de $C$ está entre 1.20 e 2.0. Quando o escalonamento gera aptidões negativas, os coeficientes $a$ e $b$ são calculados de outro modo (impondo $\mathcal{F}_{\min }=0$ ).

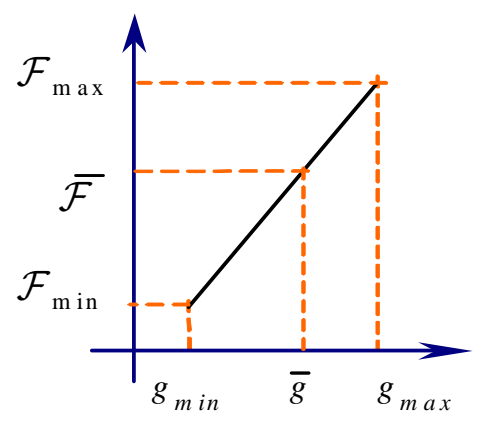

Figura 4 - 3 - Gráfico de Escalonamento da Aptidão 


\subsubsection{MÉTOdO dA ROLETA}

Um dos métodos largamente empregados para tal finalidade é o conhecido "Método da Roleta", onde cada indivíduo da população é representado de forma proporcional ao seu valor de aptidão. Assim, os indivíduos com alta aptidão recebem uma porção maior da roleta, enquanto que os de baixa aptidão ocuparão uma porção relativamente menor. Deste modo, a roleta é rodada tantas vezes quanto o número de indivíduos da população, escolhendo-se assim aqueles que darão origem a próxima geração.

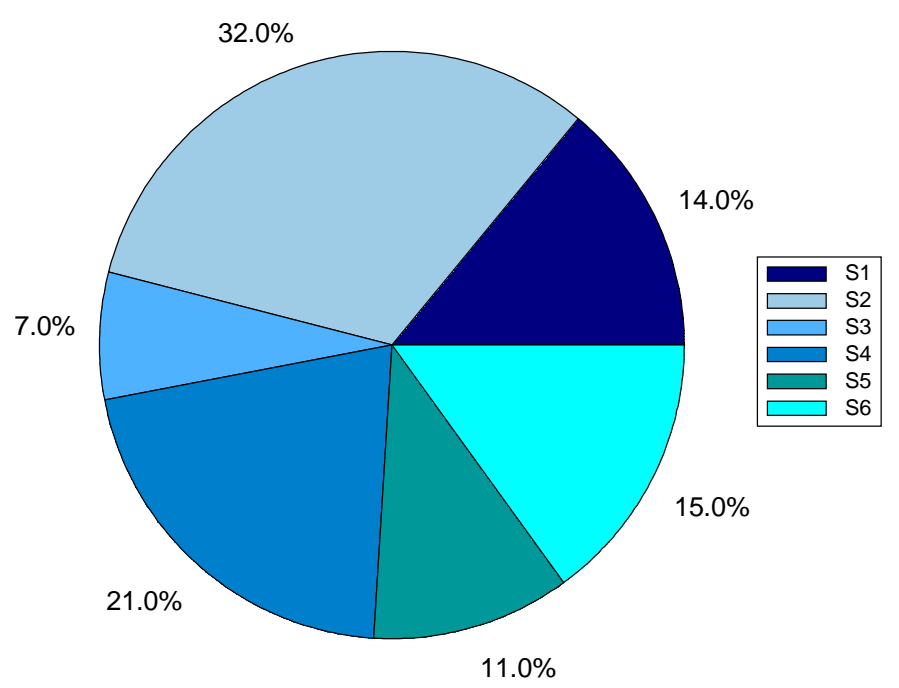

Figura 4 - 4 - Exemplo do Método da Roleta

O Método da Roleta tem a desvantagem de possuir uma alta variância, podendo levar a um grande número de cópias de um bom cromossomo, diminuindo a variabilidade da população.

Uma outra idéia, entretanto, é abandonar a magnitude da aptidão de cada elemento e utilizar somente a posição (o "ranking") de cada indivíduo na população. Deste modo, mantendo-se a população ordenada por valores decrescentes da aptidão, a probabilidade de seleção de um indivíduo para a etapa de recombinação cresce com o seu "ranking" ou seja, o primeiro do "ranking" tem maior probabilidade de seleção. 


\subsubsection{Processo de SELEÇão POR TORNEIO}

Neste método, são escolhidos aleatoriamente (com probabilidades iguais) $n$ cromossomos da população, e o cromossomo com maior aptidão é selecionado para a população intermediária. $\mathrm{O}$ processo repete-se até preencher a população intermediária. Utiliza-se, geralmente, o valor $n=2$.

A seleção por torneio não precisa de escalonamento da aptidão e nem de ordenamento. Em uma outra versão, a seleção por torneio utiliza probabilidades diferenciadas. Se o torneio envolve dois cromossomos, o primeiro ganha o torneio com probabilidade $q$ (onde $0,5<q<1$ ); e o segundo, com probabilidade $(1-q)$. Para um torneio entre $n$ cromossomos, o primeiro cromossomo ganha o torneio com probabilidade $q$, o segundo com probabilidade $q \cdot(1-q)$, o terceiro com $q \cdot(1-q)^{2}$, e assim por diante (vale notar que se $n=\mathcal{N}$, tal seleção é equivalente à seleção com ordenamento exponencial).

Aumentando o número $n$ de cromossomos do torneio ou a probabilidade $q$ do primeiro cromossomo vencer, aumenta-se a pressão de seleção, isto é, cromossomos com aptidão acima da média terão mais chances de serem selecionados.

\subsubsection{REPROdUÇÃo OU CRUZAMENTO}

O processo de seleção não introduz novos indivíduos na população temporária, apenas os chamados progenitores, que servirão como pais para a nova geração, composta pelos filhos.

$\mathrm{Na}$ etapa de reprodução, o algoritmo tenta criar novas e melhores soluções (indivíduos mais aptos). A forma mais simples e natural de cruzamento é o chamado “cruzamento em um ponto".

Como passo inicial, toda a população temporária é agrupada aleatoriamente por pares para gerar um conjunto de $\mathcal{N} / 2$ de progenitores potenciais.

O cruzamento é aprovado por um processo de decisão semelhante ao de um "lançamento de moeda". Para isto, deve-se escolher uma probabilidade de cruzamento $\mathcal{P}_{C}$ igual para cada par. O lançamento de moeda corresponde a gerar, para cada par, um valor aleatório entre 0 e 1 . Se o valor gerado for inferior a $\mathcal{P}_{C}$, o cruzamento é permitido, caso contrário, os progenitores são mantidos inalterados. 
No processo de reprodução ou cruzamento, deve-se aplicar um operador genético sobre os progenitores de forma a serem formados novos indivíduos.

\subsubsection{OPERADORES GENÉTICOS}

O princípio básico dos operadores genéticos é transformar a população através de sucessivas gerações, de forma a obter um resultado satisfatório no final do processo. Deste modo, eles são extremamente necessários para que a população se diversifique e mantenha as características de adaptação adquiridas pelas gerações anteriores.

\subsection{Cruzamento}

Com o cruzamento de pelo menos dois progenitores, uma ou mais novas soluções são criadas a partir do intercâmbio de suas informações genéticas, em um ou mais pontos que também são selecionados aleatoriamente. Este operador pode ser utilizado de várias maneiras. As mais empregadas são:

○ Cruzamento de um Ponto

- Cruzamento Multipontos

- Cruzamento Uniforme

\subsection{Cruzamento de 1 Ponto}

Os operadores de cruzamento e de mutação são os principais mecanismos dos AGs para explorar regiões desconhecidas do espaço de busca. O operador cruzamento é aplicado a um par de cromossomos retirado da população intermediária, gerando dois cromossomos filhos. Cada um dos cromossomos pais tem sua cadeia de bits cortada em uma posição aleatória, produzindo duas cabeças e duas caudas. As caudas são trocadas, gerando dois novos cromossomos. A Figura 4 - 5 ilustra o comportamento deste operador.

\begin{tabular}{|l||ccccc|ccccc|}
\hline Pai $_{1}:$ & 1 & 0 & 1 & 1 & 1 & 0 & 0 & 0 & 1 & 1 \\
\hline Pai $_{2}:$ & 1 & 1 & 0 & 1 & 0 & 0 & 1 & 0 & 0 & 1 \\
\hline filho $_{1}:$ & 1 & 0 & 1 & 1 & 1 & 0 & 1 & 0 & 0 & 1 \\
\hline filho $_{2}:$ & 1 & 1 & 0 & 1 & 0 & 0 & 0 & 0 & 1 & 1 \\
\hline
\end{tabular}

Figura 4 - 5 - Cruzamento de 1 Ponto 
O cruzamento é aplicado com uma dada probabilidade a cada par de cromossomos selecionados. Na prática, esta probabilidade, denominada de taxa de cruzamento, varia entre $60 \%$ e $90 \%$. Não ocorrendo o cruzamento, os filhos serão iguais aos pais (isto permite que algumas soluções sejam preservadas). Isto pode ser implementado, gerando números aleatórios no intervalo [0,1]. Assim, o cruzamento só é aplicado se o número gerado for menor que a taxa de cruzamento.

\subsection{Cruzamentos de 2 Pontos E N Pontos}

Os tipos de operadores cruzamento mais conhecidos para cadeias de bits são o de $n$ pontos e o uniforme. O cruzamento de 1 ponto é o mesmo apresentado na Seção 4.5.10.1.1.1. O de 2 pontos é apresentado na Figura 4 - 6. Os dois pontos de corte são escolhidos aleatoriamente, e as seções entre os dois pontos são trocadas entre os pais.

\begin{tabular}{|c|c|c|c|c|c|c|c|c|c|c|}
\hline $\mathrm{Pai}_{1}$ : & 1 & 0 & 1 & 1 & 1 & 0 & 0 & 0 & & \\
\hline $\mathrm{Pai}_{2}$ : & 1 & 1 & 0 & 1 & 0 & 0 & 1 & 0 & 0 & 1 \\
\hline filho $_{1}$ & 1 & U & 1 & 1 & U & U & 1 & U & 1 & 1 \\
\hline filho $_{2}$ & 1 & 1 & 0 & 1 & 1 & 0 & 0 & 0 & 0 & 1 \\
\hline
\end{tabular}

Figura 4 - 6 - Cruzamento de 2 Pontos

O cruzamento de $N$ pontos tende a manter juntos os genes que são codificados próximos um do outro. Existe um operador denominado Inversão (Holland, 1975) que busca o ordenamento ideal dos genes no cromossomo. Dois pontos aleatórios são escolhidos no cromossomo e os genes entre eles são invertidos. Vale frisar que a inversão não é um tipo de mutação brutal. Na verdade não ocorre mutação. A cada gene é associado um número para identificar quem é quem depois da troca de posição. Este operador, no entanto, tem sido raramente utilizado na prática.

\subsection{CruZamento Uniforme}

O cruzamento uniforme é apresentado na Figura 4 - 7. Para cada par de pais é gerada uma máscara de bits aleatórios. Se o primeiro bit da máscara possui o valor 1 , então o primeiro bit do $\mathrm{Pai}_{1}$ é copiado para o primeiro bit do filho ${ }_{1}$. Caso contrário, o primeiro bit do $\mathrm{Pai}_{2}$ é copiado para o primeiro bit do filho $o_{1}$. O processo se repete para os bits restantes do filho $o_{1}$. Na geração do filho $o_{2}$ o procedimento é invertido, ou seja, se o bit da máscara é 1 , então será copiado o bit do $P a i_{2}$. Se o bit for igual a 0 , então será copiado o bit do $P a i_{1}$. Vale notar que o cruzamento uniforme não é a mesma coisa que o 
cruzamento de ( $l-1)$ pontos ( $l$ é o número de bits do cromossomo), uma vez que este sempre leva a metade dos bits de cada pai.

\begin{tabular}{l||cccccccccccc|}
\hline Mascara & 1 & 1 & 0 & 0 & 1 & 1 & 0 & 1 & 1 & 0 & 0 & 1 \\
\hline Pai $_{1}:$ & 0 & 0 & 1 & 0 & 1 & 0 & 0 & 0 & 1 & 0 & 1 & 0 \\
\hline & $\downarrow$ & $\downarrow$ & & & $\downarrow$ & $\downarrow$ & & $\downarrow$ & $\downarrow$ & & & $\downarrow$ \\
\hline filho $_{1}:$ & 0 & 0 & 0 & 0 & 1 & 0 & 0 & 0 & 1 & 1 & 0 & 0 \\
\hline
\end{tabular}

Figura 4 - 7 - Cruzamento Uniforme

Segundo Grefenstette (1986), os AGs são robustos de tal modo que, dentro de uma faixa relativamente larga de variação de parâmetros (taxas de cruzamento e mutação, tamanho da população, etc.), não ocorre alteração significativa em seu desempenho.

\subsection{MUTAÇÃo}

O operador de mutação é necessário para a introdução e manutenção da diversidade genética da população, alterando arbitrariamente um ou mais componentes de uma estrutura escolhida, fornecendo assim, meios para introdução de novos elementos na população. Desta forma, a mutação assegura que a probabilidade de se chegar a qualquer ponto do espaço de busca nunca será zero, além de contornar o problema de mínimos locais.

O operador de mutação é aplicado aos indivíduos com uma probabilidade dada pela taxa de mutação $\mathcal{P}_{m}$. Geralmente utiliza-se uma taxa de mutação pequena, por se tratar de um operador genético secundário.

Após a operação de cruzamento, o operador de mutação é aplicado, com uma determinada probabilidade, em cada bit dos dois filhos. O operador de mutação inverte os valores de bits, de 1 para 0 ou de 0 para 1. A Figura 4 - 8 apresenta um exemplo do processo de mutação. A mutação melhora a diversidade dos cromossomos na população porém, destrói parte da informação contida, logo, deve ser utilizada uma taxa de mutação pequena (normalmente entre $0,1 \%$ a $5 \%$ ), mas suficiente para assegurar a diversidade. 


\begin{tabular}{|l|l||lllllllll|}
\hline \multirow{3}{*}{ Antes } & filho $_{1}:$ & 0 & 1 & 1 & 1 & 0 & 0 & 0 & 1 & 0 \\
\cline { 2 - 9 } & filho $_{2}:$ & 1 & 0 & 1 & 1 & 1 & 0 & 1 & 1 & 1 \\
\hline \multirow{2}{*}{ Depois } & filho $_{1}:$ & 0 & 0 & 1 & 1 & 1 & 0 & 0 & 1 & 0 \\
\cline { 2 - 9 } & filho $_{2}:$ & 1 & 0 & 1 & 1 & 1 & 0 & 1 & 1 & 1 \\
\hline
\end{tabular}

Figura 4 - 8 - Mutação

\subsection{ELITISMO}

Nos AGs quando geramos novas populações utilizando os operadores mostrados nos itens anteriores podemos facilmente observar que em muitos casos o melhor indivíduo de uma geração desaparece na geração seguinte. Para melhorar a eficiência dos AGs é interessante transferir o melhor cromossomo de uma geração para outra sem alterações. Esta estratégia é denominada Elitismo, sendo muito comum nos AGs tradicionais.

O Elitismo foi proposto por DeJong (1975), em um dos trabalhos pioneiros sobre AGs. A Figura 4 - 9 ilustra este processo de forma esquemática, onde em cada geração o indivíduo com menor (minimização) valor da função objetivo é copiado para geração seguinte sem alterações, garantindo desta forma que sempre a melhor solução encontrada em qualquer uma das gerações será mantida até o final do processo.

\begin{tabular}{|c|c|c|c|c|c|}
\hline \multicolumn{6}{|c|}{ "Geração [k-1] } \\
\hline \multicolumn{5}{|c|}{$\S$} & $f(\S)$ \\
\hline (" & 1 & 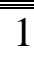 & & & 21 \\
\hline 1 & 0 & 1 & 1 & 1 & 12 \\
\hline 1 & 1 & 1 & 1 & 1 & 11 \\
\hline 1 & 1 & 0 & 1 & & 9 \\
\hline 1 & 1 & 0 & 4 & & 20 \\
\hline 0 & 0 & 0 & 1 & 0 & 18 \\
\hline$\overline{0}$ & 0 & 0 & 1 & 1 & 28 \\
\hline
\end{tabular}

\begin{tabular}{|c|c|c|c|c|c|}
\hline \multicolumn{6}{|c|}{ Geração [k] } \\
\hline \multicolumn{5}{|c|}{$\S$} & $f(\S)$ \\
\hline 1 & 1 & 0 & 1 & 1 & 9 \\
\hline 0 & 0 & 0 & ( & 0 & 12 \\
\hline 1 & 0 & 1 & 1 & 1 & 12 \\
\hline$\overline{0}$ & $\overline{0}$ & 0 & 1 & 0 & 18 \\
\hline 1 & 1 & $\overline{0}$ & 1 & 1 & 9 \\
\hline 1 & 0 & 0 & 1 & 1 & 11 \\
\hline 1 & $\overline{0}$ & $\overline{0}$ & & 1 & 8 \\
\hline
\end{tabular}

\begin{tabular}{|c|c|c|c|c|c|}
\hline \multicolumn{6}{|c|}{ "Geração [k+1] } \\
\hline & \multicolumn{4}{|c|}{$\S$} & $f(\xi)$ \\
\hline 1 & 0 & 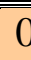 & 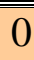 & 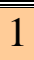 & 8 \\
\hline$\overline{0}$ & 1 & 1 & 1 & $\overline{0}$ & 21 \\
\hline 1 & 1 & 1 & 0 & 0 & 7 \\
\hline$\overline{0}$ & 1 & 1 & 1 & 1 & 6 \\
\hline 1 & 1 & 1 & 0 & 0 & 13 \\
\hline 1 & 1 & 1 & 0 & $\overline{0}$ & 13 \\
\hline 1 & 0 & 1 & 1 & 0 & 7 \\
\hline
\end{tabular}

Figura 4 - 9 - Processo Elitista 


\subsection{REPRESENTAÇÃO BINÁRIA X REAL}

A representação binária é historicamente importante, uma vez que foi utilizada nos trabalhos pioneiros de Holland (1975). É a representação tradicional, fácil de utilizar e manipular e de simples análise teórica. Contudo, se um problema tem parâmetros contínuos e o usuário quer trabalhar com boa precisão numérica, ele precisará armazenar cromossomos longos na memória, uma vez que, para cada casa decimal acrescentada na precisão, é necessário adicionar 3.3 bits na cadeia. Caso sejam necessárias 8 casas decimais, $8 \times 3.3 \approx 27$ bits serão utilizados para cada parâmetro. Quando há muitos parâmetros, obtém-se longas cadeias de bits que podem fazer o algoritmo convergir vagarosamente. Além disso, não há uniformidade nos operadores. Por exemplo, a mutação afeta mais a aptidão quando esta se processa nos primeiros bits do gene.

A representação real (i.e. com ponto flutuante) gera cromossomos menores e é compreendida mais naturalmente pelo ser humano do que a cadeia de bits. Outra vantagem da representação real é a facilidade de criar novos operadores.

\subsection{Parâmetros de InfluênCia E ConfiguraÇão}

A correta configuração dos parâmetros de influência é, sem dúvida, um dos aspectos mais relevantes dentro da estratégia dos Algoritmos Genéticos. Não existe muita literatura sobre este tema, uma vez que tais configurações irão depender entre outras coisas da aplicação resolvida, entretanto, é intuitivo perceber que este passo é de grande importância no desempenho do mecanismo de busca. A eficiência e funcionamento de um Algoritmo Genético são altamente dependentes dos seus parâmetros de controle, cujos tipos básicos são descritos a seguir.

\subsubsection{TaManho da POPUlaÇão - $\mathcal{N}$}

O tamanho da população indica o número de cromossomos em cada população, normalmente constante durante a evolução.

Uma grande população apresentará uma maior diversidade de soluções, contudo, computacionalmente será dispendioso efetuar tantas avaliações da função de aptidão. Assim, as principais influências deste parâmetro estão relacionados com o desempenho global e com a eficiência dos AGs. 
Com uma população pequena o desempenho pode cair, pois a mesma representaria apenas uma pequena parte do espaço de busca do problema. Uma grande população geralmente fornece uma cobertura representativa do domínio do problema, além de prevenir convergências prematuras para soluções locais ao invés de globais. No entanto, para se trabalhar com grandes populações, são necessários maiores recursos computacionais, ou conviver com tempos maiores de processamento.

Uma idéia interessante é relacionar o tamanho da população com o tamanho do cromossomo, ou seja, quanto maior for o cromossomo maior deverá ser o tamanho da população para uma diversidade razoável.

Muitos pesquisadores sugerem a título de grandeza, tamanhos de população entre 10 e 100 cromossomos.

\subsubsection{Taxa ou Probabilidade de Cruzamento $-\mathcal{P}_{C}$}

Este parâmetro indica com qual taxa ou probabilidade irá ocorrer o cruzamento entre indivíduos selecionados na população.

Quanto maior for esta taxa, mais rapidamente novos indivíduos serão introduzidas na população, em contrapartida, se for muito alta, indivíduos com boas aptidões poderão ser retirados mais rapidamente da população, ocorrendo perda de indivíduos de alta aptidão. Valores baixos podem tornar lenta a convergência do algoritmo.

Usualmente, a taxa de cruzamento varia entre 0.50 e 0.95 , todavia, estes números indicam apenas uma ordem de grandeza, já que existem vários tipos possíveis de cruzamentos, limitados apenas pela capacidade criativa do pesquisador.

\subsubsection{TaXa ou Probabilidade de MUtaÇão - $\mathcal{P}_{m}$}

A taxa de mutação indica a probabilidade ou taxa em que haverá a mutação de cromossomos nas populações ao longo da evolução.

A mutação é empregada para fornecer novas informações dentro das populações, prevenindo que as mesmas tornem-se saturadas com cromossomos similares na medida em que aumenta a diversidade populacional, possibilitando ainda uma maior varredura do espaço de busca. 
Há de se tomar cuidado, pois com uma taxa muito alta a busca pode tornar-se essencialmente aleatória.

Assim como os demais parâmetros, a taxa de mutação ideal dependerá da aplicação a ser resolvida, todavia, a maioria das taxas utilizadas varia entre 0.001 e 0.1 .

\subsection{VAntagens e Desvantagens dos AGS}

\subsubsection{VANTAgENS DOS Algoritmos GENÉticos}

Os Algoritmos Genéticos têm sido empregados em problemas complicados de otimização em que, muitas vezes, os demais métodos falham. Algumas vantagens dos AGs são:

- Funcionam tanto com parâmetros contínuos como discretos ou uma combinação deles.

- Realizam buscas simultâneas em várias regiões do espaço de busca, pois trabalham com uma população e não com um único ponto.

- Utilizam informações de custo ou recompensa e não derivadas ou outro conhecimento auxiliar.

- Otimizam um número grande de variáveis.

- Otimizam parâmetros de funções objetivos com superfícies complexas e complicadas, reduzindo a incidência de mínimos locais.

- Adaptam-se bem a computadores paralelos.

- Trabalham com uma codificação do conjunto de parâmetros e não com os próprios parâmetros.

- Fornecem uma lista de parâmetros ótimos e não uma simples solução.

- Trabalham com dados gerados experimentalmente e são tolerantes a ruídos e dados incompletos.

- São fáceis de serem implementados em computadores.

- São modulares e portáteis, no sentido que o mecanismo de evolução é separado da representação particular do problema considerado. Assim, eles podem ser transferidos de um problema para outro.

- São flexíveis para trabalhar com restrições arbitrárias e otimizar múltiplas funções com objetivos conflitantes. 
- São também facilmente hibridizados com outras técnicas heurísticas.

- São robustos e aplicáveis a uma grande variedade de problemas.

- São mais resistentes a se prenderem a ótimos locais.

- Apresentam um bom desempenho para uma grande escala de problemas.

Apesar dessas vantagens, os AGs não são eficientes para muitos problemas. São bastante lentos e não raro ainda estão avaliando a população inicial enquanto muitos métodos de Subida de Encosta já têm encontrado a solução. O principal campo de aplicação dos AGs é em problemas complexos, com múltiplos mínimos/máximos e para os quais não existe um algoritmo de otimização eficiente conhecido para resolvê-los.

\subsubsection{Desvantagens dos Algoritmos Genéticos}

As principais desvantagens dos Algoritmos Genéticos estão apresentadas nos tópicos abaixo:

- Dificuldade para achar o ótimo global exato;

- Requerem um grande número de avaliações das funções de aptidão e suas restrições;

- Grandes possibilidades de configurações podendo complicar a resolução.

\subsection{ESTRATÉGIAS EMPREGÁVEIS AOS AGS}

\subsubsection{HibRIDIZAÇÃo}

Uma alternativa para melhorar o funcionamento dos Algoritmos Genéticos é a hibridização, que visa acoplar algoritmos distintos com o intuito de tirar o melhor proveito de cada um deles. Assim, é possível acoplar-se aos Algoritmos Genéticos outros métodos matemáticos que efetuem uma busca local mais agressiva. Esta alternativa híbrida resultante possui a capacidade de exploração global da região viável aliada à eficiência nas buscas locais.

\subsubsection{Computação Paralela}

Os Algoritmos Genéticos são por si só um método naturalmente paralelo, uma vez que a etapa de avaliação da aptidão de cada indivíduo da população é independente das demais. Por esta razão, empregar computação paralela a Algoritmos Genéticos é 
uma estratégia que deve sempre ser considerada, pois resulta em ganho no tempo de processamento.

A etapa de seleção já necessita de certa centralização, devendo os valores de aptidão de todos os indivíduos da população estarem disponíveis simultaneamente em algum processador para a seleção natural dos indivíduos. Em seguida, aplicam-se os operadores genéticos escolhidos sobre os indivíduos (cromossomos) desejados para a evolução do processo.

Quando o paralelismo é natural como descrito acima, o resultado encontrado é o mesmo daquele encontrado pelo Algoritmo Genético seqüencial que lhe deu origem, contudo, pode-se implementar estratégias mais ousadas para se efetuar tanto a seleção quanto a criação de novos indivíduos localmente em cada processador, visando com isto a diminuição das comunicações para envio e recebimento de dados, como a aptidão e o cromossomo, por exemplo. Nestas alternativas não está garantida a obtenção das mesmas soluções encontradas seqüencialmente, tratando-se de um novo Algoritmo Genético.

Uma outra idéia é a subdivisão da população original de $p$ indivíduos em $n$ subpopulações, "residentes" nos $n$ processadores disponíveis, submetida cada uma a um Algoritmo Genético independente. Caso não ocorra nenhuma comunicação entre os processadores, tudo acontece como se o problema estivesse sendo resolvido $n$ vezes.

Entretanto, ao se permitir algumas comunicações entre eles, por exemplo, a migração de alguns indivíduos de certa subpopulação para outra(s), obtém-se um novo Algoritmo Genético. Para estes casos, novos parâmetros de controle devem ser adicionados com o objetivo de definir "quando, quais, quantos e para onde" os indivíduos irão migrar, e de que modo serão inseridos na nova população.

Assim como a maior parte dos assuntos relacionados aos Algoritmos Genéticos, a implementação computacional distribuída ainda se encontra em evolução: "evolui a técnica baseada na evolução", principalmente, pela infinidade de alternativas possíveis, restritas apenas pela própria imaginação. 


\section{Capítulo 5}

\section{ANÁLISE ESTRUTURAL}

W $\begin{aligned} & \text { ste capítulo serão abordados os conceitos referentes a análise } \\ & \text { matricial de estruturas, a verificação de estruturas de concreto }\end{aligned}$ armado e adequação de projetos aos critérios normativos. Como se verá no desenvolvimento do capítulo os tópicos abordados terão sua formulação elaborada de forma a transformar os problemas de verificação das seções de concreto armado em procedimentos relacionados a programação matemática usando desta forma os conceitos já apresentados nos capítulos anteriores desta dissertação.

"A dúvida é o princípio da Sabedoria" 


\subsection{INTRODUÇão}

Antes de apresentar os exemplos sobre otimização de estruturas de concreto armado serão apresentados neste capítulo os conceitos básicos sobre análise matricial e verificação de estruturas de concreto armado.

Este é um assunto bem mais abrangente do que será apresentado, porém os tópicos que serão abordados são suficientes para o entendimento dos processos utilizados junto com os módulos do programa de otimização. As verificações das seções transversais representam algumas das restrições que devem ser impostas na otimização de estruturas de concreto armado.

Este capítulo está subdivido em quatro partes que cobrem todas as equações que foram utilizadas dentro dos módulos do OTIMPORCA e também na otimização de um trecho de pilar a FCO, a saber:

1. Análise Matricial de Estruturas

2. Verificação de Seções Transversais a Flexão Composta Oblíqua - FCO

3. Verificação de Seções Transversais a Flexão Composta Normal - FCN

4. Critérios normativos quanto a dimensões, distribuição de armadura, taxas de armadura, flechas máxima e mínima e bitolas comerciais.

Utiliza-se Análise Matricial de Estruturas (AME), uma vez que serão feitas apenas análises lineares e por sua implementação ser mais simples que o Método dos Elementos Finitos.

A Análise Matricial de Estruturas será utilizada para obtenção dos esforços nodais nos extremos dos elementos do pórtico plano que serão posteriormente utilizados na verificação das seções transversais. Para este fim foi elaborado um programa computacional em FORTRAN 90 composto de diversos módulos, dentre eles:

- Cálculo de Vigas Contínuas

- Calculo de Treliças Planas

- Calculo de Treliças Espaciais

- Calculo de Grelhas

- Calculo de Pórticos Planos

- Calculo de Pórticos Espaciais 
Dentre estes módulos será apenas utilizado o módulo para resolução de pórticos planos acoplado ao programa de otimização via Algoritmos Genéticos.

Foram elaborados dois módulos de verificação de seções transversais: um para FCO e outro para FCN. O módulo para verificação de seções a FCO foi utilizado juntamente com o programa de minimização do custo do pilar e o módulo de FCN foi desenvolvido para ser acoplado ao programa de otimização de Pórticos Planos de Concreto Armado.

O módulo de verificação da FCO foi desenvolvido de forma a ser extremamente eficiente e dar como resposta os códigos 0 caso a seção resista aos esforços solicitantes ou 1 caso contrário. Para isso utilizou-se o Método de Newton que com 5 iterações em média fornece o resultado com uma boa precisão.

Ao utilizar otimização via Algoritmos Genéticos observou-se que a minimização do custo do pilar não foi eficiente em alguns casos pois, como os indivíduos reprovados pelo módulo de FCO eram eliminados da população, suas características eram perdidas. Desta forma o módulo de verificação a FCN fornecerá uma informação a mais que o módulo de FCO que é a distância em relação ao Estado Limite Ultimo (ELU) que servirá para penalizar os indivíduos que infringirem a esta restrição. O mesmo foi feito em relação às demais restrições do problema de minimização do custo do Pórtico Plano de Concreto Armado. Para cada uma das restrições do problema foi associada uma função de penalização e desta forma nenhum indivíduo será descartado ao longo do processo de otimização.

A seguir será apresentado de forma seqüencial cada um dos quatro itens citados anteriormente. Por serem estes tópicos clássicos da análise estrutural aqui serão apresentados de forma bastante rápida, e só será detalhado o item referente a FCN com inclusão de um parâmetro a mais para verificação da distância dos pontos de esforços solicitantes em relação ao ELU por ser algo novo e desenvolvido especificamente para ser acoplado ao OTIMPORCA. Este parâmetro será posteriormente utilizado na função de penalização das barras do pórtico plano que não atingirem o equilíbrio. 


\subsection{ANÁliSe MATricial de ESTRUTURAS}

Uma primeira idéia importante quando se trata da análise matricial de estruturas pelo método dos deslocamentos é que,

"Os deslocamentos nas extremidades de uma barra e o carregamento na barra definem de forma única os esforços nas suas extremidades e, conseqüentemente, os esforços na barra."

Antes de dar prosseguimento à formulação da análise matricial será necessário definir de forma mais clara os conceitos referentes a Matriz de Rigidez de uma barra, desta forma

- MATRIZ DE RIGIDEZ DE UMA BARRA : calcular a matriz de rigidez de uma barra significa calcular os esforços resultantes nas suas extremidades, devido a deslocamentos unitários aplicados nessas mesmas extremidades, ou seja, significa encontrar a "rigidez" da barra para cada um de seus possíveis deslocamentos nodais. Pode-se fazer uma analogia com uma mola elástica que possui apenas 1 grau de liberdade. Para uma mola vale a seguinte relação

$$
F=k \cdot x \text {, }
$$

se quisermos encontrar o coeficiente de rigidez $k$ da mola, basta aplicarmos um deslocamento unitário em sua extremidade livre e medir o esforço correspondente. Dessa forma obtém-se

$$
k=F
$$

No estudo das estruturas planas, uma barra possui até 6 graus de liberdade e, portanto, possui 6 coeficientes de rigidez ( 3 em cada extremidade) para cada um desses 6 graus de liberdade.

Considere-se uma barra no plano zy. As seções transversais desta barra pertencem ao plano xy e devem possuir simetria em relação ao eixo y (se esta simetria não existir não se pode garantir que a estrutura, quando submetida aos carregamentos, permaneça no plano zy). Utilizando-se a hipótese de Bernoulli-Euler (seções planas permanecem planas e perpendiculares ao eixo da barra) juntamente com a hipótese de linearidade geométrica, pode-se obter a equação da linha elástica da barra, onde $w$ representa o deslocamento do eixo da barra no sentido contrário do eixo y 


$$
E_{e} \cdot I_{e} \cdot \frac{d^{4} w}{d y^{4}}=0
$$

integrando-se 4 (quatro) vezes a equação acima se obtém

$$
E_{e} \cdot I_{e} \cdot w(y)=\frac{C_{1} \cdot y^{3}}{6}+\frac{C_{2} \cdot y^{2}}{2}+C_{3} \cdot y+C_{4},
$$

onde $C_{1}, C_{2}, C_{3}$ e $C_{4}$ são constantes a serem determinadas pelas condições de contorno de cada um dos casos de carregamento (deslocamentos nodais).

Define-se pelas integrais abaixo as $A_{e}$ e $I_{e}$ como sendo a área da seção do elemento e o momento de inércia da seção respectivamente.

$$
A_{e}=\iint_{A_{e}} d x d y \quad I_{e}=\iint_{A_{e}} y^{2} \cdot d x d y
$$

Representam-se os graus de liberdade da barra no sistema local pela variável $u_{i}$, onde o índice $i$ identifica cada um dos graus de liberdade conforme a Figura 5-1.

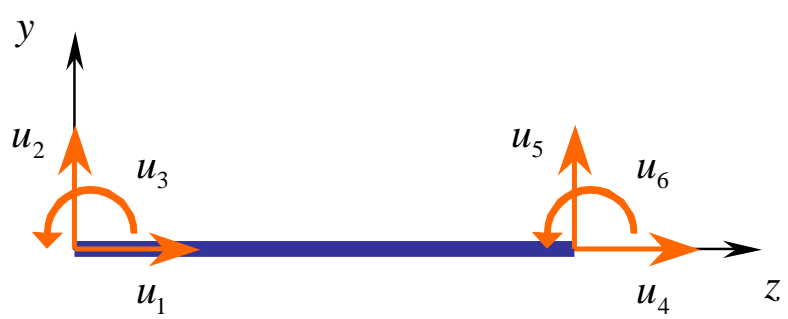

Figura $5-1$ -

Liberdade do Elemento no Sistema Local

Graus de

Para cada grau de liberdade está associado um esforço nodal externo $f_{i}$, onde o índice $i$ identifica o número do grau de liberdade a que se refere cada esforço nodal.

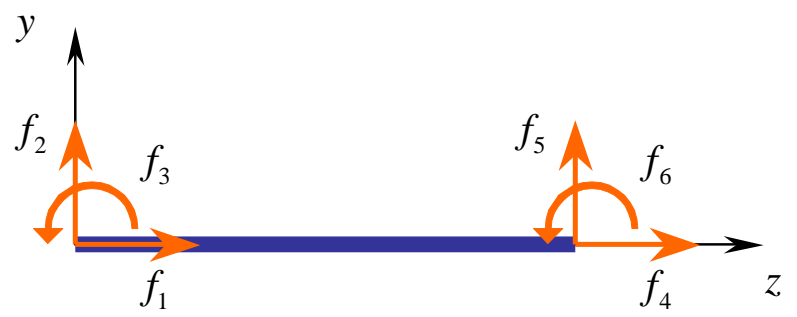

Figura 5 - 2 - Esforços Nodais do Elemento no Sistema Local 


\subsubsection{MATRIZ DE RIGIDEZ DE UM ELEMENTO DE BARRA}

Para obter a segunda coluna da Matriz de Rigidez para Barra de Bernoulli-Euler, aplica-se um deslocamento unitário na direção do $2^{\circ}$ grau de liberdade, ou seja, $u_{2}=1$, desta forma pode-se descrever o deslocamento do eixo da barra da seguinte forma $y=0 \Rightarrow w(y)=-1 \quad e \quad w^{\prime}(y)=0 \quad$ e $\quad y=L_{e} \quad \Rightarrow \quad w(y)=0 \quad$ e $\quad w^{\prime}(y)=0$, substituindo na equação da linha elástica obtém-se o valor das constantes

$$
C_{1}=-\frac{12 \cdot E_{e} \cdot I_{e}}{L_{e}^{3}} \quad C_{2}=\frac{6 \cdot E_{e} \cdot I_{e}}{L_{e}^{2}} \quad C_{3}=0 \quad C_{4}=-E_{e} \cdot I_{e},
$$

e com elas os esforços generalizados

$$
M(y)=\frac{12 \cdot E_{e} \cdot I_{e}}{L_{e}^{3}} \cdot y-\frac{6 \cdot E_{e} \cdot I_{e}}{L_{e}^{2}} \quad \mathrm{e} \quad V(y)=\frac{12 \cdot E_{e} \cdot I_{e}}{L_{e}^{3}},
$$

relacionando os esforços generalizados com as constantes da matriz de rigidez obtém-se

$$
\begin{gathered}
K_{12}^{e}=K_{42}^{e}=0 \quad K_{22}^{e}=V(0)=\frac{12 \cdot E_{e} \cdot I_{e}}{L_{e}^{3}} \quad K_{32}^{e}=-M(0)=\frac{6 \cdot E_{e} \cdot I_{e}}{L_{e}^{2}} \\
K_{52}^{e}=-V\left(L_{e}\right)=-\frac{12 \cdot E_{e} \cdot I_{e}}{L_{e}^{3}} \quad K_{62}^{e}=M\left(L_{e}\right)=\frac{6 \cdot E_{e} \cdot I_{e}}{L_{e}^{2}}
\end{gathered}
$$

Analogamente podem ser obtidos os outros 15 termos da matriz de rigidez (lembrando que a matriz de rigidez é simétrica). Desta forma pode-se escrever a matriz $\boldsymbol{K}_{\text {local }}^{e}$ da seguinte forma

$$
\boldsymbol{K}_{\text {local }}^{e}=\left[\begin{array}{cccccc}
\frac{E_{e} \cdot A_{e}}{L_{e}} & 0 & 0 & -\frac{E_{e} \cdot A_{e}}{L_{e}} & 0 & 0 \\
\cdot & 12 \cdot \frac{E_{e} \cdot I_{e}}{L_{e}^{3}} & 6 \cdot \frac{E_{e} \cdot I_{e}}{L_{e}^{2}} & 0 & -12 \cdot \frac{E_{e} \cdot I_{e}}{L_{e}^{3}} & 6 \cdot \frac{E_{e} \cdot I_{e}}{L_{e}^{2}} \\
\cdot & \cdot & 4 \cdot \frac{E_{e} \cdot I_{e}}{L_{e}} & 0 & -6 \cdot \frac{E_{e} \cdot I_{e}}{L_{e}^{2}} & 2 \cdot \frac{E_{e} \cdot I_{e}}{L_{e}} \\
\cdot & \cdot & & \frac{E_{e} \cdot A_{e}}{L_{e}} & 0 & 0 \\
\cdot & \cdot & \cdot & \cdot & 12 \cdot \frac{E_{e} \cdot I_{e}}{L_{e}^{3}} & 6 \cdot \frac{E_{e} \cdot I_{e}}{L_{e}^{2}} \\
\operatorname{sim} . & \cdot & \cdot & \cdot & 4 \cdot \frac{E_{e} \cdot I_{e}}{L_{e}}
\end{array}\right] .
$$




\subsubsection{Carregamentos no Elemento}

$\mathrm{Na}$ análise matricial de estruturas é feita a hipótese de que os elementos só possuem forças aplicadas em seus nós, portanto, quando houver carregamentos aplicados ao longo da barra, deve-se transformá-los em esforços nodais equivalentes. Como exemplo, para um carregamento uniformemente distribuído (perpendicular ao eixo do elemento) com $q$ constante, obtém-se os seguintes esforços nodais

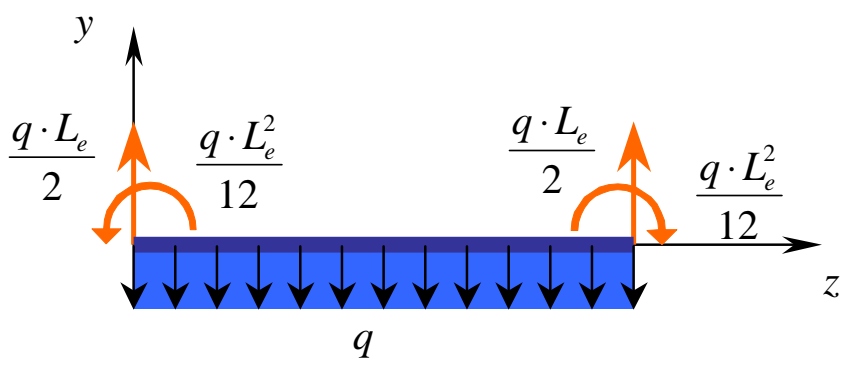

Figura 5 - 3 - Esforços Nodais de Engastamento do Elemento no Sistema Local

Estes esforços podem ser escritos vetorialmente da seguinte forma

$$
f^{e}=\left[\begin{array}{llllll}
0 & \frac{q \cdot L_{e}}{2} & -\frac{q \cdot L_{e}^{2}}{12} & 0 & \frac{q \cdot L_{e}}{2} & \frac{q \cdot L_{e}^{2}}{12}
\end{array}\right]^{T} .
$$

\subsubsection{MATRIZ DE TRANSFORMAÇÃo}

A matriz de rigidez do elemento é obtida no sistema local de referência, bem como as forças nodais equivalentes aos carregamentos distribuídos no elemento. O equilíbrio da estrutura, no entanto, é obtido no sistema global de referência.

Esta transformação é feita através da Matriz de Rotação que, quando aplicada aos deslocamentos globais, fornece os deslocamentos locais. Esta matriz é definida da seguinte forma

$$
\boldsymbol{T}_{e}=\left[\begin{array}{cccccc}
\cos \varphi & \operatorname{sen} \varphi & 0 & 0 & 0 & 0 \\
-\operatorname{sen} \varphi & \cos \varphi & 0 & 0 & 0 & 0 \\
0 & 0 & 1 & 0 & 0 & 0 \\
0 & 0 & \cos \varphi & \operatorname{sen} \varphi & 0 & 0 \\
0 & 0 & -\operatorname{sen} \varphi & \cos \varphi & 0 & 0 \\
0 & 0 & 0 & 0 & 0 & 1
\end{array}\right]
$$

onde $\varphi$ é o ângulo de inclinação da barra em relação ao sistema global medido no sentido anti-horário. 

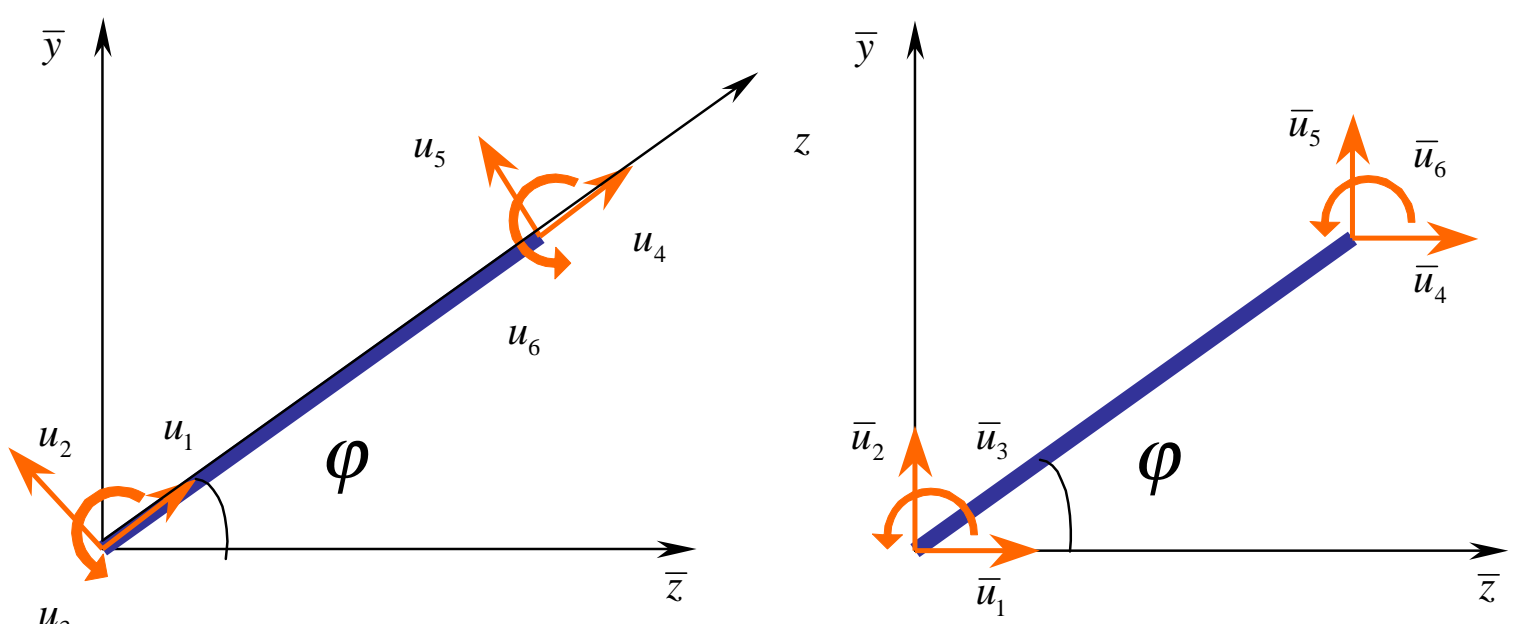

Figura 5 - 4 - Transformação dos Graus de Liberdade para o Sistema Global

Organizando os deslocamentos nodais em vetores (locais e globais) da seguinte maneira

$$
\boldsymbol{u}^{e}=\left[\begin{array}{c}
u_{1}^{e} \\
u_{2}^{e} \\
u_{3}^{e} \\
u_{4}^{e} \\
u_{5}^{e} \\
u_{6}^{e}
\end{array}\right] \quad \text { e } \quad \overline{\boldsymbol{u}}^{e}=\left[\begin{array}{c}
\bar{u}_{1}^{e} \\
\bar{u}_{2}^{e} \\
\bar{u}_{3}^{e} \\
\bar{u}_{4}^{e} \\
\bar{u}_{5}^{e} \\
\bar{u}_{6}^{e}
\end{array}\right]
$$

desta forma tais vetores podem ser relacionados da seguinte forma

$$
\boldsymbol{u}^{e}=\boldsymbol{T}_{e} \cdot \overline{\boldsymbol{u}}^{e}
$$

A mesma matriz de rotação pode ser utilizada para a transformação das forças nodais no sistema local $(\boldsymbol{f})$ e no sistema global $(\overline{\boldsymbol{f}})$, definidas por

$$
\boldsymbol{f}^{e}=\left[\begin{array}{l}
f_{1}^{e} \\
f_{2}^{e} \\
f_{3}^{e} \\
f_{4}^{e} \\
f_{5}^{e} \\
f_{6}^{e}
\end{array}\right] \quad \text { e } \quad \overline{\boldsymbol{f}}^{e}=\left[\begin{array}{c}
\bar{f}_{1}^{e} \\
\bar{f}_{2}^{e} \\
\bar{f}_{3}^{e} \\
\overline{f_{4}^{e}} \\
\bar{f}_{5}^{e} \\
\bar{f}_{6}^{e}
\end{array}\right]
$$

ou seja,

$$
\boldsymbol{f}^{e}=\boldsymbol{T}_{e} \cdot \overline{\boldsymbol{f}}^{e}
$$


A matriz de rigidez local quando multiplicada pelos deslocamentos nodais fornece o vetor das forças nodais internas (no sistema local). Esta relação pode ser colocada no seguinte formato

$$
\boldsymbol{K}_{\text {local }}^{e} \cdot \boldsymbol{u}^{e}=\boldsymbol{f}^{e}
$$

desta forma é fácil demonstrar que a matriz de rigidez do elemento no sistema global de referência fica da seguinte forma

$$
\boldsymbol{K}_{\text {global }}^{e}=\boldsymbol{T}^{T} \cdot \boldsymbol{K}_{\text {local }}^{e} \cdot \boldsymbol{T}
$$

\subsubsection{Espalhamento da Matriz de Rigidez Local na Matriz de RIGIDEZ GLOBAL}

Os graus de liberdade do elemento sempre são numerados de 1 a 6 (de 1 a 3 para os graus de liberdade do nó inicial e de 4 a 6 para os graus de liberdade do nó final). A estrutura é composta por vários nós numerados seqüencialmente pelo projetista. Devese, portanto, relacionar os graus de liberdade do elemento no sistema local com os graus de liberdade no sistema global. A operação de identificação dos números dos graus de liberdade no sistema global de referência a partir dos graus de liberdade locais normalmente é realizada através da matriz de incidência. Tradicionalmente a matriz de incidência tem uma linha para cada elemento da estrutura e duas colunas armazenando o número do nó inicial e o número do nó final do elemento.

Pode-se montar, para um elemento $e$ que possua o nó inicial de número $n_{i}$ no sistema global e nó final de número $n_{f}$, um vetor $v$ com os números de seus graus de liberdade no sistema global da seguinte forma

$$
v=\left[\begin{array}{l}
3 \cdot\left(n_{i}-1\right)+1 \\
3 \cdot\left(n_{i}-1\right)+2 \\
3 \cdot\left(n_{i}-1\right)+3 \\
3 \cdot\left(n_{f}-1\right)+1 \\
3 \cdot\left(n_{f}-1\right)+2 \\
3 \cdot\left(n_{f}-1\right)+3
\end{array}\right] .
$$

A montagem da Matriz de Rigidez Global pode ser feita com o seguinte algoritmo: 


\section{A5.1 - Montagem da Matriz de Rigidez Global}

1. Atribuir zero a todos os elementos da Matriz de Rigidez Global $\left(\overline{\boldsymbol{K}}_{\text {global }} \leftarrow 0\right.$ ) e aos elementos do vetor das forças desequilibradas $\left(\overline{\boldsymbol{f}}_{\text {global }} \leftarrow 0\right)$

2. Para os elementos $e$ (variando de 1 até o número de elementos) da estrutura execute todos os passos seguintes:

i. Montar a matriz de rotação $\boldsymbol{T}_{e}$ do elemento, montar o vetor com o número dos graus de liberdade do elemento $v$, montar a matriz de rigidez local $\boldsymbol{K}_{\text {local }}^{e}$ e montar o vetor de forças desbalanceadas no sistema local $\boldsymbol{f}_{\text {local }}^{e}$.

ii. Obter a matriz de rigidez do elemento $e$ no sistema global: $\boldsymbol{K}_{\text {global }}^{e}=\boldsymbol{T}_{e}^{T} \cdot \boldsymbol{K}_{\text {local }}^{e} \cdot \boldsymbol{T}$ e $\quad$ o vetor de forças desbalanceadas $\boldsymbol{f}_{\text {global }}^{e}=\boldsymbol{T}_{e}^{T} \cdot \boldsymbol{f}_{\text {local }}^{e}$

iii. Varie $i$ de 1 até 6 e execute todos os passos seguintes

a) $\left[\bar{f}_{\text {global }}\right]_{v_{i}} \leftarrow\left[\bar{f}_{\text {global }}\right]_{v_{i}}+\left[\bar{f}_{\text {global }}^{e}\right]_{i}$

b) Varie j de 1 a 6 e faça $\left[\bar{K}_{\text {global }}\right]_{v_{i}, v_{j}} \leftarrow\left[\bar{K}_{\text {global }}\right]_{v_{i}, v_{j}}+\left[K_{\text {global }}^{e}\right]_{i, j}$

Algoritmo 5 - 1 - Algoritmo para Montagem da Matriz de Rigidez Global

Desta forma obtém-se a matriz de rigidez da estrutura no sistema global de coordenadas $\overline{\boldsymbol{K}}_{\text {global }}$ e o vetor das forças desbalanceadas no sistema global $\overline{\boldsymbol{f}}_{\text {global }}$. A matriz de rigidez tem $3 \cdot N_{\text {nós }}$ linhas e $3 \cdot N_{\text {nós }}$ colunas e o vetor das forças desbalanceadas tem $3 \cdot N_{\text {nós }}$ linhas, onde $N_{\text {nós }}$ é o número total de nós da estrutura.

\subsubsection{RESOLUÇÃo do Sistema de EQUAÇõeS}

Depois de obtidos a matriz de rigidez da estrutura no sistema global de coordenadas $\overline{\boldsymbol{K}}_{\text {global }}$ e o vetor das forças desbalanceadas no sistema global $\overline{\boldsymbol{f}}_{\text {global }}$, será necessário resolver o seguinte sistema de equações:

$$
\overline{\boldsymbol{K}}_{\text {global }} \cdot \overline{\boldsymbol{u}}_{\text {global }}=\overline{\boldsymbol{f}}_{\text {global }}
$$


para isto, pode-se utilizar um dos processos de resolução de sistemas de equações apresentado no Capítulo 2 desta dissertação.

Apenas a título de observação, o sistema acima ainda deveria ser um pouco modificado pois seria necessário eliminar os graus de liberdade restritos ou utilizar alguma outra técnica para inclusão das condições de contorno do problema como por exemplo a técnica do número grande, a qual soma um valor de rigidez bastante alto diretamente na matriz de rigidez da estrutura nos graus de liberdade que se deseja impor as restrições. Esta técnica é muito fácil de ser programada porém nunca estaremos resolvendo exatamente o problema em função da alteração feita na matriz de rigidez do problema.

\subsubsection{OBTENÇÃO DOS ESFORÇOS NAS EXTREMIDADES DE CADA ELEMENTO}

Depois de resolvido o sistema de equações e obtidos os deslocamentos nodais da estrutura, é necessário fazer o processo inverso, separando para cada barra os seu 6 deslocamentos globais $\overline{\boldsymbol{u}}^{e}$ dentre os deslocamentos de toda estrutura $\overline{\boldsymbol{u}}_{\text {global }}$. Este processo é feito diretamente pela matriz de incidência.

Desta forma é possível obter tanto os esforços na barra no sistema global quanto no sistema local que será posteriormente utilizado para a verificação das seções transversais.

$$
\overline{\boldsymbol{f}}^{e}=\boldsymbol{K}_{\text {global }}^{e} \cdot \overline{\boldsymbol{u}}^{e} \quad \boldsymbol{f}^{e}=\boldsymbol{T}_{e} \cdot \overline{\boldsymbol{f}}^{e}
$$

A estes esforços obtidos pela equação acima ainda deverão ser acrescidos os esforços nodais de engastamento perfeito de cada elemento, obtendo os esforços seccionais finais.

\section{A5.2 - Algoritmo Geral para Análise Matricial de Estruturas}

1. Definir a incidência das Barras

2. Associar para cada barra os graus de liberdade de suas extremidades com os graus de liberdade da estrutura. (Ver item 5.2.4)

3. Montar para cada barra

i. Vetor de Esforço de Engastamento somados as Força Nodais aplicadas:

$$
f_{\text {local }}^{e} \text { e } \boldsymbol{f}_{\text {global }}^{e}
$$


ii. Matriz de Rigidez Local e Global: $\boldsymbol{K}_{\text {local }}^{e}$ e $\boldsymbol{K}_{\text {global }}^{e}$

4. Montar a Matriz de Rigidez Global $\overline{\boldsymbol{K}}_{\text {global }}$ e o vetor das forças desequilibradas $\overline{\boldsymbol{f}}_{\text {global }}$ pelo Algoritmo A5.1

5. Resolver o Sistema de Equações $\overline{\boldsymbol{K}}_{\text {global }} \cdot \overline{\boldsymbol{u}}_{\text {global }}=\overline{\boldsymbol{f}}_{\text {global }}$

6. Para cada elemento calcula

i. Deslocamento no sistema local: $\boldsymbol{u}^{e}=\boldsymbol{T}_{e} \cdot \overline{\boldsymbol{u}}^{e}$

ii. Calcular os Esforços Nodais: $\overline{\boldsymbol{f}}^{e}=\boldsymbol{K}_{\text {global }}^{e} \cdot \overline{\boldsymbol{u}}^{e} \quad$ e $\quad \boldsymbol{f}^{e}=\boldsymbol{T}_{e} \cdot \overline{\boldsymbol{f}}^{e}$

Algoritmo 5 - 2 - Algoritmo Geral para Análise Matricial de Estruturas

\subsection{ESTADOS LIMITES}

\subsubsection{ESTADO LIMITE ÚlTimo}

O colapso das peças de concreto armado é caracterizado pela ruptura do banzo comprimido do concreto (estado último de ruptura) ou pelo alongamento excessivo da armadura tracionada (estado último de alongamento plástico excessivo). Como consequiência do início do fenômeno físico de ruptura do concreto ser de difícil identificação experimental, convencionou-se que o concreto atinge a ruptura quando seu encurtamento atinge determinados valores experimentalmente justificados (estado último de encurtamento do concreto).

Tendo em vista as dificuldades de caracterização do esgotamento da capacidade resistente das peças submetidas a solicitações normais, considera-se um estado limite último convencional, designado por estado limite último de ruptura ou de deformação plástica excessiva. Este estado limite último é alcançado quando na fibra mais comprimida do concreto o encurtamento atinge um valor último convencional $\varepsilon_{c c u}$, ou quando na armadura tracionada a barra de aço mais deformada tem seu alongamento igual a um valor último convencional $\varepsilon_{s u}$. Para ser alcançado o estado limite último, necessariamente deverá estar satisfeita pelo menos uma das duas condições últimas

Estado Limite Último de Ruptura do Concreto : $2 \% \circ \leq \varepsilon_{c c u} \leq 3.5 \%$ o

Estado Limite Último de Alongamento Excessivo do Aço $: \varepsilon_{s u}=10 \%$ o 


\subsubsection{ESTAdo LIMITE DE UTILIZAÇÃo OU DE SERVIÇO}

Os estados limites de serviço são aqueles relacionados à durabilidade das estruturas, aparência, conforto do usuário e a sua utilização funcional, seja em relação aos usuários, às máquinas ou aos equipamentos utilizados.

A segurança das estruturas de concreto pode exigir, segundo a NBR 6118, a verificação de alguns dos seguintes estados limites de serviço:
a) Estado limite de formação de fissuras;
b) Estado limite de abertura de fissuras;
c) Estado limite de deformações excessivas;
d) Estado limite de descompressão;
e) Estado limite de compressão excessiva
f) Estado limite de vibrações excessivas.

\subsection{DOMÍNIOS DE DEFORMAÇÃO}

As possíveis configurações últimas do diagrama de deformações específicas ao longo da seção transversal da peça definem os cinco domínios de deformação. Os domínios 1 e 2 são fixados pelo ponto A, os domínios 3 e 4 pelo ponto $\mathbf{B}$ e o domínio 5 pelo ponto C. Os diagramas de deformações referentes aos diferentes domínios variam desde a tração uniforme, até a compressão uniforme.

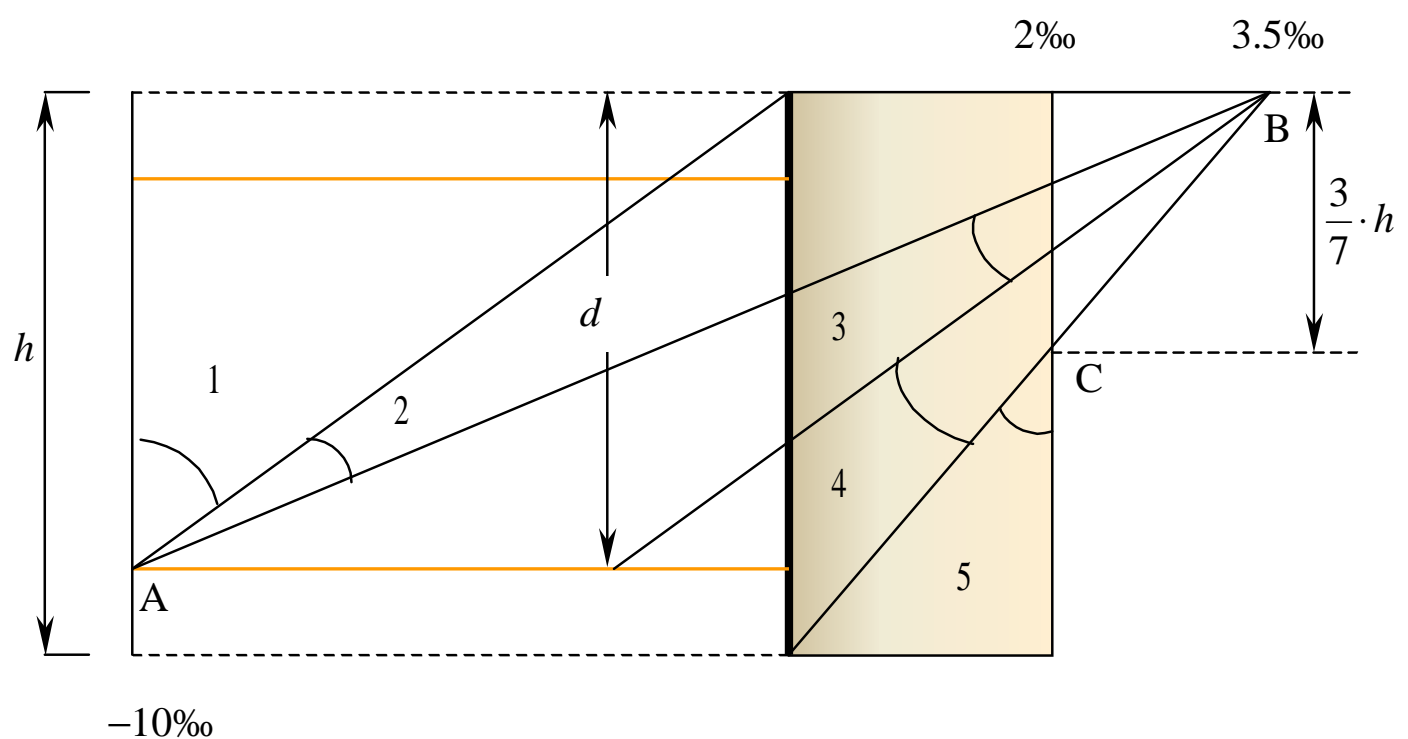

Figura 5 - 5 - Domínios de Deformação 
O ponto C encontra-se a uma distância igual a $\frac{3}{7} \cdot h$, contada a partir da borda mais comprimida (ponto de giro da seção).

Abaixo é feita uma pequena descrição de cada um dos domínios de deformação apresentados na Figura 5 - 5.

Domínio 1 : caracterizado pela seção totalmente tracionada e deformação $\varepsilon_{s d}=10 \%$ na armadura. A linha neutra é externa à seção transversal. Abrange os casos de tração axial e tração com pequena excentricidade. O concreto está totalmente fissurado e os esforços são resistidos apenas pelas armaduras.

Domínio 2 : caracterizado pela deformação $\varepsilon_{s d}=10 \%$ na armadura. A linha neutra corta a seção transversal, havendo um banzo tracionado e outro comprimido.

Domínio 3 : caracterizado pela deformação $\varepsilon_{s d}=3.5 \%$. A linha neutra corta a seção transversal, havendo um banzo tracionado e outro comprimido. Na situação última, a deformação é pelo menos igual à deformação de início de escoamento. Assim, a ruptura do concreto ocorre simultaneamente com o escoamento da armadura.

Domínio 4 : caracterizado pela deformação $\varepsilon_{s d}=3.5 \%$. A linha neutra corta a seção transversal, havendo um banzo tracionado e outro comprimido. No estado último, a deformação da armadura é inferior à deformação de início de escoamento.

Domínio 5 : abrange os casos de flexo-compressão com pequena excentricidade e o caso limite de compressão centrada. A linha neutra não corta a seção transversal, totalmente comprimida. Neste domínio, a deformação última do concreto varia de $2 \%$ o na compressão uniforme a 3.5\% na flexo-compressão com linha neutra tangente à seção.

\subsection{MATERIAIS}

\subsubsection{AÇO}

Para os aços das armaduras passivas adota-se o módulo de deformação

$$
E_{s}=210.000 \mathrm{MPa} \quad\left(1 \mathrm{MPa}=10 \mathrm{kgf} / \mathrm{cm}^{2}\right)
$$

Para esses aços, admite-se um comportamento na compressão simétrico ao comportamento na tração. Pelo fato do concreto solidário às armaduras sofrer ruptura 
com encurtamentos não superiores a 3.5\%o, o diagrama é truncado nesse valor na região de compressão

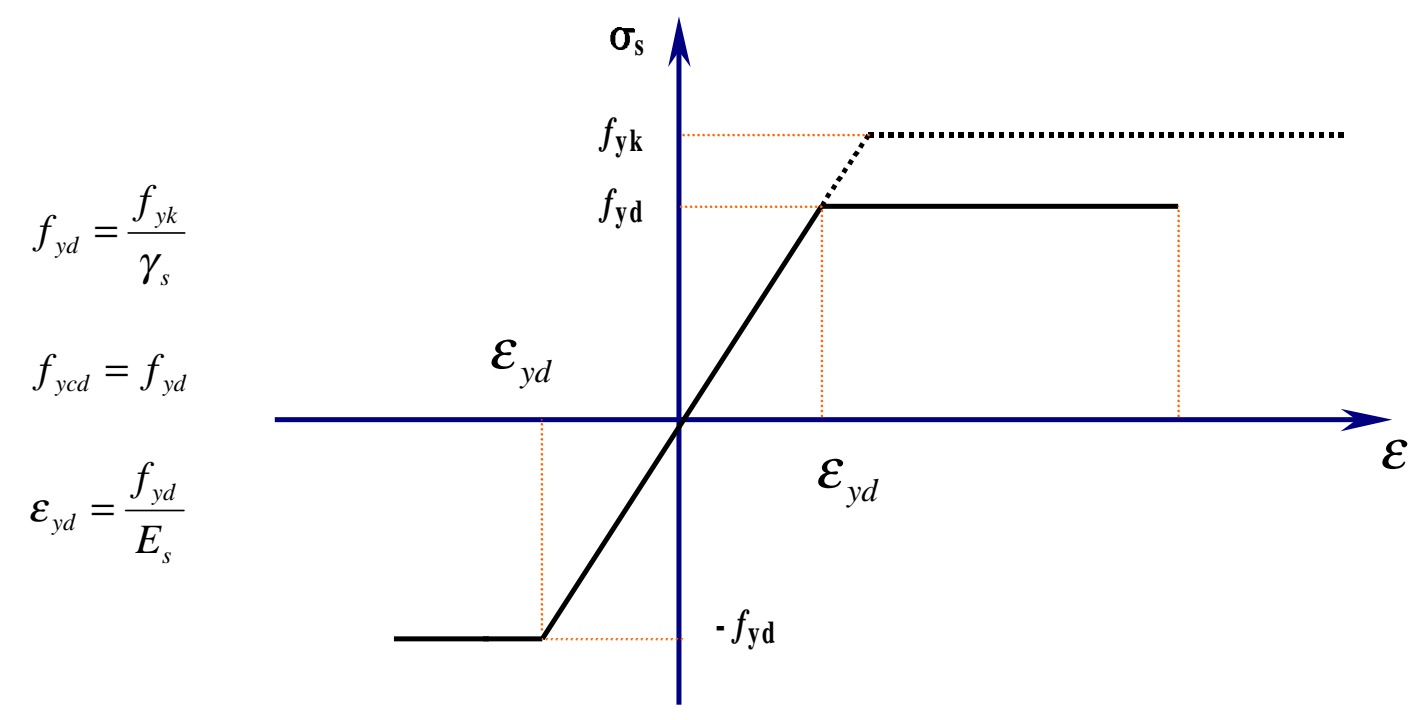

Figura 5 - 6 - Diagrama Tensão x Deformação para o Aço

$$
\sigma_{s}=\left\{\begin{array}{cc}
-f_{y d} & \text { para } \varepsilon_{s}<-\varepsilon_{y d} \\
E_{s} \cdot \varepsilon_{s} & \text { para }-\varepsilon_{y d} \leq \varepsilon_{s} \leq \varepsilon_{y d} \\
f_{y d} & \text { para } \varepsilon_{s}>\varepsilon_{y d}
\end{array}\right.
$$

\subsubsection{CONCRETO}

O diagrama de tensão $\mathrm{x}$ deformação para o concreto pode ser visto na

Figura 5 - 7 mostrada abaixo (diagrama parábola-retângulo).

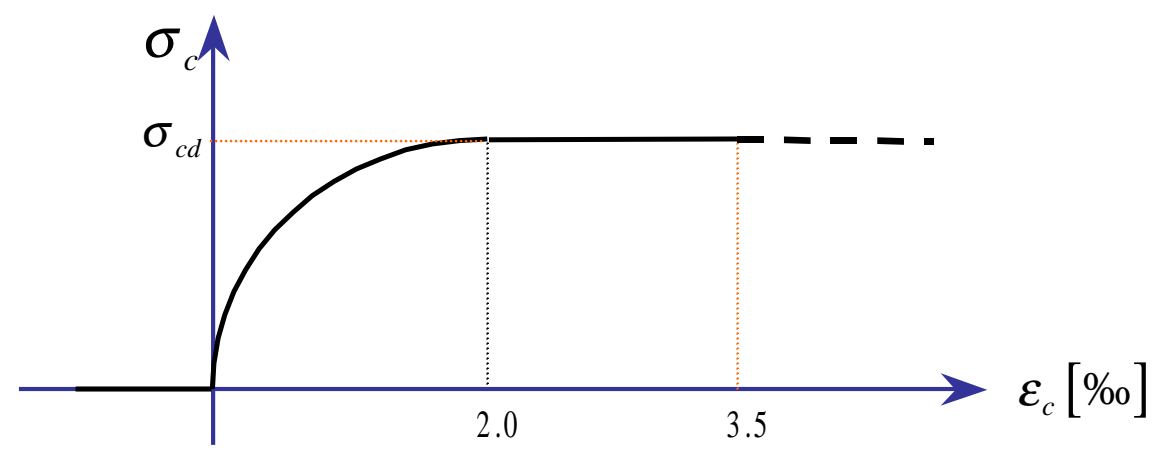

Figura 5 - 7 - Diagrama Tensão x Deformação para o Concreto

$$
\sigma_{c d}=0.85 \cdot \frac{f_{c k}}{\gamma_{c}} \quad \sigma_{c}=\left\{\begin{array}{cc}
0 & \text { para } \varepsilon_{c}<0 \\
\sigma_{c d} \cdot\left(\varepsilon_{c}-\frac{\varepsilon_{c}^{2}}{4}\right) & \text { para } 0 \leq \varepsilon_{c}<2 \% o \\
\sigma_{c d} & \text { para } 2 \% 0 \leq \varepsilon_{c} \leq 3.5 \% o
\end{array}\right.
$$




\subsection{FleXÃo COMPOSTA OBLÍQUA - FCO}

A teoria apresentada nesta seção será utilizada no primeiro exemplo do Capítulo 6 no qual será otimizado um trecho de pilar solicitado por dois momentos fletores $M_{S x d}$ e $M_{\text {Syd }}$ e um esforço normal $N_{S d}$. O processo de verificação da FCO nos dará como resultado os valores da deformação axial $\varepsilon_{0}$ e das curvaturas $\kappa_{x}$ e $\kappa_{y}$. Se a determinação destes valores for possível isto nos garante que o equilíbrio da seção transversal é possível. Este processo de verificação está mais amplamente discutido em ([M-3], [M-4] e [M-5]). Um outro módulo foi acoplado a este programa para que sejam feitas as verificações referentes às deformações máximas, permitidas pela Norma Brasileira (Domínios de Deformação).

Pode-se definir a deformação $\varepsilon$ de um ponto qualquer $(x, y)$ de uma seção pela seguinte equação

$$
\varepsilon\left(\varepsilon_{0}, \kappa_{x}, \kappa_{y}\right)=\varepsilon_{0}+\kappa_{y} \cdot x-\kappa_{x} \cdot y
$$

onde, $\varepsilon_{0}$ é deformação axial na origem do sistema de coordenadas e $\kappa_{x}$ e $\kappa_{y}$ são os módulos das curvaturas da seção na direção $x$ e $y$ respectivamente.

Nas equações a seguir será adotada a seguinte convenção de sinais:

$$
\begin{aligned}
& \varepsilon[+] \rightarrow \text { compressão } \\
& \sigma[+] \rightarrow \text { compressão } \\
& N[+] \rightarrow \text { compressão } \\
& M[+] \rightarrow \text { Regrada mão direita }
\end{aligned}
$$

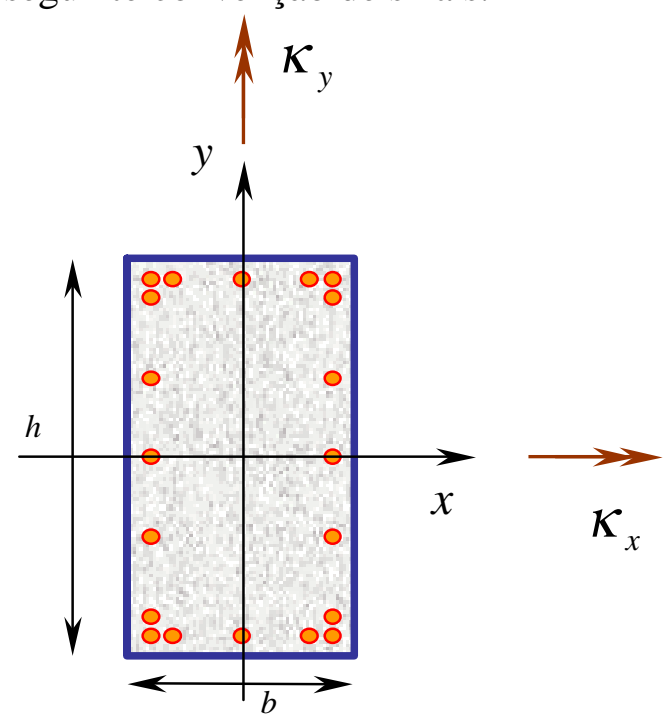

Pode-se definir o problema na forma de minimização para que possa resolver pelo Método de Newton. Para isso estaremos definindo uma $f(\boldsymbol{x})$ que contêm as 3 equações de equilíbrio da seção transversal da seguinte forma 


$$
f(\boldsymbol{x})=\left\{\begin{array}{c}
N_{S d}-N_{R d} \\
M_{S x d}-M_{R x d} \\
M_{S y d}-M_{R y d}
\end{array}\right\}=\boldsymbol{0}
$$

onde temos,

$$
\boldsymbol{x}=\left[\begin{array}{l}
\varepsilon_{0} \\
\kappa_{x} \\
\kappa_{y}
\end{array}\right]
$$

resolver este sistema de equações não-lineares pelo Método de Newton significa resolver o seguinte problema,

$$
\left[\begin{array}{c}
\varepsilon_{0} \\
\kappa_{x} \\
\kappa_{y}
\end{array}\right]^{k+1}=\left[\begin{array}{c}
\varepsilon_{0} \\
\kappa_{x} \\
\kappa_{y}
\end{array}\right]^{k}-\left[\nabla f(\boldsymbol{x})^{k}\right]^{-1} \cdot f\left(\varepsilon_{0}, \kappa_{x}, \kappa_{y}\right)^{k},
$$

utilizando a notação da matriz Jacobiana já apresentada anteriormente tem-se a seguinte equação iterativa

$$
\boldsymbol{x}^{k+1}=\boldsymbol{x}^{k}-\left[\mathbb{J}^{k}\right]^{-1} \cdot f\left(\boldsymbol{x}^{k}\right) .
$$

Nos passos seguintes serão descritas as expressões para calculo de cada um dos termos desta equação.

\subsubsection{INTEGRAIS DOS ESFORÇOS RESISTENTES}

O calculo dos esforços resistentes da seção transversal será aqui subdividido em duas partes, uma parcela dos esforços resistentes devido ao concreto " $c$ " e uma segunda parcela referente ao aço "s".

$$
\begin{gathered}
N_{R d}\left(\varepsilon_{0}, \kappa_{x}, \kappa_{y}\right)=N_{R c d}\left(\varepsilon_{0}, \kappa_{x}, \kappa_{y}\right)+N_{R s d}\left(\varepsilon_{0}, \kappa_{x}, \kappa_{y}\right) \\
M_{R x d}\left(\varepsilon_{0}, \kappa_{x}, \kappa_{y}\right)=M_{R x c d}\left(\varepsilon_{0}, \kappa_{x}, \kappa_{y}\right)+M_{R x s d}\left(\varepsilon_{0}, \kappa_{x}, \kappa_{y}\right) \\
M_{R y d}\left(\varepsilon_{0}, \kappa_{x}, \kappa_{y}\right)=M_{R y c d}\left(\varepsilon_{0}, \kappa_{x}, \kappa_{y}\right)+M_{R y s d}\left(\varepsilon_{0}, \kappa_{x}, \kappa_{y}\right)
\end{gathered}
$$

As equações abaixo fornecem os esforços resistentes da seção e desta forma a função $f(\boldsymbol{x})$ para cada iteração do método.

$$
N_{R c d}=\iint_{A_{c}} \sigma_{c}(\varepsilon) \cdot d x d y \quad M_{R x c d}=-\iint_{A_{c}} \sigma_{c}(\varepsilon) \cdot y \cdot d x d y \quad M_{R y c d}=\iint_{A_{c}} \sigma_{c}(\varepsilon) \cdot x \cdot d x d y
$$




$$
N_{R s d}=\sum_{i=1}^{n s}\left[\sigma_{s}(\varepsilon) \cdot A_{s}\right]_{i} \quad M_{R x s d}=-\sum_{i=1}^{n s}\left[\sigma_{s}(\varepsilon) \cdot y_{s} \cdot A_{s}\right]_{i} \quad M_{R y s d}=\sum_{i=1}^{n s}\left[\sigma_{s}(\varepsilon) \cdot x_{s} \cdot A_{s}\right]_{i}
$$

onde $n s$ é o número de barras de aço na seção transversal e $A_{s}$ é a área de cada barra de aço.

\subsubsection{Cálculo da Jacobiana dos EsforÇos RESISTENTES}

Pode-se subdividir a Matriz Jacobiana em duas parcelas, uma referente ao concreto e a outra referente ao aço, ou seja,

$$
\begin{gathered}
\mathbb{J}=\mathbb{J}_{c}+\mathbb{J}_{s} \\
\mathbb{J}_{\mathrm{c}}=\left[\begin{array}{ccc}
\frac{\partial N_{R c d}}{\partial \varepsilon_{0}} & \frac{\partial N_{R c d}}{\partial \kappa_{x}} & \frac{\partial N_{R c d}}{\partial \kappa_{y}} \\
\frac{\partial M_{R x c d}}{\partial \varepsilon_{0}} & \frac{\partial M_{R x c d}}{\partial \kappa_{x}} & \frac{\partial M_{R x c d}}{\partial \kappa_{y}} \\
\frac{\partial M_{R y c d}}{\partial \varepsilon_{0}} & \frac{\partial M_{R y c d}}{\partial \kappa_{x}} & \frac{\partial M_{R y c d}}{\partial \kappa_{y}}
\end{array}\right] \quad \mathbb{J}_{\mathrm{s}}=\left[\begin{array}{ccc}
\frac{\partial N_{R s d}}{\partial \varepsilon_{0}} & \frac{\partial N_{R s d}}{\partial \kappa_{x}} & \frac{\partial N_{R s d}}{\partial \kappa_{y}} \\
\frac{\partial M_{R x s d}}{\partial \varepsilon_{0}} & \frac{\partial M_{R x s d}}{\partial \kappa_{x}} & \frac{\partial M_{R x s d}}{\partial \kappa_{y}} \\
\frac{\partial M_{R y s d}}{\partial \varepsilon_{0}} & \frac{\partial M_{R y s d}}{\partial \kappa_{x}} & \frac{\partial M_{R y s d}}{\partial \kappa_{y}}
\end{array}\right]
\end{gathered}
$$

A seguir são apresentadas as equações para cada um dos termos das Matrizes Jacobianas dos esforços resistentes mostradas acima, desta forma estão apresentados abaixo os 18 termos destas matrizes.

$$
\frac{\partial \varepsilon}{\partial \varepsilon_{0}}=1 \quad \frac{\partial \varepsilon}{\partial \kappa_{x}}=-y \quad \frac{\partial \varepsilon}{\partial \kappa_{y}}=x
$$

As expressões referentes aos termos do concreto para o calculo de $\mathbb{J}_{c}$ são:

$$
\begin{array}{cl}
\frac{\partial N_{R c d}}{\partial \varepsilon_{0}}=\int_{A_{c}} \frac{\partial \sigma_{c}(\varepsilon)}{\partial \varepsilon} \cdot d x d y & \frac{\partial N_{R c d}}{\partial \kappa_{x}}=-\int_{A_{c}} \frac{\partial \sigma_{c}(\varepsilon)}{\partial \varepsilon} \cdot y \cdot d x d y \\
\frac{\partial N_{R c d}}{\partial \kappa_{y}}=\int_{A_{c}} \frac{\partial \sigma_{c}(\varepsilon)}{\partial \varepsilon} \cdot x \cdot d x d y & \frac{\partial M_{R x c d}}{\partial \varepsilon_{0}}=-\int_{A_{c}} \frac{\partial \sigma_{c}(\varepsilon)}{\partial \varepsilon} \cdot y \cdot d x d y \\
\frac{\partial M_{R x c d}}{\partial \kappa_{x}}=\int_{A_{c}} \frac{\partial \sigma_{c}(\varepsilon)}{\partial \varepsilon} \cdot y^{2} \cdot d x d y & \frac{\partial M_{R x c d}}{\partial \kappa_{y}}=-\int_{A_{c}} \frac{\partial \sigma_{c}(\varepsilon)}{\partial \varepsilon} \cdot y \cdot x \cdot d x d y
\end{array}
$$




$$
\begin{gathered}
\frac{\partial M_{R y c d}}{\partial \varepsilon_{0}}=\int_{A_{c}} \frac{\partial \sigma_{c}(\varepsilon)}{\partial \varepsilon} \cdot x \cdot d x d y \quad \frac{\partial M_{R y c d}}{\partial \kappa_{x}}=-\int_{A_{c}} \frac{\partial \sigma_{c}(\varepsilon)}{\partial \varepsilon} \cdot x \cdot y \cdot d x d y \\
\frac{\partial M_{R y c d}}{\partial \kappa_{y}}=\int_{A_{c}} \frac{\partial \sigma_{c}(\varepsilon)}{\partial \varepsilon} \cdot x^{2} \cdot d x d y
\end{gathered}
$$

Da mesma forma que para o concreto, têm-se as parcelas da matriz $\mathscr{J}_{\mathrm{s}}$ para o aço mostradas abaixo:

$$
\begin{array}{cc}
\frac{\partial N_{R s d}}{\partial \varepsilon_{0}}=\sum_{i=1}^{n s}\left[\frac{\partial \sigma_{s}(\varepsilon)}{\partial \varepsilon} \cdot A_{s}\right]_{i} & \frac{\partial N_{R s d}}{\partial \kappa_{x}}=-\sum_{i=1}^{n s}\left[\frac{\partial \sigma_{s}(\varepsilon)}{\partial \varepsilon} \cdot y_{s} \cdot A_{s}\right]_{i} \\
\frac{\partial N_{R s d}}{\partial \kappa_{y}}=\sum_{i=1}^{n s}\left[\frac{\partial \sigma_{s}(\varepsilon)}{\partial \varepsilon} \cdot x_{s} \cdot A_{s}\right]_{i} & \frac{\partial M_{R x s d}}{\partial \varepsilon_{0}}=-\sum_{i=1}^{n s}\left[\frac{\partial \sigma_{s}(\varepsilon)}{\partial \varepsilon} \cdot y_{s} \cdot A_{s}\right]_{i} \\
\frac{\partial M_{R x s d}}{\partial \kappa_{x}}=\sum_{i=1}^{n s}\left[\frac{\partial \sigma_{s}(\varepsilon)}{\partial \varepsilon} \cdot y_{s}^{2} \cdot A_{s}\right]_{i} & \frac{\partial M_{R x s d}}{\partial \kappa_{y}}=-\sum_{i=1}^{n s}\left[\frac{\partial \sigma_{s}(\varepsilon)}{\partial \varepsilon} \cdot y_{s} \cdot x_{s} \cdot A_{s}\right]_{i} \\
\frac{\partial M_{R y s d}}{\partial \varepsilon_{0}}=\sum_{i=1}^{n s}\left[\frac{\partial \sigma_{s}(\varepsilon)}{\partial \varepsilon} \cdot x_{s} \cdot A_{s}\right]_{i} & \frac{\partial M_{R y s d}}{\partial \kappa_{x}}=-\sum_{i=1}^{n s}\left[\frac{\partial \sigma_{s}(\varepsilon)}{\partial \varepsilon} \cdot y_{s} \cdot x_{s} \cdot A_{s}\right]_{i} \\
\frac{\partial M_{R y s d}}{\partial \kappa_{y}}=\sum_{i=1}^{n s}\left[\frac{\partial \sigma_{s}(\varepsilon)}{\partial \varepsilon} \cdot x_{s}^{2} \cdot A_{s}\right]_{i}
\end{array}
$$

Definindo-se as funções $D_{c}(\varepsilon)$ e $D_{s}(\varepsilon)$ como mostrado a seguir

$$
\begin{aligned}
& D_{c}(\varepsilon)=\frac{\partial \sigma_{c}(\varepsilon)}{\partial \varepsilon}=\left\{\begin{array}{cc}
0 & \text { se } \quad \varepsilon<0 \\
1000 \cdot \sigma_{c d} \cdot\left(1-\frac{\varepsilon}{2}\right) & \text { se } \quad 0 \leq \varepsilon \leq 2 \\
0 & \text { se } \varepsilon>2
\end{array}\right. \\
& D_{s}(\varepsilon)=\frac{d \sigma_{s}(\varepsilon)}{d \varepsilon}=\left\{\begin{array}{cc}
0 & \text { se } \varepsilon<-\varepsilon_{y d} \\
E_{s} & \text { se }-\varepsilon_{y d} \leq \varepsilon \leq \varepsilon_{y d} \\
0 & \text { se } \varepsilon>\varepsilon_{y d}
\end{array}\right.
\end{aligned}
$$

é possível escrever a matriz Jacobiana $\mathbb{J}$ que será utilizado no Método de Newton de forma simplificada pelas seguintes expressões 


$$
\mathbb{J}_{c}=\left[\begin{array}{ccc}
\iint_{A_{c}} D_{c}(\varepsilon) \cdot d x d y & -\iint_{A_{c}} D_{c}(\varepsilon) \cdot y \cdot d x d y & \iint_{A_{c}} D_{c}(\varepsilon) \cdot x \cdot d x d y \\
-\iint_{A_{c}} D_{c}(\varepsilon) \cdot y \cdot d x d y & \iint_{A_{c}} D_{c}(\varepsilon) \cdot y^{2} \cdot d x d y & -\iint_{A_{c}} D_{c}(\varepsilon) \cdot x \cdot y \cdot d x d y \\
\iint_{A_{c}} D_{c}(\varepsilon) \cdot x \cdot d x d y & -\iint_{A_{c}} D_{c}(\varepsilon) \cdot x \cdot y \cdot d x d y & \iint_{A_{c}} D_{c}(\varepsilon) \cdot x^{2} \cdot d x d y
\end{array}\right]
$$

e para o aço tem-se

$$
\mathbb{J}_{\mathrm{s}}=\left[\begin{array}{ccc}
\sum_{i=1}^{n s}\left[D_{s}(\varepsilon) \cdot A_{s}\right]_{i} & -\sum_{i=1}^{n s}\left[D_{s}(\varepsilon) \cdot y_{s} \cdot A_{s}\right]_{i} & \sum_{i=1}^{n s}\left[D_{s}(\varepsilon) \cdot x_{s} \cdot A_{s}\right]_{i} \\
-\sum_{i=1}^{n s}\left[D_{s}(\varepsilon) \cdot y_{s} \cdot A_{s}\right]_{i} & \sum_{i=1}^{n s}\left[D_{s}(\varepsilon) \cdot y_{s}^{2} \cdot A_{s}\right]_{i} & -\sum_{i=1}^{n s}\left[D_{s}(\varepsilon) \cdot x_{s} \cdot y_{s} \cdot A_{s}\right]_{i} \\
\sum_{i=1}^{n s}\left[D_{s}(\varepsilon) \cdot x_{s} \cdot A_{s}\right]_{i} & -\sum_{i=1}^{n s}\left[D_{s}(\varepsilon) \cdot x_{s} \cdot y_{s} \cdot A_{s}\right]_{i} & \sum_{i=1}^{n s}\left[D_{s}(\varepsilon) \cdot x_{s}^{2} \cdot A_{s}\right]_{i}
\end{array}\right]
$$

Com as expressões acima é possível resolver de forma rápida e eficiente o problema da verificação de seções transversais sujeitas à Flexão Composta Oblíqua.

\subsection{FLEX̃̃o COMPOSTA NORMAL - FCN}

A formulação para verificação das seções transversais das vigas e pilares do pórtico à Flexão Composta Normal, é feita de forma análoga ao apresentado para verificação da FCO. Para evitar que indivíduos que possuam um ou mais de seus elementos reprovados pela verificação sejam eliminados, introduziu-se um parâmetro $\alpha$ que representa o quanto estão afastados do equilíbrio.

Esse parâmetro é utilizado na penalização proporcional desses indivíduos, diminuindo sua probabilidade de transmitir características durante o cruzamento, sem eliminá-los do processo.

Esse parâmetro representa uma inovação no processo de verificação de seções transversais. Na formulação proposta por MENDES (2000) [M-3], quando o equilíbrio não é possível, o Método de Newton não converge, e é interrompido após um número máximo de iterações não fornecendo informação sobre o quão distante se encontra a condição de equilíbrio. Com o parâmetro $\alpha$ introduzido, é possível avaliar precisamente essa situação. 
Como a capacidade resistente da seção é sempre calculado no ELU, também é possível utilizar-se do método para calcular o excesso de segurança dos elementos, situações onde o coeficiente $\alpha$ assume valores menores que 1 .

A extensão desse processo para FCO aliada à otimização, pode servir de ferramenta para uma nova metodologia de segurança para dimensionamento de estruturas de concreto armado.

Na FCN, cada seção é solicitada por um par de esforços $\left(N_{S}, M_{S}\right)$ que deve ser resistido pela seção transversal de concreto armado.

Pode-se definir a deformação $\varepsilon$ de um ponto qualquer de uma seção pela seguinte equação,

$$
\varepsilon\left(\varepsilon_{0}, \kappa_{x}\right)=\varepsilon_{0}-\kappa_{x} \cdot y
$$

onde, $\varepsilon_{0}$ é deformação axial na origem do sistema de coordenadas e $\kappa_{x}$ é o módulo da curvatura da seção na direção $x$.

Será adotada a seguinte convenção de sinais

$$
\begin{aligned}
& \varepsilon[+] \rightarrow \text { compressão } \\
& \sigma[+] \rightarrow \text { compressão } \\
& N[+] \rightarrow \text { compressão } \\
& M[+] \rightarrow \text { Regra da mão direita }
\end{aligned}
$$

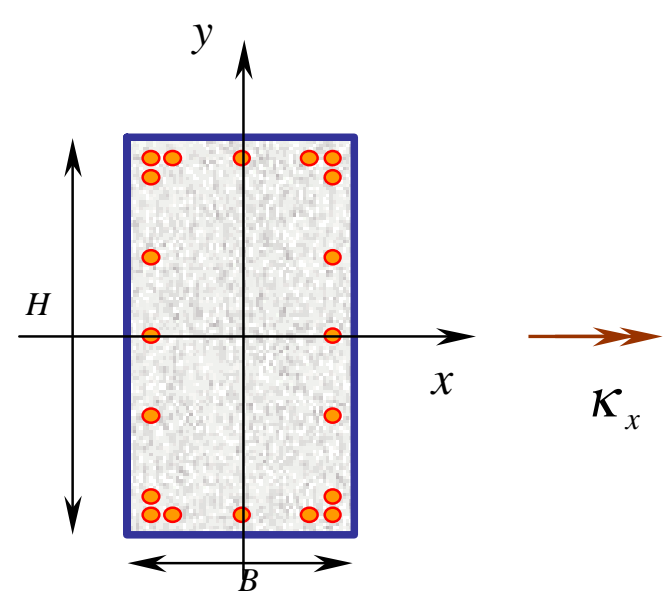

Definindo o problema na forma de minimização para que possa resolver pelo Método de Newton define-se uma $f(\boldsymbol{x})$ que contêm as 2 equações de equilíbrio da seção transversal da seguinte forma

$$
f(\boldsymbol{x})=\left\{\begin{array}{c}
N_{S d}-\alpha \cdot N_{R d} \\
M_{S x d}-\alpha \cdot M_{R x d}
\end{array}\right\}=\left\{\begin{array}{l}
f_{1} \\
f_{2}
\end{array}\right\}=\mathbf{0}
$$

onde temos,

$$
\boldsymbol{x}=\left[\begin{array}{l}
\kappa_{x} \\
\alpha
\end{array}\right]
$$


resolver este sistema de equações pelo Método de Newton significa resolver o seguinte problema,

$$
\left[\begin{array}{c}
\kappa_{x} \\
\alpha
\end{array}\right]^{k+1}=\left[\begin{array}{c}
\kappa_{x} \\
\alpha
\end{array}\right]^{k}-\left[\nabla f(\boldsymbol{x})^{k}\right]^{-1} \cdot f\left(\kappa_{x}, \alpha\right)^{k},
$$

utilizando a notação da Matriz Jacobiana já apresentada anteriormente teremos a seguinte equação iterativa

$$
\boldsymbol{x}^{k+1}=\boldsymbol{x}^{k}-\left[\mathbb{J}^{k}\right]^{-1} \cdot f\left(\boldsymbol{x}^{k}\right) .
$$

Os esforços resistentes da seção transversal são função de $\varepsilon_{0}$ e $\kappa_{x}$, porém, para resolver o problema de verificação que neste caso possui 2 equações de equilíbrio e passou a ter 3 incógnitas, $\varepsilon_{0}, \kappa_{x}$ e $\alpha$. acrescentou-se mais uma equação ao problema, obtida a partir das correlações existentes dentro de cada um dos domínios de deformação entre $\varepsilon_{0}$ e $\kappa_{x}$. Desta forma podemos escrever as seguintes equações:

1. Para os Domínios 1 e 2

$$
\kappa_{x}=-\frac{10 \% o+\varepsilon_{0}}{d-\frac{h}{2}}
$$

2. Para os Domínios 3 e 4

$$
\kappa_{x}=\frac{2 \cdot\left(\varepsilon_{0}-3.5 \%\right)}{h}
$$

3. Para o Domínio 5

$$
\kappa_{x}=\frac{14 \cdot\left(\varepsilon_{0}-2.0 \% 0\right)}{h}
$$

Desta forma é possível escrever as equações para $N_{R d}$ e $M_{R d}$ apenas em função de $\kappa_{x}$.

O Método de Newton é aplicado dentro de cada um dos três grupos: Domínios 1 e 2, Domínios 3 e 4 ou Domínio 5, encontrando o equilíbrio da seção em um deles.

No programa computacional implementado, uma vez encontrado o equilíbrio em qualquer um dos 3 casos, pode-se parar a verificação e não verificar os demais casos ainda restantes (caso não seja este o ultimo a ser verificado). A ordem de busca dentro do algoritmo foi feita de forma a tornar o algoritmo o mais rápido possível. Como a estrutura a ser otimizada é um pórtico plano, sabe-se que a maior parte das seções 
estarão dentro dos Domínios 3 e 4, depois são testados os Domínios 1 e 2 e por último é testado o Domínio 5.

Abaixo são apresentadas as expressões utilizadas no cálculo da função $f(\boldsymbol{x})$ e na Matriz Jacobiana $\mathbb{J}$ que compõem a fórmula iterativa do Método de Newton.

\subsubsection{INTEGRAIS DOS ESFORÇOS RESISTENTES}

O cálculo dos esforços resistentes da seção transversal será aqui subdividido em duas partes, uma parcela dos esforços resistentes devido ao concreto "c" e uma segunda parcela referente a aço "s".

$$
\begin{gathered}
N_{R d}\left(\varepsilon_{0}, \kappa_{x}\right)=N_{R c d}\left(\varepsilon_{0}, \kappa_{x}\right)+N_{R s d}\left(\varepsilon_{0}, \kappa_{x}\right) \\
M_{R d}\left(\varepsilon_{0}, \kappa_{x}\right)=M_{R c d}\left(\varepsilon_{0}, \kappa_{x}\right)+M_{R s d}\left(\varepsilon_{0}, \kappa_{x}\right)
\end{gathered}
$$

As equações abaixo fornecem os esforços resistentes da seção e desta forma a função $f(\boldsymbol{x})$ para cada iteração do método.

$$
\begin{array}{ll}
N_{R c d}=\iint_{A_{c}} \sigma_{c}(\varepsilon) \cdot d x d y & M_{R c d}=-\iint_{A_{c}} \sigma_{c}(\varepsilon) \cdot y \cdot d x d y \\
N_{R s d}=\sum_{i=1}^{n s}\left[\sigma_{s}(\varepsilon) \cdot A_{s}\right]_{i} & M_{R s d}=-\sum_{i=1}^{n s}\left[\sigma_{s}(\varepsilon) \cdot y_{s} \cdot A_{s}\right]_{i}
\end{array}
$$

onde $n s$ é o número de barras de aço na seção transversal e $A_{s}$ é a área de cada barra de aço.

\subsubsection{Cálculo da Matriz Jacobiana para FCN}

Pode-se subdividir a Matriz Jacobiana em duas parcelas, uma referente ao concreto e a outra referente ao aço, ou seja,

$$
\mathbb{J}=\left[\begin{array}{ll}
\frac{\partial f_{1}}{\partial \kappa_{x}} & \frac{\partial f_{1}}{\partial \alpha} \\
\frac{\partial f_{2}}{\partial \kappa_{x}} & \frac{\partial f_{2}}{\partial \alpha}
\end{array}\right]
$$




$$
\begin{array}{cl}
\frac{\partial f_{1}}{\partial \kappa_{x}}=-\alpha \cdot\left(\frac{\partial N_{R c d}}{\partial \kappa_{x}}+\frac{\partial N_{R s d}}{\partial \kappa_{x}}\right) & \frac{\partial f_{2}}{\partial \kappa_{x}}=-\alpha \cdot\left(\frac{\partial M_{R c d}}{\partial \kappa_{x}}+\frac{\partial M_{R s d}}{\partial \kappa_{x}}\right) \\
\frac{\partial f_{1}}{\partial \alpha}=-\left(N_{R c d}+N_{R s d}\right) & \frac{\partial f_{2}}{\partial \alpha}=-\left(M_{R c d}+M_{R s d}\right)
\end{array}
$$

Como os esforços $N_{R c d}, N_{R s d}, M_{R c d}$ e $M_{R s d}$ são funções de $\varepsilon_{0}$ e $\kappa_{x}$, as derivadas da função $f$ em relação a variável $\kappa_{x}$ ficam da seguinte forma

$$
\begin{gathered}
\frac{\partial f_{1}}{\partial \kappa_{x}}=-\alpha \cdot\left(\frac{\partial N_{R c d}}{\partial \kappa_{x}}+\frac{\partial N_{R c d}}{\partial \varepsilon_{0}} \cdot \frac{\partial \varepsilon_{0}}{\partial \kappa_{x}}+\frac{\partial N_{R s d}}{\partial \kappa_{x}}+\frac{\partial N_{R s d}}{\partial \varepsilon_{0}} \cdot \frac{\partial \varepsilon_{0}}{\partial \kappa_{x}}\right) \\
\frac{\partial f_{2}}{\partial \kappa_{x}}=-\alpha \cdot\left(\frac{\partial M_{R c d}}{\partial \kappa_{x}}+\frac{\partial M_{R c d}}{\partial \varepsilon_{0}} \cdot \frac{\partial \varepsilon_{0}}{\partial \kappa_{x}}+\frac{\partial M_{R s d}}{\partial \kappa_{x}}+\frac{\partial M_{R s d}}{\partial \varepsilon_{0}} \cdot \frac{\partial \varepsilon_{0}}{\partial \kappa_{x}}\right)
\end{gathered}
$$

e é a partir destas expressões que se obtêm a Matriz Jacobiana.

As expressões desenvolvidas para os Domínios 1 e 2 são,

$$
\begin{gathered}
\frac{\partial \varepsilon_{0}}{\partial \kappa_{x}}=-\left(d-\frac{h}{2}\right) \\
\frac{\partial f_{1}}{\partial \kappa_{x}}=-\alpha \cdot\left(-\int_{A_{c}} \frac{\partial \sigma_{c}(\varepsilon)}{\partial \varepsilon} \cdot y \cdot d x d y-\frac{\partial N_{R c d}}{\partial \varepsilon_{0}} \cdot\left(d-\frac{h}{2}\right)+\frac{\partial N_{R s d}}{\partial \kappa_{x}}-\frac{\partial N_{R s d}}{\partial \varepsilon_{0}} \cdot\left(d-\frac{h}{2}\right)\right) \\
\frac{\partial f_{2}}{\partial \kappa_{x}}=-\alpha \cdot\left(\frac{\partial M_{R c d}}{\partial \kappa_{x}}-\frac{\partial M_{R c d}}{\partial \varepsilon_{0}} \cdot\left(d-\frac{h}{2}\right)+\frac{\partial M_{R s d}}{\partial \kappa_{x}}-\frac{\partial M_{R s d}}{\partial \varepsilon_{0}} \cdot\left(d-\frac{h}{2}\right)\right)
\end{gathered}
$$

As expressões desenvolvidas para os Domínios 3 e 4 são,

$$
\begin{gathered}
\frac{\partial \varepsilon_{0}}{\partial \kappa_{x}}=\frac{h}{2} \\
\frac{\partial f_{1}}{\partial \kappa_{x}}=-\alpha \cdot\left(\frac{\partial N_{R c d}}{\partial \kappa_{x}}+\frac{\partial N_{R c d}}{\partial \varepsilon_{0}} \cdot \frac{h}{2}+\frac{\partial N_{R s d}}{\partial \kappa_{x}}+\frac{\partial N_{R s d}}{\partial \varepsilon_{0}} \cdot \frac{h}{2}\right) \\
\frac{\partial f_{2}}{\partial \kappa_{x}}=-\alpha \cdot\left(\frac{\partial M_{R c d}}{\partial \kappa_{x}}+\frac{\partial M_{R c d}}{\partial \varepsilon_{0}} \cdot \frac{h}{2}+\frac{\partial M_{R s d}}{\partial \kappa_{x}}+\frac{\partial M_{R s d}}{\partial \varepsilon_{0}} \cdot \frac{h}{2}\right)
\end{gathered}
$$

As expressões desenvolvidas para o Domínio 5 são, 


$$
\begin{gathered}
\frac{\partial \varepsilon_{0}}{\partial \kappa_{x}}=\frac{h}{14} \\
\frac{\partial f_{1}}{\partial \kappa_{x}}=-\alpha \cdot\left(\frac{\partial N_{R c d}}{\partial \kappa_{x}}+\frac{\partial N_{R c d}}{\partial \varepsilon_{0}} \cdot \frac{h}{14}+\frac{\partial N_{R s d}}{\partial \kappa_{x}}+\frac{\partial N_{R s d}}{\partial \varepsilon_{0}} \cdot \frac{h}{14}\right) \\
\frac{\partial f_{2}}{\partial \kappa_{x}}=-\alpha \cdot\left(\frac{\partial M_{R c d}}{\partial \kappa_{x}}+\frac{\partial M_{R c d}}{\partial \varepsilon_{0}} \cdot \frac{h}{14}+\frac{\partial M_{R s d}}{\partial \kappa_{x}}+\frac{\partial M_{R s d}}{\partial \varepsilon_{0}} \cdot \frac{h}{14}\right)
\end{gathered}
$$

As expressões referentes aos termos do concreto são :

$$
\begin{aligned}
\frac{\partial N_{R c d}}{\partial \kappa_{x}}=-\int_{A_{c}} \frac{\partial \sigma_{c}(\varepsilon)}{\partial \varepsilon} \cdot y \cdot d x d y & \frac{\partial N_{R c d}}{\partial \varepsilon_{0}}=\int_{A_{c}} \frac{\partial \sigma_{c}(\varepsilon)}{\partial \varepsilon} \cdot d x d y \\
\frac{\partial M_{R c d}}{\partial \kappa_{x}}=\int_{A_{c}} \frac{\partial \sigma_{c}(\varepsilon)}{\partial \varepsilon} \cdot y^{2} \cdot d x d y & \frac{\partial M_{R c d}}{\partial \varepsilon_{0}}=-\int_{A_{c}} \frac{\partial \sigma_{c}(\varepsilon)}{\partial \varepsilon} \cdot y \cdot d x d y
\end{aligned}
$$

Da mesma forma que para o concreto, têm-se das derivadas parciais para o aço

$$
\begin{array}{ll}
\frac{\partial N_{R s d}}{\partial \kappa_{x}}=-\sum_{i=1}^{n s}\left[\frac{\partial \sigma_{s}(\varepsilon)}{\partial \varepsilon} \cdot y_{s} \cdot A_{s}\right]_{i} & \frac{\partial N_{R s d}}{\partial \varepsilon_{0}}=\sum_{i=1}^{n s}\left[\frac{\partial \sigma_{s}(\varepsilon)}{\partial \varepsilon} \cdot A_{s}\right]_{i} \\
\frac{\partial M_{R s d}}{\partial \kappa_{x}}=\sum_{i=1}^{n s}\left[\frac{\partial \sigma_{s}(\varepsilon)}{\partial \varepsilon} \cdot y_{s}^{2} \cdot A_{s}\right]_{i} & \frac{\partial M_{R s d}}{\partial \varepsilon_{0}}=-\sum_{i=1}^{n s}\left[\frac{\partial \sigma_{s}(\varepsilon)}{\partial \varepsilon} \cdot y_{s} \cdot A_{s}\right]_{i}
\end{array}
$$

Com as expressões acima é possível resolver de forma rápida e eficiente o problema da verificação de seções transversais sujeitas à Flexão Composta Normal.

\subsection{Critérios Normativos}

Os dados que constam no texto a seguir forma retirados do Projeto de Revisão da NBR 6118 - 2000. Boa parte deles foi implementada no programa de otimização de pórticos de concreto armado sob a forma de restrições.

\subsubsection{SeguranÇa EM RelaÇão aOS ELU}

Quando se dimensiona ou se verifica uma estrutura, é preciso ter em mente que estamos verificando seções de elementos.

É a segurança dessas seções que pode, usualmente, ser expressa analiticamente. 
É fundamental que essa segurança seja estendida ao restante dos elementos, através de um detalhamento adequado que permita solidarizar elementos que cheguem a um mesmo nó e suas partes.

Em relação aos ELU, além de se garantir a segurança adequada, isto é, uma probabilidade suficientemente pequena de ruína, é necessário garantir uma boa dutilidade, de forma que uma eventual ruína ocorra de forma suficientemente avisada, alertando os usuários.

\subsubsection{SEGURANÇA EM RELAÇÃO AOS ELS (DESEMPENHO EM SERVIÇO)}

$\mathrm{Na}$ verificação da segurança em relação aos ELS, também devem ser satisfeitas expressões analíticas de segurança e regras construtivas.

Para garantir o bom desempenho de uma estrutura em serviço, deve-se respeitar limitações de flechas, de abertura de fissuras, ou de vibrações, juntamente com aspectos relativos a estanqueidade, conforto térmico ou acústico, etc.

\subsubsection{TAXas da ARMADURA}

\subsubsection{PrincíPIOS BÁSICOS}

a) Armaduras Mínimas: par evitar a ruptura frágil das seções transversais, quando da formação da primeira fissura, considerando-se, para o cálculo das armaduras, um momento correspondente ao que levaria à ruptura da seção de concreto simples, supondo que a resistência a tração do concreto seja dada por $f_{c t, k s u p}$.

b) Armaduras Máximas: a especificação de valores máximos para as armaduras decorre da necessidade de se assegurar condições de dutilidade e de se respeitar o campo de validade dos ensaios que deram origem às prescrições de funcionamento do conjunto aço-concreto.

\subsubsection{TAXA DE ARMAdura PARA VigaS}

A armadura mínima de tração, em peças armadas, é aquela determinada pelo dimensionamento da seção a um momento fletor mínimo dado pela expressão abaixo

$$
M_{d, \min }=0.80 \cdot W_{0} \cdot f_{c t k, \text { sup }},
$$


onde $W_{0}$ é o módulo de resistência da seção transversal bruta de concreto, relativo à fibra mais tracionada e $f_{c t, k s u p}$ é a resistência característica superior do concreto à tração.

O dimensionamento para $M_{d \text {,min }}$ é considerado atendido se forem respeitadas as taxas mínimas de armadura da Tabela 5 - 1.

\begin{tabular}{|c|c|c|c|c|c|c|c|c|}
\hline \multirow{2}{*}{$\begin{array}{l}\text { Armadura mínima de } \\
\text { Flexão }\end{array}$} & \multicolumn{8}{|c|}{ Valores de $\rho_{\min }(\%)$ para CA50, $\gamma_{c}=1,4$ e $\gamma_{s}=1,15$} \\
\hline & $\mathbf{f}_{\mathrm{ck}}$ & 20 & 25 & 30 & 35 & 40 & 45 & 50 \\
\hline Forma da seção & \multicolumn{8}{|l|}{$\omega_{\min }$} \\
\hline Retangular & 0,035 & 0,115 & 0,144 & 0,173 & 0,201 & 0,230 & 0,259 & 0,288 \\
\hline T (mesa comprimida) & 0,024 & 0,100 & 0,100 & 0,118 & 0,138 & 0,158 & 0,177 & 0,197 \\
\hline $\mathrm{T}$ (mesa tracionada) & 0,031 & 0,102 & 0,127 & 0,153 & 0,178 & 0,204 & 0,229 & 0,255 \\
\hline Circular & 0,070 & 0,230 & 0,288 & 0345 & 0,403 & 0,460 & 0,518 & 0,575 \\
\hline
\end{tabular}

Tabela 5 - 1- Taxas Mínima de Armadura de Flexão para Vigas [NBR - 6118]

Os valores máximos para as armaduras de tração e de compressão podem ser dados da seguinte forma, a soma das armaduras de tração e de compressão $\left(A_{s}+A_{s}^{\prime}\right)$ não deve ter valor maior que $4.0 \% \cdot A_{c}$, contado fora da zona de emendas.

\subsubsection{TaXa de ARmadura Para Pilares}

A taxa de armadura é definida como $\rho=\frac{A_{s}}{A_{c}}$.

Para as armaduras longitudinais de pilares e tirantes, os valores mínimos devem ser:

$$
\rho_{\text {min }}=0.15 \cdot \frac{f_{c d}}{f_{y d}} \cdot v \geq 0.40 \%
$$

onde $v=\frac{N_{d}}{A_{c} \cdot f_{c d}}$ é o valor da força normal em termos adimensionais.

A maior taxa de armadura possível em pilares é de $8 \%$ da seção real, considerando-se a sobreposição de armadura existente em regiões de emenda, ou seja,

$$
\rho_{\max }=8.0 \%
$$




\subsubsection{DiSTRIBUIÇÃO DAS ARMADURAS}

\subsubsection{ESPAÇAMENTO ENTRE B ARRAS DA ARMADURA NAS VigaS}

$\mathrm{O}$ espaçamento mínimo livre entre as faces das barras longitudinais, medido no plano da seção transversal, deve ser igual ou superior ao maior dos seguintes valores:

a) no sentido horizontal:

$$
a_{h} \geq\left\{\begin{array}{l}
20 \mathrm{~mm} \\
\text { diâmetro da barra } \\
1.2 \text { vezes o diâmetro máximo do agregado }
\end{array}\right.
$$

b) no sentido vertical:

$$
a_{v} \geq\left\{\begin{array}{l}
20 \mathrm{~mm} \\
\text { diâmetro da barra } \\
0.5 \text { vezes o diâmetro máximo do agregado }
\end{array}\right.
$$

Esses valores se aplicam também às regiões de emendas por transpasse das barras.

\subsubsection{ESPaÇamentos ENTRE ARMaduras nos PilareS}

As armaduras longitudinais devem ser dispostas na seção transversal de forma a garantir a adequada resistência da peça. Em seções poligonais, deve existir pelo menos uma barra em cada vértice; em seções circulares, no mínimo seis barras distribuídas ao longo do perímetro.

O espaçamento livre entre as armaduras, medido no plano da seção transversal, fora da região de emendas, deve ser igual ou superior ao maior dos seguintes valores:

1. $40 \mathrm{~mm}$;

2. 4 vezes o diâmetro da barra;

3. O mínimo de 1.2 vezes o diâmetro máximo do agregado, inclusive nas emendas.

Quando estiver previsto no plano de concretagem o adensamento através de abertura lateral na face da forma, o espaçamento das armaduras deve ser suficiente para permitir a passagem do vibrador. 
O espaçamento máximo entre eixos das barras, ou de centros de feixes de barras, deve ser menor ou igual a 2 vezes a menor dimensão no trecho considerado, sem exceder $400 \mathrm{~mm}$.

\subsubsection{DESLOCAMENTOS LIMITES}

Deslocamentos limites são valores práticos utilizados para verificação do estado limite de deformações excessivas da estrutura.

Deslocamentos excessivos e tendência à vibração dos elementos estruturais podem ser indesejáveis por diversos motivos.

Esses motivos podem ser classificados em quatro grupos básicos, conforme detalhados a seguir e indicados na Tabela 5 - 2 .

- Aceitabilidade sensorial

- Estrutura em serviço

- Efeitos em elementos não estruturais

- Efeitos em elementos estruturais

Observações:

1) Todos os valores limites de deslocamentos supõem elementos de vão $L$, suportados em ambas as extremidades por apoios que não se movem. Quando se tratar de balanços, o vão equivalente a ser considerado deve ser o dobro do comprimento do balanço.

2) Para o caso de elementos de superfície, os limites consideram que o valor L é o menor vão, exceto em casos de verificação de paredes e divisórias, onde interessa a direção na qual a parede ou divisória se desenvolve, limitando-se este valor a duas vezes o vão menor.

3) O deslocamento total será obtido a partir da combinação das ações características ponderadas pelos coeficientes de acompanhamento definidos no capítulo 12.

4) Deslocamentos excessivos podem ser parcialmente compensados por contraflechas. 


\begin{tabular}{|c|c|c|c|c|}
\hline \multicolumn{5}{|c|}{ Aceitabilidade sensorial } \\
\hline $\begin{array}{c}\text { Razões } \\
\text { da } \\
\text { limitação }\end{array}$ & \multicolumn{2}{|c|}{ Exemplos } & $\begin{array}{l}\text { Deslocamento } \\
\text { limite }\end{array}$ & Deslocamento a considerar \\
\hline Visual & \multicolumn{2}{|c|}{$\begin{array}{l}\text { Deslocamentos em elementos } \\
\text { estruturais visíveis }\end{array}$} & \begin{tabular}{|l|l|} 
SS & L/250 \\
\end{tabular} & Deslocamento total \\
\hline Outros & \multicolumn{2}{|c|}{$\begin{array}{l}\text { Vibrações que podem ser } \\
\text { sentidas no piso }\end{array}$} & $L / 350$ & $\begin{array}{l}\text { Deslocamentos devidos a } \\
\text { carga acidental }\end{array}$ \\
\hline \multicolumn{5}{|c|}{ Estrutura em serviço } \\
\hline \multicolumn{2}{|c|}{ Razões da limitação } & Exemplos & $\begin{array}{c}\text { Deslocamento } \\
\text { Limite }\end{array}$ & $\begin{array}{c}\text { Deslocamento a } \\
\text { considerar }\end{array}$ \\
\hline \multicolumn{2}{|c|}{$\begin{array}{l}\text { Superfícies que devem } \\
\text { drenar água }\end{array}$} & $\begin{array}{l}\text { Coberturas e } \\
\text { varandas }\end{array}$ & $\mathrm{L} / 250^{1 /}$ & Deslocamento total \\
\hline \multirow{2}{*}{\multicolumn{2}{|c|}{$\begin{array}{l}\text { Pavimentos que } \\
\text { devem permanecer } \\
\text { Planos }\end{array}$}} & \multirow{2}{*}{$\begin{array}{l}\text { Ginásios e pistas } \\
\text { de boliche }\end{array}$} & $\begin{array}{l}\text { L/350 + contra- } \\
\text { flecha } 2 \text { ) } \\
\end{array}$ & Deslocamento total \\
\hline & & & $L / 600$ & $\begin{array}{l}\text { Deslocamento incremental } \\
\text { após a construção do piso }\end{array}$ \\
\hline \multicolumn{2}{|c|}{$\begin{array}{l}\text { Elementos que } \\
\text { suportam } \\
\text { equipamentos } \\
\text { sensíveis } \\
\end{array}$} & $\begin{array}{l}\text { Laboratórios de } \\
\text { medidas de } \\
\text { grande precisão }\end{array}$ & $\begin{array}{l}\text { De acordo com } \\
\text { recomendação do } \\
\text { fabricante }\end{array}$ & \begin{tabular}{l|l} 
Deslocamentos que \\
ocorram após nivelamento \\
do aparelho
\end{tabular} \\
\hline \multicolumn{5}{|c|}{ Efeitos em elementos não estruturais } \\
\hline $\begin{array}{l}\text { Razões da } \\
\text { limitação }\end{array}$ & \multicolumn{2}{|c|}{ Exemplos } & $\begin{array}{l}\text { Deslocamento } \\
\text { limite }\end{array}$ & Deslocamento a considerar \\
\hline \multirow[t]{5}{*}{ Paredes } & \multirow{3}{*}{\multicolumn{2}{|c|}{$\begin{array}{l}\text { Alvenaria, caixilhos e } \\
\text { revestimentos } \\
\text { Divisórias leves e } \\
\text { caixilhos telescópicos } \\
\text { Movimento lateral de } \\
\text { edifícios }\end{array}$}} & $\begin{array}{l}\mathrm{L} / 500^{3)} \text { ou } 10 \mathrm{~mm} \\
\text { ou } \theta=0,0017 \mathrm{rad}^{4)}\end{array}$ & \multirow{2}{*}{$\begin{array}{l}\text { Deslocamento ocorridos após } \\
\text { construção da parede } \\
\text { Deslocamento ocorridos após } \\
\text { instalação da divisória }\end{array}$} \\
\hline & & & $\mathrm{L} / 250^{3)}$ ou $25 \mathrm{~mm}$ & \\
\hline & & & $\begin{array}{l}\mathrm{H} / 2500 \text { ou } \\
\text { Hi/1250) entre } \\
\text { pavimentos }\end{array}$ & $\begin{array}{l}\text { Deslocamento provocado pela } \\
\text { ação do vento para } \\
\text { combinação freqüente } \\
\left(\psi_{1}=0,20\right)\end{array}$ \\
\hline & \multicolumn{2}{|c|}{$\begin{array}{l}\text { Movimentos térmicos } \\
\text { verticais }\end{array}$} & $\mathrm{L} / 400^{7)}$ ou $15 \mathrm{~mm}$ & $\begin{array}{l}\text { Deslocamento provocado por } \\
\text { diferença de temperatura }\end{array}$ \\
\hline & \multicolumn{2}{|c|}{$\begin{array}{l}\text { Movimentos térmicos } \\
\text { horizontais }\end{array}$} & $\mathrm{Hi} / 500$ & $\begin{array}{l}\text { Deslocamento relativo } \\
\text { provocado por diferença de } \\
\text { temperatura }\end{array}$ \\
\hline \multirow[t]{2}{*}{ Forros } & \multirow{2}{*}{\multicolumn{2}{|c|}{$\begin{array}{l}\text { Revestimentos } \\
\text { colados } \\
\text { Revestimentos } \\
\text { pendurados ou com } \\
\text { juntas }\end{array}$}} & $\mathrm{L} / 350$ & $\begin{array}{l}\text { Deslocamento ocorrido após } \\
\text { construção do forro }\end{array}$ \\
\hline & & & L/175 & $\begin{array}{l}\text { Deslocamento ocorrido após } \\
\text { construção do forro }\end{array}$ \\
\hline $\begin{array}{l}\text { Ponte } \\
\text { Rolante } \\
\end{array}$ & $\begin{array}{l}\text { Desalinh } \\
\text { trilhos }\end{array}$ & amento dos & $\mathrm{H} / 400$ & $\begin{array}{l}\text { Deslocamento provocado pelas } \\
\text { ações decorrentes da frenação }\end{array}$ \\
\hline
\end{tabular}

Tabela 5 - 2- Limites para Deslocamentos [NBR - 6118] 


\section{Capítulo 6}

\section{APLICAÇõeS AO CONCRETO ARMADO}

este capítulo serão apresentadas três aplicações para os métodos de
otimização via Algoritmos Genéticos. Os exemplos propostos neste capitulo serviram como validação dos programas implementados. Cada um dos módulos foram testados com diversos outros exemplos, de forma a garantir o funcionamento do programa para todos os casos práticos possíveis.

"Se teus esforços forem vistos com indiferença, não desanimes, pois o sol ao nascer dá um espetáculo todo especial, e no entanto a platéia continua dormindo". 
Os exemplos que aqui serão apresentados foram elaborados de forma a explorar os diversos conceitos que envolvem tanto os aspectos referentes ao cálculo de estruturas de concreto armado como os referentes ao uso dos algoritmos genéticos como ferramenta na otimização estrutural. Os exemplos pretendem mostrar o quanto é robusto este método de otimização e como pode ser aplicado a grandes sistemas estruturais. Alguns dos exemplos não obtiveram bons resultados em função da forma como foram elaborados, mesmo assim são apresentados para mostrar que a eficiência deste método está intimamente ligada à forma como são escolhidas as variáveis, à maneira como são codificadas e como são dispostas nos cromossomos.

\subsection{Otimização de UM Trecho de Pilar a FleXão COMPOSTA OBLÍQUa}

O exemplo a seguir apresenta a metodologia utilizada na aplicação de AGs na otimização de um trecho de pilar sujeito à Flexão Composta Oblíqua, com armadura qualquer e com diversas combinações de carregamento. Para isso, desenvolveu-se um programa utilizando o MathCad, o que se mostrou bastante útil pois possibilitou entender os diversos passos do algoritmo e foi o início de todo este trabalho.

Serão apresentados 3 exemplos de aplicação deste programa, que possibilitaram diversas conclusões extremamente úteis para a implementação do programa de otimização do pórtico plano, tema principal desta dissertação. É importante salientar que a forma como o primeiro exemplo foi implementado não é a mais adequada.

No Anexo $C$ encontra-se um fluxograma desse programa onde estão apresentados os passos do processo de otimização.

\subsubsection{DesCrição do Problema de O TIMIZaÇão}

O problema que se deseja resolver nestes exemplos consiste em se obter a seção retangular e o respectivo arranjo de armadura que resistam a um determinado conjunto de esforços e que possua o menor custo. Neste processo de otimização diversas restrições quanto à distribuição das armaduras devem ser verificadas. 


\subsubsection{DESCRIÇão DAS VARIÁVEIS}

As variáveis escolhidas para o problema são $h, \phi$ e Nbar que representam respectivamente a altura da seção do pilar, a bitola das barras de aço e o número de barras utilizado. A largura da seção é considerada constante para cada um dos exemplos.

O número mínimo e máximo de barras obedece aos critérios estabelecidos pela NBR 6118. A altura da seção é igual a $h_{\min }+\alpha \cdot$ Passo $_{h}$, isto é, uma altura mínima, adotada $20 \mathrm{~cm}$, mais um múltiplo do passo estabelecido, e inferior a $5 \cdot b$. As bitolas $\phi$ que podem ser escolhidas são : $10.0 \mathrm{~mm}, 12.5 \mathrm{~mm}, 16.0 \mathrm{~mm}, 20.0 \mathrm{~mm}$ e $25.0 \mathrm{~mm}$, que são as bitolas comerciais comumente usadas em projeto.

\subsubsection{A F UNÇão OBJETIVO}

A função objetivo para este problema corresponde ao custo por metro da seção de concreto que se deseja dimensionar e é definida da seguinte forma

$$
\operatorname{Custo}(h, \phi, N b a r)=C C \cdot b \cdot h+C A \cdot N b a r \cdot A r e a(\phi)+C F \cdot(2 \cdot b+2 \cdot h),
$$

e as variáveis $C C, C A$ e $C F$ são respectivamente o custo do concreto em $\mathrm{R} \$ / \mathrm{m}^{3}$, o custo do aço em $\mathrm{R} \$ / \mathrm{Kg}$ e o custo da forma em $\mathrm{R} \$ \mathrm{~m}^{2}$.

\subsubsection{As Restrições do Problema}

As restrições impostas para problema são:

1. Verificação a Flexão Composta Oblíqua (FCO)

\subsection{Equilíbrio}

1.2. Deformações Admissíveis (Domínios de Deformação)

2. Taxa de Armadura Mínima $\geq 0.40 \%$ b.h (NBR 6118)

3. Taxa de Armadura Máxima $\leq 4 \%$ b.h (NBR 6118)

Por ser o primeiro exemplo apresentado, procurou-se reduzir o número de restrições aplicadas durante o processo de otimização. Desta forma, as recomendações de norma quanto ao espaçamento entre barras, bitolas utilizadas ou número de camadas de armadura foram impostas diretamente sobre os indivíduos durante sua geração. 
Todos os indivíduos da população inicial são gerados atendendo a essas recomendações.

Foram criadas funções que enumeram todas as possíveis soluções para o problema, a partir dos dados inicias.

- Primeira Função: existe uma relação entre as variáveis $h, \phi$ e $N b a r$ pois $\phi$ depende de $h$ e Nbar é uma função de $\phi, b$ e $h$, desta forma a melhor forma de criar esta função é através de uma matriz onde cada um de seus elementos também são matrizes. Para cada $h$ calcula-se os valores de Nbar máximo e mínimo para cada valor de $\phi$ e desta forma são enumerados todos os pontos do espaço de busca de forma seqüenciada.

- Segunda Função: optou-se por enumerar para todos os valores de $h$ o Nbar máximo e mínimo para cada valor de $\phi$, desta forma, todas as seções que possuem a mesma bitola estão reunidas em um mesmo bloco do espaço de busca. Na função anterior Primeira Função todas as seções com a mesma altura da seção $h$ é que estavam reunidas de forma seqüencial.

Nas Figuras 6-2 e 6-3 estão representados os pontos do espaço de busca em função do custo. Pode-se observar que a distribuição dos pontos é bastante irregular. Outros comentários sobre esta forma de codificação serão feitos juntamente com os exemplos elaborados.

\subsubsection{EXEMPLOS}

Os dados gerais para os três exemplos que serão apresentados a seguir estão descritos logo abaixo:

1) PARÂMETROS DO ALGORITMO GENÉTICO:

Tamanho da População = 20 indivíduos

Número Máximo de Gerações = 10 Gerações

Probabilidade de Cruzamentos $=0,80$ [80\%]

Probabilidade de Mutação = 0,05 [5\%] 
2) DADOS DOS MATERIAIS :

Resistência Característica do Concreto $\left[f_{c k}\right]=20 \mathrm{MPa}$

Resistência Característica do Aço $\left[f_{y k}\right]=500 \mathrm{MPa}$

Módulo de Elasticidade do Aço $\left[E_{s}\right]=210 \mathrm{GPa}$

3) COEFICIENTES DE MINORAÇÃO E MAJORAÇÃO:

Coeficiente de Majoração dos Esforços $\left[\gamma_{f}\right]=1,40$

Coeficiente de Minoração da Resistência do Concreto $\left[\gamma_{c}\right]=1,40$

Coeficiente de Minoração da Resistência do Aço $\left[\gamma_{s}\right]=1,15$

4) DADOS GEOMÉTRICOS DA SEÇÃO:

Espaçamento mínimo entre barras $=5 \mathrm{~cm}$

Espaçamento máximo entre barras $=40 \mathrm{~cm}$

Passo de $h=5 \mathrm{~cm}$

Altura Mínima $=20 \mathrm{~cm}$

Cobrimento $=3 \mathrm{~cm}$

5) ESFORÇOS SOLICITANTES:

\begin{tabular}{|c|c|}
\hline Esforços na Base do Pilar & Esforços na Base do Pilar \\
\hline $\mathrm{N}_{\mathrm{bk}}=2000 \mathrm{KN}$ & $\mathrm{N}_{\mathrm{tk}}=2000 \mathrm{KN}$ \\
\hline $\mathrm{M}_{\mathrm{x} \mathrm{bk}}=50 \mathrm{KN} . \mathrm{m}$ & $\mathrm{M}_{\mathrm{x}_{\mathrm{tk}}}=70 \mathrm{KN} . \mathrm{m}$ \\
\hline $\mathrm{M}_{\mathrm{ybk}}=100 \mathrm{KN} . \mathrm{m}$ & $\mathrm{M}_{\mathrm{y}_{\mathrm{tk}}}=150 \mathrm{KN} . \mathrm{m}$ \\
\hline
\end{tabular}

6) PREÇO DOS MATERIAIS :

Custo do Concreto $=120 \mathrm{R} \$ / \mathrm{m}^{3}$

Custo do Aço $=3 \mathrm{R} \$ / \mathrm{Kg}$

Custo da Forma $=10 \mathrm{R} \$ / \mathrm{m}^{2}$ 
Esses dados se mantêm constantes para todos os exemplos, variando-se apenas o valor da base da seção do pilar $b$. Nota-se, ao final, que a eficiência dos AGs varia em função da forma da função objetivo que se pretende otimizar.

\subsubsection{EXEMPLO 1-A}

Para este primeiro exemplo optou-se por utilizar $b=20 \mathrm{~cm}$, desta forma o número total de indivíduos com "Geometria Viável" obtidos pela enumeração de todos os pontos discretos do espaço de busca perfazem um total de 627. Para comparar o ponto de mínimo obtido pelo programa de otimização com o ponto de mínimo exato foi implementado um outro programa que percorre todos os indivíduos do espaço de busca, verifica o equilíbrio e calculo o custo de cada indivíduo obtendo assim o custo mínimo.

São 11 os indivíduos que atendem à condição de equilíbrio da FCO e, dentre estes o custo mínimo obtido (mínimo global) foi de $\mathrm{R} \$ 180.80$ por metro, correspondente à seguinte configuração de seção,

$$
\begin{array}{ll}
h=95 \mathrm{~cm} & \phi=20.0 \mathrm{~mm} \quad \text { Nbar }=18 \\
\text { Nbar }_{x}=2 & \text { Nbar }_{y}=9
\end{array}
$$

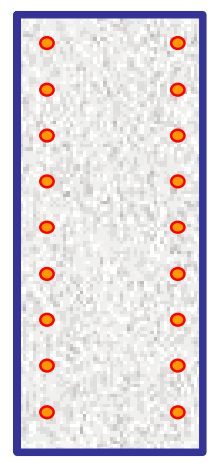

No primeiro exemplo pode-se observar que o número de indivíduos viáveis era muito pequeno em relação ao número total de indivíduos da população e como o número de indivíduos de cada geração era de 20 indivíduos o programa demorava muito tempo tentando montar uma primeira população de indivíduos viáveis sem obter sucesso. Mesmo quando se reduziu o número de indivíduos para 10 o processo tornouse extremamente demorado. $\mathrm{O}$ que se pode notar é que, neste caso, o algoritmo genético foi menos eficiente que o processo de verificação de todos os indivíduos da população. Isso ocorre porque cada indivíduo é gerado de forma aleatória e, como o número total de indivíduos viáveis é muito pequeno, o algoritmo gera diversas vezes o mesmo indivíduo não viável e o verifica para poder completar a população e, então, iniciar o processo. 


\subsubsection{EXEMPLO 1-B}

Para este exemplo se optou por utilizar $b=30 \mathrm{~cm}$, desta forma o número total de indivíduos com "Geometria Viável" obtidos pela enumeração de todos os pontos discretos do espaço de busca perfazem um total de 3117 elementos.

Verificando-se todos os indivíduos da população, observou-se que 2470 indivíduos atendem à condição de equilíbrio da FCO e, dentre estes o custo mínimo obtido (mínimo global) foi de $\mathrm{R} \$ 82.40$ por metro, correspondente à seguinte configuração de seção,

$$
\begin{array}{ll}
h=85 \mathrm{~cm} & \phi=16.0 \mathrm{~mm} \quad \text { Nbar }=6 \\
\text { Nbar }_{x}=2 & \text { Nbar }_{y}=3
\end{array}
$$

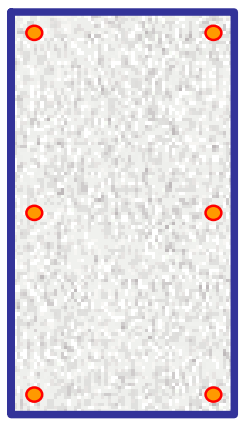

Através do programa de AGs implementado, obteve-se como solução, após 10 gerações, o custo mínimo de $\mathrm{R} \$ 82.86$ por metro, correspondente à seguinte configuração da seção transversal,

$$
\begin{array}{ll}
h=90 \mathrm{~cm} & \phi=10.0 \mathrm{~mm} \quad \text { Nbar }=14 \\
\text { Nbar }_{x}=3 & \text { Nbar }_{y}=6
\end{array}
$$

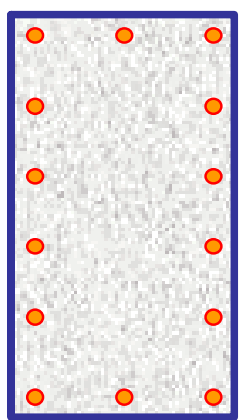

Neste caso pode-se observar que o programa efetuou, nas 10 gerações, 210 verificações da seção e obteve um valor muito próximo do mínimo global exato. Comparando com o número total de indivíduos da população que é de 3117 indivíduos que foram verificados anteriormente para obtenção do ponto de mínimo global, pode-se observar que o algoritmo genético verificou aproximadamente apenas $6.7 \%$ da população obtendo um resultado muito próximo em custo em relação ao mínimo exato. Este exemplo mostra claramente que pontos com características completamente 
diferentes podem ter valores de custo muito próximos, dificultando a obtenção do ótimo global. A forma como os indivíduos estão distribuídos é mostrado nos gráficos abaixo.

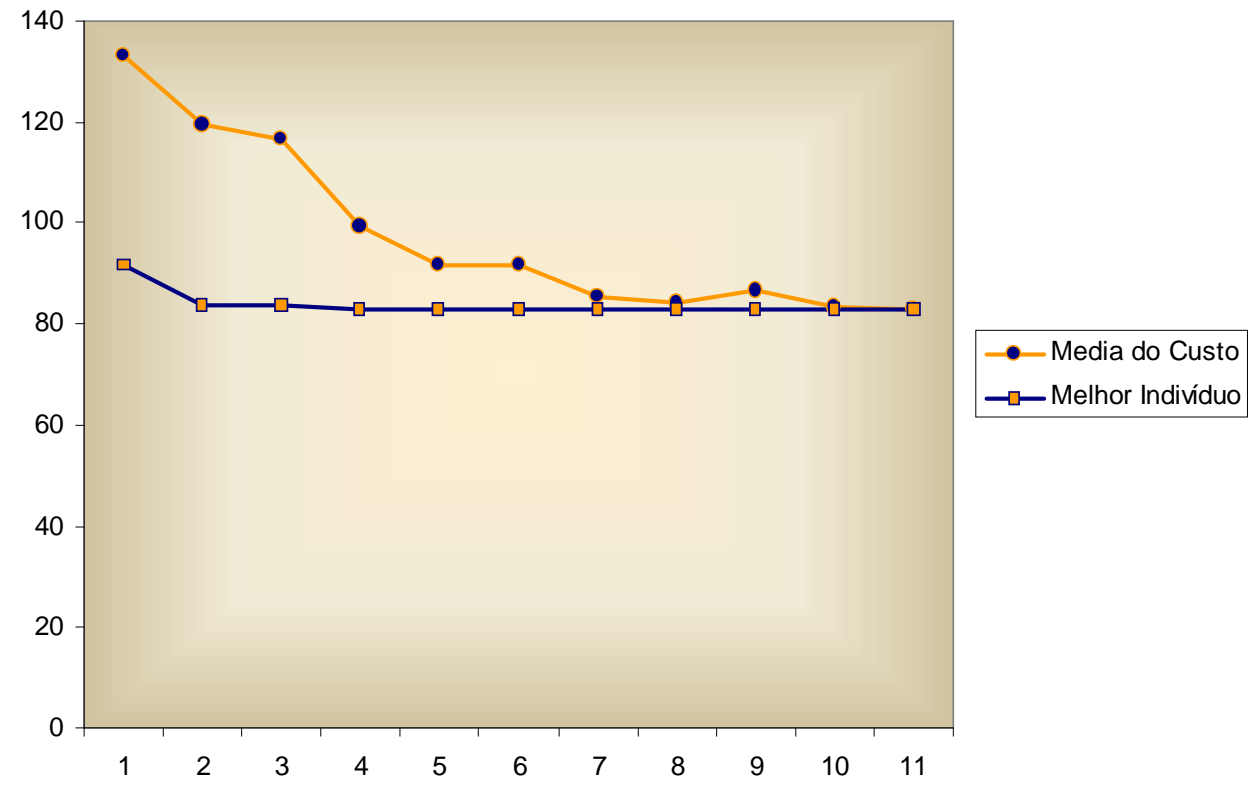

Figura 6 - 1 Convergência ao longo das 10 Gerações

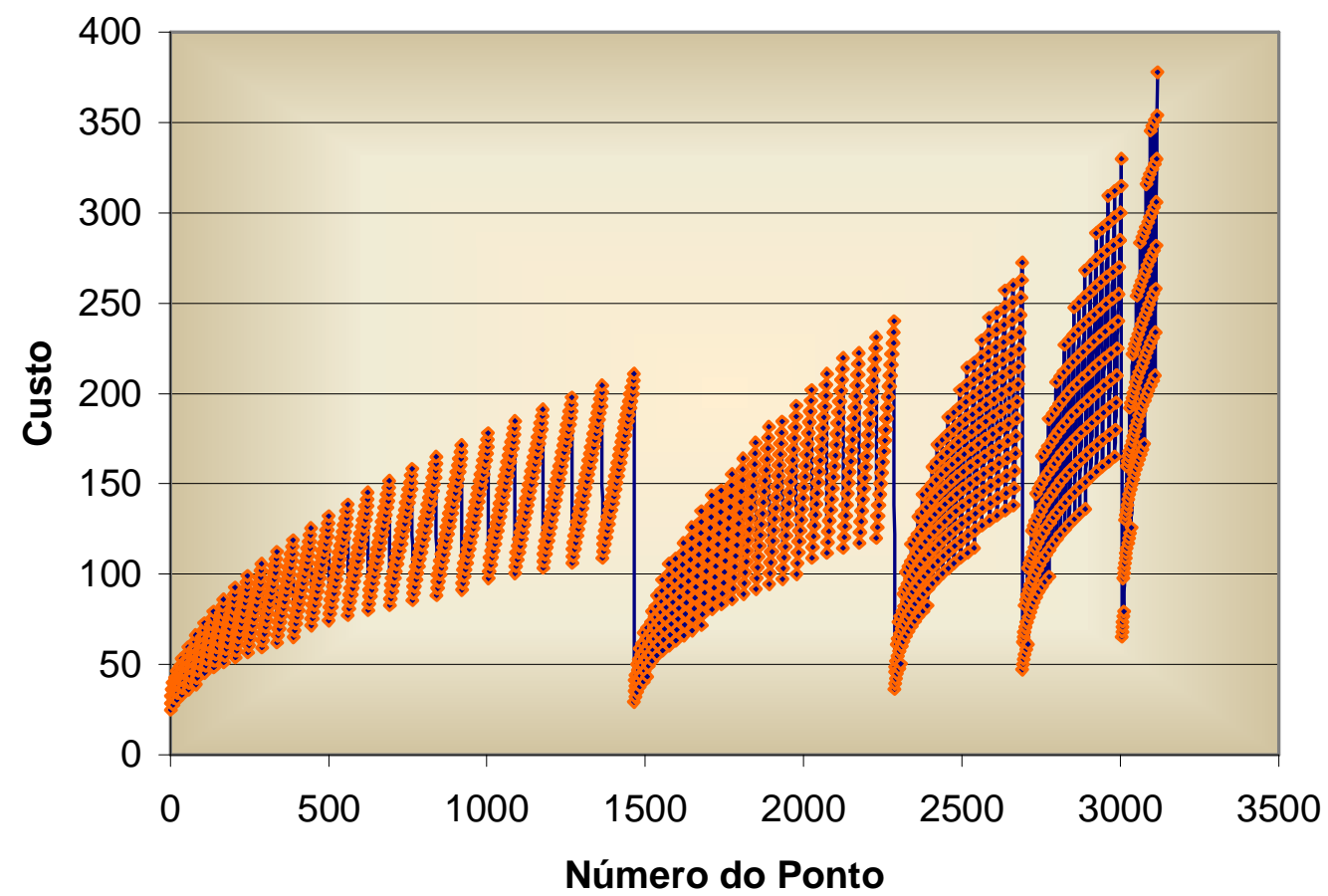

Figura 6 - 2 Distribuição dos indivíduos pela função de enumeração 1 


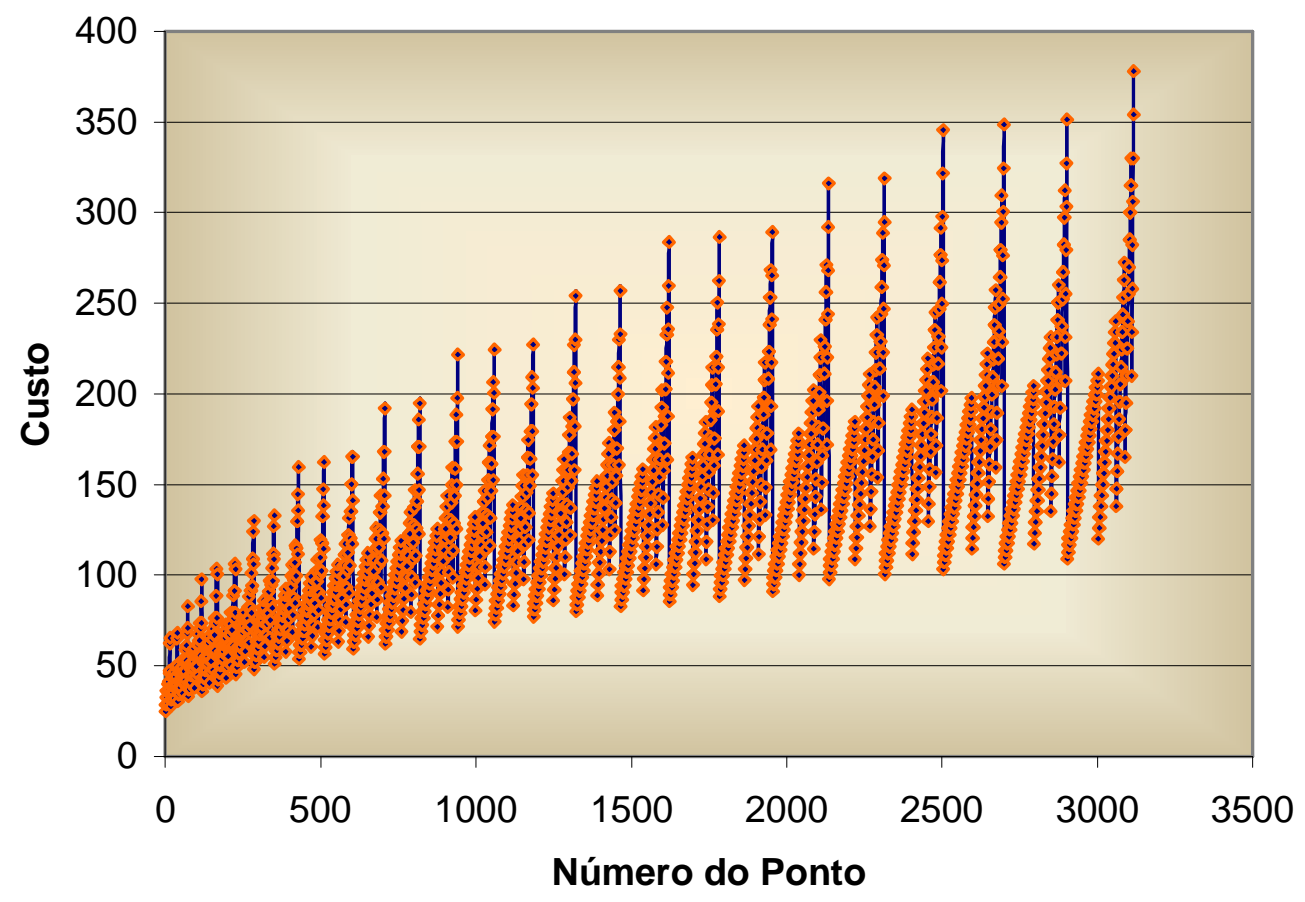

Figura 6 - 3 Distribuição dos indivíduos pela função de enumeração 2

\subsubsection{EXEMPLO 1-C}

Para este exemplo se optou por utilizar $b=40 \mathrm{~cm}$, desta forma o número total de indivíduos com "Geometria Viável" obtidos pela enumeração de todos os pontos discretos do espaço de busca perfazem um total de 8364 .

O número de indivíduos da população que verificam a FCO é de 8001 e dentre estes o valor do custo mínimo foi de $69.40 \mathrm{R} \$ / \mathrm{m}$.

Características do Indivíduo:

$$
\begin{array}{ll}
h=55 \mathrm{~cm} & \phi=12.5 \mathrm{~mm} \quad \text { Nbar }=8 \\
\text { Nbar }_{x}=2 & \text { Nbar }_{y}=4
\end{array}
$$

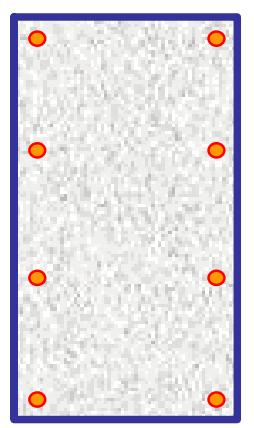

Utilizando o programa de AGs, obteve-se, após 10 gerações, o indivíduo ótimo correspondente ao custo mínimo de $\mathrm{R} \$ 70.72$ / m. 
Características do Indivíduo:

$$
h=70 \mathrm{~cm} \quad \phi=10.0 \mathrm{~mm} \quad \text { Nbar }=8
$$

$$
\operatorname{Nbar}_{x}=2 \quad \operatorname{Nbar}_{y}=4
$$

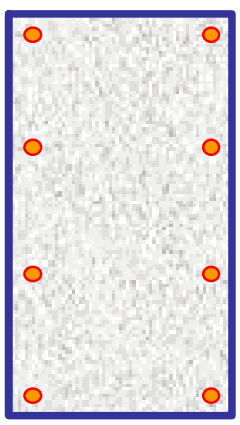

Neste caso, o programa efetuou, nas 10 gerações, 210 verificações de seção e obteve um valor muito próximo do mínimo global exato. Comparando com o número total de indivíduos da região viável que é de 8364 indivíduos que foram verificados anteriormente para obtenção do ponto de mínimo global, pode-se observar que o algoritmo genético verificou apenas $2.5 \%$ da população obtendo um resultado muito próximo, em custo, em relação ao anterior.

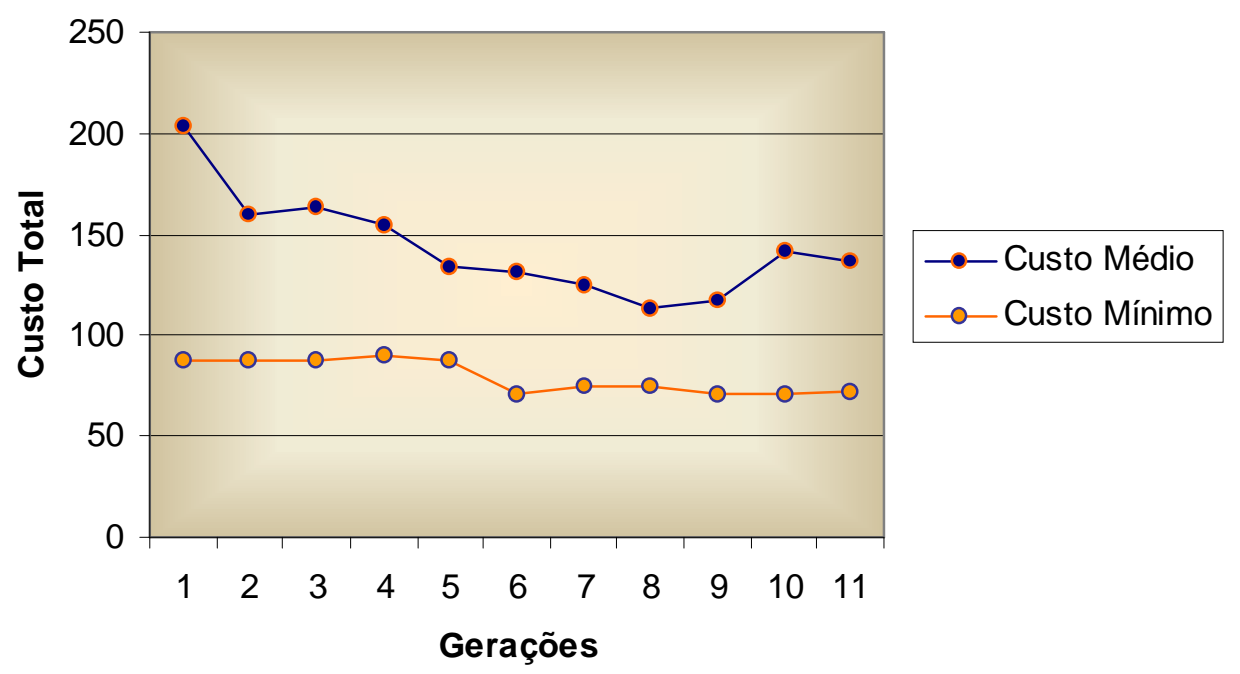

Figura 6 - 4 Convergência ao longo das 10 Gerações

Como está mostrado na Figura 6 - 4 esta forma de enumeração dos parâmetros faz com que o processo, mesmo obtendo pontos próximos do mínimo global, não tenha a convergência esperada, pois o custo médio após 10 gerações ainda continua bastante diferente do custo mínimo. Na Figura 6 - 2 Pode-se notar que temos pontos de mínimo local bastante próximos em praticamente todas as bitolas, porém, quando fazemos o cruzamento entre eles podemos obter facilmente indivíduos com custo superior aos de seus progenitores. 


\subsubsection{Conclusões Preliminares}

$\mathrm{Na}$ versão inicialmente implementada para estes exemplos, as recomendações de norma como espaçamentos máximos e mínimos entre barras, relação entre $b$ e $h$ e outras, foram introduzidas como restrições a serem atendidas durante o processo de otimização. Observou-se, porém, que a maioria dos indivíduos gerados não atendiam a essas restrições e eram, portanto, descartados da população. Optou-se, então, pelos processos de enumeração já descritos, onde todos os indivíduos eram gerados dentro das recomendações de norma, obtendo, assim, um processo mais eficaz que o anterior. Esse procedimento, embora eficiente para o caso estudado, não é viável para os problemas de otimização em geral pois :

1. A forma da função objetivo pode tornar-se bastante irregular cheia de máximos e mínimos locais;

2. Nem sempre é possível enumerar todas as possíveis soluções de um problema, principalmente quando o número de variáveis for muito grande;

3. Neste exemplo foi possível criar uma função que, para cada indivíduo, associa um único ponto do espaço de busca, mas, para problemas complicados, mesmo que se consiga enumerar todos os possíveis indivíduos, a obtenção destas funções pode não ser fácil. Desta forma pode ser necessário armazenar todos os indivíduos criados em algum arquivo que será lido ao longo do processo, tornando o processo mais lento.

Com isso é possível concluir que, ao tratar de problemas mais complexos, como serão os próximos abordados, é mais eficiente utilizar funções de penalização para as diversas restrições do problema, nunca descartando indivíduos da população. Aos que não atendem uma ou mais restrições, terão acrescentado em seu custo (função objetivo) um custo "fictício" que representa o quanto este indivíduo está infringindo a esta(s) restrição(ões). No próximo exemplo serão detalhadas de forma mais clara as funções de penalização.

Pode-se observar também que a utilização do Mathcad para problemas grandes de otimização tornaria o processo muito lento, desta forma optou-se por elaborar, em FORTRAN 90, o programa OTIMPORCA para otimização de pórticos de concreto armado. 


\subsection{Otimização De UM Pórtico Plano de Concreto A RMAD 0}

Os exemplos que serão apresentados a seguir pretendem mostrar a eficiência da utilização dos AGs na otimização de estruturas complexas como é o caso dos Pórticos de Concreto Armado. Ao longo da descrição do problema serão comentados os diversos módulos do programa e suas respectivas funções. O Exemplo apresentado nesta seção pode ser encontrado de forma mais detalhada nos Anexos $B$ e $C$.

O problema que se deseja resolver consiste em obter o pórtico de concreto armado de menor custo e que resista a um determinado carregamento. Como se verá na sequiência, o carregamento devido o peso próprio da estrutura será recalculado para cada indivíduo (pórtico) em função das suas dimensões.

A estrutura considerada ótima será a que atender às seguintes condições:

1. O menor custo total

2. Verificar as restrições quanto às flechas horizontais e verticais máximas prescritas pela Norma Brasileira (NBR6118)

3. Verificar as restrições quanto às dimensões máximas e mínimas das seções dos pilares a das vigas.

4. Verificar as restrições quanto aos espaçamentos da armadura máximos e mínimos tanto para as vigas como para os pilares.

5. Verificar as restrições quanto às taxas de armadura máxima e mínima prescrita na Norma.

6. Verificar o equilíbrio das seções transversais das vigas e dos pilares. (Equilíbrio - Deformações Admissíveis) - ELU

Além destas, pode-se citar outras duas verificações que deveriam ser feitas, porém neste trabalho foram desconsiderados devido a sua dificuldade de cálculo, que são:

1. Verificação da fissuração das peças de concreto em relação a abertura máxima de fissuras prescrita na Norma Brasileira.

2. Verificação da estabilidade da estrutura. 
No Anexo $C$ podemos encontrar um fluxograma do programa implementado para este exemplo, nele estão detalhados cada um dos passos do processo de otimização utilizado.

Para facilitar a compreensão do processo de otimização de pórticos de concreto armado, optou-se por subdividir sua análise em duas etapas:

1. Otimizar as dimensões (alturas das seções de vigas e pilares) como variáveis discretas e as áreas de aço $\left(A_{s}\right.$ e $\left.A_{s}^{\prime \prime}\right)$ como variáveis reais[OTIMPORCA 1]

2. Otimizar as áreas de aço de forma exata, considerando sua distribuição segundo os critérios da norma e as bitolas comerciais [OTIMPORCA 2]

\subsubsection{DesCrição do Problema de O TIMIZAÇão}

O problema de otimização consiste em determinar o pórtico de concreto armado de menor custo que satisfaça as condições de contorno.

Primeiramente faremos a otimização das dimensões como variáveis discretas e das áreas de aço como variáveis reais [OTIMPORCA 1] para em seguida adaptar as áreas de aço obtidas para as bitolas comerciais [OTIMPORCA 2]. Isso foi feito porque, no primeiro caso, o pórtico precisa ser recalculado a cada iteração, pois a altura das peças se alteram, enquanto no segundo o pórtico é calculado apenas $1 \mathrm{vez}$, passando para a otimização do arranjo da armadura.

\subsubsection{DESCRIÇÃO DAS VARIÁVEIS}

As variáveis escolhidas para o problema são $\left(h_{\text {vigas }}, h_{\text {pilares }}, A_{s}, A_{s}^{\prime}\right)$, que representarão respectivamente a altura da seção da viga, do pilar e respectivas áreas de aço. São criados 4 cromossomos para representar cada indivíduo da população, um para cada variável do problema.

No OTIMPORCA 1, o primeiro cromossomo possui informações sobre as alturas das vigas, o segundo sobre a altura dos pilares, o terceiro sobre as áreas de aço $A_{s}$ usadas nas vigas e pilares e o último sobre a área de aço $A_{s}^{\prime}$ usadas nas vigas.

No OTIMPORCA 2, o primeiro cromossomo carrega informações sobre a bitola das armaduras $A_{s}$ das vigas e pilares, o segundo sobre a bitola da armadura $A_{s}^{\prime}$ das 
vigas, o terceiro sobre o número de barras relativas a $A_{s}$ e o último sobre o número de barras referentes a $A_{s}^{\prime}$. No segundo processamento, as áreas de aço obtidas são ajustadas para as bitolas comerciais existentes.

As bitolas que podem ser escolhidas são: $8.0 \mathrm{~mm}, 10.0 \mathrm{~mm}, 12.5 \mathrm{~mm}, 16.0 \mathrm{~mm}$ e $20.0 \mathrm{~mm}$ para as vigas, e $10.0 \mathrm{~mm}, 12.5 \mathrm{~mm}, 16.0 \mathrm{~mm}, 20.0 \mathrm{~mm}$ e $25.0 \mathrm{~mm}$ para os pilares.

\subsubsection{A F UNÇÃO OBJETIVO}

A função objetivo foi escolhida como sendo a somatória dos custos de cada um dos elementos do pórtico e é definida da seguinte forma,

$$
\operatorname{Custo}\left(h_{\text {vigas }}, h_{\text {pilaes }}, A_{s}, A_{s}^{\prime}\right)=\sum_{i=1}^{\text {nvigas }} \operatorname{Custo}_{\text {viga }}+\sum_{i=1}^{\text {npilares }} \text { Custo }_{\text {pilar }}
$$

Custo $_{\text {viga }}\left(h_{\text {viga }}, A_{s}, A_{s}^{\prime}\right)=\left[C C_{\text {viga }} \cdot b \cdot h_{\text {viga }}+C A \cdot N b a r \cdot \operatorname{Area}(\phi)+C F_{\text {viga }} \cdot\left(b+2 \cdot h_{\text {viga }}\right)\right] \cdot L_{\text {viga }}$ Custo $_{\text {pilar }}\left(h_{\text {pilar }}, A_{s}\right)=\left[C C_{\text {pilar }} \cdot b \cdot h_{\text {pilar }}+C A \cdot \operatorname{Nbar} \cdot \operatorname{Area}(\phi)+C F_{\text {pilar }} \cdot\left(2 \cdot b+2 \cdot h_{\text {pilar }}\right)\right] \cdot L_{P i l a r}$

onde temos

$$
\begin{aligned}
& C C_{\text {viga }}=\text { Custo do Concreto das Vigas em } \mathrm{R} \$ / \mathrm{m}^{3} \text { (lançado e vibrado) } \\
& C C_{\text {pilar }}=\text { Custo do Concreto dos Pilares em } \mathrm{R} \$ / \mathrm{m}^{3} \text { (lançado e vibrado) } \\
& C A=\text { Custo do Aço em } \mathrm{R} \$ / \mathrm{Kg} \\
& C F_{\text {viga }}=\text { Custo da Forma das Vigas em } \mathrm{R} \$ / \mathrm{m}^{2} \\
& C F_{\text {pilar }}=\text { Custo da Forma dos Pilares em } \mathrm{R} \$ / \mathrm{m}^{2} \\
& L_{\text {viga }}=\text { Comprimento do Trecho de Viga em metros } \\
& L_{\text {pilar }}=\text { Comprimento do Trecho de Pilar em metros }
\end{aligned}
$$

Para os pilares adota-se sempre armadura simétrica, desta forma as informações sobre a armadura dos pilares estarão contidas no cromossomo $A_{s}$.

\subsubsection{As Restrições do Problema}

As restrições impostas a este problema foram :

1. Flechas horizontais e verticais máximas prescritas pela Norma Brasileira [NBR-6118].

2. Dimensões máximas e mínimas das seções dos pilares e vigas. 
3. Espaçamentos máximos e mínimos da armadura, tanto para as vigas como para os pilares.

4. Taxas de armadura máxima e mínima prescrita pela Norma.

5. Equilíbrio das seções transversais das vigas e dos pilares.

6. Domínios de Deformação.

Não foi imposta a restrição $\frac{h}{b} \leq 5$ (hipótese das seções planas permanecerem planas), com o intuito de se reduzir o número de restrições do problema. Desta forma cada vez que um indivíduo gerado possuir $h>5 \cdot b$, será adotada a altura máxima $5 \cdot b$.

As restrições do problema foram impostas através de funções de penalização que oneram o custo do indivíduo. Para cada uma das 5 restrições acima admitiu-se um parâmetro de penalidade, desta forma nenhum dos indivíduos da população é descartado durante o processo de otimização.

\subsubsection{F unÇões de PENALIZAÇÃo}

São as seguintes as funções de penalização, caracterizadas por diferentes parâmetros $\alpha$ :

A função de penalização para a taxa de armadura máxima é expressa por

$$
P_{\rho, \max }=\left(\text { Custo }_{\text {viga }} \text { ou } \text { Custo }_{\text {pilar }}\right) \cdot 10 \cdot\left\langle\alpha_{\rho, \max }\right\rangle^{2}
$$

onde, $\alpha_{\rho, \max }$ é expresso pela seguinte equação

$$
\alpha_{\rho, \max }=\frac{\rho-\rho_{\max }}{\rho_{\max }}
$$

A função de penalização para a taxa de armadura máxima é expressa por

$$
P_{\rho, \min }=\left(\text { Custo }_{\text {viga }} \text { ou } \text { Custo }_{\text {pilar }}\right) \cdot 10 \cdot\left\langle\alpha_{\rho, \min }\right\rangle^{2}
$$

onde, $\alpha_{\rho, \min }$ é expresso pela seguinte equação

$$
\alpha_{\rho, \min }=\frac{\rho_{\min }-\rho}{\rho_{\min }} .
$$


Para flexão composta normal (equilíbrio da seção): $\alpha_{F C N}$ é obtido diretamente na rotina de verificação de FCN

$$
P_{F C N}=\left(\text { Custo }_{\text {viga }} \text { ou } \text { Custo }_{\text {pilar }}\right) \cdot 10 \cdot\left\langle\alpha_{F C N}-1\right\rangle^{2}
$$

A função de penalização para flecha máxima horizontal é expressa por

$$
P_{\text {horizontal }}=\left(\frac{\text { Custo }_{\text {refer. }}}{2}\right) \cdot\left\langle\frac{350 \cdot f_{H}}{H_{\text {portico }}}-1\right\rangle^{2} .
$$

A função de penalização para flecha máxima horizontal é expressa por

$$
P_{\text {vertical }}=\left(\frac{\text { Custo }_{\text {refer. }}}{2}\right) \cdot\left\langle\frac{500 \cdot f_{V}}{L_{\text {viga }}}-1\right\rangle^{2} \text {. }
$$

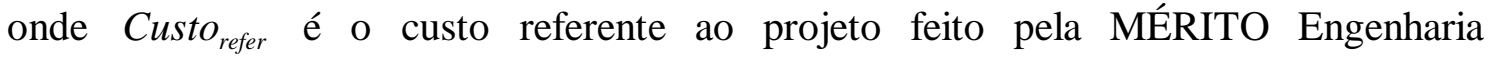
$(\mathrm{R} \$ 1.600,00), f_{H}$ e $f_{V}$ são, respectivamente, a maior flecha horizontal e vertical obtidas no processamento, $H_{\text {portico }}$ é a altura total do pórtico e $L_{\text {viga }}$ é o comprimento da viga correspondente a maior flecha vertical.

\subsubsection{Critérios de Parada (Convergência)}

Utilizou-se dois parâmetros de controle para serem utilizados como critério de parada do processamento:

1. Número de gerações $\leq$ Valor máximo : o processamento é interrompido sem que o indivíduo de custo mínimo seja obtido;

2. $\frac{\text { Custo }_{\text {min }}}{\text { Custo }_{\text {medio }}} \leq T O L:$ o processamento é interrompido com a obtenção do indivíduo ótimo; 


\subsubsection{ESQUEMa ESTRUTURAL Do Pórtico}

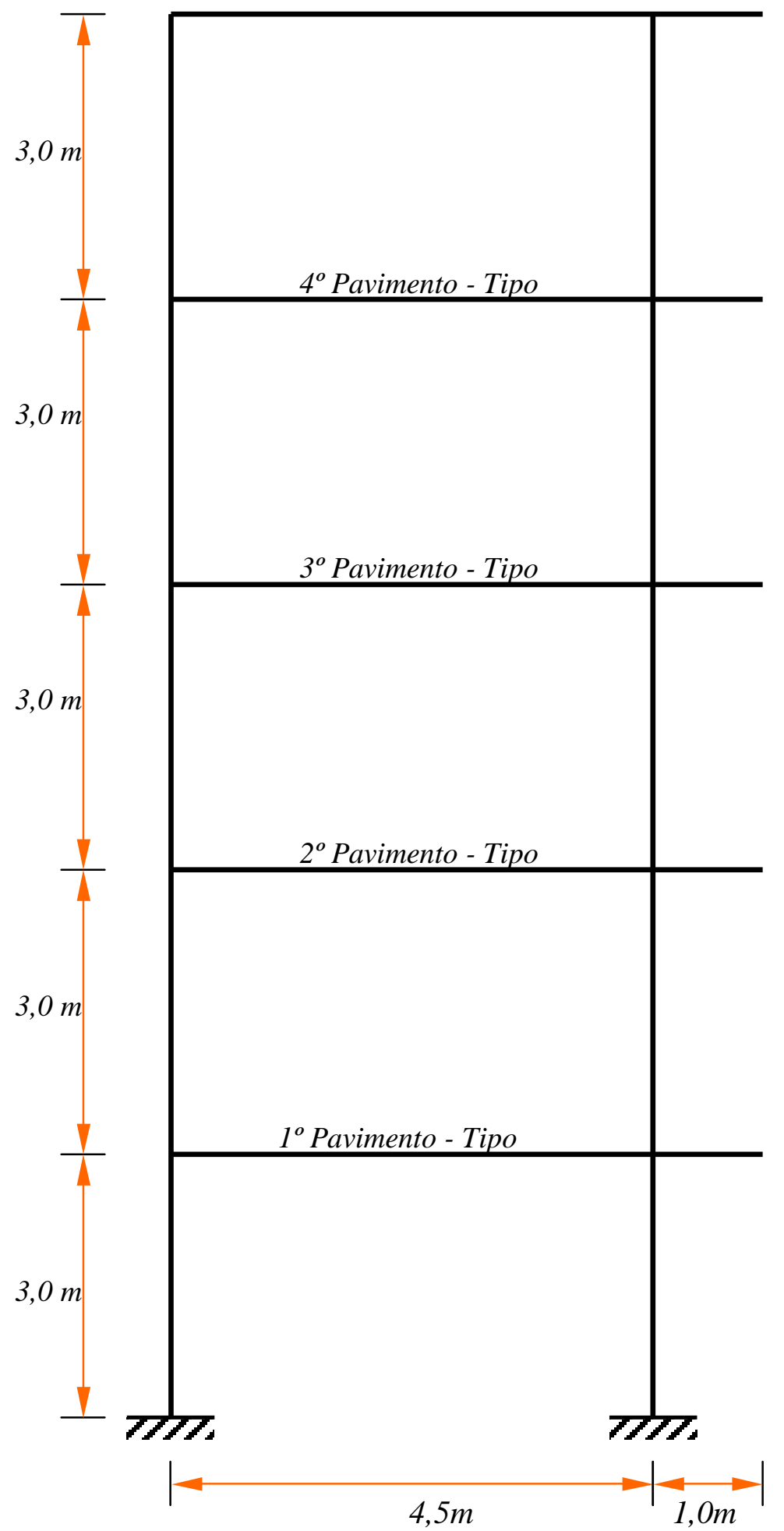

Figura 6 - 5 Esquema Estrutural do Pórtico de Concreto Armado 
Para o exemplo apresentado são mostradas abaixo a variação do custo dos indivíduos ao longo das gerações.

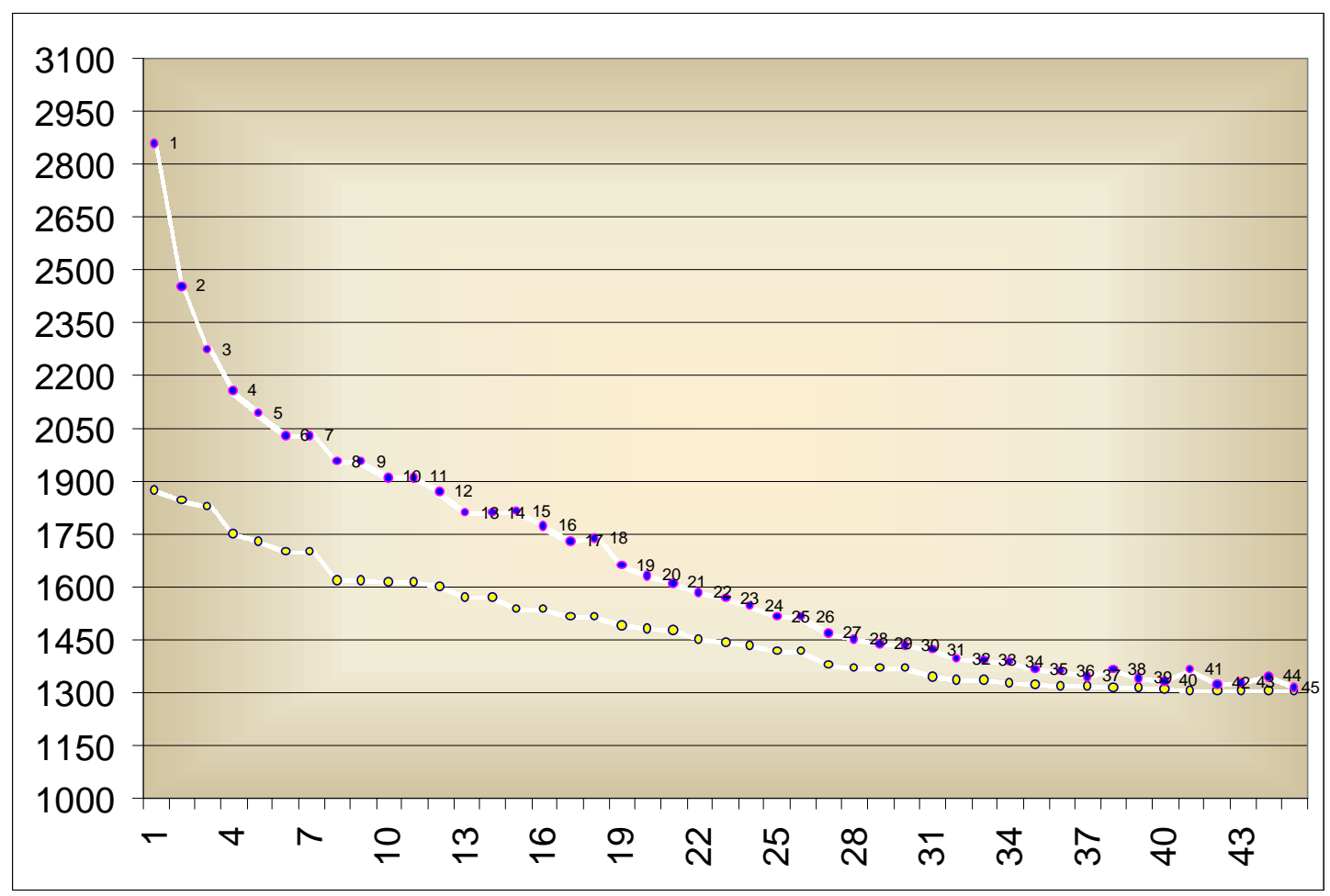

Figura 6 - 6 Custo Médio e Custo Mínimo dos Indivíduos em cada Geração

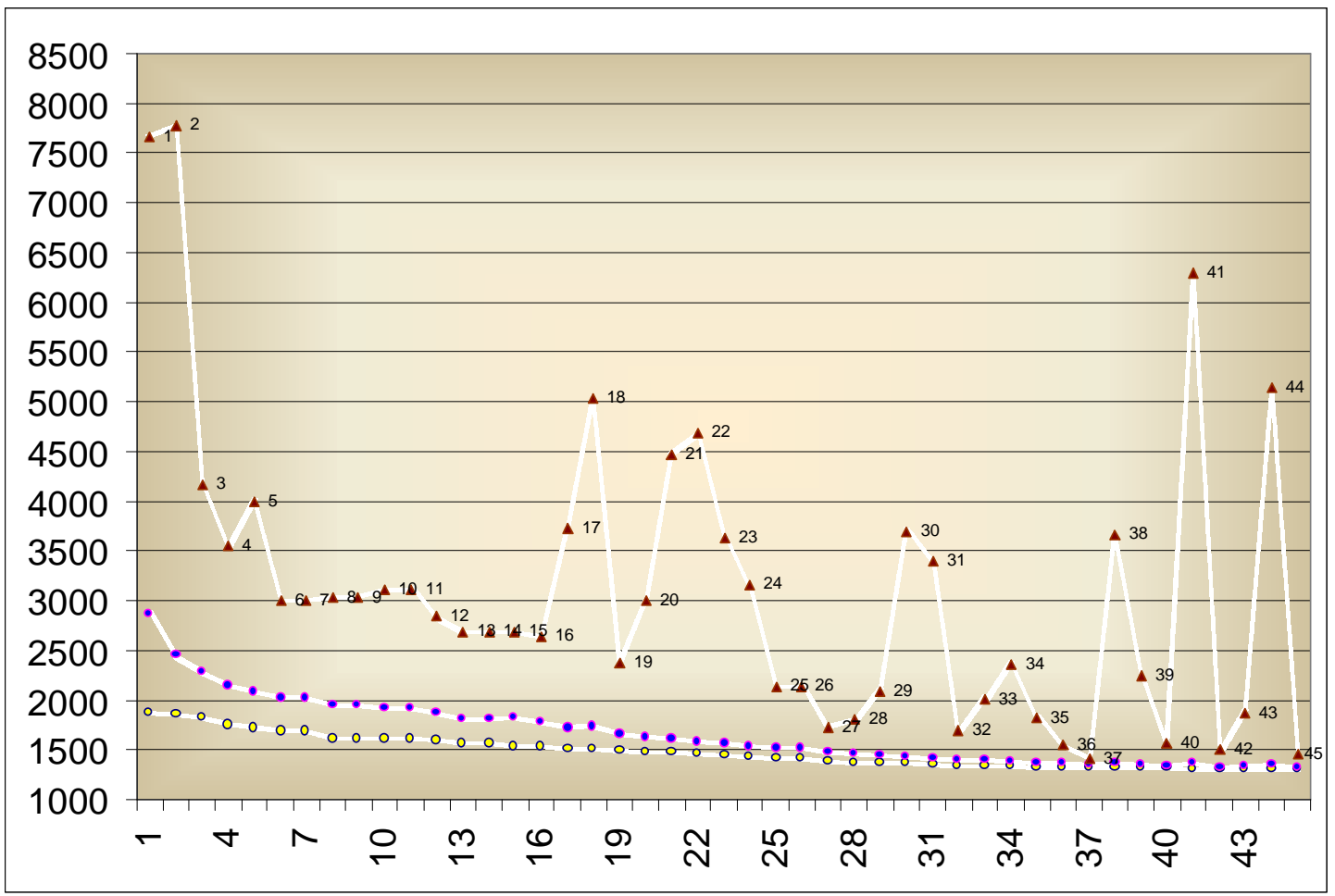

Figura 6 - 7 Custo Máximo, Médio e Mínimo dos Indivíduos em cada Geração 


\subsubsection{Conclusões Preliminares}

Os cromossomos que descrevem cada um dos indivíduos são bastante grandes, chegando a possuir cerca de 1000 bits de informação codificada. O cruzamento de indivíduos codificados dessa forma não é eficiente pois demora muito a gerar populações suficientemente diversificadas, o que retarda a convergência do método. A estratégia adotada para contornar o problema foi dividir o cromossomo principal em 4 outros cromossomos, cada um deles carregando informação sobre uma determinada variável, o que permite ainda uma maior facilidade na sua codificação e decodificação.

Essa abordagem revelou-se bastante eficaz, dando origem a populações diversificadas, convergindo mais rapidamente para o ponto de mínimo da função objetivo.

Outro procedimento utilizado, que também revelou-se muito eficiente, é o Método da Penalização amplamente discutido anteriormente. Penalizar os indivíduos que não atendem às restrições, permitindo que continuem cruzando e transmitindo suas características às gerações seguintes, contribui para a diversidade das populações e para a convergência do método. É importante notar que esses indivíduos, embora transgridam algumas das restrições, possuem outras características "boas", que não devem ser eliminadas.

Embora o exemplo apresentado seja de um pórtico de 5 pavimentos, os programas OTIMPORCA 1 e 2 funcionam para qualquer tipo de pórtico plano, com os tipos de carregamento usuais.

A otimização de pórticos de concreto se apresentou como uma ferramenta viável para outros estudos, desta forma deve-se a partir de agora buscar ampliar os aspectos abordados nesta dissertação incluindo outros parâmetros no processo de otimização buscando cada vez mais obter soluções viáveis e econômicas.

Os Algoritmos Genéticos são extremamente versáteis, o que facilitou bastante o uso da técnica para otimização de pórticos de concreto armado, idéia que se considerava extremamente complicada. Pode-se perceber que a problema'tica dos processos de otimização via algoritmos genéticos está muito mais ligada a descrição do problema que se deseja otimizar do que na técnica de minimização em si. 
Espera-se que com o desenvolvimento de formulação que demandem de menos restrições do que as apresentadas neste trabalho possam tornar estes algoritmos mais rápidos. O tempo de processamento desta estrutura demorou em média 30 minutos num Pentium II - 233 MHz com 128 Mb de memória RAM. 


\section{Capítulo 7}

\section{CONCLUSÕES E COMENTÁRIOS}

"O único lugar onde o sucesso vem antes do trabalho é no dicionário" 


\subsection{Sobre a OTIMIZAÇÃO de ESTRUTURAS}

Um dos importantes avanços da Engenharia de Estruturas da segunda metade do século XX ocorreu na área de Métodos Numéricos para Análise de Tensões, principalmente através do Método dos Elementos Finitos. Dada uma estrutura, seja ela formada por barras, placas, cascas, sólidos ou uma combinação destes elementos, já é possível obter os respectivos campos de deslocamentos, deformações e tensões, estudar modos de vibração natural, condições de instabilidade, etc. Estes desenvolvimentos aliados aos avanços ocorridos na área de computação, propiciaram a massificação do uso de computadores nas empresas de cálculo de projetos estruturais, possibilitando análises muito mais precisas e detalhadas que as realizadas há uma ou duas décadas passadas.

A fronteira de conhecimento que agora se coloca, é determinar qual a estrutura capaz de atender a todas as condições de segurança e que, além disso, seja ótima em relação a um ou mais critérios pré-estabelecidos, tais como, menor peso, menor custo dentre outros.

É nesse cenário que surgem os processos de otimização tentando tornar os computadores cada vez mais capazes de fazer escolhas sobre qual ou quais estruturas são mais viáveis "dimensionar". Dentre os diversos processos de otimização, os AGs tem se mostrado extremamente eficazes na resolução de problemas de engenharia estrutural pois se adaptam bem a problemas com variáveis discretas, funções objetivo complicadas e restrições as mais diversas possíveis.

Vale observar que a otimização de estruturas é multidisciplinar pois, além da engenharia estrutural, ela abrange outras áreas como estatística, métodos construtivos, planejamento de obras, metodologia de compra e contratação de serviços, além de ser variável no tempo pois, a estrutura mais econômica hoje não é necessariamente a mesma para o período subseqüente.

Não há dúvida que a próxima e importante vantagem competitiva a ser buscada pelo mercado de engenharia de projetos estruturais são os métodos de otimização, principalmente pelo critério econômico, e cabe aos pesquisadores desenvolvê-los para que o mercado os utilize. 
Embora de uso ainda restrito, seja pela dificuldade de utilização ou pelo alto custo de aquisição, já existem programas de análise estrutural pelo Método dos Elementos Finitos, disponíveis no mercado, capazes de fazer otimização de estruturas, porém, por serem programas de aplicação geral, demandam conhecimento teórico e experiência para a modelagem, processamento e interpretação dos resultados.

Há um amplo espaço no mercado de softwares para análise de estruturas de concreto armado capazes de, de forma amigável e especializada, modelar as estruturas mais usuais (pórticos espaciais combinados com elementos de casca), efetuar análises lineares e, principalmente, não-lineares e processar estudos de otimização topológica e de componentes.

Com certeza, esse desenvolvimento trará grande impacto na maneira como se introduz a segurança na metodologia de projeto, possibilitando dar tratamento distinto aos coeficientes de segurança de diferentes partes da estrutura (pilares, vigas e lajes) e de diferentes arranjos estruturais (hiperestaticidade).

\subsection{Sobre os AlgoritMos Genéticos}

Embora este trabalho tenha dado uma maior abordagem da utilização dos Algoritmos Genéticos para a resolução de problemas de otimização estrutural, inúmeras outras aplicações da técnica são possíveis e já foram empregadas, tais como:

- Modelagem e estudo de problemas em Ecologia, genética populacional e na relação entre aprendizagem do indivíduo e evolução da espécie;

- Construção automática de programas para a realização de tarefas específicas e outras estruturas computacionais como redes neurais;

- Criação de imagens, texturas, músicas e estruturas complexas.

Pelas suas características de robustez, flexibilidade e relativa facilidade de implementação, os Algoritmos Genéticos irão ganhar uma maior atenção com o decorrer do tempo, principalmente, pela rápida evolução dos computadores que tornarão suas aplicações cada vez mais viáveis e engenhosas.

Para os próximos anos um maior número de alternativas "mistas" da idéia genética com outras estratégias, que lhe agreguem novas capacidades, serão 
desenvolvidas, aprimoradas e difundidas no meio técnico, aumentando o leque de aplicações e trazendo novos benefícios na resolução dos problemas já tratados.

Outras sofisticações têm sido desenvolvidas e incorporadas aos Algoritmos Genéticos para aumentarem suas potencialidades, tais como Adaptação e Distribuição Uniforme da População Inicial.

A adaptação usualmente é estática, ou seja, são escolhidos parâmetros, funções e/ou operadores no início do algoritmo e levados até o fim da execução. Entretanto, uma maior atenção vem sendo dada à adaptação dinâmica, isto é, dentro do processo evolutivo o próprio algoritmo seleciona os parâmetros de configuração e/ou os operadores genéticos a serem utilizados, e possivelmente, até mesmo a função objetivo, principalmente em casos de aplicação de penalidades.

As vantagens da utilização dos Algoritmos Genéticos para problemas de otimização são inegáveis, enquanto que suas desvantagens serão sanadas por uma maior consolidação da técnica e pelo desenvolvimento de computadores com uma maior capacidade de processamento.

\subsection{Sobre a Análise Estrutural}

A determinação dos esforços solicitantes necessários para o dimensionamento das seções transversais dos elementos do pórtico (vigas e pilares) foi feita por um programa de análise matricial que, sendo válidas as hipóteses de linearidade física e geométrica, fornece a solução exata. Mantendo a topologia, a otimização ocorre tanto pela alteração dos parâmetros das seções quanto pela conseqüente redistribuição dos esforços pelo pórtico. Efeitos devido ao comportamento não-linear do concreto (viscosidade e plasticidade) e à não-linearidade geométrica (grandes deslocamentos e deformações) poderiam ter sido considerados de forma aproximada seguindo as recomendações de norma. Optou-se, porém, em fazê-lo de forma exata na tese de doutorado que dará sequiência a esse trabalho, através de um programa de análise nãolinear que utiliza o Método dos Elementos Finitos.

A análise não-linear possibilitará a consideração da deformação lenta do concreto (viscosidade), plastificação de seções e a conseqüente redistribuição dos esforços, determinação precisa dos parâmetros de instabilidade da estrutura e consideração exata dos efeitos devido a carregamentos horizontais (vento). Embora os 
efeitos devido à deformação lenta onerem a estrutura, os demais combinados levarão a economias importantes quando comparados com os resultados obtidos pela análise linear.

O processo usual de verificação de barras sujeitas a FCN consiste em percorrer uma grande quantidade de pontos $\left(\varepsilon_{c}, \varepsilon_{s}\right)$ obedecendo aos limites impostos pelos Domínios de Deformação, integrando os diagramas de tensões correspondentes e plotando os esforços resistentes $\left(N_{R d}, M_{R d}\right)$, obtendo assim os chamados Diagramas de Interação.

A verificação da FCO é feita a partir de duas FCN, ajustadas por parâmetros fornecidos pela norma. É fácil perceber que este processo se presta muito bem para cálculos manuais de verificação, não sendo apropriado, porém, para automatização.

O algoritmo de verificação da FCO utilizado nos exemplos dos pilares isolados, resolve um sistema não-linear de equações de equilíbrio, pelo Método de Newton, obtendo a resposta em termos da deformação axial $\varepsilon_{0}$ e das curvaturas $\kappa_{x}$ e $\kappa_{y}$, com as quais, facilmente, se obtêm o vetor dos esforços resistentes da seção transversal. Esse algoritmo é bastante eficaz, fornecendo os resultados, quando o equilíbrio é possível, em, no máximo, 5 iterações. Para validação dos resultados obtidos é preciso comparálos com os valores admissíveis dos Domínios de Deformação. Caso não os satisfaçam, o equilíbrio é considerado "não possível".

O pórtico analisado, por ser plano e com carregamento no seu plano, não possui peças sujeitas a FCO, apenas a FCN, cuja verificação pode ser feita de modo análogo ao descrito para FCO. Porém, para evitar que indivíduos com elementos (pilares) reprovados fossem descartados, introduziu-se um parâmetro $\alpha$ que "mede" o quão distante a seção se encontra do equilíbrio para, então, penalizá-la proporcionalmente a este valor. Isso possibilita que esses indivíduos passem suas características para as gerações seguintes.

A Norma de Concreto Armado é composta por um conjunto de regras de fácil aplicação para metodologias de projeto manuais ou pouco automatizadas, diferentes das atuais, onde se utiliza informática de forma maciça. A automatização das rotinas de dimensionamento e verificação de peças de concreto armado precisa de um conjunto de recomendações elaboradas de modo a facilitar sua implementação. Espera-se que a 
revisão da norma de concreto armado, prestes a entrar em vigor, contemple essa nova realidade.

\subsection{SOBRE OS EXEMPLOS ELABORADOS}

Pode-se observar no exemplo de otimização do pilar que, a estratégia de enumerar todos os indivíduos da população que já satisfaçam a um certo número de restrições, não é eficaz, pois pode resultar em funções objetivo extremamente descontínuas e com diversos pontos de mínimo local, o que dificulta bastante a pesquisa do ponto extremo da função objetivo pelo AG. Mesmo assim, pode-se observar que dentre os três casos apresentados, o AG convergiu rapidamente para o ponto de mínimo nos local em apenas dois, nos quais o número de indivíduos da região viável era suficientemente superior ao número máximo de indivíduos de cada geração, atingindo valores muito próximos dos mínimos globais da função. Dependendo do tipo de problema esta técnica pode resultar em soluções bastante distintas do mínimo da função, sendo desaconselhável o seu uso.

Nos exemplos de otimização do pórtico de concreto, pode-se observar que os AGs são bastante eficientes na busca de soluções, mesmo para problemas complexos, com grande número de variáveis envolvidas e sujeitos a várias restrições como é este caso. Desta forma pode-se pensar agora em generalizar os conceitos desenvolvidos na otimização de estruturas de grande porte ou mesmo estruturas tridimensionais.

A estratégia de penalização dos indivíduos não aptos mostrou-se ser mais eficiente que a eliminação dos indivíduos da população. Outra vantagem do processo de penalização consiste na facilidade com que pode ser acoplada aos AGs, somando-se diretamente à função objetivo do problema. Desta forma as verificações de penalização serão sempre um pós-processamento nos problemas de otimização de estruturas de concreto, não influindo nas sub-rotinas de verificação das seções transversais.

Mesmo tendo-se feito a otimização de estruturas de concreto com uma análise linear, observou-se no exemplo apresentado uma economia de $22.7 \%$ em relação a solução pelo programa comercial EBERICK, feita tanto por mim quanto pela MÉRITO Engenharia onde foi pedido ao projetista que tentasse obter a estrutura de concreto armado mais econômica possível, mostrando o quão promissor é o método. Desta forma se pretende dar continuidade à idéia inicial do trabalho propondo processos de cálculo 
de esforços computacionalmente mais eficientes e passando a incluir otimização topológica em seu escopo.

Deve-se ainda ressaltar que, embora a ênfase deste trabalho tenham sido as seções retangulares de concreto armado, a grande maioria dos conceitos e discussões apresentados podem, sem dificuldade, ser transpostos a qualquer outra seção com materiais elásticos, homogênea ou não. Tanto a obtenção dos esforços resistentes das seções transversais quanto a análise do pórtico plano propriamente dito são, de certa forma, genéricas, ou seja, não estão relacionadas a um material em particular. A extensão fica restrita às considerações sobre o Estado Limite Ultimo que é bastante particular ao concreto armado.

\subsection{Sugestões Para Trabalhos Futuros}

Abaixo são expostas algumas sugestões para trabalhos futuros nesta área:

- Otimização de Pórticos Planos de Concreto Armado com considerações de não linearidade geométrica e física exatos e comparar com os resultados obtidos com o mesmo problema resolvido com os métodos aproximando para consideração da não-linearidade física e geométrica propostos pela NBR-6118;

- Generalização da verificação de seções transversais para o caso da Flexão Composta Oblíqua de forma a se poder verificar o equilíbrio da seção transversal sem que se faça necessários usar os Domínios de Deformação propostos pela Norma Brasileira, de forma a tornar o processo mais eficiente;

- Otimização de Pórticos Espaciais de Concreto Armado;

- Otimização de Estruturas de Concreto Armado baseado em conceitos de Segurança e Confiabilidade, usando critérios estatísticos para consideração da variabilidade dos materiais e a determinação a influência da hiperestaticidade da estrutura;

- Otimização Topológica de Estruturas de Concreto Armado utilizando Algoritmos Genéticos;

- Determinação de parâmetros de calibração dos Algoritmos Genéticos para problemas complicados como por exemplo o caso de otimização de pórticos, onde haja mais de um cromossomo para caracterização dos indivíduos. 
Um assunto que ainda merece estudo mais aprofundado é a caracterização da segurança nas análises não-lineares de estruturas. Os exemplos realizados neste trabalho sempre se utilizaram dos mesmos materiais (e coeficiente de segurança) tanto para análise quanto para a verificação (de seções) no Estado Limite Último. Pretende-se dar continuidade a este trabalho de forma a propor formulações de segurança em análises não-lineares de estruturas de concreto armado, usando a otimização como ferramenta para determinação de parâmetros que possam correlacionar as análises não-lineares com as análises lineares convencionais garantindo a segurança das estruturas. 


\section{REFERÊNCIAS BIBLIOGRÁFICAS}

[A-1] AMADIEU, O.; PARISOT, C. Algoritmes Génétiques, "http://www.essi.fr/ parisot/GA200/ga.html", 1997.

[A-2] ASSOCIAÇÃO BRASILERIA DE NORMAS TECNICAS - ABNT. Projeto e execução de Obras de Concreto Armado e Protendido - NBR 6118. Rio de Janeiro, 1980.

[B-1] BARCELlOS, J. $\quad$ C. $\quad$ H. Algoritmos Genéticos Adaptativos: um estudo comparativo (Dissertação de Mestrado), EPUSP, São Paulo, 2000.

[B-2] BANDEIRA, A. A. Uma Introdução à Análise de Problemas de Contado, (Dissertação de Mestrado), EPUSP, São Paulo, 1997.

[C-1] CASTRO E. R.; BARBOSA, H. J. C. Otimização Estrutural com MultiObjetivos Via Algoritmos Genéticos, COPPE/UFRJ, Rio de Janeiro, 1998.

[C-2] COEllo, C. C.; CHRISTAINSEN, A. D.; HERNÁNDEZ, F. $\quad$ S. A $\quad$ A Simple Genetic Algorithm for the Design of Reinforced Concrete Beams, United States, Engineering with Computers, Vol. 13, pp. 185-196, 1997.

[C-3] COELlO, C. C.; CHRISTAINSEN, A. D.; FARRERA, F. A. A Genetic Algorithm for the Optimal Design of Axially Loaded Non-Prismatic Columns, Civil Engineering Systems, Vol. 14, pp. 111-146, 1996. 
[D-1] DAVIS, L. Handbook of Genetic Algorithms, Van Nostrand Reinhold, New York, 1991.

[D-2] DEMIDOVICH, B. P.; MARON, Computational Mathematics, Mir Publishers, Moscow, 1976.

[F-1] FLETCHER, R. Practical Methods of Optimization - Unconstrained Optimization, University of Dundee, Scotland, 1985.

[F-2] FLETCHER, R. Practical Methods of Optimization - Constrained Optimization, University of Dundee, Scotland, 1985.

[F-3] FUSCO, P. B. Técnicas de Armar as Estruturas de Concreto, PINI, São Paulo, 1995.

[F-4] FUSCO, P. B. Estruturas de Concreto - Solicitações Normais, Guanabara Dois, São Paulo, 1986.

[G-1] GILL, P. $\quad$ E.; MURRAY, W. Numerical Methods for Constrained Optimization + Practical Optimization, New York: Academic Press, 1974.

[G-2] GOLDENBER, D. E. Genetic Algorithms in Search, Optimization and Machine Learning, Addison Wesley Publishing Company, USA, 1989.

[G-3] GERE, J. M.; WEAVER JUNIOR, W. Análise Matricial de Estruturas Reticuladas, Guanabara Dois, 1981.

[H-1] HOROWITZ, B. Desing of Columns Subjected to Biaxial Bending, ACI Structural Jornal, November-December 1989. 
[H-2] HANN, B. D. Fortran 90 for Scientists and Engineers, University of Cape Town, Department of Applied Mathematics, 1993.

[L-1] LACERDA, E.G.M., CARVALHO, A.C.P.L.F., GALVÃO, C.O., VALENÇA, M.J.S., VIEIRA, V.P.P.B., DINIZ, L.S., LUDERMIR, T.B. Sistemas Inteligentes - Aplicações a Recursos Hídricos e Ciências Ambientais, Editora da Universidade/UFRGS/ABRH, 1999.

[L-2] LEONHARDT, F.; MONNIG, E. Construções de Concreto, Interciência, Rio de Janeiro, 1977.

[L-3] LUENBERGER, D.G. Programacion Linear y No Linear, Stanford University, California, 1989.

[M-1] MACGREGOR, J. G. Reinforced Concrete: Mechanics and Design, Englewood Cliffs, N.J. : Prentice Hall, 1996.

[M-2] MEDRANO, M. S. Aplicações de Programação Matemática em Análise Estrutural (Dissertação de Mestrado), EPUSP, São Paulo, 1994.

[M-3] MENDES, N. F. Tópicos sobre a Análise Não-Linear de pórticos Planos de Concreto Armado (Tese de Doutorado), EPUSP, São Paulo, 2000.

[M-4] MENDES, N. F.; PIMENTA, P. M. Análise Eficiente de Seções Transversais Retangulares de Concreto Armado submetidas à Flexão Normal Composta, IV Simpósio EPUSP sobre Estruturas de Concreto, São Paulo, São Paulo, 2000. 
[M-5] MENDES, N. F.; PIMENTA, P. M. Sobre o Cálculo dos Esforços Seccionais Resistentes, XX CILANCE (20th Iberian Latin-American Congress on Computational Methods in Engineering), São Paulo, 1999.

[M-6] MENDES, N. F.; PIMENTA, P. M. Considerações sobre o Diagrama de Domínios para o Dimensionamento e a Verificação de Seções Transversais de Concreto Armado, IV Simpósio EPUSP sobre Estruturas de Concreto, São Paulo, São Paulo, 2000.

[M-7] MICHALEWICZ, Z. Genetic Algorithms + Data Structures = Evolution Programs, Springer-Verlag, New York, USA, 1996.

[N-1] NEVES, F. A. Programação com Multi-Ojetivos Aplicada à otimização de Pontes Estaiadas, (Tese de Doutorado), COPPE / UFRJ, Rio de Janeiro, 1997.

[N-2] NONATO, L. V. Tópicos sobre a Análise Não-Linear de Pórticos de Concreto Armado (Tese de Doutoramento), EPUSP, São Paulo, 2000.

[N-3] NETO, F. M. Aplicação de Algoritmos Genéticos ao Palnejamento de levantamentos Oceanográficos (Tese de Doutoramento), EPUSP, São Paulo, 1997.

[O-1] OLIVEIRA, S. R. O Algoritmo Genético na Otimização do Projeto Estrutural de Embarcações, (Tese de Doutorado), EPUSP, São Paulo, 1998.

[0-2] OLIVEIRA, R. S. Análise de pavimentos de edifícios de concreto armado com a consideração da não-linearidade física - modelagem e metodologia de aplicação a projetos, (Tese de Doutorado), EESC/USP, São Paulo , 1998. 
[P-1] PFEIL, W. Concreto Protendido: Processos Construtivos, Perdas de Protensão, EDC ed.didática e Científica, Rio de Janeiro, 1991.

[P-2] PINTO, C. M. Algoritmos Genéticos Aplicados na Engenharia de Estruturas (Dissertação de Mestrado), EPUSP, São Paulo, 2001.

[P-3] PERDIGÃO, R. S. Roteiro para Dimensionamento Não Linear de edifícios de Concreto Armado Segundo as Normas Norte-Americanas (Dissertação de Mestrado), UFPE, Recife, 2000.

[R-1] RICE, J. R. Numerical Methods, Software, and Analysis, McGraw-Hill, Purdue University, 1983.

[S-1] SHAFFER, R. Practical Guide to Genetic Algorithms, Naval Research Laboratory, Chemistry Division, "http://www.chem1.nrl.navy.mil".

[S-2] SILVA, M. A. Sobre a Otimização de Estruturas Submetidas a Carregamento Dinâmico, (Tese de Doutorado), EPUSP, São Paulo, 2000.

[S-3] SOARES, R. C. Um estudo sobre modelos mecânico-probabilístico para pórticos de concreto armado, (Tese de Doutorado), EESC/USP, São Paulo, 2000.

[W-1] WHITLEY, D. A Genetic Algorithm Tutorial, Statistic and Computing, Vol. 4, pp. 65-85, 1994. 


\section{ANEXOA}

Abaixo estão listados alguns dos algoritmos utilizados nos Métodos de Programação Matemática para determinação dos pontos de mínimo de funções:

\section{A 3.1 - ALgORITMO PARA O MÉTODO DE NEWTON-RAPHSON}

Passo $1: k=0 \rightarrow$ estimar $\boldsymbol{x}^{0}$

Passo 2: calcular $f\left(\boldsymbol{x}^{k}\right)$

Passo 3: se $\left\|f\left(\boldsymbol{x}^{k}\right)\right\|<T O L$, onde $T O L=\varepsilon \cdot\left\|f\left(\boldsymbol{x}^{0}\right)\right\|$, pare $\boldsymbol{x}^{k}$ é solução caso contrário vá para o Passo 4

Passo 4: Calcule a Jacobiana: $\nabla f\left(\boldsymbol{x}^{k}\right)$

Passo 5: Resolva

$$
\left[\nabla f\left(\boldsymbol{x}^{k}\right)\right]^{T} \cdot \boldsymbol{d}^{k}=f\left(\boldsymbol{x}^{k}\right)
$$

Passo 6: $\boldsymbol{x}^{k+1}=\boldsymbol{x}^{k}-\boldsymbol{d}^{k}$

Passo 7: $k=k+1$ e vá ao Passo 2

Algoritmo 3 - 1 - Algoritmo para o Método de Newton-Raphson

\section{A 3.2 - A LGORITMO PARA BUSCA UNIDIMENSIONAL}

Passo 1: Inicialmente faça $\rightarrow s=1$

Passo 2: calcular

$$
\begin{aligned}
& G_{c}=\nabla f\left(\boldsymbol{x}^{k}\right) \cdot \boldsymbol{d}^{k} \\
& G(s)=\nabla f\left(\boldsymbol{x}^{k}-s \cdot \boldsymbol{d}^{k}\right) \cdot \boldsymbol{d}^{k}
\end{aligned}
$$

Passo 3: Estimar um valor STOL (tolerância)

$$
\begin{aligned}
& \text { Se }\left[|G(s)|>S T O L \cdot\left|G_{c}\right| \text { ou } G(s) \cdot G_{C}<0\right] \text {, então, itere para } \\
& s \in(0,1] \text { até }|G(s)| \leq S T O L \cdot\left|G_{c}\right|
\end{aligned}
$$




\section{A 3.3 - AlgoritMo PARA 0 MÉTOdo DE N-R COM BUSCA UNIDIMENSIONAL}

Passo $1: k=0 \rightarrow$ estimar $\boldsymbol{x}^{0}$

Passo 2: Calcular $\nabla f\left(\boldsymbol{x}^{k}\right)$

Passo 3: se $\left\|\nabla f\left(\boldsymbol{x}^{k}\right)\right\|<T O L$ pare $\boldsymbol{x}^{k}$ é solução, caso contrário vá para o Passo 4

Passo 4: Calcule a Hessiana: $\nabla^{2} f\left(\boldsymbol{x}^{k}\right)$

Passo 5: Resolva: $\left[\nabla^{2} f\left(\boldsymbol{x}^{k}\right)\right]^{T} \cdot \boldsymbol{d}^{k}=\nabla f\left(\boldsymbol{x}^{k}\right)$

Passo 6: Busca Unidimensional (calcular $s^{k}$ )

Minimizar $\left\{\phi(s)=f\left(\boldsymbol{x}^{k}-s \cdot \boldsymbol{d}^{k}\right)\right\}$, com $s \geq 0$ em relação à $s$.

$s^{k}$ é a solução do problema de minimização acima

Passo 7: $\boldsymbol{x}^{k+1}=\boldsymbol{x}^{k}-s^{k} \cdot \boldsymbol{d}^{k}$

Passo 8: $\quad k=k+1$ e vá ao Passo 2

Algoritmo 3 - 3 - Algoritmo para o Método de N - R com Busca Unidimensional

Descrição do Passo 6 do algoritmo 3-3

$$
\begin{gathered}
\text { Minimizar } \quad \varphi(s)=f\left(\boldsymbol{x}-s \cdot \boldsymbol{d}^{k}\right) \\
\left\{\begin{array}{c}
s=0 \Rightarrow \varphi(0)=f\left(\boldsymbol{x}^{k}\right) \\
s=1 \Rightarrow \varphi(1)=f\left(\boldsymbol{x}^{k}-\boldsymbol{d}^{k}\right)
\end{array}\right.
\end{gathered}
$$

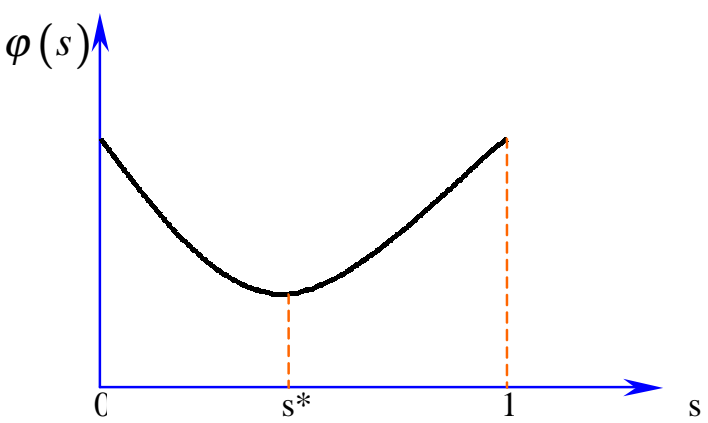

o escalar $s$ deve pertencer a intervalo $s \in(0,1]$, de forma a garantir o decréscimo suficiente.

A busca unidimensional tem como objetivo resolver o problema de minimização acima mencionado. A condição necessária de mínimo de $\varphi(s)$ é dada por $\frac{d \varphi}{d s}(s)=0$, $\log 0$

$$
-\frac{d \varphi}{d s}(s)=G(s)=\nabla f\left(\boldsymbol{x}^{k}-s \cdot \boldsymbol{d}^{k}\right) \cdot \boldsymbol{d}^{k}=0
$$

$s \in(0,1]$, se $s^{k}$ estiver fora desse intervalo, adotamos o valor 1 para $s^{k}$. 


\section{A 3.4 - Algoritmo Para O MÉTOdO de QUASE-NEWTON (BFGS)}

Passo 1: $k=0 \rightarrow$ estimar $\boldsymbol{x}^{0}$ e $\boldsymbol{B}^{0}$

Passo 2: calcular: $\nabla f\left(\boldsymbol{x}^{k}\right)$

Passo 3: se $\left\|\nabla f\left(\boldsymbol{x}^{k}\right)\right\|<T O L$, onde $T O L=\varepsilon \cdot\left\|\nabla f\left(\boldsymbol{x}^{0}\right)\right\|$

pare $\boldsymbol{x}^{k}$ é solução

caso contrário vá para o Passo 4

Passo 4: Calcule a direção $\boldsymbol{d}^{k}$

$$
\boldsymbol{d}^{k}=\boldsymbol{B}^{k} \cdot \nabla f\left(\boldsymbol{x}^{k}\right) \quad \text { ver A } \lg 0 \text { ritmo } 3-5
$$

Passo 5: Busca Unidimensional

Calcular $s^{k}$

Minimizar $\left\{\phi(s)=f\left(\boldsymbol{x}^{k}-s \cdot \boldsymbol{d}^{k}\right)\right\} \quad$ ver A lgoritmo 3 - 2

Com $s \geq 0$ em relação à $s$.

$s^{k}$ é a solução do problema de minimização acima

Passo 6: $\quad \boldsymbol{x}^{k+1}=\boldsymbol{x}^{k}-s^{k} \cdot \boldsymbol{d}^{k}$

Passo 7: $k=k+1$ e vá ao Passo 2

Algoritmo 3 - 4 - Algoritmo para o Método Quase-Newton (BFGS)

$$
\begin{gathered}
\boldsymbol{\delta}^{k}=\boldsymbol{x}^{k+1}-\boldsymbol{x}^{k} \quad \boldsymbol{\gamma}^{k}=\nabla f\left(\boldsymbol{x}^{k+1}\right)-\nabla f\left(\boldsymbol{x}^{k}\right) \\
\boldsymbol{B}^{k} \cdot \boldsymbol{\gamma}^{k}=\boldsymbol{\delta}^{k} \\
\boldsymbol{B}^{k+1}=\boldsymbol{B}^{k}+\left(1+\frac{\left(\boldsymbol{\gamma}^{k}\right)^{T} \cdot \boldsymbol{B}^{k} \cdot \boldsymbol{\gamma}^{k}}{\left(\boldsymbol{\delta}^{k}\right)^{T} \cdot \boldsymbol{\gamma}^{k}}\right) \cdot \frac{\boldsymbol{\delta}^{k} \cdot\left(\boldsymbol{\delta}^{k}\right)^{T}}{\left(\boldsymbol{\delta}^{k}\right)^{T} \cdot \boldsymbol{\gamma}^{k}}-\left(\frac{\boldsymbol{\delta}^{k} \cdot\left(\boldsymbol{\gamma}^{k}\right)^{T} \cdot \boldsymbol{B}^{k}+\boldsymbol{B}^{k} \cdot \boldsymbol{\gamma}^{k} \cdot\left(\boldsymbol{\delta}^{k}\right)^{T}}{\left(\boldsymbol{\delta}^{k}\right)^{T} \cdot \boldsymbol{\gamma}^{k}}\right)
\end{gathered}
$$




\section{A 3.5 - AlgORITMO PARA RESOLUÇão do Sistema}

Passo 1: $k=$ "o mesmo contador da iteração do BFGS"

$$
\boldsymbol{p}=\nabla f\left(\boldsymbol{x}^{k}\right)
$$

Passo 2: Itere em $i$, de $i=k$ até $i=1 \mathrm{de}-1$ em -1

$$
\boldsymbol{p}=\left(\boldsymbol{I}+\boldsymbol{\omega}^{i} \cdot\left(\boldsymbol{v}^{i}\right)^{T}\right) \cdot \boldsymbol{p}
$$

Passo 3: $\boldsymbol{q}=\boldsymbol{B}^{0} \cdot \boldsymbol{p}$

Passo 4: Itere em $i$, de $i=1$ até $i=k$ de 1 em 1

$$
\boldsymbol{q}=\left(\boldsymbol{I}+\boldsymbol{\omega}^{i} \cdot\left(\boldsymbol{v}^{i}\right)^{T}\right) \cdot \boldsymbol{q}
$$

Então a direção $\boldsymbol{d}^{k}=\boldsymbol{q}$

\section{Algoritmo 3 - 5 - Algoritmo para Resolução do Sistema}

As equações estão comentadas no item 3.3.2.1.2. do Capítulo 3.

$$
\begin{gathered}
\boldsymbol{v}^{k}=\frac{\boldsymbol{\delta}^{k}}{\boldsymbol{\delta}^{k} \cdot \boldsymbol{\gamma}^{k}} \quad \alpha^{k}=\sqrt{\frac{-s^{k} \cdot \boldsymbol{\gamma}^{k} \cdot \boldsymbol{\delta}^{k}}{\nabla f\left(\boldsymbol{x}^{k-1}\right) \cdot \boldsymbol{\delta}^{k}}} \quad \boldsymbol{\omega}^{k}=-\boldsymbol{\gamma}^{k}+\alpha^{k} \cdot \nabla f\left(\boldsymbol{x}^{k-1}\right) \\
\boldsymbol{d}^{k}=\left(\boldsymbol{I}+\boldsymbol{v}^{k} \cdot\left(\boldsymbol{\omega}^{k}\right)^{T}\right) \cdot \boldsymbol{B}^{k-1} \cdot\left(\boldsymbol{I}+\boldsymbol{\omega}^{k} \cdot\left(\boldsymbol{v}^{k}\right)^{T}\right) \cdot \nabla f\left(\boldsymbol{x}^{k}\right)
\end{gathered}
$$




\section{A 3.6 - Algoritmo Para o Método Newton/QuaSe-Newton}

Passo 1: a) Estimar os valores de $\boldsymbol{x}^{0}$

b) Calcule o valor da função $\nabla f\left(\boldsymbol{x}^{0}\right)$ e da Hessiana $\nabla^{2} f\left(\boldsymbol{x}^{0}\right)$

c) Calcule a direção inicial $\boldsymbol{d}^{0}$ resolvendo a equação linear:

$$
\left[\nabla^{2} f\left(\boldsymbol{x}^{0}\right)\right]^{T} \cdot \boldsymbol{d}^{0}=\nabla f\left(\boldsymbol{x}^{0}\right)
$$

d) Inicie $G_{c}=\boldsymbol{d}^{0} \cdot \nabla f\left(\boldsymbol{x}^{0}\right)$ e faça $G I=G_{c}$

e) Inicie o contador $j$ das iterações do BFGS, o contador $i$ do método de Newton e o contador $k$ do Lagrangiano: $i=0 ; j=0$.

Passo 2: Itere em i até atingir a solução:

a) Busca unidimensional

i) Inicialmente faça $\rightarrow s^{i}=1$

ii) Calcular $\rightarrow \quad G\left(s^{i}\right)=\boldsymbol{d}^{i} \cdot \nabla f\left(\boldsymbol{x}^{i}-s^{i} \cdot \boldsymbol{d}^{i}\right)$

iii) Estim ar um valor STOL (tolerância)

$$
\begin{aligned}
& \text { Se }\left[\left|G\left(s^{i}\right)\right|>S T O L \cdot\left|G_{c}\right| \text { ou } G\left(s^{i}\right) \cdot G_{C}<0\right], \text { então, itere para } \\
& s \in(0,1] \text { até }\left|G\left(s^{i}\right)\right| \leq S T O L \cdot\left|G_{c}\right|
\end{aligned}
$$

iv) Incremente: $\boldsymbol{x}^{i+1}=\boldsymbol{x}^{i}-s^{i} \cdot \boldsymbol{d}^{i}$

b) Teste a divergência:

Se $\left\|\nabla f\left(\boldsymbol{x}^{i+1}\right)\right\|>\left\|\nabla f\left(\boldsymbol{x}^{i}\right)\right\|$, então vá para o Algoritmo 3 - 7

c) Teste a solução do problema:

Se $G_{c} \leq E T O L \cdot G I$, então vá para o Passo 3, solução satisfeita

d) Analise o passo da busca:

Se $s^{i}<0.001$, então vá para o Algoritmo $3-7$

e) Teste o limite de iterações do BFGS:

Se $j=\max _{B F G S}$ então vá para o Algoritmo 3 - 7

f) Vá para 0 Algoritmo 3 - 8 


\section{A 3.7 - Calculo da Direção di Pelo Método de NeWton}

Passo 1: Incremente o contador da iteração: $i=i+1$

i) Calcule o valor da função $\nabla f\left(\boldsymbol{x}^{i}\right)$ e da Hessiana $\nabla^{2} f\left(\boldsymbol{x}^{i}\right)$

ii) Calcule a direção inicial $\boldsymbol{d}^{i}$ resolvendo 0 sistema de equações

$$
\text { lineares: }\left[\nabla^{2} f\left(\boldsymbol{x}^{i}\right)\right]^{T} \cdot \boldsymbol{d}^{i}=\nabla f\left(\boldsymbol{x}^{i}\right)
$$

iii) Atualize $G_{c}=\boldsymbol{d}^{i} \cdot \nabla f\left(\boldsymbol{x}^{i}\right)$

iv) Faça $j=0$ e vá para o Passo 2 do Algoritmo 3 - 6

Algoritmo 3 - 7 - Algoritmo para o Cálculo da direção $\boldsymbol{d}^{i}$ pelo Método de Newton

\section{A 3.8 - Calculo da DiReÇão $d^{\mathrm{i}}$ MÉTOdo do BFGS}

Passo 1: Incremente as iterações: $i=i+1 ; j=j+1$

Passo 2: (Fórmula do Produto do BFGS)

Calcule os vetores $\boldsymbol{v}^{i}$ e $\boldsymbol{\omega}^{i}$, onde:

i) $\boldsymbol{v}^{i}=\frac{\boldsymbol{d}^{i-1}}{\boldsymbol{d}^{i-1} \cdot\left(\nabla f\left(\boldsymbol{x}^{i}\right)-\nabla f\left(\boldsymbol{x}^{i-1}\right)\right)}$

ii) $\alpha^{j}=\sqrt{\frac{-\mathrm{s}^{i-1} \cdot\left(\nabla f\left(\boldsymbol{x}^{i}\right)-\nabla f\left(\boldsymbol{x}^{i-1}\right)\right) \cdot \boldsymbol{d}^{i-1}}{\nabla f\left(\boldsymbol{x}^{i-1}\right) \cdot \boldsymbol{d}^{i-1}}}$

iii) $\boldsymbol{\omega}^{i}=-\left(\nabla f\left(\boldsymbol{x}^{i}\right)-\nabla f\left(\boldsymbol{x}^{i-1}\right)\right)+\alpha^{j} \cdot \nabla f\left(\boldsymbol{x}^{i-1}\right)$

iv) $\boldsymbol{B}^{j}=\left(\boldsymbol{I}+\boldsymbol{v}^{i} \cdot \boldsymbol{\omega}^{i^{T}}\right) \cdot \boldsymbol{B}^{j-1} \cdot\left(\boldsymbol{I}+\boldsymbol{\omega}^{i} \cdot \boldsymbol{v}^{i^{T}}\right)$

Passo 3: Calcule $\boldsymbol{d}^{i}$ resolvendo o sistema $\boldsymbol{d}^{i}=\boldsymbol{B}^{i} \cdot \nabla f\left(\boldsymbol{x}^{i}\right)$ pelo Algoritmo 3 - 5

Passo 4: A tualize $G_{c}=\boldsymbol{d}^{i} \cdot \nabla f\left(\boldsymbol{x}^{i}\right)$

Passo 5: Vá para o Passo 2 do Algoritmo 3 - 6

Algoritmo 3 - 8 - Algoritmo para o Cálculo da direção $\boldsymbol{d}^{i}$ pelo Método BFGS 


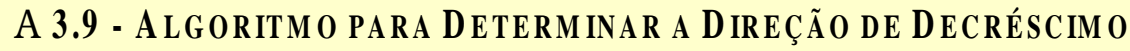

PARA O MÉTODO DO LAGRANGIANO

Passo 1: Calcular: $\boldsymbol{A}^{-1}$

$$
\boldsymbol{v}=\boldsymbol{A}^{-1} \cdot \boldsymbol{f}_{1}
$$

Passo 2: Calcular :

$$
\boldsymbol{w}=-\boldsymbol{B}^{T} \cdot \boldsymbol{v}+\boldsymbol{f}_{2}
$$

Passo 3: Resolver o sistema de equações lineares: $\boldsymbol{d}_{2}^{k}$

$$
\left[\boldsymbol{B}^{T} \cdot \boldsymbol{A}^{-1} \cdot \boldsymbol{B}\right] \cdot \boldsymbol{d}_{2}^{k}=\boldsymbol{w}
$$

Passo 4: Calcular o vetor incógnita: $\boldsymbol{d}_{1}^{k}$

$$
\boldsymbol{d}_{1}^{k}=-\boldsymbol{v}-\boldsymbol{A}^{-1} \cdot \boldsymbol{B} \cdot \boldsymbol{d}_{2}^{k}
$$

Algoritmo 3 - 9 - Algoritmo para determinar a Direção de Decréscimo

\section{A 3.10 - AlgORITMO PARA 0 MÉTODO DO LAGRANGIANO COM RESTRIÇÕES DE IGUALDADE}

Passo 1: Resolver o seguinte sistem a de equações não-lineares:

$$
\left\{\begin{array}{c}
\nabla f\left(\boldsymbol{x}^{*}\right)+\sum_{i=1}^{m} \lambda_{i}^{*} \cdot \nabla g_{i}\left(\boldsymbol{x}^{*}\right) \\
\nabla g_{1}\left(\boldsymbol{x}^{*}\right) \\
\vdots \\
\nabla g_{m}\left(\boldsymbol{x}^{*}\right)
\end{array}\right\}=0
$$

Utilizando o Método de Newton tem-se

$$
\left[\begin{array}{l}
\boldsymbol{x} \\
\lambda
\end{array}\right]^{k+1}=\left[\begin{array}{l}
\boldsymbol{x} \\
\lambda
\end{array}\right]^{k}-\left[\nabla t\left(\boldsymbol{x}^{k}, \lambda^{K}\right)\right]^{-1} \cdot t\left(\boldsymbol{x}^{k}, \lambda^{K}\right)
$$

fazendo

$\boldsymbol{A}=\nabla^{2} f\left(\boldsymbol{x}^{k}\right)+\sum_{i=1}^{m} \lambda_{i}^{k} \cdot \nabla^{2} g_{i}\left(\boldsymbol{x}^{k}\right)$ e $\boldsymbol{B}=\nabla g\left(\boldsymbol{x}^{k}\right)$ pode-se resolver o problem a pelo

A lgoritmo $3-9$.

Algoritmo 3 - 10 - Algoritmo para o Método do Lagrangiano com Restrições de Igualdade 


\section{A 3.11 - Algoritmo Para 0 MÉtodo da Penalidade COM RESTRIÇÕES DE IGUALDADE}

Passo 1: Escolha uma seqüência $\left\{\xi^{k}\right\} \rightarrow \infty$ por exemplo $\left\{1,10,10^{2}, 10^{3}, 10^{4}, \ldots\right\}$

Passo 2: Resolva o problema de minimização abaixo:

$$
\begin{aligned}
& \text { Minimizar } P\left(\boldsymbol{x}, \boldsymbol{\xi}^{k}\right) \\
& P\left(\boldsymbol{x}, \boldsymbol{\xi}^{k}\right)=f(\boldsymbol{x})+\frac{1}{2} \cdot \xi^{k} \cdot \sum_{i=1}^{m} g_{i}^{2}(\boldsymbol{x})
\end{aligned}
$$

obtendo como solução $\boldsymbol{x}^{k}$

Passo 3: Seja TOL um parâmetro de convergência.

Se $\boldsymbol{x}^{k}$ satisfizer $\|g(\boldsymbol{x})\|<T O L \Rightarrow$ parar

Coso contrário, faça $\xi^{k+1}$ igual ao próxim o valor da seqüência e vá para

o Passo 2.
Algoritmo 3 - 11 - Algoritmo para o Método da Penalidade com Restrições de Igualdade

\section{A 3.12 - AlgoritMo PARA O MÉTOdo do LAgRANGiano A UMENTAdo COM RESTRIÇÕES DE IGUALDADE}

Passo 1: Estimar os valores de $\xi$ e $\lambda^{0}$ e faça $k=0$

Passo 2: Resolva o problema de minimização abaixo:

Minimizar $A(\boldsymbol{x}, \lambda, \xi)$

$\operatorname{Com} A\left(\boldsymbol{x}, \lambda^{\mathrm{k}}, \boldsymbol{\xi}\right)=f(\boldsymbol{x})+\sum_{i=1}^{m} \lambda_{i}^{k} \cdot g_{i}(\boldsymbol{x})+\frac{1}{2} \cdot \xi \cdot \sum_{i=1}^{m} g_{i}^{2}(\boldsymbol{x})$

obtendo como solução $\boldsymbol{x}^{k}$

Passo 3: Seja TOL um parâmetro de convergência.

Se $\left[\boldsymbol{x}^{k}, \lambda^{k}\right]$ satisfizer $\left\|\nabla A\left(\boldsymbol{x}^{k}, \lambda^{k}, \xi\right)\right\|<T O L \Rightarrow$ parar

Coso contrário, vá para o Passo 4.

Passo 4: A tualize : $\lambda^{k+1}=\lambda^{k}+\xi \cdot g(\boldsymbol{x})$

Passo 5: $k=k+1$, e vá ao Passo 2. 
Algumas observações sobre o Método da Penalidade:

1. A seqüência dos números $\xi^{k}$ pode ser arbitrária, ou seja, não necessariamente a apresentada juntamente com 0 algoritm 0 ;

2. Deve-se observar que ao serem somados números muito grandes em função de valores altos do parâmetro $\xi^{k}$, o sistema de equações resultantes pode tornar-se mal condicionado, ou mesmo perder informações importantes em função dos critérios da aritmética de ponto flutuante;

3. Nunca conseguiremos obter o resultado exato de um problema usando o método da Penalidade pois isto ocorreria quando $\xi^{k} \rightarrow \infty$ o que não é possível de ser feito computacionalmente.

\section{A 3.13 - Algoritmo Para o Método da Penalidade} COM RESTRIÇõeS DE DESIGUALDADE

Passo 1: Escolha uma seqüência $\left\{\xi^{k}\right\} \rightarrow \infty$ por exemplo $\left\{1,10,10^{2}, 10^{3}, 10^{4}, \ldots\right\}$

Passo 2: Resolva o problema de minimização abaixo:

$$
\begin{aligned}
& \text { Minimizar } P\left(\boldsymbol{x}, \boldsymbol{\xi}^{k}\right) \\
& P\left(\boldsymbol{x}, \boldsymbol{\xi}^{k}\right)=f(\boldsymbol{x})+\frac{1}{2} \cdot \xi^{k} \cdot \sum_{j=1}^{q}\left\langle g_{j}(\boldsymbol{x})\right\rangle^{2}
\end{aligned}
$$

obtendo como solução $\boldsymbol{x}^{k}$

Passo 3: Seja TOL um parâmetro de convergência.

Se $\boldsymbol{x}^{k}$ satisfizer $|g(\boldsymbol{x})|<T O L \Rightarrow$ parar

Coso contrário, faça $\xi^{k+1}$ igual ao próximo valor da seqüência e vá para

o Passo 2.

Algoritmo 3 - 13 - Algoritmo para o Método da Penalidade com Restrições de Desigualdade 


\section{A 3.14 - ALgORITMO PARA 0 MÉTODO DO LAGRANGIANO AUMENTADO COM RESTRIÇÕES DE DESIGUALDADE}

Passo 1: Estimar os valores de $\xi$ e $\lambda^{0}$ e faça $k=0$

Passo 2: Resolva o problema de minimização abaixo:

$$
\begin{aligned}
& \text { Minimizar } A\left(\boldsymbol{x}, \lambda^{\mathrm{k}}, \xi\right) \\
& \text { Com } A\left(\boldsymbol{x}, \lambda^{\mathrm{k}}, \boldsymbol{\xi}\right)=f(\boldsymbol{x})+\sum_{j=1}^{q} \lambda_{j}{ }^{k} \cdot\left\langle g_{j}(\boldsymbol{x})\right\rangle+\sum_{j=1}^{q} \frac{1}{2} \cdot \xi \cdot\left\langle g_{j}(\boldsymbol{x})\right\rangle^{2} \\
& \text { obtendo como solução } \boldsymbol{x}^{k}
\end{aligned}
$$

Passo 3: Seja TOL um parâmetro de convergência.

$$
\text { Se }\left[\boldsymbol{x}^{k}, \lambda^{k}\right] \text { satisfizer }\left\|\nabla A\left(\boldsymbol{x}^{k}, \lambda^{k}, \boldsymbol{\xi}\right)\right\|<T O L \Rightarrow \text { parar }
$$

Caso contrário, vá para o Passo 4.

Passo 4: A tualize $\lambda^{k+1}=\left\langle\lambda^{k}+\xi \cdot g(\boldsymbol{x})\right\rangle$

Passo 5: $k=k+1$, e vá ao Passo 2.

Algoritmo 3 - 14 - Algoritmo para o Método do Lagrangiano Aumentado com Restrições de Desigualdade

\section{A 3.15 - Algoritmo Para o Método da Penalidade COM RESTRIÇÕES MISTAS}

Passo 1: Escolha uma seqüência $\left\{\xi^{k}\right\} \rightarrow \infty$ por exemplo $\left\{1,10,10^{2}, 10^{3}, 10^{4}, \ldots\right\}$

Passo 2: Resolva o problema de minimização abaixo:

Minimizar $P\left(x, \xi^{k}\right)$

$$
P\left(x, \xi^{k}\right)=f(x)+\frac{1}{2} \cdot \xi^{k} \cdot \sum_{i=1}^{m}\left(g_{i}(x)\right)^{2}+\frac{1}{2} \cdot \xi^{k} \cdot \sum_{j=1}^{q}\left\langle g_{j}(x)\right\rangle^{2}
$$

obtendo como solução $\boldsymbol{x}^{k}$

Passo 3: Seja TOL um parâmetro de convergência.

$$
\text { Se } \boldsymbol{x}^{k} \text { satisfizer }|g(\boldsymbol{x})|<T O L \Rightarrow \text { parar }
$$

Coso contrário, faça $\xi^{k+1}$ igual ao próxim o valor da seqüência e vá para

o Passo 2.

\section{Algoritmo 3 - 15 - Algoritmo para o Método da Penalidade com Restrições Mistas}




\section{A 3.16 - M INIM IZAÇÃo PELO MÉTOdO DE NEWTON}

Passo 1: Incremente 0 contador da iteração; $i=i+1$

a) Calcule 0 valor da função $\nabla A\left(\boldsymbol{x}^{i}, \lambda^{k}, \xi\right)$ e da Hessiana $\nabla^{2} A\left(\boldsymbol{x}^{i}, \lambda^{k}, \xi\right)$

b) Calcule a direção inicial $\boldsymbol{d}^{i}$ resolvendo o sistema de equações lineares:

$$
\left[\nabla^{2} A\left(\boldsymbol{x}^{i}, \lambda^{k}, \xi\right)\right]^{T} \cdot \boldsymbol{d}^{i}=\nabla A\left(\boldsymbol{x}^{i}, \lambda^{k}, \xi\right)
$$

c) A tualize $G_{c}=\boldsymbol{d}^{i} \cdot \nabla A\left(\boldsymbol{x}^{i}, \lambda^{k}, \xi\right)$

d) Faça $j=0$ e vá para o Passo 2 do Algoritmo $3-17$

Algoritmo 3 - 16 - Algoritmo para o Minimização pelo Método de Newton

\section{A 3.17 - AlgoritMo Para o MÉtodo do Lagrangiano A UMENTAdo COM RESTRIÇÕES MISTAS}

Passo 1: (Processo de inicialização das iterações)

a) Estimar os valores de $\xi, \lambda^{0}$ e $\boldsymbol{x}^{0}$

b) Calcule 0 valor da função $\nabla A\left(\boldsymbol{x}^{0}, \boldsymbol{\lambda}^{0}, \boldsymbol{\xi}\right)$ e da Hessiana $\nabla^{2} A\left(\boldsymbol{x}^{0}, \lambda^{0}, \xi\right)$

c) Calcule a direção inicial $\boldsymbol{d}^{0}$ resolvendo a equação linear:

$$
\left[\nabla^{2} A\left(\boldsymbol{x}^{0}, \lambda^{0}, \xi\right)\right]^{T} \cdot \boldsymbol{d}^{0}=\nabla A\left(\boldsymbol{x}^{0}, \lambda^{0}, \xi\right)
$$

d) Inicie $G_{c}=\boldsymbol{d}^{0} \cdot \nabla A\left(\boldsymbol{x}^{0}, \boldsymbol{\lambda}^{0}, \boldsymbol{\xi}\right)$ e faça $G I=G_{c}$

e) Inicie o contador $j$ das iterações do BFGS, o contador $i$ do Método de New ton e o contador $k$ do Lagrangiano:

$$
i=0 ; j=0 ; k=0
$$

Passo 2: Itere em i até atingir a solução:

a) Busca unidimensional

i) Inicialmente faça $\rightarrow s^{i}=1$

ii) Calcular $\rightarrow \quad G\left(s^{i}\right)=\boldsymbol{d}^{i} \cdot \nabla A\left(\boldsymbol{x}^{i}-s^{i} \cdot \boldsymbol{d}^{i}, \lambda^{k}, \xi\right)$

iii) Estimar um valor STOL (tolerância) 


$$
\begin{aligned}
& \text { Se }\left[\left|G\left(s^{i}\right)\right|>S T O L \cdot\left|G_{c}\right| \text { ou } G\left(s^{i}\right) \cdot G_{c}<0\right] \text {, então, itere } \\
& \text { para } s^{i} \in(0,1] \text { até }\left|G\left(s^{i}\right)\right| \leq S T O L \cdot\left|G_{c}\right|
\end{aligned}
$$

b) Teste a divergência:

Se $\left\|\nabla A\left(x^{i+1}, \lambda^{k}, \xi\right)\right\|>\nabla A\left(x^{i}, \lambda^{k}, \xi\right) \|$, então vá para o Algoritmo 3 - 16

c) Teste a solução do problema:

Se $G_{c} \leq E T O L \cdot G I$, então vá para o Passo 3, solução satisfeita

d) Analise o passo da busca:

Se $s^{i}<0,001$, então vá para 0 Algoritmo $3-16$

e) Teste o limite de iterações do BFGS:

Se $j=\max _{B F G S}$ então vá para o Algoritmo 3 - 16

f) Vá para o Algoritmo $3-18$

Passo 3: A tualização dos multiplicadores de Lagrange:

a) Calcule os novos multiplicadores $\boldsymbol{\lambda}_{t r}$ : para todas as restrições

$$
\begin{aligned}
& \lambda^{k+1}=\lambda^{k}+\xi \cdot g(\boldsymbol{x}) \rightarrow \text { Para restrições de igualdade } \\
& \lambda^{k+1}=\left\langle\lambda^{k}+\xi \cdot g(\boldsymbol{x})\right\rangle \rightarrow \text { Para restrições de desigualdade }
\end{aligned}
$$

b) Teste a Convergência dos Multiplicadores:

$$
\frac{\left\|\lambda^{k+1}-\lambda^{k}\right\|}{\left\|\lambda^{k}\right\|} \leq K T O L \Rightarrow \text { Parar com as iterações }
$$

c) A tualize os Multiplicadores:

$$
\begin{aligned}
& \text { i. } \lambda^{k+1}=\lambda_{\mathrm{tr}} \\
& \text { ii. } k=k+1
\end{aligned}
$$

d) Reinicialize com os novos Multiplicadores:

i. Calcule o novo Resíduo: $\nabla A\left(\boldsymbol{x}^{i}, \lambda^{\mathrm{k}}, \boldsymbol{\xi}\right)$

ii. Calcule a direção inicial resolvendo 0 sistema de equações




$$
\text { lineares: }\left[\nabla^{2} A\left(\boldsymbol{x}^{i}, \lambda^{\mathrm{k}}, \xi\right)\right]^{T} \cdot \boldsymbol{d}^{i}=\nabla A\left(\boldsymbol{x}^{i}, \lambda^{\mathrm{k}}, \xi\right)
$$

iii. A tualize: $G_{c}=\boldsymbol{d}^{i} \cdot \nabla A\left(\boldsymbol{x}^{i}, \lambda^{\mathrm{k}}, \boldsymbol{\xi}\right)$

e) Repetir até atingir a solução: vá ao Passo 2

\section{Algoritmo 3 - 17 - Algoritmo para o Método do Lagrangiano Aumentado com Restrições Mistas}

\section{A 3.18 - M INIM IZAÇÃo PELO M ÉTOdO DO BFGS}

Passo 1: Incremente as iterações: $i=i+1 ; j=j+1$

Passo 2: (Fórmula do Produto do BFGS) - Calcule os vetores $\boldsymbol{v}^{i}$ e $\boldsymbol{\omega}^{i}$, onde:

i. $\quad \boldsymbol{v}^{i}=\frac{\boldsymbol{d}^{i-1}}{\boldsymbol{d}^{i-1} \cdot\left(\nabla f\left(\boldsymbol{x}^{i}\right)-\nabla f\left(\boldsymbol{x}^{i-1}\right)\right)}$

ii. $\alpha^{j}=\sqrt{\frac{-s^{i-1} \cdot\left(\nabla f\left(\boldsymbol{x}^{i}\right)-\nabla f\left(\boldsymbol{x}^{i-1}\right)\right) \cdot \boldsymbol{d}^{i-1}}{\nabla f\left(\boldsymbol{x}^{i-1}\right) \cdot \boldsymbol{d}^{i-1}}}$

iii. $\boldsymbol{\omega}^{i}=-\left(\nabla f\left(\boldsymbol{x}^{i}\right)-\nabla f\left(\boldsymbol{x}^{i-1}\right)\right)+\alpha^{j} \cdot \nabla f\left(\boldsymbol{x}^{i-1}\right)$

iv. $\boldsymbol{B}^{j}=\left(\boldsymbol{I}+\boldsymbol{v}^{i} \cdot \boldsymbol{\omega}^{i}\right) \cdot \boldsymbol{B}^{j-1} \cdot\left(\boldsymbol{I}+\boldsymbol{\omega}^{i} \cdot \boldsymbol{v}^{i^{T}}\right)$

Passo 3: Calcule $\boldsymbol{d}^{i}$ resolvendo o sistema $\boldsymbol{d}^{i}=\boldsymbol{B}^{j} \cdot \nabla A\left(\boldsymbol{x}^{i}, \lambda^{k}, \xi\right)$ via Algoritmo 3 5

Passo 4: A tualize $G_{c}=\boldsymbol{d}^{i} \cdot \nabla A\left(\boldsymbol{x}^{i}, \lambda^{k}, \xi\right)$

Passo 5: Vá para o Passo 2 do Algoritmo 3 - 17

Algoritmo 3 - 18 - Algoritmo para Minimização pelo Método BFGS 


\section{ANEXO B}

Abaixo está apresentada a sequiência de comandos que compõem o arquivo de entrada do programa OTIMPORCA.

1. Nome para Estrutura

[Nome]

2. Parâmetro de Controle

[No Nós] [No Elementos] [Cond. Contorno] [Nº Mat.] [N Séc.] [Código]

Obs.: O código neste caso é [3] para utilização do módulo de pórtico plano

3. Coordenadas dos Nós da Estrutura (m)

Para cada Nó acrescentar uma linha com as seguintes informações:

[No Nos] [Coord. X] [Coord. Y]

4. Conectividade e Materiais

Para cada Elemento acrescentar uma linha contendo as informações:

[No Elem.] [No Nó Inic.] [ $\mathrm{N}^{\mathrm{o}}$ Nó Fin.] [No Mat.] [N Sec.] [Código]

Obs.: O código neste caso é [1] para vigas e [2] para pilares

5. Materiais

Para cada Material acrescentar uma linha contendo as informações:

[ $\mathrm{N}^{\mathrm{o}}$ Material] [Mod. Elast. Longit.] [Mod. Elast. Tansv.]

6. Definição das Seções

Para cada Seção acrescentar uma linha com as seguintes informações:

[No Seção] [Base] [Código] - OTIMPORCA 1

ou

[Nº Seção] [Base] [Altura] [Código] - OTIMPORCA 2

Obs.: O código neste caso é [1] para vigas e [2] para pilares;

7. Definição das Restrições

Para cada Restrição acrescentar uma linha contendo as informações:

[No Nó.] [Código.] [Desl. X.] [Desl. Y.] [Desl. Z.]

Obs.: O código neste é representado por um conjunto de 6 números que podem ser [0] ou [1] em função dos 6 graus de liberdade do nó em questão serem livres ou restritos respectivamente.

8. Número de Casos de Carregamento

[ $\mathrm{N}^{\circ}$ Carregamentos] 
Para cada caso de carregamento entre com:

a. Nome do Caso de Carregamento

[Nome Caso]

b. Cargas Concentradas (tf)

Para cada Carga Concentrada a mais acrescentar uma linha contendo:

[No Nó.] [Força X] [Força Y]

Para concluir colocar uma linha com zeros

c. Cargas Distribuídas (tf/m)

Para cada Carga Distribuída a mais acrescentar uma linha contendo:

[No Elemento.] [Força X] [Força Y]

Para concluir colocar uma linha com zeros

9. Número de Indivíduos da População por Geração

[No Indivíduos]

10. Número Máximo de Gerações

[Maxgen]

11. Probabilidade Inicial de Cruzamento

[Pcros inicial]

12. Probabilidade Final de Cruzamento

[Pcros fianl]

13. Probabilidade Inicial de Mutação

[Pmut inicial]

14. Probabilidade Final de Mutação

[Pmut final]

15. Fck das Vigas (MPa)

[Fck Vigas]

16. Fck dos Pilares (MPa)

[Fck Pilares]

17. Fyk das Vigas (MPa)

[Fyk Vigas]

18. Fyk dos Pilares (MPa)

[Fyk Pilares]

19. Cobrimento da Armadura nas Vigas (cm)

[Cob. Vigas]

20. Cobrimento da Armadura nos Pilares $(\mathrm{cm})$

[Cob. Pilares] 
21. Altura Mínima da Seção para as Vigas (cm)

[Hmin Vigas]

22. Altura Mínima da Seção para Pilares (cm) [Hmin Pilares]

23. Passo de $\mathrm{H}$ [altura da seção] para Vigas (cm) [Passo H_V]

24. Passo de H [altura da seção] para os Pilares $(\mathrm{cm})$ [Passo H_P]

25. Número de faixas para integração de tensões nas seções das vigas [ $\mathrm{N}^{\mathrm{o}}$ faixas Vigas]

26. Número de faixas para integração de tensões nas seções dos pilares [ $\mathrm{N}^{\circ}$ faixas Pilares]

27. Preço do Concreto por metro cúbico para Vigas $\left(\mathrm{R} \$ / \mathrm{m}^{3}\right)$ [Custo Concreto Vigas]

28. Preço do Concreto por metro cúbico para Pilares $\left(\mathrm{R} \$ / \mathrm{m}^{3}\right)$ [Custo Concreto Pilares]

29. Preço da Forma por metro quadrado para Vigas $\left(\mathrm{R} \$ / \mathrm{m}^{2}\right)$ [Custo Forma Vigas]

30. Preço da Forma por metro quadrado para Pilares $\left(\mathrm{R} \$ / \mathrm{m}^{2}\right)$ [Custo Forma Pilares]

31. Preço do Aço $(\mathrm{R} \$ / \mathrm{Kg})$

[Custo Aço]

Abaixo é mostrado um arquivo de entrada do OTIMPORCA. Os dados estão dispostos em duas colunas apenas para impressão do arquivo.

\section{ARQUIVO DE ENTRADA}

\begin{tabular}{|c|c|c|}
\hline \multicolumn{3}{|c|}{ ** PORTICO ** } \\
\hline 47 & 50 & $\begin{array}{lll}1 & 12 & 3\end{array}$ \\
\hline 01 & 0.00 & 0.00 \\
\hline 02 & 4.50 & 0.00 \\
\hline 03 & 0.00 & 3.00 \\
\hline 04 & 0.75 & 3.00 \\
\hline 05 & 1.50 & 3.00 \\
\hline 06 & 2.25 & 3.00 \\
\hline 07 & 3.00 & 3.00 \\
\hline 08 & 3.75 & 3.00 \\
\hline 09 & 4.50 & 3.00 \\
\hline
\end{tabular}

$10 \quad 5.00 \quad 3.00$

115.503 .00

$\begin{array}{lll}12 & 0.00 & 6.00\end{array}$

$\begin{array}{lll}13 & 0.75 & 6.00\end{array}$

$\begin{array}{lll}14 & 1.50 & 6.00\end{array}$

$\begin{array}{lll}15 & 2.25 & 6.00\end{array}$

$\begin{array}{lll}16 & 3.00 & 6.00\end{array}$

$\begin{array}{lll}17 & 3.75 & 6.00\end{array}$

$\begin{array}{lll}18 & 4.50 & 6.00\end{array}$

$\begin{array}{lll}19 & 5.00 \quad 6.00\end{array}$

$20 \quad 5.50 \quad 6.00$ 


\begin{tabular}{|c|c|c|c|c|c|c|c|c|}
\hline 21 & \multicolumn{3}{|c|}{$0.00 \quad 9.00$} & 2417 & 18 & 11 & 11 & 1 \\
\hline 22 & \multicolumn{3}{|c|}{0.759 .00} & 2518 & 19 & 11 & 11 & 1 \\
\hline 23 & \multicolumn{3}{|c|}{$1.50 \quad 9.00$} & 2619 & 20 & 1 & 11 & 1 \\
\hline 24 & \multicolumn{3}{|c|}{2.259 .00} & 2721 & 22 & 11 & 11 & 1 \\
\hline 25 & \multicolumn{3}{|c|}{3.009 .00} & 2822 & 23 & 11 & 11 & 1 \\
\hline 26 & \multicolumn{3}{|c|}{3.759 .00} & 2923 & 24 & 11 & 11 & 1 \\
\hline 27 & \multicolumn{3}{|c|}{$4.50 \quad 9.00$} & 3024 & 25 & 11 & 11 & 1 \\
\hline 28 & \multicolumn{3}{|c|}{$5.00 \quad 9.00$} & 3125 & 26 & 11 & 11 & 1 \\
\hline 29 & \multicolumn{3}{|c|}{$5.50 \quad 9.00$} & 3226 & 27 & 11 & 11 & 1 \\
\hline 30 & \multicolumn{3}{|c|}{0.0012 .00} & 3327 & 28 & 11 & 11 & 1 \\
\hline 31 & \multicolumn{3}{|c|}{0.7512 .00} & 3428 & 29 & 11 & 11 & 1 \\
\hline 32 & \multicolumn{3}{|c|}{1.5012 .00} & 3530 & 31 & 11 & 11 & 1 \\
\hline 33 & \multicolumn{3}{|c|}{2.2512 .00} & 3631 & 32 & 1 & 11 & 1 \\
\hline 34 & \multicolumn{3}{|c|}{3.0012 .00} & 3732 & 33 & 11 & 11 & 1 \\
\hline 35 & \multicolumn{3}{|c|}{3.7512 .00} & 3833 & 34 & 11 & 11 & 1 \\
\hline 36 & \multicolumn{3}{|c|}{4.5012 .00} & 3934 & 35 & 11 & 11 & 1 \\
\hline 37 & \multicolumn{3}{|c|}{$5.00 \quad 12.00$} & 4035 & 36 & 11 & 11 & 1 \\
\hline 38 & \multicolumn{3}{|c|}{5.5012 . } & 4136 & 37 & 11 & 11 & 1 \\
\hline 39 & \multicolumn{3}{|c|}{0.0015 .00} & 4237 & 38 & 11 & 11 & 1 \\
\hline 40 & \multicolumn{3}{|c|}{0.7515 .00} & 4339 & 40 & 11 & 12 & 1 \\
\hline 41 & 1.50 & 15.00 & & 4440 & 41 & 1 & 12 & 1 \\
\hline 42 & 2.25 & 15.00 & & 4541 & 42 & 1 & 12 & 1 \\
\hline 43 & 3.00 & 15.00 & & 4642 & 43 & 11 & 12 & 1 \\
\hline 44 & 3.75 & 15.00 & & 4743 & 44 & 11 & 12 & 1 \\
\hline 45 & 4.50 & 15.00 & & 4844 & 45 & 1 & 12 & 1 \\
\hline 46 & 5.00 & 15.00 & & 4945 & 46 & 11 & 12 & 1 \\
\hline 47 & 5.50 & 15.00 & & 5046 & 47 & 1 & 12 & 1 \\
\hline 01 & 010 & $\begin{array}{lll}3 & 1 & 01\end{array}$ & 2 & 12.10 & $E+6$ & & $00 \mathrm{E}$ & +5 \\
\hline 02 & 0312 & 2103 & 2 & 120.0 & 2 & & & \\
\hline 03 & 122 & 1105 & 2 & 220.0 & 2 & & & \\
\hline 04 & 2130 & $\begin{array}{lll}0 & 1 & 07\end{array}$ & 2 & 320.0 & 2 & & & \\
\hline 05 & 303 & $\begin{array}{lll}9 & 1 & 09\end{array}$ & 2 & 420.0 & 2 & & & \\
\hline 06 & 02 & $\begin{array}{lll}9 & 1 & 02\end{array}$ & 2 & 520.0 & 2 & & & \\
\hline 07 & $091 \varepsilon$ & $\begin{array}{lll}8 & 1 & 04\end{array}$ & 2 & 620.0 & 2 & & & \\
\hline 08 & 1827 & $\begin{array}{lll}7 & 1 & 06\end{array}$ & 2 & 720.0 & 2 & & & \\
\hline 09 & 2736 & $\begin{array}{lll}6 & 1 & 08\end{array}$ & 2 & 820.0 & 2 & & & \\
\hline 10 & $36 \quad 45$ & $\begin{array}{lll}5 & 1 & 10\end{array}$ & 2 & 920.0 & 2 & & & \\
\hline 11 & 0304 & $\begin{array}{lll}4 & 1 & 11\end{array}$ & 1 & 1020 & 02 & & & \\
\hline 12 & 0405 & $\begin{array}{lll}5 & 1 & 11\end{array}$ & 1 & 1115 & 01 & & & \\
\hline 13 & 0506 & $\begin{array}{lll}6 & 1 & 11\end{array}$ & 1 & 1215 & 01 & & & \\
\hline 14 & $06 \quad 07$ & $\begin{array}{lll}7 & 1 & 11\end{array}$ & 1 & 11111 & 111 & $0.0 \mathrm{C}$ & 0.0 & 0.0 \\
\hline 15 & 0708 & $\begin{array}{lll}8 & 1 & 11\end{array}$ & 1 & 21111 & 111 & $0.0 c$ & 0.0 & 0.0 \\
\hline 16 & 0809 & $\begin{array}{lll}9 & 1 & 11\end{array}$ & 1 & 01 & & & & \\
\hline 17 & 0910 & $\begin{array}{lll}0 & 1 & 11\end{array}$ & 1 & SOBRE & EC_I & VEN & ITO & \\
\hline 18 & 1011 & $\begin{array}{lll}1 & 1 & 11\end{array}$ & 1 & 030.5 & $0 \overline{0}$ & .00 & 0.00 & \\
\hline 19 & 1213 & $\begin{array}{lll}3 & 1 & 11\end{array}$ & 1 & 120.5 & 00 & .00 & 0.00 & \\
\hline 20 & 1314 & $\begin{array}{lll}4 & 1 & 11\end{array}$ & 1 & 210.7 & 50. & .00 & 0.00 & \\
\hline 21 & 1415 & $\begin{array}{lll}5 & 1 & 11\end{array}$ & 1 & $\begin{array}{ll}30 & 0.7\end{array}$ & 50. & .00 & 0.00 & \\
\hline 22 & 1516 & $\begin{array}{lll}6 & 1 & 11\end{array}$ & 1 & 391.0 & 00. & .00 & 0.00 & \\
\hline 23 & 1617 & $\begin{array}{lll}7 & 1 & 11\end{array}$ & 1 & 050.0 & $0-1$ & .00 & 0.00 & \\
\hline
\end{tabular}




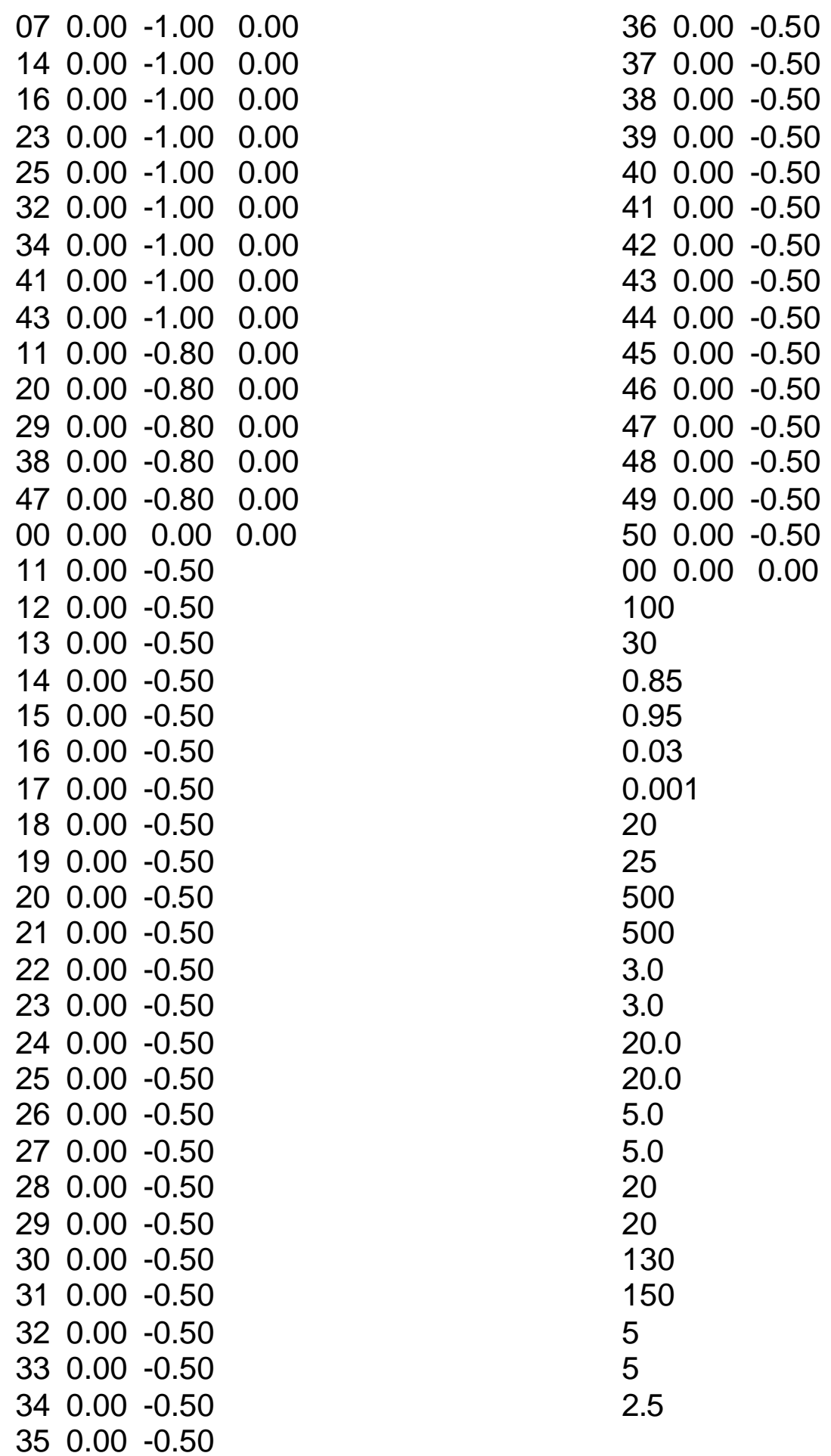

Arquivo de saída com os resultados obtidos pelo OTIMPORCA. Neste arquivo estão apenas as características do melhor indivíduo da população. Outros arquivos são gerados com os dados de todos os indivíduos de todas as gerações. 


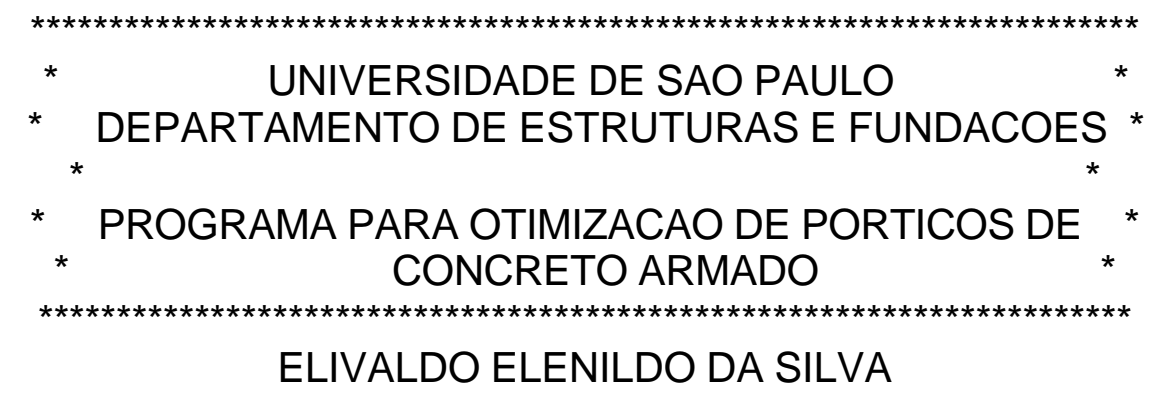

*** DADOS GEOMETRICOS DO PORTICO DE CONCRETO

PORTICO

Numero de pontos nodais : $\quad 47$

Numero de elementos: $\quad 50$

Numero de condições de contorno : 2

Numero de tipos de material : $\quad 1$

Numero de tipos de seção : $\quad 12$

Numero do tipo de elemento : $\quad 3$

Coordenadas de pontos nodais :

No Cord. X Cord.Y

$\begin{array}{lll}01 & 0.00 & 0.00 \\ 02 & 4.50 & 0.00 \\ 03 & 0.00 & 3.00 \\ 04 & 0.75 & 3.00 \\ 05 & 1.50 & 3.00 \\ 06 & 2.25 & 3.00 \\ 07 & 3.00 & 3.00 \\ 08 & 3.75 & 3.00 \\ 09 & 4.50 & 3.00 \\ 10 & 5.00 & 3.00 \\ 11 & 5.50 & 3.00 \\ 12 & 0.00 & 6.00 \\ 13 & 0.75 & 6.00 \\ 14 & 1.50 & 6.00 \\ 15 & 2.25 & 6.00 \\ 16 & 3.00 & 6.00 \\ 17 & 3.75 & 6.00 \\ 18 & 4.50 & 6.00 \\ 19 & 5.00 & 6.00 \\ 20 & 5.50 & 6.00 \\ 21 & 0.00 & 9.00 \\ 22 & 0.75 & 9.00 \\ 23 & 1.50 & 9.00 \\ 24 & 2.25 & 9.00\end{array}$




$\begin{array}{lll}25 & 3.00 & 9.00 \\ 26 & 3.75 & 9.00 \\ 27 & 4.50 & 9.00 \\ 28 & 5.00 & 9.00 \\ 29 & 5.50 & 9.00 \\ 30 & 0.00 & 12.00 \\ 31 & 0.75 & 12.00 \\ 32 & 1.50 & 12.00 \\ 33 & 2.25 & 12.00 \\ 34 & 3.00 & 12.00 \\ 35 & 3.75 & 12.00 \\ 36 & 4.50 & 12.00 \\ 37 & 5.00 & 12.00 \\ 38 & 5.50 & 12.00 \\ 39 & 0.00 & 15.00 \\ 40 & 0.75 & 15.00 \\ 41 & 1.50 & 15.00 \\ 42 & 2.25 & 15.00 \\ 43 & 3.00 & 15.00 \\ 44 & 3.75 & 15.00 \\ 45 & 4.50 & 15.00 \\ 46 & 5.00 & 15.00 \\ 47 & 5.50 & 15.00\end{array}$

Caracterização dos Elementos :

Elemento No inicial No final Material Seção Viga ou Pilar

$\begin{array}{rrrrrr}01 & 1 & 3 & 1 & 3 & 2 \\ 02 & 3 & 12 & 1 & 5 & 2 \\ 03 & 12 & 21 & 1 & 7 & 2 \\ 04 & 21 & 30 & 1 & 9 & 2 \\ 05 & 30 & 39 & 1 & 11 & 2 \\ 06 & 2 & 9 & 1 & 4 & 2 \\ 07 & 9 & 18 & 1 & 6 & 2 \\ 08 & 18 & 27 & 1 & 8 & 2 \\ 09 & 27 & 36 & 1 & 10 & 2 \\ 10 & 36 & 45 & 1 & 12 & 2 \\ 11 & 3 & 4 & 1 & 1 & 1 \\ 12 & 4 & 5 & 1 & 1 & 1 \\ 13 & 5 & 6 & 1 & 1 & 1 \\ 14 & 6 & 7 & 1 & 1 & 1 \\ 15 & 7 & 8 & 1 & 1 & 1 \\ 16 & 8 & 9 & 1 & 1 & 1 \\ 17 & 9 & 10 & 1 & 1 & 1 \\ 18 & 10 & 11 & 1 & 1 & 1 \\ 19 & 12 & 13 & 1 & 1 & 1 \\ 20 & 13 & 14 & 1 & 1 & 1 \\ 21 & 14 & 15 & 1 & 1 & 1 \\ 22 & 15 & 16 & 1 & 1 & 1\end{array}$




$\begin{array}{llllll}23 & 16 & 17 & 1 & 1 & 1 \\ 24 & 17 & 18 & 1 & 1 & 1 \\ 25 & 18 & 19 & 1 & 1 & 1 \\ 26 & 19 & 20 & 1 & 1 & 1 \\ 27 & 21 & 22 & 1 & 1 & 1 \\ 28 & 22 & 23 & 1 & 1 & 1 \\ 29 & 23 & 24 & 1 & 1 & 1 \\ 30 & 24 & 25 & 1 & 1 & 1 \\ 31 & 25 & 26 & 1 & 1 & 1 \\ 32 & 26 & 27 & 1 & 1 & 1 \\ 33 & 27 & 28 & 1 & 1 & 1 \\ 34 & 28 & 29 & 1 & 1 & 1 \\ 35 & 30 & 31 & 1 & 1 & 1 \\ 36 & 31 & 32 & 1 & 1 & 1 \\ 37 & 32 & 33 & 1 & 1 & 1 \\ 38 & 33 & 34 & 1 & 1 & 1 \\ 39 & 34 & 35 & 1 & 1 & 1 \\ 40 & 35 & 36 & 1 & 1 & 1 \\ 41 & 36 & 37 & 1 & 1 & 1 \\ 42 & 37 & 38 & 1 & 1 & 1 \\ 43 & 39 & 40 & 1 & 2 & 1 \\ 44 & 40 & 41 & 1 & 2 & 1 \\ 45 & 41 & 42 & 1 & 2 & 1 \\ 46 & 42 & 43 & 1 & 2 & 1 \\ 47 & 43 & 44 & 1 & 2 & 1 \\ 48 & 44 & 45 & 1 & 2 & 1 \\ 49 & 45 & 46 & 1 & 2 & 1 \\ 50 & 46 & 47 & 1 & 2 & 1\end{array}$

Propriedades de Material :

Material Mod.Elast.Long. Mod.Elast.Transv.

$12100000 . \quad 840000$.

Seção Base [cm] Altura [cm] Viga[1] ou Pilar[2]

$\begin{array}{cccc}1 & 15 . & 40 . & 1 \\ 2 & 15 . & 40 . & 1 \\ 3 & 20 . & 30 . & 2 \\ 4 & 20 . & 30 . & 2 \\ 5 & 20 . & 30 . & 2 \\ 6 & 20 . & 30 . & 2 \\ 7 & 20 . & 30 . & 2 \\ 8 & 20 . & 30 . & 2 \\ 9 & 20 . & 30 . & 2 \\ 10 & 20 . & 30 . & 2 \\ 11 & 20 . & 30 . & 2 \\ 12 & 20 . & 30 . & 2\end{array}$


Condições de apoio :

$\begin{array}{llll}\text { No Restring. Codigo Desl. X Desl. Y Rot. Z } & \end{array}$

$\begin{array}{ccccc}1 & 111111 & 0.000 \mathrm{E}+00 & 0.000 \mathrm{E}+00 & 0.000 \mathrm{E}+00 \\ 2 & 111111 & 0.000 \mathrm{E}+00 & 0.000 \mathrm{E}+00 & 0.000 \mathrm{E}+00\end{array}$

Desl.X,Y, e Z são deslocamentos prescritos ou apoios elásticos Numero de Casos de Carregamento : 1

Dados do Carregamento : 1

Carga Concentradas

SOBR

No Forca X Forca Y Momento Z

$\begin{array}{llll}03 & 0.500 & 0.000 & 0.000 \\ 12 & 0.500 & 0.000 & 0.000 \\ 21 & 0.750 & 0.000 & 0.000 \\ 30 & 0.750 & 0.000 & 0.000 \\ 39 & 1.000 & 0.000 & 0.000 \\ 05 & 0.000 & -1.000 & 0.000 \\ 07 & 0.000 & -1.000 & 0.000 \\ 14 & 0.000 & -1.000 & 0.000 \\ 16 & 0.000 & -1.000 & 0.000 \\ 23 & 0.000 & -1.000 & 0.000 \\ 25 & 0.000 & -1.000 & 0.000 \\ 32 & 0.000 & -1.000 & 0.000 \\ 34 & 0.000 & -1.000 & 0.000 \\ 41 & 0.000 & -1.000 & 0.000 \\ 43 & 0.000 & -1.000 & 0.000 \\ 11 & 0.000 & -0.800 & 0.000 \\ 20 & 0.000 & -0.800 & 0.000 \\ 29 & 0.000 & -0.800 & 0.000 \\ 38 & 0.000 & -0.800 & 0.000 \\ 47 & 0.000 & -0.800 & 0.000\end{array}$

Carga Distribuidas

Elemento Q Distr X Q Distr Y

$\begin{array}{lll}11 & 0.000 & -0.500 \\ 12 & 0.000 & -0.500 \\ 13 & 0.000 & -0.500 \\ 14 & 0.000 & -0.500 \\ 15 & 0.000 & -0.500 \\ 16 & 0.000 & -0.500\end{array}$




$\begin{array}{lll}17 & 0.000 & -0.500 \\ 18 & 0.000 & -0.500 \\ 19 & 0.000 & -0.500 \\ 20 & 0.000 & -0.500 \\ 21 & 0.000 & -0.500 \\ 22 & 0.000 & -0.500 \\ 23 & 0.000 & -0.500 \\ 24 & 0.000 & -0.500 \\ 25 & 0.000 & -0.500 \\ 26 & 0.000 & -0.500 \\ 27 & 0.000 & -0.500 \\ 28 & 0.000 & -0.500 \\ 29 & 0.000 & -0.500 \\ 30 & 0.000 & -0.500 \\ 31 & 0.000 & -0.500 \\ 32 & 0.000 & -0.500 \\ 33 & 0.000 & -0.500 \\ 34 & 0.000 & -0.500 \\ 35 & 0.000 & -0.500 \\ 36 & 0.000 & -0.500 \\ 37 & 0.000 & -0.500 \\ 38 & 0.000 & -0.500 \\ 39 & 0.000 & -0.500 \\ 40 & 0.000 & -0.500 \\ 41 & 0.000 & -0.500 \\ 42 & 0.000 & -0.500 \\ 43 & 0.000 & -0.500 \\ 44 & 0.000 & -0.500 \\ 45 & 0.000 & -0.500 \\ 46 & 0.000 & -0.500 \\ 47 & 0.000 & -0.500 \\ 48 & 0.000 & -0.500 \\ 49 & 0.000 & -0.500 \\ 50 & 0.000 & -0.500\end{array}$

*** DADOS DE CALIBRACAO DO ALGORITMO GENETICO ***

Tamanho da População =

Numero Maximo de Gerações =

Probabilidade de Cruzamentos Inicial[0.80] $=0.800$

Probabilidade de Cruzamentos Final $[1.00]=1.000$

Probabilidade de Mutação Inicial $[0.05]=0.050$

Probabilidade de Mutação Final $[0.01]=0.010$

Fck das Vigas $[\mathrm{MPa}]=20.0$ 
Fck dos Pilares $[\mathrm{MPa}]=25.0$

Fyk das Vigas $[\mathrm{MPa}]=500.0$

Fyk Dos Pilares $[\mathrm{MPa}]=500.0$

Cobrimento para Vigas $[\mathrm{cm}]=3.0$

Cobrimento para Pilares $[\mathrm{cm}]=3.0$

Altura Mínima das Vigas [cm]= 20.0

Altura Mínima dos Pilares [cm]= 20.0

Variação da Altura das Vigas [cm] $=5.0$

Variação da Altura dos Pilares $[\mathrm{cm}]=5.0$

Numero de Fatias para Integração das Vigas = 40

Numero de Fatias para Integração dos Pilares $=\quad 40$

${ }^{* * *}$ DADOS DE CUSTO DOS MATERIAIS DO PORTICO ***

Custo do Concreto das Vigas $[\mathrm{R} \$ / \mathrm{m} 3]=130.00$

Custo do Concreto dos Pilares $[R \$ / \mathrm{m} 3]=150.00$

Custo da Forma para Vigas $[R \$ / \mathrm{m} 2]=\quad 5.00$

Custo da Forma para pilares $[\mathrm{R} \$ / \mathrm{m} 2]=\quad 5.00$

Custo do Aço por Quilo $[\mathrm{R} \$ / \mathrm{kg}]=\quad 2.50$

Propriedades da Seção :

Seção Área Inércia Área cort.

$01 \quad 0.600 \mathrm{E}-01 \quad 0.800 \mathrm{E}-03 \quad 0.000 \mathrm{E}+00$

$02 \quad 0.600 \mathrm{E}-01 \quad 0.800 \mathrm{E}-03 \quad 0.000 \mathrm{E}+00$

$03 \quad 0.600 \mathrm{E}-01 \quad 0.450 \mathrm{E}-03 \quad 0.000 \mathrm{E}+00$

$04 \quad 0.600 \mathrm{E}-01 \quad 0.450 \mathrm{E}-03 \quad 0.000 \mathrm{E}+00$

$05 \quad 0.600 \mathrm{E}-01 \quad 0.450 \mathrm{E}-03 \quad 0.000 \mathrm{E}+00$

$06 \quad 0.600 \mathrm{E}-01 \quad 0.450 \mathrm{E}-03 \quad 0.000 \mathrm{E}+00$

$07 \quad 0.600 \mathrm{E}-01 \quad 0.450 \mathrm{E}-03 \quad 0.000 \mathrm{E}+00$

$08 \quad 0.600 \mathrm{E}-01 \quad 0.450 \mathrm{E}-03 \quad 0.000 \mathrm{E}+00$

$09 \quad 0.600 \mathrm{E}-01 \quad 0.450 \mathrm{E}-03 \quad 0.000 \mathrm{E}+00$

$10 \quad 0.600 \mathrm{E}-01 \quad 0.450 \mathrm{E}-03 \quad 0.000 \mathrm{E}+00$

$11 \quad 0.600 \mathrm{E}-01 \quad 0.450 \mathrm{E}-03 \quad 0.000 \mathrm{E}+00$

$12 \quad 0.600 \mathrm{E}-01 \quad 0.450 \mathrm{E}-03 \quad 0.000 \mathrm{E}+00$

Resultados do Caso de Carregamento : 1

Deslocamentos nodais [m]:

$\begin{array}{lll}\text { No } & \text { Desl. X Desl. Y Rot. Z }\end{array}$

$01 \quad 0.4636 \mathrm{E}-15-0.2165 \mathrm{E}-14 \quad-0.9539 \mathrm{E}-15$ 
$02 \quad 0.6232 \mathrm{E}-15 \quad-0.9136 \mathrm{E}-14 \quad-0.1113 \mathrm{E}-14$

$03 \quad 0.7515 \mathrm{E}-02-0.1605 \mathrm{E}-03 \quad-0.2641 \mathrm{E}-02$

04 0.7515E-02 -0.1639E-02 -0.1294E-02

$05 \quad 0.7514 \mathrm{E}-02 \quad-0.2113 \mathrm{E}-02 \quad 0.9171 \mathrm{E}-05$

$06 \quad 0.7514 \mathrm{E}-02 \quad-0.1719 \mathrm{E}-02 \quad 0.9385 \mathrm{E}-03$

$07 \quad 0.7514 \mathrm{E}-02 \quad-0.8814 \mathrm{E}-03 \quad 0.1163 \mathrm{E}-02$

$08 \quad 0.7514 \mathrm{E}-02 \quad-0.2330 \mathrm{E}-03 \quad 0.3521 \mathrm{E}-03$

$09 \quad 0.7513 \mathrm{E}-02 \quad-0.6948 \mathrm{E}-03 \quad-0.1825 \mathrm{E}-02$

$10 \quad 0.7513 \mathrm{E}-02 \quad-0.1674 \mathrm{E}-02 \quad-0.2060 \mathrm{E}-02$

$11 \quad 0.7513 \mathrm{E}-02 \quad-0.2727 \mathrm{E}-02-0.2128 \mathrm{E}-02$

$12 \quad 0.1781 \mathrm{E}-01-0.3018 \mathrm{E}-03-0.2574 \mathrm{E}-02$

$13 \quad 0.1781 \mathrm{E}-01-0.1764 \mathrm{E}-02-0.1315 \mathrm{E}-02$

$14 \quad 0.1781 \mathrm{E}-01-0.2279 \mathrm{E}-02 \quad-0.7554 \mathrm{E}-04$

$15 \quad 0.1781 \mathrm{E}-01 \quad-0.1965 \mathrm{E}-02 \quad 0.8136 \mathrm{E}-03$

$16 \quad 0.1781 \mathrm{E}-01 \quad-0.1229 \mathrm{E}-02 \quad 0.1022 \mathrm{E}-02$

$17 \quad 0.1780 \mathrm{E}-01 \quad-0.6845 \mathrm{E}-03 \quad 0.2191 \mathrm{E}-03$

$18 \quad 0.1780 \mathrm{E}-01-0.1236 \mathrm{E}-02 \quad-0.1926 \mathrm{E}-02$

$19 \quad 0.1780 \mathrm{E}-01-0.2265 \mathrm{E}-02 \quad-0.2161 \mathrm{E}-02$

$20 \quad 0.1780 \mathrm{E}-01 \quad-0.3369 \mathrm{E}-02 \quad-0.2229 \mathrm{E}-02$

$21 \quad 0.2704 \mathrm{E}-01-0.4222 \mathrm{E}-03 \quad-0.2276 \mathrm{E}-02$

22 0.2704E-01 -0.1786E-02 -0.1330E-02

$23 \quad 0.2704 \mathrm{E}-01 \quad-0.2390 \mathrm{E}-02 \quad-0.2748 \mathrm{E}-03$

$24 \quad 0.2704 \mathrm{E}-01 \quad-0.2254 \mathrm{E}-02 \quad 0.5598 \mathrm{E}-03$

$25 \quad 0.2703 \mathrm{E}-01 \quad-0.1688 \mathrm{E}-02 \quad 0.8432 \mathrm{E}-03$

$26 \quad 0.2703 \mathrm{E}-01 \quad-0.1209 \mathrm{E}-02 \quad 0.2446 \mathrm{E}-03$

27 0.2703E-01 -0.1624E-02 -0.1567E-02

$28 \quad 0.2703 \mathrm{E}-01-0.2474 \mathrm{E}-02-0.1802 \mathrm{E}-02$

29 0.2703E-01 -0.3398E-02 -0.1869E-02

$30 \quad 0.3420 \mathrm{E}-01-0.5124 \mathrm{E}-03-0.1737 \mathrm{E}-02$

$31 \quad 0.3420 \mathrm{E}-01-0.1647 \mathrm{E}-02-0.1228 \mathrm{E}-02$

$32 \quad 0.3420 \mathrm{E}-01-0.2286 \mathrm{E}-02-0.4450 \mathrm{E}-03$

$33 \quad 0.3420 \mathrm{E}-01 \quad-0.2328 \mathrm{E}-02 \quad 0.2804 \mathrm{E}-03$

$34 \quad 0.3419 \mathrm{E}-01 \quad-0.1962 \mathrm{E}-02 \quad 0.6178 \mathrm{E}-03$

$35 \quad 0.3419 \mathrm{E}-01 \quad-0.1581 \mathrm{E}-02 \quad 0.2366 \mathrm{E}-03$

$36 \quad 0.3419 \mathrm{E}-01-0.1870 \mathrm{E}-02 \quad-0.1194 \mathrm{E}-02$

37 0.3419E-01 -0.2533E-02 -0.1429E-02

$38 \quad 0.3419 \mathrm{E}-01-0.3271 \mathrm{E}-02-0.1496 \mathrm{E}-02$

39 0.3906E-01 $-0.5609 \mathrm{E}-03 \quad-0.1655 \mathrm{E}-02$

$40 \quad 0.3905 E-01-0.1752 E-02 \quad-0.1433 E-02$

$41 \quad 0.3904 \mathrm{E}-01 \quad-0.2599 \mathrm{E}-02 \quad-0.7670 \mathrm{E}-03$

$42 \quad 0.3904 \mathrm{E}-01 \quad-0.2874 \mathrm{E}-02 \quad 0.1106 \mathrm{E}-04$

$43 \quad 0.3903 \mathrm{E}-01 \quad-0.2637 \mathrm{E}-02 \quad 0.5710 \mathrm{E}-03$

$44 \quad 0.3902 \mathrm{E}-01 \quad-0.2155 \mathrm{E}-02 \quad 0.5821 \mathrm{E}-03$

$45 \quad 0.3902 \mathrm{E}-01-0.1984 \mathrm{E}-02 \quad-0.2862 \mathrm{E}-03$

$46 \quad 0.3902 \mathrm{E}-01 \quad-0.2194 \mathrm{E}-02 \quad-0.5211 \mathrm{E}-03$

$47 \quad 0.3902 \mathrm{E}-01 \quad-0.2477 \mathrm{E}-02 \quad-0.5887 \mathrm{E}-03$

Esforços de extremidade nos elemento : 


\begin{tabular}{|c|c|c|c|c|}
\hline Elemento & No & Normal & Cortante & M.Fletor \\
\hline \multirow[t]{2}{*}{01} & 1 & 6.967 & 1.492 & 3.070 \\
\hline & 3 & -6.517 & -1.492 & 1.406 \\
\hline \multirow[t]{2}{*}{02} & 3 & 6.160 & 1.040 & 1.538 \\
\hline & 12 & -5.710 & -1.040 & 1.581 \\
\hline \multirow[t]{2}{*}{03} & 12 & 5.281 & 0.822 & 1.139 \\
\hline & 21 & -4.831 & -0.822 & 1.327 \\
\hline \multirow[t]{2}{*}{04} & 21 & 4.015 & 0.477 & 0.546 \\
\hline & 30 & -3.565 & -0.477 & 0.885 \\
\hline \multirow[t]{2}{*}{05} & 30 & 2.261 & -0.172 & 0.097 \\
\hline & 39 & -0.097 & -1.811 & -0.120 \\
\hline \multirow[t]{2}{*}{06} & 2 & 29.407 & 2.006 & 3.584 \\
\hline & 9 & 28.957 & -2.006 & 2.434 \\
\hline \multirow[t]{2}{*}{07} & 9 & 22.940 & 1.959 & 2.970 \\
\hline & 8 & -22.490 & -1.959 & 2.906 \\
\hline \multirow[t]{2}{*}{08} & 18 & 16.544 & 1.675 & 2.399 \\
\hline & 27 & -16.094 & -1.675 & 2.625 \\
\hline \multirow[t]{2}{*}{09} & 27 & 10.535 & 1.269 & 1.787 \\
\hline & 36 & -10.085 & -1.269 & 2.021 \\
\hline \multirow[t]{2}{*}{10} & 36 & 5.014 & 1.094 & 1.355 \\
\hline & 45 & -4.564 & -1.094 & 1.927 \\
\hline \multirow[t]{2}{*}{11} & 3 & 0.047 & 0.357 & -2.944 \\
\hline & 4 & -0.047 & 0.130 & 3.030 \\
\hline \multirow[t]{2}{*}{12} & 3 & 0.047 & 0.357 & -2.944 \\
\hline & 4 & -0.047 & 0.130 & 3.030 \\
\hline \multirow[t]{2}{*}{13} & 5 & 0.047 & -1.618 & -2.749 \\
\hline & 6 & -0.047 & 2.105 & 1.353 \\
\hline \multirow[t]{2}{*}{14} & 6 & 0.047 & -2.105 & 2.593 \\
\hline & 7 & -0.047 & -1.353 & -0.408 \\
\hline \multirow[t]{2}{*}{15} & 7 & 0.047 & -3.593 & 4.080 \\
\hline & 8 & -0.047 & 0.408 & -3.286 \\
\hline \multirow[t]{2}{*}{16} & 8 & 0.047 & -4.080 & 4.568 \\
\hline & 9 & -0.047 & 3.286 & -6.528 \\
\hline \multirow[t]{2}{*}{17} & 9 & 0.000 & 1.450 & -1.125 \\
\hline & 10 & 0.000 & 1.125 & -0.481 \\
\hline \multirow[t]{2}{*}{18} & 10 & 0.000 & 1.125 & -0.800 \\
\hline & 11 & 0.000 & 0.481 & 0.000 \\
\hline \multirow[t]{2}{*}{19} & 12 & 0.282 & 0.429 & 0.058 \\
\hline & 13 & -0.282 & -2.720 & 2.859 \\
\hline \multirow[t]{2}{*}{20} & 13 & 0.282 & -0.058 & 0.546 \\
\hline & 14 & -0.282 & -2.859 & 2.632 \\
\hline \multirow[t]{2}{*}{21} & 14 & 0.282 & -1.546 & 2.033 \\
\hline & 15 & -0.282 & -2.632 & 1.290 \\
\hline \multirow[t]{2}{*}{22} & 15 & 0.282 & -2.033 & 2.521 \\
\hline & 16 & -0.282 & -1.290 & -0.417 \\
\hline 23 & 16 & 0.282 & -3.521 & 4.008 \\
\hline & 17 & -0.282 & 0.417 & -3.241 \\
\hline 24 & 17 & 0.282 & -4.008 & 4.496 \\
\hline & 18 & -0.282 & 3.241 & -6.430 \\
\hline
\end{tabular}




\begin{tabular}{|c|c|c|c|c|}
\hline \multirow[t]{2}{*}{25} & 18 & 0.000 & 1.450 & -1.125 \\
\hline & 19 & 0.000 & 1.125 & -0.481 \\
\hline \multirow[t]{2}{*}{26} & 19 & 0.000 & 1.125 & -0.800 \\
\hline & 20 & 0.000 & 0.481 & 0.000 \\
\hline \multirow[t]{2}{*}{27} & 21 & 0.405 & 0.816 & -0.328 \\
\hline & 22 & -0.405 & -1.873 & 2.302 \\
\hline \multirow[t]{2}{*}{28} & 22 & 0.405 & 0.328 & 0.159 \\
\hline & 23 & -0.405 & -2.302 & 2.365 \\
\hline \multirow[t]{2}{*}{29} & 23 & 0.405 & -1.159 & 1.647 \\
\hline & 24 & -0.405 & -2.365 & 1.313 \\
\hline \multirow[t]{2}{*}{30} & 24 & 0.405 & -1.647 & 2.134 \\
\hline & 25 & -0.405 & -1.313 & -0.105 \\
\hline \multirow[t]{2}{*}{31} & 25 & 0.405 & -3.134 & 3.622 \\
\hline & 26 & -0.405 & 0.105 & -2.638 \\
\hline \multirow{2}{*}{32} & 26 & 0.405 & -3.622 & 4.109 \\
\hline & 27 & -0.405 & 2.638 & -5.537 \\
\hline \multirow[t]{2}{*}{33} & 27 & 0.000 & 1.450 & -1.125 \\
\hline & 28 & 0.000 & 1.125 & -0.481 \\
\hline \multirow[t]{2}{*}{34} & 28 & 0.000 & 1.125 & -0.800 \\
\hline & 29 & 0.000 & 0.481 & 0.000 \\
\hline \multirow[t]{2}{*}{35} & 30 & 0.177 & 1.304 & -0.816 \\
\hline & 31 & -0.177 & -0.713 & 1.508 \\
\hline \multirow[t]{2}{*}{36} & 31 & 0.177 & 0.816 & -0.329 \\
\hline & 32 & -0.177 & -1.508 & 1.938 \\
\hline \multirow[t]{2}{*}{37} & 32 & 0.177 & -0.671 & 1.159 \\
\hline & 33 & -0.177 & -1.938 & 1.251 \\
\hline \multirow[t]{2}{*}{38} & 33 & 0.177 & -1.159 & 1.646 \\
\hline & 34 & -0.177 & -1.251 & 0.199 \\
\hline \multirow[t]{2}{*}{39} & 34 & 0.177 & -2.646 & 3.134 \\
\hline & 35 & -0.177 & -0.199 & -1.968 \\
\hline \multirow[t]{2}{*}{40} & 35 & 0.177 & -3.134 & 3.621 \\
\hline & 36 & -0.177 & 1.968 & -4.501 \\
\hline \multirow[t]{2}{*}{41} & 36 & 0.000 & 1.450 & -1.125 \\
\hline & 37 & 0.000 & 1.125 & -0.481 \\
\hline \multirow[t]{2}{*}{42} & 37 & 0.000 & 1.125 & -0.800 \\
\hline & 38 & 0.000 & 0.481 & 0.000 \\
\hline \multirow[t]{2}{*}{43} & 39 & 1.097 & 1.811 & -1.323 \\
\hline & 40 & -1.097 & 0.120 & 1.056 \\
\hline \multirow[t]{2}{*}{44} & 40 & 1.097 & 1.323 & -0.836 \\
\hline & 41 & -1.097 & -1.056 & 1.865 \\
\hline \multirow[t]{2}{*}{45} & 41 & 1.097 & -0.164 & 0.652 \\
\hline & 42 & -1.097 & -1.865 & 1.560 \\
\hline \multirow[t]{2}{*}{46} & 42 & 1.097 & -0.652 & 1.139 \\
\hline & 43 & -1.097 & -1.560 & 0.888 \\
\hline 47 & 43 & 1.097 & -2.139 & 2.627 \\
\hline & 44 & -1.097 & -0.888 & -0.899 \\
\hline 48 & 44 & 1.097 & -2.627 & 3.114 \\
\hline & 45 & -1.097 & 0.899 & -3.052 \\
\hline 49 & 45 & 0.000 & 1.450 & -1.125 \\
\hline & 46 & 0.000 & 1.125 & -0.481 \\
\hline
\end{tabular}


50

$\begin{array}{ll}46 & 0.000 \\ 47 & 0.000\end{array}$

1.125

$-0.800$

0.481

0.000

Reações de Apoio :

No Restring. Forca $X$ Forca $Y$ Momento

$$
\begin{array}{cccc}
1 & -1.492 & 6.967 & 3.070 \\
2 & -2.006 & 29.407 & 3.584
\end{array}
$$

Soma do Carregamento Aplicado

Momento Calculado em Relação a Origem

$$
3.500-36.375-139.031
$$

3.501

Diferença de Equilíbrio :

\begin{tabular}{|c|c|c|c|c|c|c|}
\hline ELEMENTO & BITOLA As & BITOLA AsI & CAM_1 & CAM_2 & CAM_3 & CAM_4 \\
\hline 01 & 10.0 & 10.0 & 3 & $\overline{1}$ & 3 & 1 \\
\hline 02 & 10.0 & 10.0 & 2 & 0 & 2 & 0 \\
\hline 03 & 10.0 & 10.0 & 2 & 0 & 2 & 0 \\
\hline 04 & 10.0 & 10.0 & 2 & 0 & 2 & 0 \\
\hline 05 & 10.0 & 10.0 & 2 & 0 & 2 & 0 \\
\hline 06 & 10.0 & 10.0 & 2 & 0 & 2 & 0 \\
\hline 07 & 10.0 & 10.0 & 2 & 0 & 2 & 0 \\
\hline 08 & 10.0 & 10.0 & 2 & 0 & 2 & 0 \\
\hline 09 & 10.0 & 10.0 & 2 & 0 & 2 & 0 \\
\hline 10 & 12.5 & 12.5 & 2 & 0 & 2 & 0 \\
\hline 11 & 8.0 & 16.0 & 2 & 0 & 2 & 0 \\
\hline 12 & 8.0 & 16.0 & 3 & 0 & 2 & 1 \\
\hline 13 & 8.0 & 16.0 & 3 & 0 & 2 & 1 \\
\hline 14 & 8.0 & 16.0 & 2 & 0 & 2 & 0 \\
\hline 15 & 8.0 & 16.0 & 2 & 0 & 2 & 0 \\
\hline 16 & 8.0 & 16.0 & 3 & 0 & 2 & 1 \\
\hline 17 & 8.0 & 16.0 & 3 & 0 & 2 & 1 \\
\hline 18 & 8.0 & 16.0 & 2 & 0 & 2 & 0 \\
\hline 19 & 8.0 & 16.0 & 3 & 0 & 2 & 1 \\
\hline 20 & 8.0 & 16.0 & 2 & 0 & 2 & 0 \\
\hline 21 & 8.0 & 16.0 & 2 & 0 & 2 & 0 \\
\hline 22 & 8.0 & 16.0 & 2 & 0 & 2 & 0 \\
\hline 23 & 8.0 & 16.0 & 2 & 0 & 2 & 0 \\
\hline 24 & 8.0 & 16.0 & 3 & 0 & 2 & 1 \\
\hline 25 & 8.0 & 16.0 & 3 & 0 & 2 & 1 \\
\hline 26 & 8.0 & 16.0 & 2 & 0 & 2 & 0 \\
\hline 27 & 8.0 & 16.0 & 2 & 0 & 2 & 0 \\
\hline 28 & 8.0 & 16.0 & 2 & 0 & 2 & 0 \\
\hline 29 & 8.0 & 16.0 & 2 & 0 & 2 & 0 \\
\hline 30 & 8.0 & 16.0 & 2 & 0 & 2 & 0 \\
\hline
\end{tabular}

$$
\begin{array}{lll}
0.002 & 0.000 & -0.044
\end{array}
$$

CROMOSSOMO NUMERO $=163$ 


$\begin{array}{lllllll}31 & 8.0 & 16.0 & 3 & 1 & 2 & 2 \\ 32 & 8.0 & 16.0 & 3 & 1 & 2 & 2 \\ 33 & 8.0 & 16.0 & 3 & 1 & 2 & 2 \\ 34 & 8.0 & 16.0 & 3 & 1 & 2 & 1 \\ 35 & 8.0 & 16.0 & 2 & 0 & 2 & 0 \\ 36 & 8.0 & 16.0 & 3 & 0 & 2 & 1 \\ 37 & 8.0 & 16.0 & 2 & 0 & 2 & 0 \\ 38 & 8.0 & 16.0 & 2 & 0 & 2 & 0 \\ 39 & 8.0 & 16.0 & 2 & 0 & 2 & 0 \\ 40 & 8.0 & 16.0 & 3 & 0 & 2 & 0 \\ 41 & 8.0 & 16.0 & 2 & 0 & 2 & 0 \\ 42 & 8.0 & 16.0 & 2 & 0 & 2 & 0 \\ 43 & 8.0 & 10.0 & 2 & 0 & 2 & 0 \\ 44 & 8.0 & 10.0 & 3 & 0 & 3 & 0 \\ 45 & 8.0 & 10.0 & 3 & 1 & 3 & 0 \\ 46 & 8.0 & 10.0 & 3 & 1 & 2 & 0 \\ 47 & 8.0 & 10.0 & 2 & 0 & 2 & 0 \\ 48 & 8.0 & 10.0 & 3 & 1 & 3 & 1 \\ 49 & 8.0 & 10.0 & 3 & 1 & 3 & 1 \\ 50 & 8.0 & 10.0 & 2 & 0 & 2 & 0\end{array}$

$\begin{array}{cccc}\text { ELEMENTO } & \text { ALFA [FCN1] } & \text { ALFA [FCN2] } & \text { ALFA [RO] } \\ 01 & 1.040 & 0.368 & \\ 02 & 0.701 & 0.770 & 1.000 \\ 03 & 0.465 & 0.644 & 1.000 \\ 04 & 0.164 & 0.402 & 1.000 \\ 05 & 0.056 & 0.042 & 1.000 \\ 06 & 1.049 & 0.772 & 1.000 \\ 07 & 0.881 & 0.862 & 1.000 \\ 08 & 0.740 & 0.862 & 1.000 \\ 09 & 0.601 & 0.777 & 1.000 \\ 10 & 0.452 & 0.780 & 1.000 \\ 11 & 0.615 & 0.633 & 1.000 \\ 12 & 0.526 & 0.454 & 1.000 \\ 13 & 0.454 & 0.223 & 1.000 \\ 14 & 0.254 & 0.101 & 1.000 \\ 15 & 0.101 & 0.823 & 1.000 \\ 16 & 0.597 & 1.086 & 1.000 \\ 17 & 0.205 & 0.088 & 1.000 \\ 18 & 0.121 & 0.000 & 1.000 \\ 19 & 0.449 & 0.472 & 1.000 \\ 20 & 0.597 & 0.521 & 1.000 \\ 21 & 0.521 & 0.243 & 1.000 \\ 22 & 0.243 & 0.097 & 1.000 \\ 23 & 0.097 & 0.804 & 1.000 \\ 24 & 0.585 & 1.065 & 1.000 \\ 25 & 0.205 & 0.088 & 1.000 \\ 26 & 0.121 & 0.000 & 1.000 \\ 27 & 0.371 & 0.480 & 1.000 \\ & & & 1.000\end{array}$




$\begin{array}{llll}28 & 0.480 & 0.468 & 1.000 \\ 29 & 0.468 & 0.247 & 1.000 \\ 30 & 0.247 & 0.022 & 1.000 \\ 31 & 0.020 & 0.386 & 1.000 \\ 32 & 0.386 & 0.812 & 1.000 \\ 33 & 0.166 & 0.071 & 1.000 \\ 34 & 0.087 & 0.000 & 1.000 \\ 35 & 0.168 & 0.299 & 1.000 \\ 36 & 0.833 & 0.320 & 1.000 \\ 37 & 0.384 & 0.235 & 1.000 \\ 38 & 0.235 & 0.156 & 1.000 \\ 39 & 0.156 & 0.488 & 1.000 \\ 40 & 0.483 & 1.014 & 1.000 \\ 41 & 0.282 & 0.121 & 1.000 \\ 42 & 0.121 & 0.000 & 1.000 \\ 43 & 0.036 & 0.804 & 1.000 \\ 44 & 0.552 & 1.059 & 1.000 \\ 45 & 0.824 & 0.675 & 1.000 \\ 46 & 0.675 & 0.349 & 1.000 \\ 47 & 0.650 & 0.436 & 1.000 \\ 48 & 0.236 & 0.920 & 1.000 \\ 49 & 0.358 & 0.153 & 1.000 \\ 50 & 0.290 & 0.000 & 1.000\end{array}$

CUSTO TOTAL DO PÓRTICO [R\$] = 1304.493 


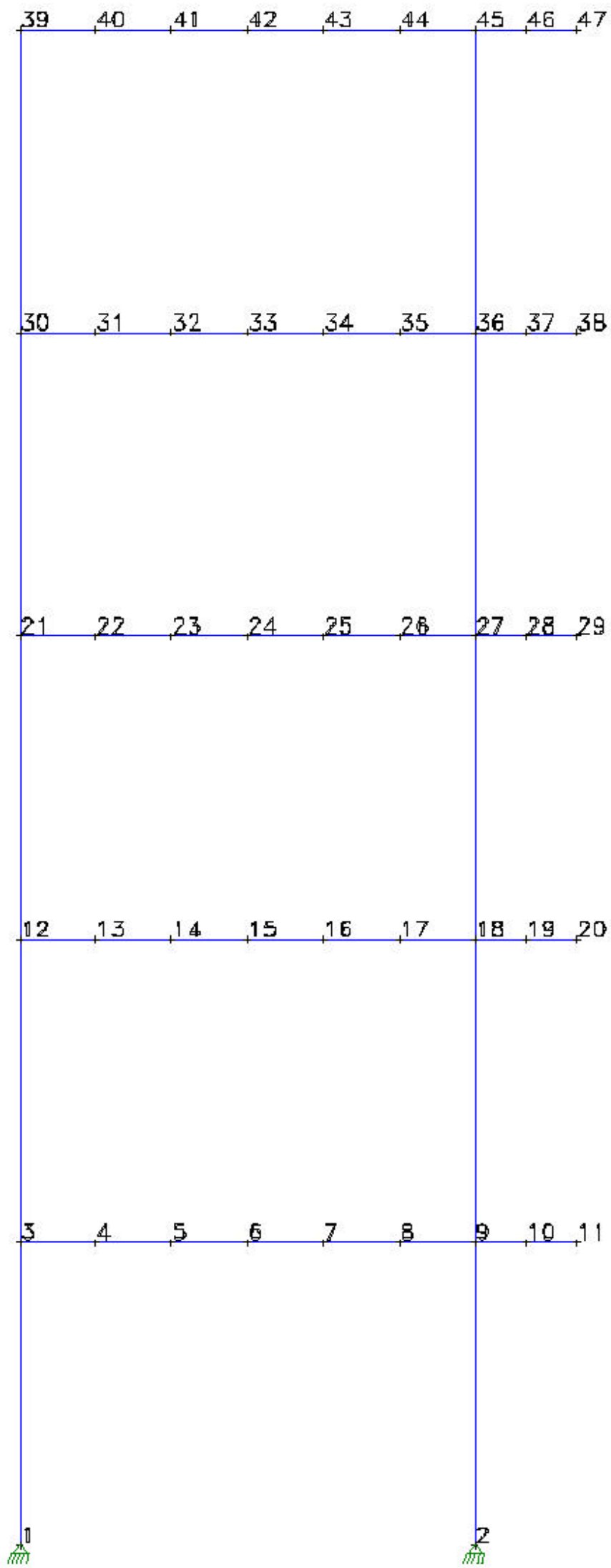

Figura B-1 - Numeração dos Nós da Estrutura 


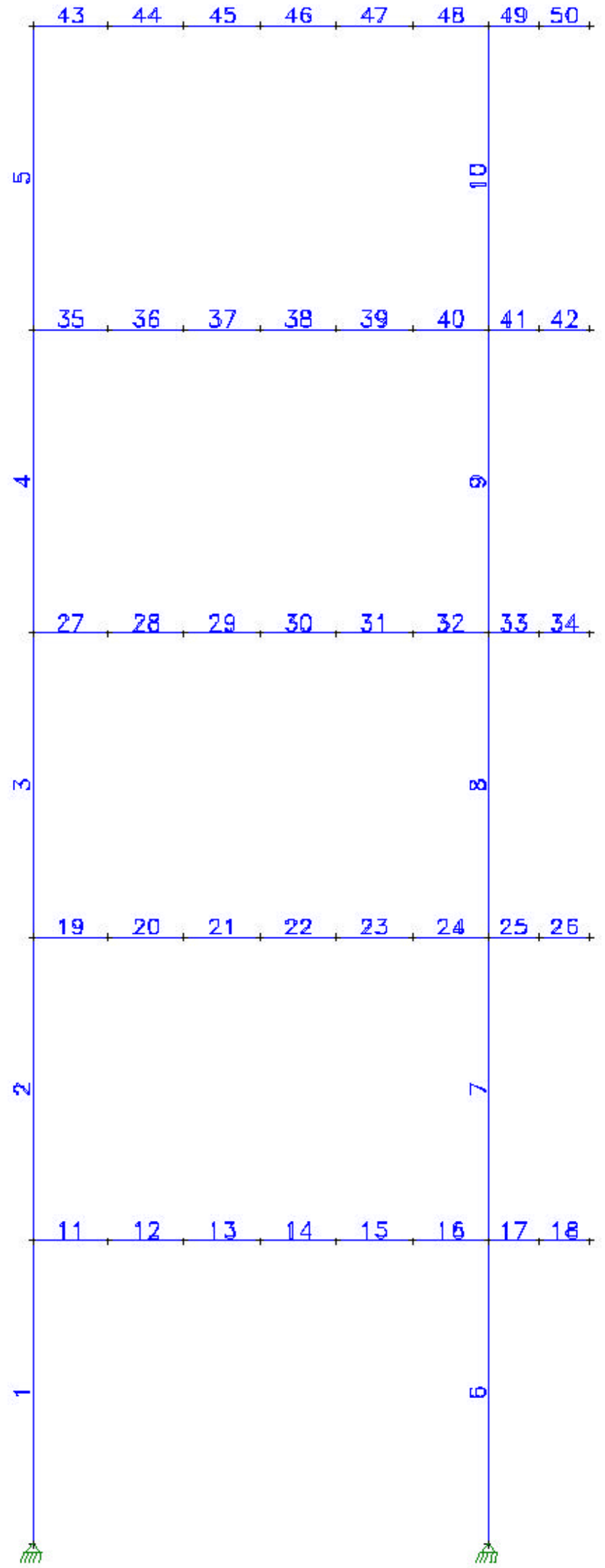

Figura B-2 - Numeração dos Elementos de Barra do Pórtico de Concreto Armado 


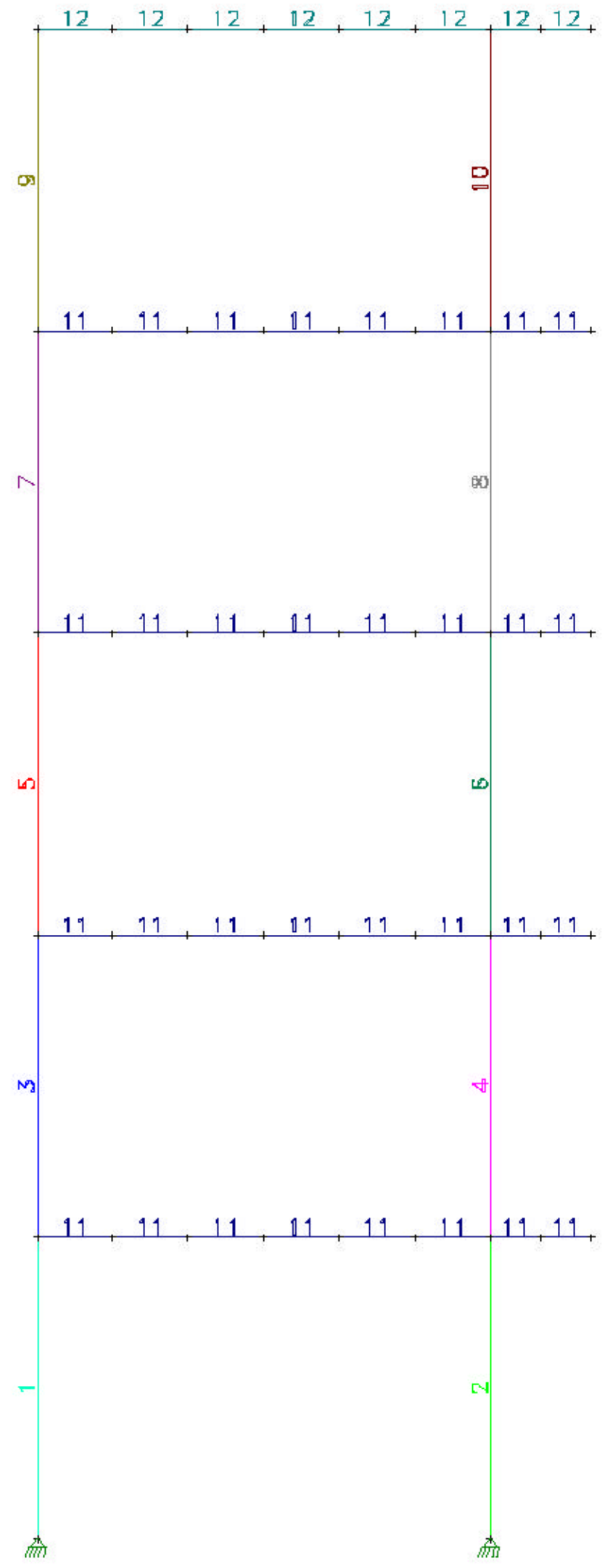

Figura B-3 - Numeração das Propriedades das Seções dos Elementos 


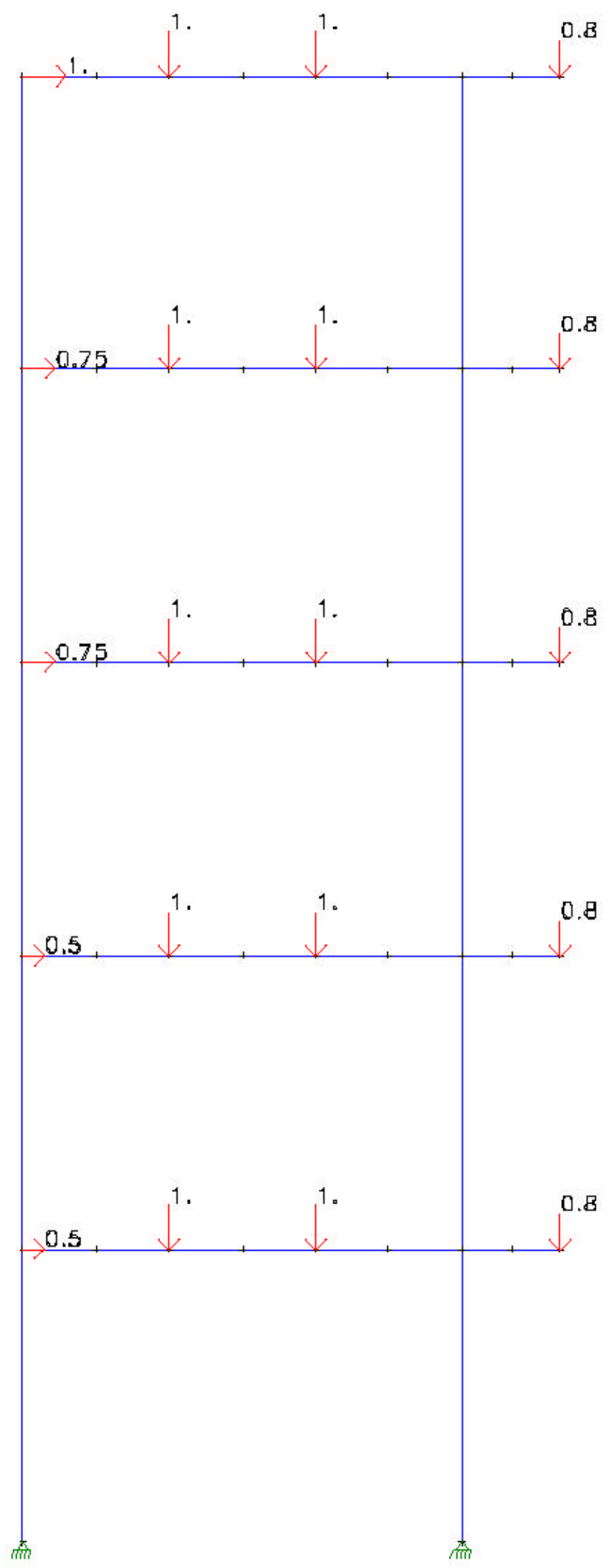

Figura B-4 - Cargas Concentradas Aplicadas nos Nós da Estrutura 


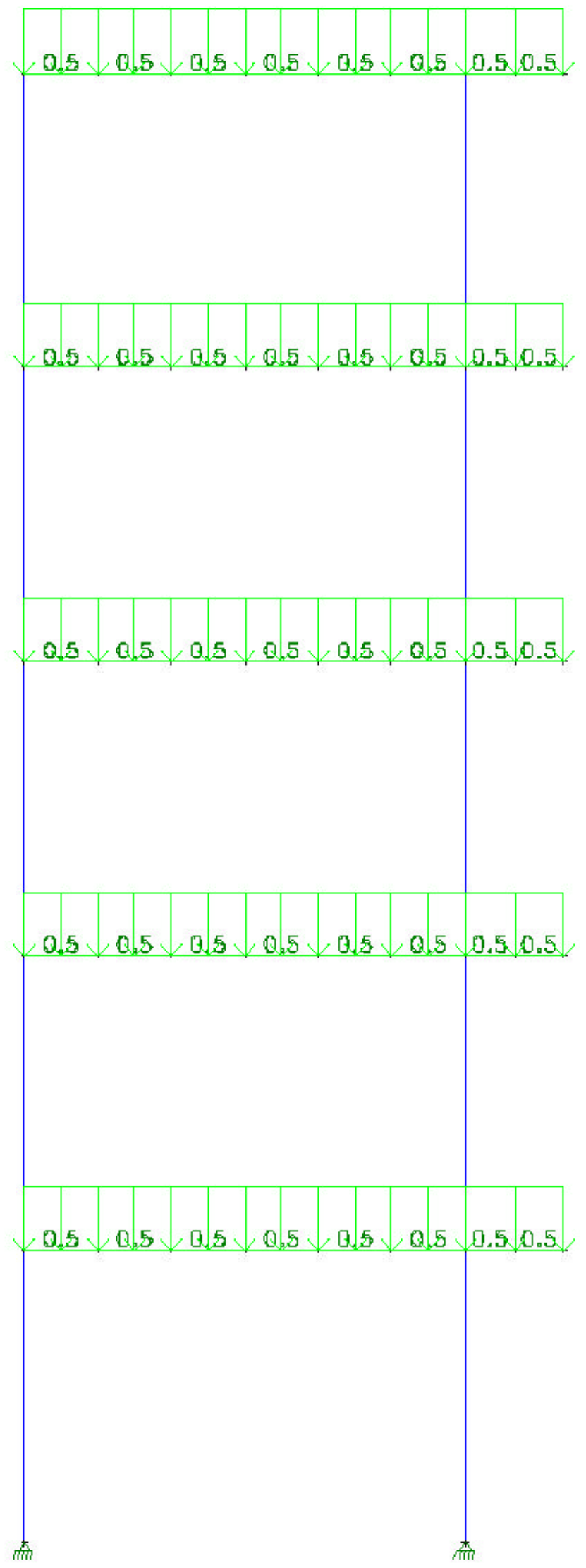

Figura B-5 - Cargas Distribuídas Aplicadas nas Vigas da Estrutura 


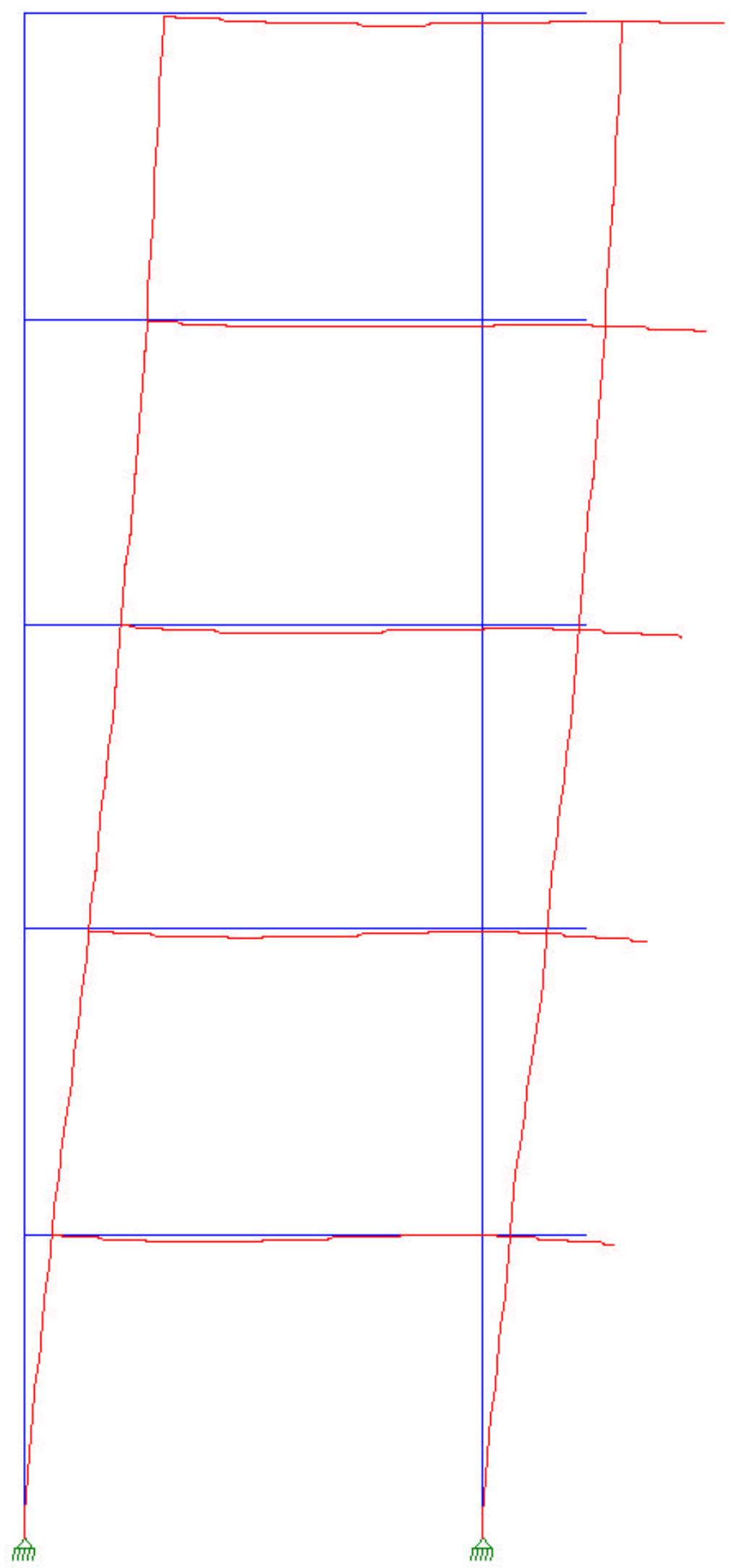

Figura B-6 - Forma da Deformada do Pórtico de Concreto Armado 


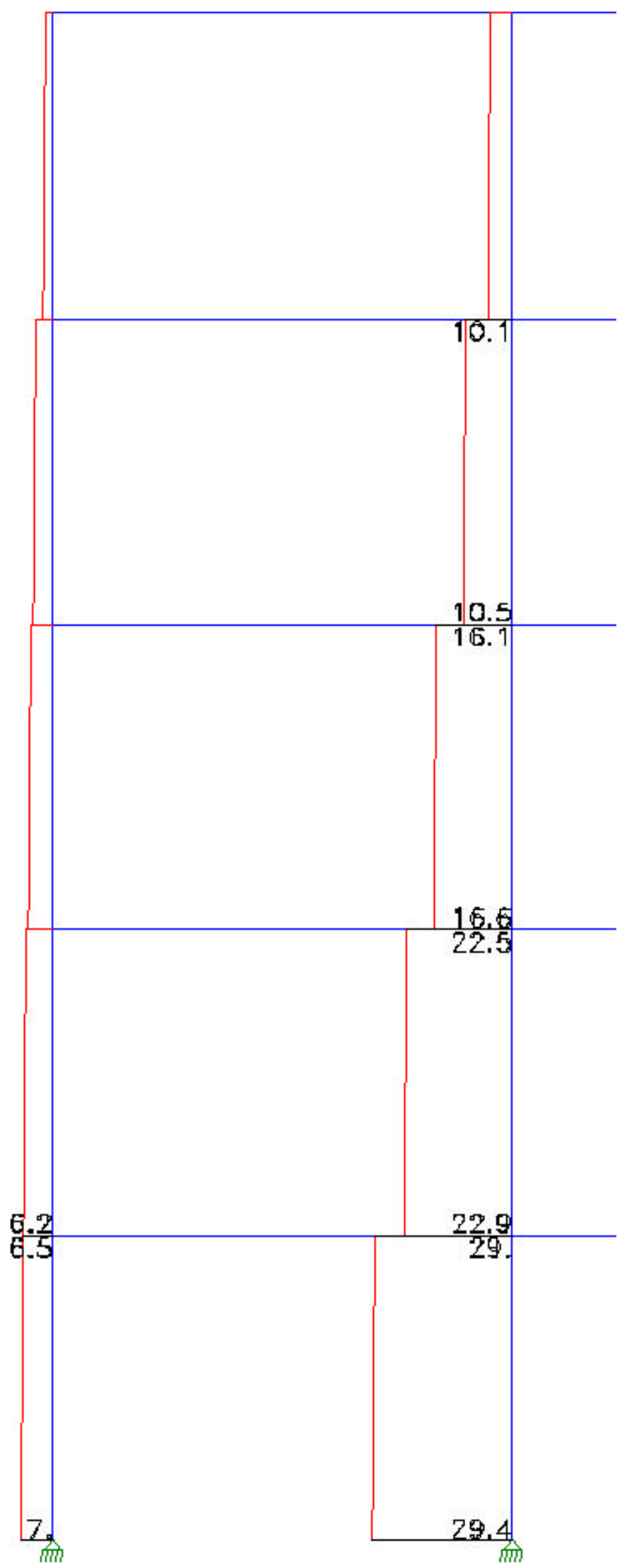

Figura B-7 - Diagrama de Esforço Normal do Pórtico de Concreto Armado 


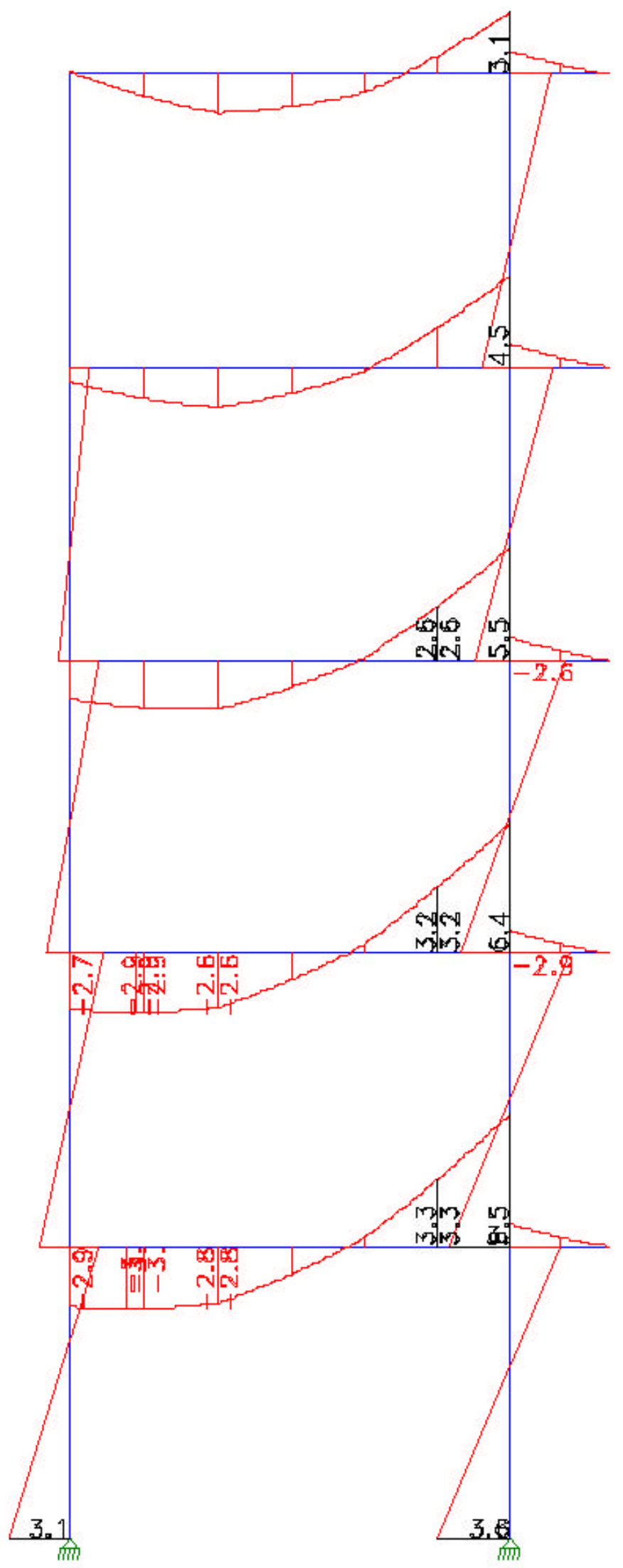

Figura B-8 - Diagrama de Momentos Fletores do Pórtico de Concreto Armado 


\section{ANEXO C}

Os diversos módulos que foram implementados para o OTIMPORCA estão enumerados nos itens a seguir:

1. Módulo de Leitura dos Dados de Entrada;

2. Gerador de Números Aleatórios;

3. Gerador de Cromossomos - Codificador (cadeia de bits);

4. Decodificadores para dada um dos diversos cromossomos;

5. Operador para de Cruzamento de 2 Pontos;

6. Operador para Mutação Uniforme;

7. Ordenador de Número;

8. Módulo para fazer o Ranking dos Indivíduos;

9. Operadores de Seleção de Indivíduos para Cruzamentos;

10. Módulo de Análise Matricial de Estruturas - Cálculo dos Esforços do Pórtico;

11. Módulo de Verificação das Seções Transversais FCN (Penalização);

a. Verificação de Equilíbrio;

b. Verificação de Deformações Compatíveis.

12. Módulo para Cálculo do Custo da Estrutura;

13. Módulo Verificador das Dimensões e Distribuição das Armaduras (Penalização);

14. Módulo para Cálculo das Flechas Horizontal e Vertical (Penalização);

15. Módulo para Cálculo das Taxas de Armadura das Seções (Penalização);

16. Módulo de Cálculo da Média do Custo dos indivíduos e verificação da Convergência;

17. Operador de Elitismo da População (10\% melhores são guardados para próxima geração);

18. Módulo de Geração dos Arquivos de Saída.

a. Arquivo com os dados de cada da população;

b. Arquivo com o resumo para cada geração;

c. Arquivo com os dados do melhor indivíduo obtido .

Para que se possa visualizar melhor o processo de otimização de estruturas de concreto armado, são apresentados a seguir alguns fluxogramas tanto para o exemplo de Otimização do Pilar Isolado como para o OTIMPORCA 1, a diferença entre a versão 1 e 2 está apenas na escolha das variáveis para o problema como discutido no Capitulo 6. 
Abaixo será apresentado o fluxograma para o programa de otimização de pilares sujeito solicitados por FCO:

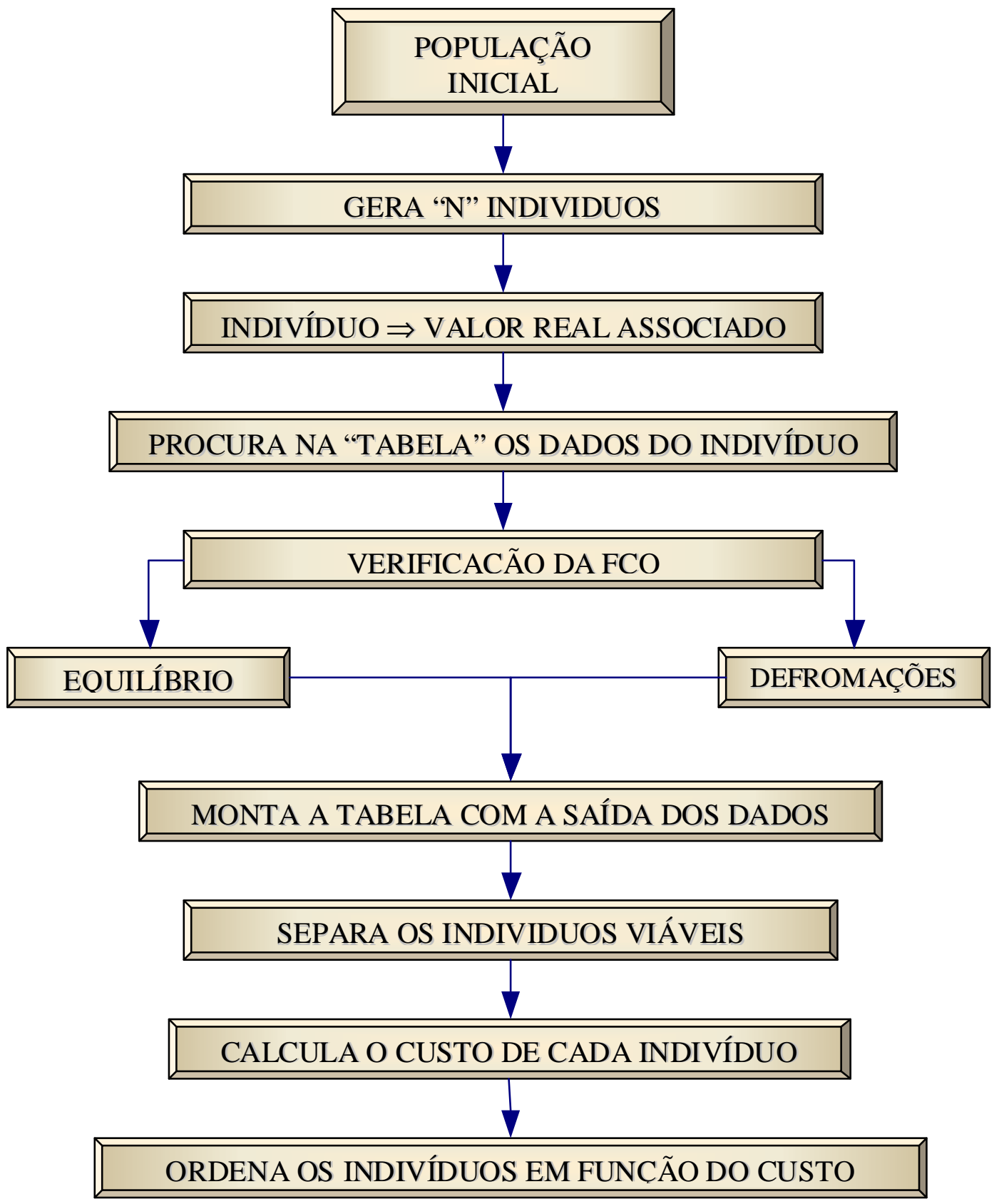

Fluxograma C-1 - Otimização de um Trecho de Pilar a FCO - [1/2] 


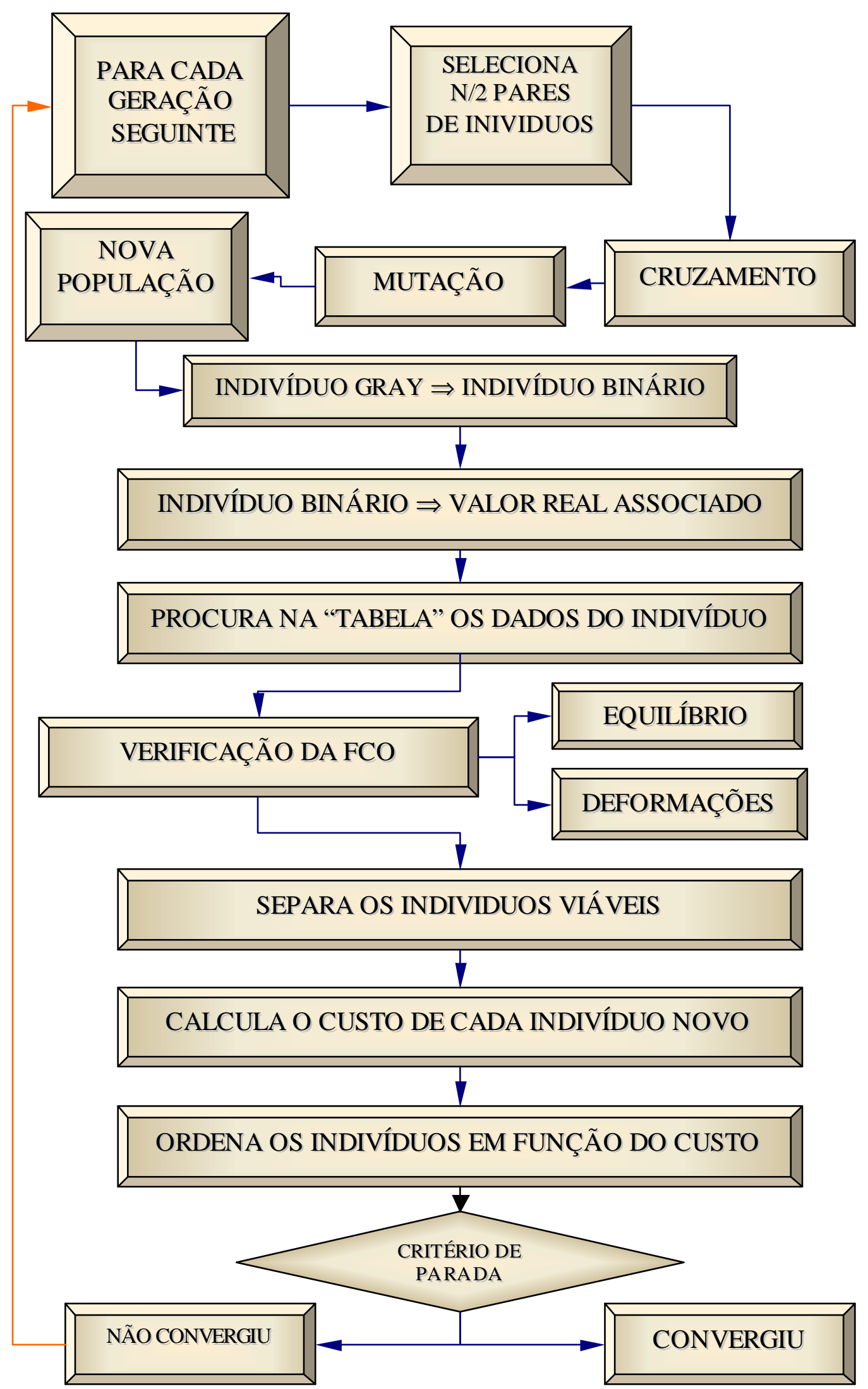

Fluxograma C-2 - Otimização de um Trecho de Pilar a FCO - [2/2] 
Abaixo será apresentado um fluxograma com os módulos que foram implementados para o OTIMPORCA 1. O fluxograma apresenta as principais etapas do algoritmo de otimização, desta forma esta apresentação é apenas ilustrativa para processo, não contendo todos os detalhes da implementação.

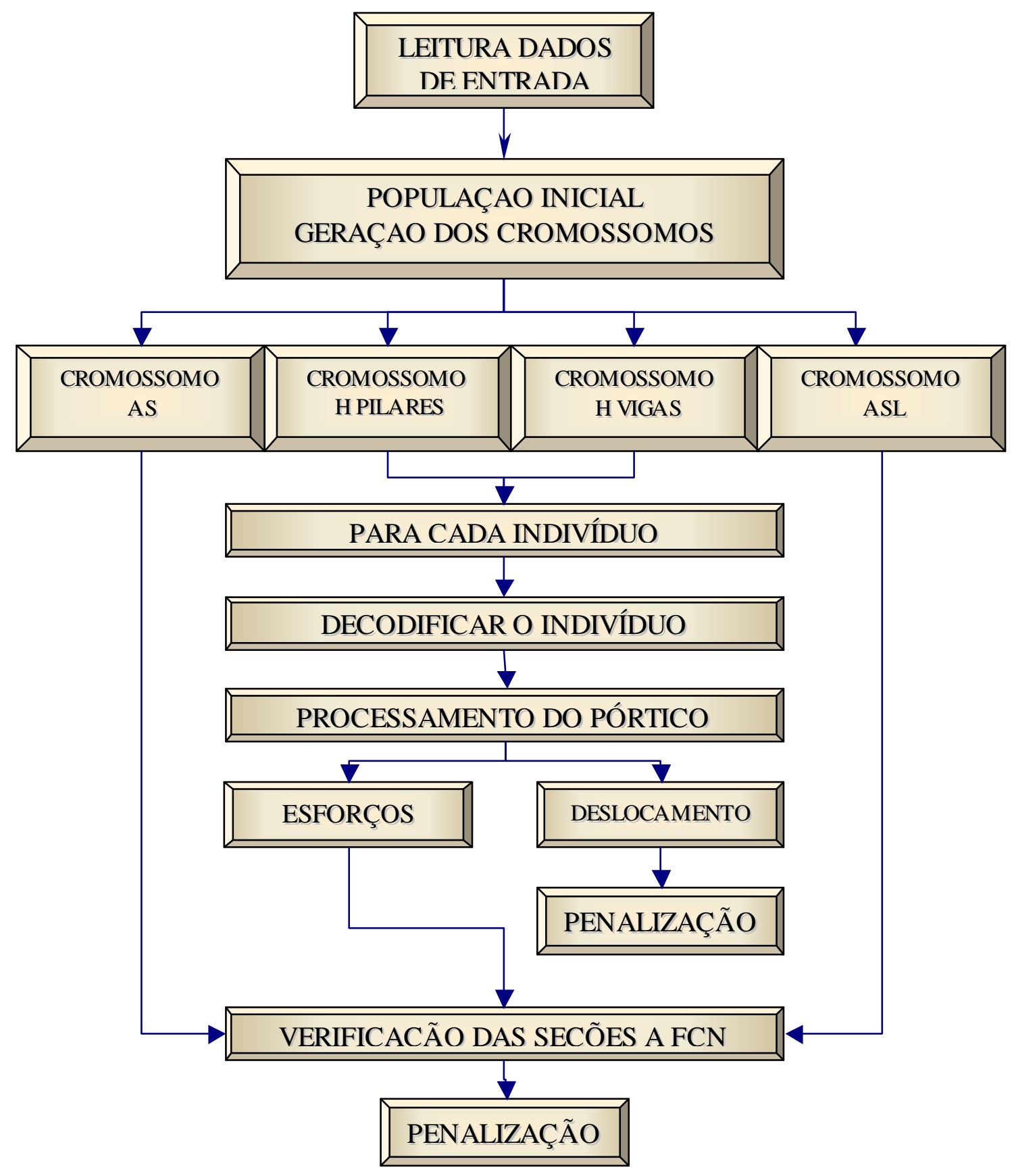

Fluxograma C-3 - Fluxograma para o OTIMPORCA 1 - [1/4] 
Continuação do Módulo da Primeira Geração

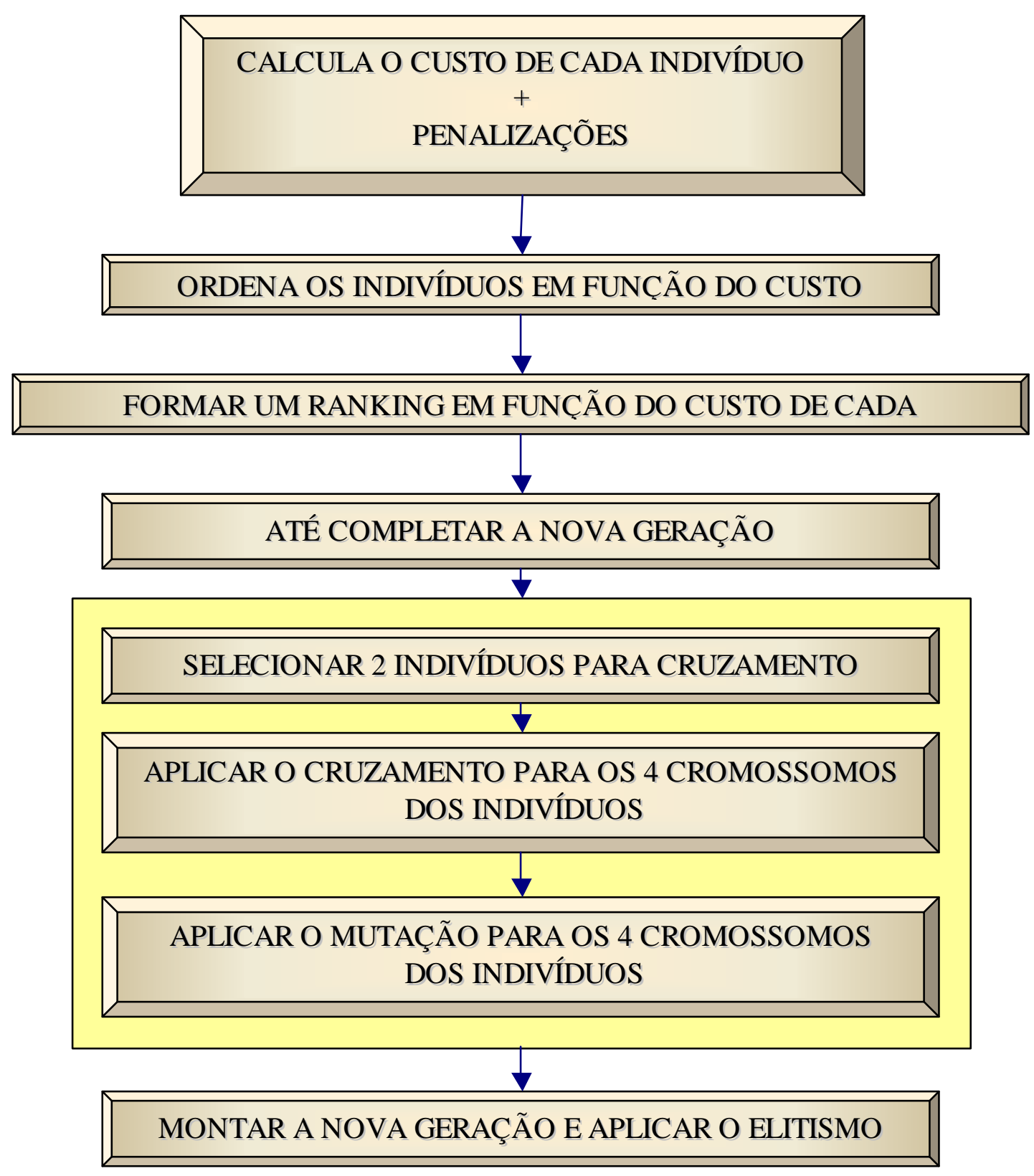

Fluxograma C-4 - Fluxograma para o OTIMPORCA 1 - [2/4] 
Para as demais Gerações Seguir os Fluxogramas mostrados logo abaixo:

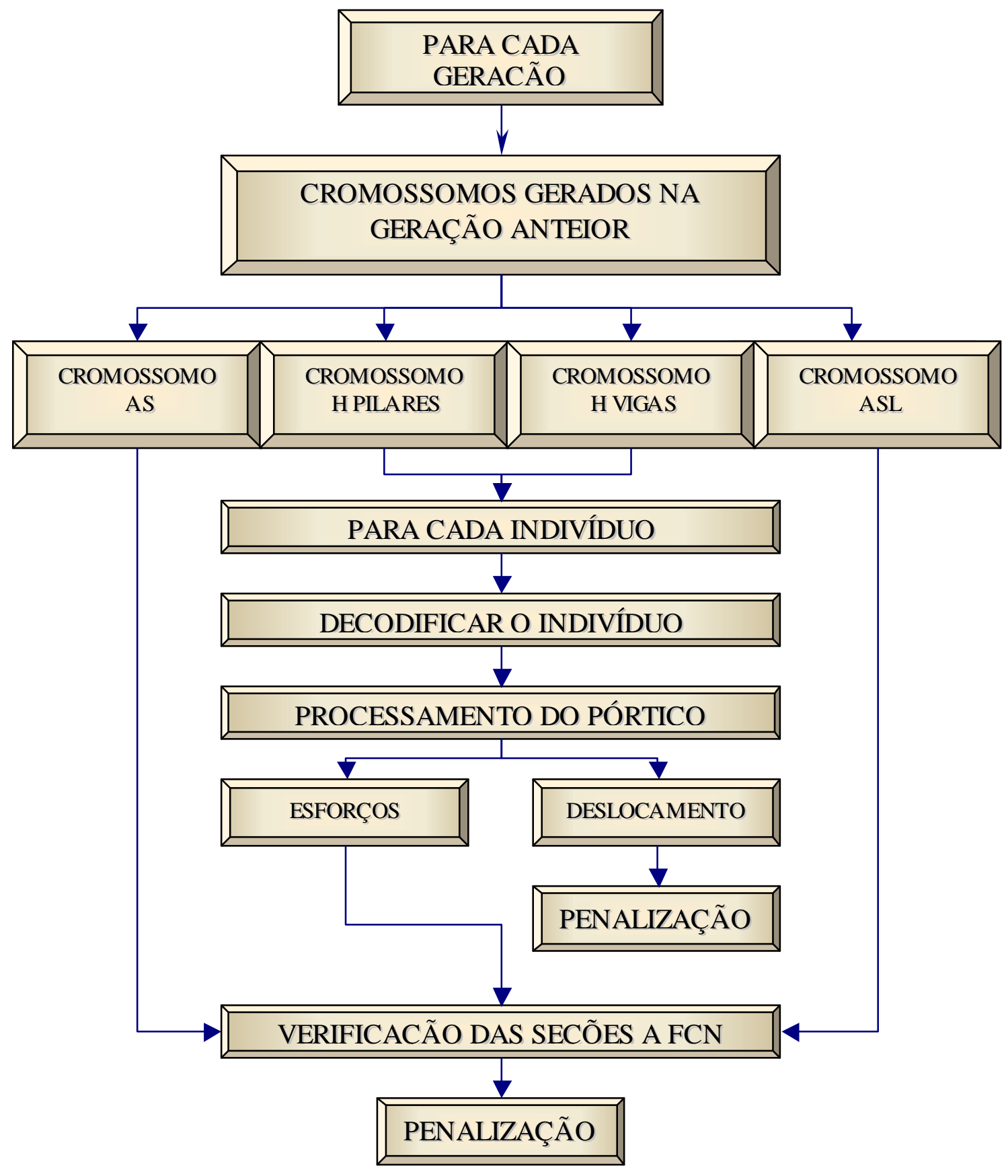

Fluxograma C-5 - Fluxograma para o OTIMPORCA 1 - [3/4] 


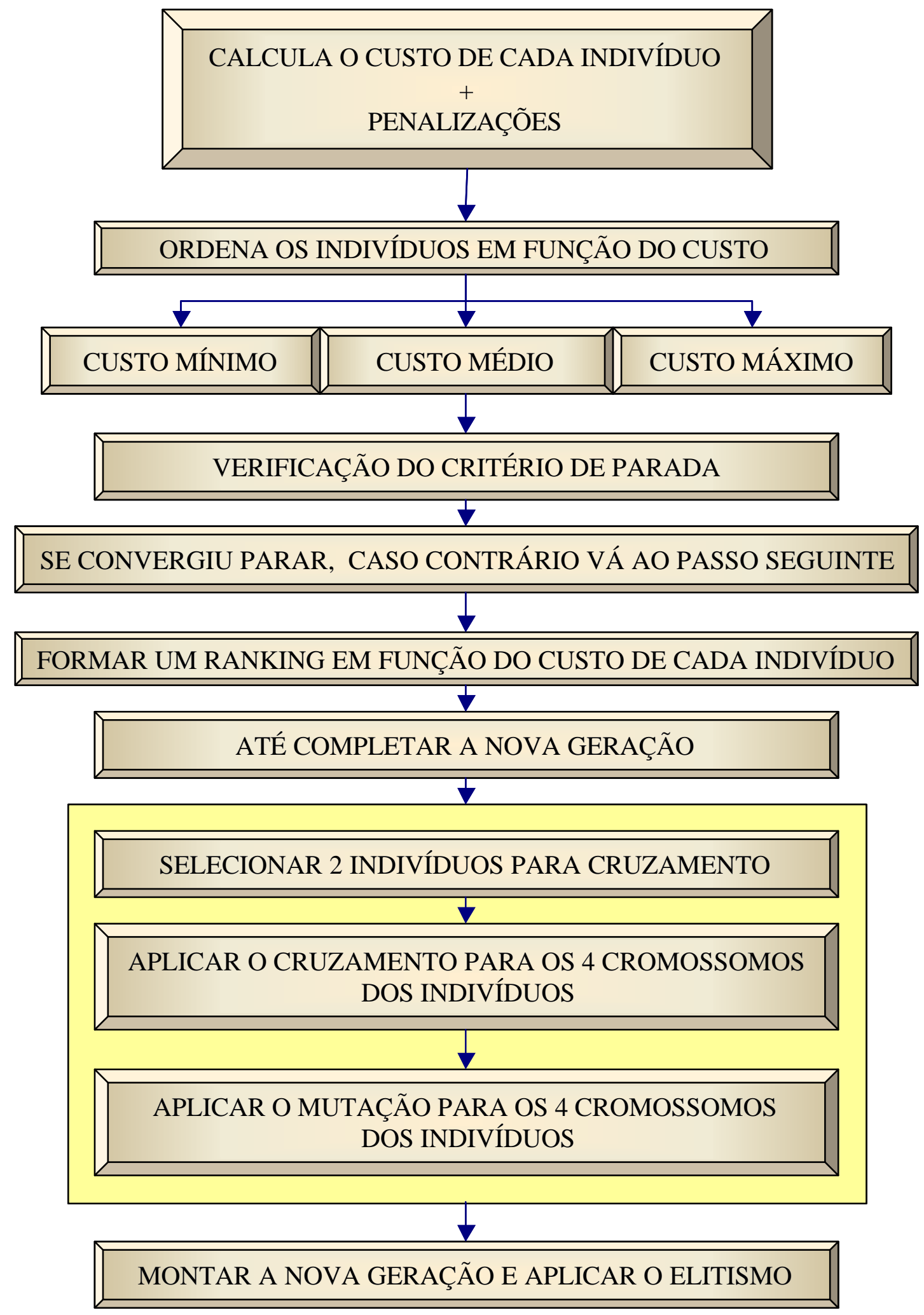

Fluxograma C-6 - Fluxograma para o OTIMPORCA 1 - [4/4] 